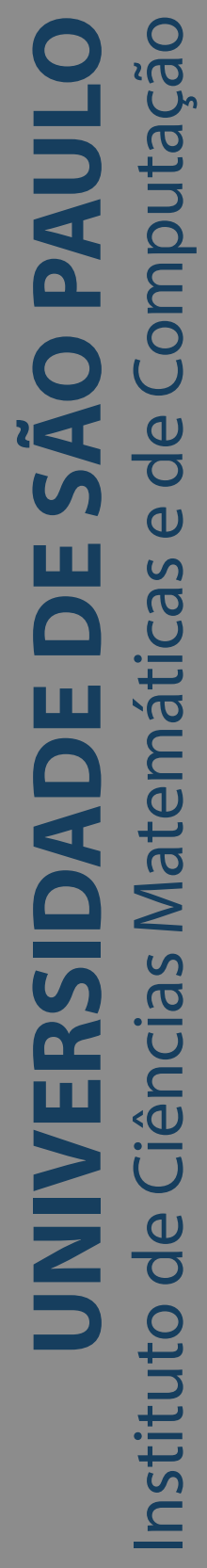

\title{
Modelos de custo e estatísticas para consultas por
} similaridade

\section{Marcos Vinicius Naves Bedo}

Tese de Doutorado do Programa de Pós-Graduação em Ciências de Computação e Matemática Computacional (PPG-CCMC) 

Data de Depósito:

Assinatura:

\title{
Marcos Vinicius Naves Bedo
}

\section{Modelos de custo e estatísticas para consultas por similaridade}

\author{
Tese apresentada ao Instituto de Ciências \\ Matemáticas e de Computação - ICMC-USP, \\ como parte dos requisitos para obtenção do título \\ de Doutor em Ciências - Ciências de Computação e \\ Matemática Computacional. VERSÃO REVISADA \\ Área de Concentração: Ciências de Computação e \\ Matemática Computacional \\ Orientador: Prof. Dr. Caetano Traina Júnior
}


Ficha catalográfica elaborada pela Biblioteca Prof. Achille Bassi e Seção Técnica de Informática, ICMC/USP, com os dados fornecidos pelo(a) autor(a)

Bedo, Marcos Vinicius Naves
Modelos de custo e estatisticas para consultas por
similaridade / Marcos Vinicius Naves Bedo; orientador
Caetano Traina Júnior. - São Carlos - SP, 2017.
196 p.
Tese (Doutorado - Programa de Pós-Graduação em
Ciências de Computação e Matemática Computacional)
- Instituto de Ciências Matemáticas e de Computação,
Universidade de São Paulo, 2017.
1. Consultas por similaridade. 2. Otimização.
3. Concentração de distâncias. I. Júnior, Caetano
Traina, orient. II. Título.




\section{Marcos Vinicius Naves Bedo}

\section{Cost models and statistics for similarity searching}

Doctoral dissertation submitted to the Instituto de Ciências Matemáticas e de Computação - ICMC-USP, in partial fulfillment of the requirements for the degree of the Doctorate Program in Computer Science and Computational Mathematics. FINAL VERSION

Concentration Area: Computer Science and Computational Mathematics

Advisor: Prof. Dr. Caetano Traina Júnior

USP - São Carlos

November 2017 

Dedicado a todos aqueles que buscam alguma resposta para quaisquer dos infinitos mistérios da Natureza. 



\section{Agradecimentos}

Agradeço a todos aqueles que, em algum momento e de alguma forma, exerceram a função de professores e me ensinaram no caminho até aqui. Dessa forma, primeiro agradecer aos professores de facto, ou aqueles não-professores de ofício, que exerceram grande influência em minha formação. Em particular, agradeço aos meus avós, por mostrar, ainda que indiretamente, as virtudes e os defeitos da resiliência e os efeitos do tempo sobre nossas ações. Ao meus pais, por todos os valores fundamentais ensinados e por demonstrar a dualidade das decisões que tomamos. Ao meu irmão e maior amigo, por mostrar que o conhecimento não compartilhado pouco vale, que duas cabeças não necessariamente pensam melhor do que uma, embora as duas possam achar graça da mesma situação e aprender lições diferentes do mesmo momento. A minha esposa, por valorizar o planejamento de longo prazo e com diversos pontos de vista.

Passar, então, ao agradecimento dos professores de jure, ou aqueles professores de ofício, que contribuíram para minha formação técnica e pessoal. E aqui, muitas vezes, o termo "professor" também se confunde com o termo "amigo". Dos tempos em que fui aluno do Ensino Fundamental da Escola Municipal Jerônimo Barbosa Sandoval até o Ensino Médio na Escola Estadual Dr. Júlio Cardoso, ambas em Franca/SP, agradecer aos professores que nesses locais me ensinaram, como os Profs. Lucélia, Rosângela e Vágner, dentre tantos outros cuja lembrança do nome me falha. Ao amigo, Prof. Paulo C. R. Mello, hoje no Centro Universitário Euroamericano, que muito contribuiu em minha forma de raciocinar, escrever e ver o mundo.

A todos os professores do Instituto de Ciências Matemáticas e de Computação. Em particular, a Profa. Sarita Bruschi pelo tempo dispensado na época de minha participação no Programa de Educação Tutorial, aos Profs. Renata P. Fortes e Marcos Santana pela disposição e auxílio no exercício de cargos de chefia do curso de Bacharelado de Ciências de Computação e aos Profs. Maria Pimentel e Adenilso Simão também pelo auxílio enquanto no exercício de cargos de chefia do curso de Pós-Graduação em Ciências de Computação e Matemática Computacional. Ao Prof. Francisco J. O. Bernal, da Universidad de Deusto, pelo acolhimento enquanto coordenador do Curso de Computação, no período em que fui aluno Erasmus-Mundus. 
Agradecer, em especial, ao meu orientador, o Prof. Caetano Traina Jr. pelas diversas horas de discussão, brilhantes ideias e direcionamentos (desde o período de iniciação científica) que se refletem sobre todo o texto deste trabalho. Um agradecimento, também especial, à Profa. Agma J. M. Traina, por tantos conselhos e sugestões durante a execução de todas as atividades desta tese. Aos demais professores do Grupo de Bases de Dados e Imagens, Profs. Elaine Parros, José F. R. Júnior e Robson Cordeiro pelos ensinamentos colhidos nas disciplinas, reuniões de grupo e conversas individuais. Não obstante, agradecer também ao Prof. Daniel S. Kaster, da Universidade de Londrina, pelas (muitas) horas gastas em vídeo-conferências discutindo implicações (filosóficas, práticas ou não-correlatas) de muitas das premissas deste trabalho.

Finalmente, agradecer aos amigos da Universidade de São Paulo que compartilharam essa jornada em termos de tempo, ensinaram-me muitas coisas e aprenderam de mim outras tantas, e que, agora, partem em suas jornadas por diferentes locais do país. Por ordem alfabética, agradeço aos Srs. Daniel Chino, Davi P. Santos, Lúcio F. D. Santos, Luiz Olmes e Willian D. Oliveira. Aos demais professores e amigos, com os dois termos agora já quase indistinguíveis, cujo nome, por acaso, tenha me escapado nas linhas anteriores deixo aqui também o meu sincero agradecimento.

Pesquisa parcialmente desenvolvida com apoio de bolsa institucional do Programa de Pós-Graduação em Ciências de Computação e Matemática Computacional PROEX-5991854/D oriunda da Coordenação de Aperfeiçoamento de Pessoal de Nível Superior (CAPES) no período de 07/2014 a 04/2016. A execução deste trabalho só foi possível devido a infra-estrutura disponibilizada pelo Instituto de Ciências Matemáticas e de Computação e devido ao auxílio dos competentes servidores técnico-administrativos do referido Instituto. Um agradecimento especial à Profa. Angela C. P. Giampedro, atualmente na chefia do Centro Cultural da Universidade de São Paulo em São Carlos, pela imensurável ajuda na escrita dos textos em inglês relacionados a esta tese. 
"Rerum omnium magister usus"

(A experiência é a mestra de todas as coisas, tradução livre)

- Gaius Iulius Caesar, benfeitor romano 



\section{RESUMO}

BEDO, M. V. N.. Modelos de custo e estatísticas para consultas por similaridade. 2017. 196 p. Tese (Doutorado em Ciências - Ciências de Computação e Matemática Computacional) Instituto de Ciências Matemáticas e de Computação (ICMC/USP), São Carlos - SP.

Consultas por similaridade constituem um paradigma de busca que fornece suporte à diversas tarefas computacionais, tais como agrupamento, classificação e recuperação de informação. Neste contexto, medir a similaridade entre objetos requer comparar a distância entre eles, o que pode ser formalmente modelado pela teoria de espaços métricos. Recentemente, um grande esforço de pesquisa tem sido dedicado à inclusão de consultas por similaridade em Sistemas Gerenciadores de Bases de Dados (SGBDs), com o objetivo de ( $i$ ) permitir a combinação de comparações por similaridade com as comparações por identidade e ordem já existentes em SGBDs e (ii) obter escalabilidade para grandes bases de dados. Nesta tese, procuramos dar um próximo passo ao estendermos também o otimizador de consultas de um SGBD. Em particular, propomos a ampliação de dois módulos do otimizador: o módulo de Espaço de Distribuição de Dados e o módulo de Modelo de Custo. Ainda que o módulo de Espaço de Distribuição de Dados permita representar os dados armazenados, essas representações são insuficientes para modelar o comportamento das comparações em espaços métricos, sendo necessário estender este módulo para contemplar distribuições de distância. De forma semelhante, o módulo Modelo de Custo precisa ser ampliado para dar suporte à modelos de custo que utilizem estimativas sobre distribuições de distância. Toda a investigação aqui conduzida se concentra em cinco contribuições. Primeiro, foi criada uma nova sinopse para distribuições de distância, o Histograma Compactado de Distância (CDH), de onde é possível inferir valores de seletividade e raios para consultas por similaridade. Uma comparação experimental permitiu mostrar os ganhos das estimativas da sinopse CDH com relação à diversos competidores. Também foi proposto um modelo de custo baseado na sinopse $\mathrm{CDH}$, o modelo Stockpile, cujas estimativas se mostraram mais precisas na comparação com outros modelos. Os Histogramas-Omni são apresentados como a terceira contribuição desta tese. Estas estruturas de indexação, construídas a partir de restrições de particionamento de histogramas, permitem a execução otimizada de consultas que mesclam comparações por similaridade, identidade e ordem. A quarta contribuição de nossa investigação se refere ao modelo RVRM, que é capaz de indicar quanto é possível empregar as estimativas das sinopses de distância para otimizar consultas por similaridade em conjuntos de dados de alta dimensionalidade. O modelo RVRM se mostrou capaz de identificar intervalos de dimensões para os quais essas consultas podem ser executadas eficientes. Finalmente, a última contribuição desta tese propõe a integração das sinopses e modelos revisados em um sistema com sintaxe de alto nível que pode ser acoplado em um otimizador de consultas.

Palavras-chave: Consultas por similaridade, Otimização, Concentração de distâncias. 



\section{ABSTRACT}

BEDO, M. V. N.. Cost models and statistics for similarity searching. 2017. 196 p. Thesis (Doutorado em Ciências - Ciências de Computação e Matemática Computacional) - Instituto de Ciências Matemáticas e de Computação (ICMC/USP), São Carlos - SP.

Similarity searching is a foundational paradigm for many modern computer applications, such as clustering, classification and information retrieval. Within this context, the meaning of "similarity" is related to the distance between objects, which can be formally expressed by the Metric Spaces Theory. Many studies have focused on the inclusion of similarity search into Database Management Systems (DBMSs) for ( $i$ ) enabling similarity comparisons to be combined with the DBMSs' identity and order comparisons and (ii) providing scalability for very large databases. As a step further, we propose the extension of the DBMS Query Optimizer and, particularly, the extension of two modules of the Query Optimizer, namely Data Distribution Space and Cost Model modules. Although the Data Distribution Space enables representations of stored data, such representations are unsuitable for modeling the behavior of similarity comparisons, which requires the extension of the module to support distance distributions. Likewise, the Cost Model module must be extended to support cost models that depend on distance distributions. Our study is based on five contributions. A new synopsis for distance distributions, called Compact-Distance Histogram ( $\mathrm{CDH})$, is proposed and enables radius and selectivity estimation for similarity searching. An experimental comparison showed the gains of the estimates drawn from $\mathrm{CDH}$ in comparison to several competitors. A cost model based on the $\mathrm{CDH}$ synopsis and with accurate estimates, called Stockpile, is also proposed. Omni-Histograms are presented as the third contribution of the thesis. Such indexing structures are constructed according to histogram partition constraints and enable the optimization of queries that combine similarity, identity and order comparisons. The fourth contribution refers to the model RVRM, which indicates the possible use of the estimates obtained from distance-based synopses for the query optimization of high-dimensional datasets and identifies intervals of dimensions where similarity searching can be efficiently executed. Finally, the thesis proposes the integration of the reviewed synopses and cost models into a single system with a high-level language that can be coupled to a DBMS Query Optimizer.

Key-words: Similarity Searching, Query optimization, Distance concentration. 



\section{Lista de ilustrações}

Otimizador de consultas e seus módulos internos . . . . . . . . . . . 32 Exemplos de consultas por similaridade considerando critérios de abrangência e vizinhança. . . . . . . . . . . . . . . . . . . . 4 45 Exemplo de uma consulta por vizinhança diversificada $k=3$ usando a métrica

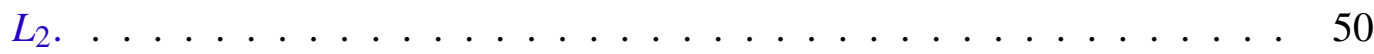

Uma consulta envolvendo Junção por Vizinhança e dois planos de execução válidos, porém não equivalentes. . . . . . . . . . . . . . . . 53 Tipos de particionamento adotados por estratégias de indexação métricas . 55 Princípio do limite inferior para descarte de bolas em espaços métricos . . . 56 Um mesmo conjunto de dados indexado por duas M-Trees diferentes . . . . 57 Um particionamento Slim-tree para quinze elementos . . . . . . . . . . . . 58 Clustered-Pivot Table para um conjunto de seis elementos . . . . . . . . . . 62 Estrutura de dados de uma SPB-Tree . . . . . . . . . . . . . . . . . 64

12 Construção da região mbOr para uma consulta por abrangência usando um método da Família Omni. . . . . . . . . . . . . . . . . . . . . . . . 65

13 Exemplos de variações de classes de histogramas de acordo com a restrição de particionamento. . . . . . . . . . . . . . . . 73 Aproximações do parâmetro-fonte com particionamento ótimo e de erro fixo. 75 Exemplo de histograma multidimensional com a restrição de Muralikrishna e DeWitt (1988) . . . . . . . . . . . . . . . . . . . . 76 Exemplo de histograma multidimensional com restrição MHIST. . . . . . . . 77 Representação da estrutura de um Histograma NN . . . . . . . . . . . 80 Exemplo de estimativa de raio usando uma sinopse Evento de Busca . . . 82 Distance Plot da frequência acumulada para um conjunto de dados sintético. 83 Distance Plot para estimativa de raio máximo de uma consulta $k$-NN. . . 85 Sinopse do modelo de custo STAIRCASE-15. . . . . . . . . . . . . . . 89 
Diferentes histogramas para compactar a mesma distribuição $\mathcal{T}_{p} \operatorname{com} \beta=4$ Comparação de erro de aproximação em função da quantidade de faixas . 96

Comparação da média e desvio padrão para Erro\% considerando-se previsões de oito sinopses.

Mapa de calor construído a partir dos $p$-valores de Nemenyi considerando-se Erro\% . . . . . . . . . . . . . . . . .

Comparação da média e desvio padrão para o tempo de execução de consultas por vizinhança considerando as previsões de raio por oito sinopses. . . . . . 104 Mapa de calor construído a partir dos $p$-valores de Nemenyi considerando-se o tempo de execução de consultas por vizinhança. . . . . . . . . . . . . 105 Comparação entre os modelos de custo para consultas por abrangência . . . 111 Comparação entre os modelos de custo para consultas por vizinhança . . . . 112 Mapeamento de um espaço métrico para um espaço multidimensional. . . . 117 Exemplos de Histogramas-Omni para um conjunto de dados geográfico. 120 Exemplo de particionamento de um conjunto de dados por um Histograma-Omni. . . . . . . . . . . . . . . . . . . 121

Estrutura de um Histograma-Omni generalizado para consultas híbridas. . . Exemplo de uma consulta híbrida por vizinhança sobre um Histograma-Omni para um centro de consulta arbitrário $s_{q}$ e norma $L_{2} \ldots$. . . . . . . 125 Comparação do desempenho de diferentes restrições de particionamento de Histogramas-Omni na execução das consultas por vizinhança. . . . . . . . Comparação de Histogramas-Omni e os métodos de acesso SeqScan, LAESA e Omni R-Tree com relação ao tempo gasto para executar consultas por vizinhança. . . . . . . . . . . . . . . . . e Omni R-Tree com relação ao tempo gasto para executar consultas híbridas. 131

Visão geral do modelo de dados para o Componente de Catálogo. . . . . 136 Variância relativa para um conjunto de dados sintético e um conjunto de dados real

Função de concentração para métrica $L_{2}$ com relação à um conjunto de dados sintético e dois conjuntos reais. . . . . . . . . . . . . . . 152 diversas dimensionalidades. . . . . . . . . . . . . . . . . . 163 
Quantidade de cálculos de distâncias necessários para executar uma consulta por vizinhança considerando-se as dimensionalidades intrínseca, de concentração e de imersão. . . . . . . . . . . . . . . . . . . . . . . . 165 



\section{Lista de algoritmos}

Algoritmo 1 - Algoritmo de construção de histogramas com garantias de erro para $\mathcal{T}_{p} \quad . \quad 95$

Algoritmo 2 - Algoritmo CDH-kNN para estender a estratégia bf-kNN limitada . . . . 98

Algoritmo 3 - Algoritmo de construção de Histogramas-Omni CriarOmniHistogra$\operatorname{ma}\left(\mathcal{S}, A, \mathcal{R}_{1}, \mathcal{R}_{2}, \beta_{1}, \beta_{2}\right) \ldots \ldots \ldots \ldots \ldots$

Algoritmo 4 - Algoritmo para consulta híbrida omni_hist-kNN $\left(s_{q}, k, A_{c}\right) \ldots \ldots$. . 127

Algoritmo 5 - $\operatorname{Algoritmo} \operatorname{RVRM}\left(\mathcal{S}, \phi, L_{p}, \mathcal{D}, \mathcal{E}, \alpha\right)$ que representa o Modelo de Redução por Variância Relativa. . . . . . . . . . . . . . . . . . . . . . . 158 



\section{Lista de tabelas}

Tipos de otimização empregados para os operadores por similaridade revisados 54 Conjuntos de dados empregados na comparação de sinopses para previsão de raio e seletividade . . . . . . . . . . . . . . . . . . 100

Quantidade de memória (em kB) gasta por cada sinopse avaliada. . . . . . . 101

Conjuntos de dados empregados na avaliação de modelos de custos . . . . . 110

Conjunto de dados e parâmetros empregados na avaliação de Histogramas-Omni . . . . . . . . . . . . . . . . . . . . . . 128

Sinopses implementadas pelo sistema Merkurion . . . . . . . . . . . . 137

Critérios de seleção de pivôs disponíveis no protótipo Merkurion . . . . . . 139

Conjuntos de dados empregados na avaliação do modelo RVRM . . . . . . . 160

11 Avaliação do modelo RVRM junto ao classificador $\mathrm{Ib} k$. . . . . . . . . . . 162

12 Descrição de todos os conjuntos de dados usados nos experimentos desta tese 193 



\section{Lista de siglas e símbolos}

A - Atributo de uma relação $T$.

$b *$ - Uma Omni-faixa.

$B_{\mathcal{S}}$ - Coordenadas das Omni-faixas para os elementos do conjunto de dados $\mathcal{S}$.

$B\left(s_{i}\right)$ - Coordenadas da Omni-faixa para um elemento $s_{i} \in \mathcal{S}$.

$C_{1}, C_{2}$ - Constantes do modelo Stockpile.

$c(j)$ - Valor de distância acumulado em uma determinada posição $j$ em um histograma.

CDH — Histograma Compactado de Distância.

$d$ - Valor de dimensionalidade.

$D$ - Conjunto de valores de dimensionalidade.

DBA - Administrador da Base de Dados.

$\mathcal{D}$ — Dimensão intrínseca de um conjunto de dados.

$\mathcal{E}$ — Dimensão de imersão de um conjunto de dados.

$f_{\phi}(d)$ - Função de concentração discretizada.

$f_{p}(x)$ - Função linear por partes correspondente a um CDH com pivô $p$.

$f_{\text {req }(j)}$ - Frequência de um histograma para um valor $v(j)$.

$F_{p}(x)$ - Primitiva para a função $f_{p}(x)$.

$\bar{F}_{p}(x)$ - Normalização da função $F_{p}(x)$.

FM — Método redutor FastMap.

$g_{\phi}(x)$ - Função de aproximação para a função de concentração discretizada $f_{\phi}(d)$.

$h$ - Altura de uma árvore métrica $T$.

$H_{p}$ - Histograma de distância associado a um pivô $p$. 
$H(x)$ - Função discretizada que toma valores em um histograma.

$H_{g}(x)$ — Função discretizada de um histograma normalizado de pares de distância.

$H(p, k)$ - Valor de distância para o $k$-ésimo vizinho em um Histograma NN.

$\mathcal{H}$ - Um Histograma-Omni.

$k$-NN - Consulta aos $k$-vizinhos mais próximos.

$\operatorname{low}_{p}(l)$ - Limite inferior de distância em uma faixa $l$ de um CDH.

$L$ — Limite da função $g_{\phi}(x)$.

$L_{p}$ - Métricas da família Mikowski.

$m_{p}$ - Quantidade de diferentes distâncias em uma distribuição de distância por pivôs.

$m_{q}$ - Quantidade de diferentes distâncias em uma distribuição de pares de distância.

max_k — Quantidade máxima de vizinhos para um Histograma NN.

$M$ - Quantidade máxima de valores em um histograma.

$M\left(\mathcal{S}, B_{\mathcal{S}}\right)$ - Mapeamento de elementos às suas coordenadas de Omni-faixas.

$M\left(O_{\mathcal{S}}, B_{\mathcal{S}}\right)$ - Mapeamento de coordenadas Omni e Omni-faixas.

$M\left(\mathcal{S}, O_{\mathcal{S}}\right)$ - Mapeamento de elementos às suas coordenadas Omni.

$\mathcal{M}$ - Espaço métrico dado pelo par associado $\langle\mathbb{S}, \delta\rangle$.

N — Conjunto de nós de uma árvore métrica.

$\mathrm{N}_{d}$ - Nó diretório de uma árvore métrica.

$\mathrm{N}_{l}$ - Nó folha de uma árvore métrica.

$O_{\mathcal{S}}$ - Conjunto de coordenadas Omni para um conjunto de dados $\mathcal{S}$.

$O\left(s_{i}\right)$ - Coordenadas Omni para um elemento $s_{i} \in \mathcal{S}$.

PCA — Análise de Componentes Principais.

PCo - Método redutor por Coeficiente de Pearson.

$\mathcal{P}$ — Conjunto de pivôs para um dado conjunto de dados $\mathcal{S}$.

$R$ - Distância máxima entre quaisquer dois elementos do conjunto $\mathcal{S}$.

RMSE — Erro quadrado médio relativo.

RVRM — Modelo de Redução por Variância Relativa.

$R q\left(\mathcal{S}, s_{q}, \xi\right)$ - Consulta por abrangência para $s_{q}$ limitada por $\xi$.

$\operatorname{Rng}(\delta, \xi)$ — Operador de comparação por abrangência.

$\mathcal{R}$ - Restrição de particionamento de um histograma. 
$s_{\phi}(x)$ - Função de concentração contínua que aproxima $f_{\phi}(d)$.

SGBD — Sistema gerenciador de bases de dados.

$\mathcal{S}$ - Conjunto de dados.

$\mathbb{S}$ - Domínio de um atributo.

T — Relação de uma base de dados.

$T$ — Uma árvore métrica.

$\mathcal{T}$ — Distribuição de pares de distância.

$\mathcal{T}^{\mathcal{C}}$ — Distribuição acumulada de pares de distância.

$\mathcal{T}_{d}$ - Distribuição de dados.

$\mathcal{T}_{d}^{\mathcal{C}}$ - Distribuição acumulada de dados.

$\mathcal{T}_{p}$ - Distribuição de distâncias baseadas em pivô.

$\mathcal{T}_{p}^{\mathcal{C}}$ — Distribuição acumulada de distâncias baseadas em pivô.

$\overline{\mathcal{T}}$ — Distribuição de pares de distância normalizada.

$u p_{p}(l)$ - Limite superior de distância em uma faixa $l$ de um CDH.

$\mathcal{V}$ - Conjunto de valores de dados.

$\beta-$ Quantidade máxima de faixas para um histograma.

$\delta$ — Função de distância métrica.

$\varepsilon-$ Um extrator de características.

$\theta$ - Operador de comparação a ser usado por um operador relacional.

$\ddot{\theta}$ - Operador de comparação com suporte à comparações por abrangência.

$\lambda_{0}, \ldots, \lambda_{10}-$ Constantes do modelo RVRM.

$\mu(\mathcal{T})$ - Média dos valores para uma distribuição de pares de distância.

$\xi$ - Valor real usado como limite (raio) em consultas por similaridade.

$\xi_{s_{q} s_{k}}$ - Valor de distância entre um elemento de consulta e seu $k$-ésimo vizinho.

$\sigma(\mathcal{T})$ - Desvio padrão dos valores para uma distribuição de pares de distância.

$\sigma$ - Operador relacional de Seleção.

$\phi(d, \mathcal{S}), \phi$ - Método redutor de dimensionalidade.

$\varphi$ — Função linear para a aproximação de frequências em uma faixa de um CDH. 

1 Introdução . . . . . . . . . . . . . . . . . . . . 29

1.1 Motivação . . . . . . . . . . . . . . . . . . . 31

1.2 Hipótese e Proposta . . . . . . . . . . . . . . . . . . 35

1.3 Contribuições . . . . . . . . . . . . . . . . . 36

1.4 Estrutura do documento . . . . . . . . . . . . . . . . . . . 38

2 Consultas por Similaridade . . . . . . . . . . . . . . . . . . 41

2.1 Critérios empregados em consultas por similaridade . . . . . . . . . . . . 45

2.2 Operadores relacionais e consultas por similaridade . . . . . . . . . . . 51

2.3 Estratégias de indexação . . . . . . . . . . . . . . . . . 54

2.4 Considerações Finais . . . . . . . . . . . . . . . . . . 65

3 Sinopses e distribuições de distâncias em espaços métricos . . . . . . . . 67

3.1 Sinopses e seu uso no contexto de um SGBD . . . . . . . . . . . . . . . 68

3.2 Distribuição de Dados . . . . . . . . . . . . . . . . . . . . 70

3.3 Histogramas . . . . . . . . . . . . . . . . . . . 70

3.4 Histogramas com erro controlado . . . . . . . . . . . . . . . . . 74

3.5 Histogramas multidimensionais . . . . . . . . . . . . . . . 76

3.6 Distribuição de distâncias . . . . . . . . . . . . . . . . . . . . . 77

3.7 Estimativa de abrangência para consultas por vizinhança . . . . . . . . . . 79

3.8 Modelos de custo . . . . . . . . . . . . . . . . . . . 86

3.9 Considerações Finais . . . . . . . . . . . . . . . . . . . . 90

4 Histogramas Compactados de Distância e seu uso na otimização de consultas por similaridade . . . . . . . . . . . . . . . . . . . . 91

4.1 Histogramas Compactados de Distância - CDH . . . . . . . . . . . . . . 93

4.2 Comparação de sinopses por qualidade de previsões . . . . . . . . . . . . . 99

4.3 O modelo de custo Stockpile . . . . . . . . . . . . . . . 106

4.4 Avaliação do modelo Stockpile . . . . . . . . . . . . . . . . . . 110

4.5 Considerações Finais . . . . . . . . . . . . . . . . . . . . 113

5 Histogramas-Omni e métodos de acesso derivados . . . . . . . . . . 115

5.1 Histogramas não independentes . . . . . . . . . . . . . . . . . 117

5.2 Particionamento de tabelas de pivôs e métodos Omni . . . . . . . . . . . 118

5.3 Histogramas-Omni . . . . . . . . . . . . . . . . . . . . . 119

5.4 Histogramas-Omni para consultas híbridas . . . . . . . . . . . . . 122 
5.5 Resolução de consultas híbridas com Histogramas-Omni . . . . . . . . . . 124

5.6 Avaliação de Histogramas-Omni . . . . . . . . . . . . . . . . . 128

5.7 Considerações Finais . . . . . . . . . . . . . . . . . . . . . . 131

6 Um protótipo de otimizador com suporte à consultas por similaridade . . . 133

6.1 O protótipo Merkurion . . . . . . . . . . . . . . . . 135

6.2 A Interface Linha de Comando do Merkurion . . . . . . . . . . . . . . . 139

6.3 Estudo de caso para o conjunto de dados CITIES . . . . . . . . . . . . . 140

6.4 Merkurion e Histogramas-Omni . . . . . . . . . . . . . . . . . . 144

6.5 Ambiente de Testes . . . . . . . . . . . . . . . . . . . . . . 145

6.6 Considerações Finais . . . . . . . . . . . . . . . . . . . . 145

7 Um modelo para averiguar quando sinopses não devem ser usadas . . . . 147

7.1 Referencial teórico para concentração de distâncias . . . . . . . . . . . . . . . 148

7.2 Modelo RVRM para concentração de distâncias . . . . . . . . . . . . . . . . . 152

7.3 Avaliação do modelo RVRM . . . . . . . . . . . . . . . . . . . 159

7.4 Considerações finais . . . . . . . . . . . . . . . . . . 167

8 Conclusão . . . . . . . . . . . . . . . . . . . . . . . . . . . . . 169

8.1 Dificuldades . . . . . . . . . . . . . . . . . 170

8.2 Contribuições . . . . . . . . . . . . . . . . . . 171

8.3 Desdobramentos futuros . . . . . . . . . . . . . . . . . . 172

8.4 Publicações geradas . . . . . . . . . . . . . . . . . . . 173

Referências . . . . . . . . . . . . . . . . . . . . . 175

A Apêndice 1 - Sintaxe de comandos Merkurion . . . . . . . . . . . . . 191

B Apêndice 2 - Conjuntos de dados avaliados . . . . . . . . . . . . . . 193 


\section{Introdução}

Sistemas Gerenciadores de Bases de Dados (SGBDs) que possuem por base teórica o modelo relacional (CODD, 1970; ASTRAHAN et al., 1976; STONEBRAKER; ROWE, 1986; STONEBRAKER; WEISBERG, 2013; KIM et al., 2017; SADAGOPAN et al., 2017) têm demonstrado durante décadas desempenho sólido e confiável para dar suporte aos mais diversos tipos de sistema de informação (WORBOYS; DUCKHAM, 2004; STEFANIDIS; PITOURA; VASSILIADIS, 2007; KORTH; SUDARSHAN; SILBERSCHATZ, 2010). Esse embasamento teórico é desejável na maioria dos cenários, uma vez que propicia o armazenamento com redundância controlada, recuperação eficiente de dados e o controle de grandes volumes de dados de forma escalável (PAVLO et al., 2009; SADAGOPAN et al., 2017). Tradicionalmente, SGBDs permitem a recuperação de números, datas e pequenas cadeias de caracteres por meio da aqui denominada Relação de Identidade, que depende dos operadores de comparação por igualdade e desigualdade $(=, \neq)$ (KANELLAKIS, 1989; KORTH; SUDARSHAN; SILBERSCHATZ, 2010). Tais operadores podem ser vistos como de aplicabilidade universal (CODD, 1970), embora o seu uso nem sempre seja o mais adequado. Por exemplo, a consulta "Recupere todas as imagens cujos pixeis sejam exatamente iguais aos da imagem da 'Monalisa' que tenho em mãos” tem pouco sentido prático.

Uma segunda forma de comparação presente nos SGBDs é a chamada Relação de Ordem, que depende dos operadores de comparação por ordem $(>, \geq,<, \leq)$. Estes operadores são irrestritamente aplicáveis a conjuntos ordenáveis (GANTER; WILLE, 2012). Na medida em que um critério de ordenação é definido para pequenas cadeias de caracteres e datas, tais operadores também podem ser usados na recuperação destes domínios no contexto de um SGBD (KANELLAKIS, 1989; CODD, 1970). Não obstante, consultas baseadas em Relações de Ordem também apresentam problemas semânticos similares aos vistos na Relação de Identidade. Por exemplo, a consulta "Recupere todas as imagens cuja largura seja maior do que a da imagem da 'Monalisa' que tenho em mãos” também tem pouco sentido prático.

Com o objetivo de comparar dados por conteúdo, operadores semanticamente mais convenientes são aqueles baseados na avaliação por (dis)similaridade (CHÁVEZ et al., 2001; ZEZULA et al., 2006; SAMET, 2006). Aqui denominamos Relação de Similaridade as avaliações por meio de operadores de comparação que fazem uso de uma função de distância para expressar 
a similaridade entre dois tipos de dados como um valor real. Nesse contexto, quanto maior o valor de distância obtido, maior a dissimilaridade entre o par de elementos comparados (ZEZULA et al., 2006; PESTOV, 2000; SILVA et al., 2013). Por exemplo, a consulta "Recupere as cinco imagens mais parecidas a imagem da 'Monalisa' que tenho em mãos considerando a similaridade entre elas" pode se valer do uso de uma função de distância para recuperar as imagens similares de acordo com uma expectativa visual do usuário.

O uso de comparadores por similaridade possibilita a execução de consultas por similaridade em uma ampla gama de aplicações, tais como recuperar músicas que são parecidas com um determinado trecho de som (ARENTZ; HETLAND; OLSTAD, 2005), identificar plágio e padrões em um conjunto de documentos (NAVARRO; NEKRICH, 2012), recuperar um conjuntos de imagens mais parecidas (BATKO et al., 2010; SEDMIDUBSKY; MIC; ZEZULA, 2015) ou até mesmo recuperar casos e laudos passados que tenham as imagens mais parecidas com a de um exame ainda não diagnosticado para um radiologista (DEPEURSINGE et al., 2010). Consultas por similaridade têm sido estudadas com profundo interesse por diferentes comunidades, uma vez que essas consultas são a base (total ou parcial) de outras tarefas computacionais modernas, incluindo classificação (HOULE et al., 2010; PESTOV, 2013; TOMAŠEV et al., 2014), agrupamento (SIM et al., 2013; TOMASEV et al., 2014b) e recuperação por conteúdo (CHÁVEZ et al., 2001; TANGELDER; VELTKAMP, 2004; SILVA et al., 2013; LOKOČ; BLAŽEK; SKOPAL, 2014).

Dada a possibilidade de otimizar o funcionamento de todas essas tarefas, um grande esforço de pesquisa tem sido colocado na inclusão de consultas por similaridade dentro do contexto de um SGBD relacional. As vantagens decorrentes dessa integração vão além do suporte escalável a grandes bases de dados multimídia, uma vez que um SGBD com suporte à consultas por similaridade também poderia responder a consultas usando combinações das Relações de Identidade, Ordem e Similaridade (ALY; AREF; OUZZANI, 2012; MARRI et al., 2016). De maneira geral, essa integração depende do cumprimento de cinco requisitos:

1. Definição de novos operadores relacionais para dar suporte aos operadores de comparação por similaridade.

2. Expressão em álgebra relacional para definir as propriedades dos novos operadores.

3. Definição de estruturas de indexação e operadores físicos para agilizar a execução destes novos operadores relacionais.

4. Extensão da linguagem SQL para dar suporte à consultas por similaridade.

5. Extensão do otimizador de consultas que possibilite a melhor forma de executar consultas envolvendo comparações por similaridade.

Aqui destacamos que diversas iniciativas têm procurado, de formas diferentes, atender a esses requisitos. Por exemplo, alguns protótipos (middlewares (BARIONI et al., 2006; SILVA et al., 
2010; LOKOČ; GROŠUP; SKOPAL, 2012), APIs (KASTER et al., 2010) e frameworks (BATKO; NOVAK; ZEZULA, 2007)) vêm sendo desenvolvidos na literatura para possibilitar a tratativa de consultas por similaridade em SGBD tradicionais. Muitos desses protótipos também definem extensões para a linguagem SQL (AMATO; MAINETTO; SAVINO, 1997; BARIONI et al., 2009; BUDIKOVA; BATKO; ZEZULA, 2012) e utilizam estruturas de indexação concebidas especificamente para consultas por similaridade (CIACCIA; PATELLA; ZEZULA, 1997; TRAINA JR. et al., 2000; SKOPAL; POKORNỲ; SNASEL, 2004; NOVAK; BATKO; ZEZULA, 2011; CHEN et al., 2017b). De forma paralela, trabalhos recentes têm focado na extensão da álgebra relacional para definir novos operadores relacionais que incluam os comparadores por distância (SILVA et al., 2010; MARRI et al., 2014; TANG et al., 2016). Portanto, dentre os pontos acima destacados, o otimizador de consultas é o ponto que apresenta menor desenvolvimento, pois, além de depender das definições algébricas dos itens 1 e 2, depende também da definição de um ferramental estatístico diferente do usado para as Relações de Identidade e Ordem já presentes em um SGBD. Desta forma, nesta tese, procuramos avançar em diversos aspectos a extensão do otimizador de consultas para dar suporte à buscas por similaridade considerando-se o contexto de um SGBD.

\subsection{Motivação}

Os SGBDs tradicionais podem empregar otimizadores de consultas para escolher dentre os planos de execução de consultas ${ }^{1}$ equivalentes aquele mais adequado (ou, computacionalmente, mais barato). A Figura 1 mostra a sequência de passos em um otimizador de consultas, com foco na estrutura do Planejador de consultas e seus módulos de suporte, onde o custo é efetivamente calculado (GRAEFE; MCKENNA, 1993; GRAEFE, 1995; IOANNIDIS, 1996; GARCIAMOLINA; ULLMAN; WIDOM, 2000). Inicialmente a consulta é representada por meio de uma sequência de operadores relacionais que definem os dados a serem recuperados e os critérios empregados na busca. Na sequência, essa representação algébrica é transformada em um grupo de representações equivalentes que são, então, submetidas ao Planejador para terem seus custos avaliados. A representação de custo mais adequada é selecionada e executada para resolver a consulta (GRAEFE; MCKENNA, 1993; GRAEFE, 1995).

Portanto, um SGBD com suporte à consultas por similaridade também deveria ser capaz de usar o Planejador para calcular o custo de consultas envolvendo comparações por similaridade, desde que as representações algébricas fossem entregues adequadamente (FERREIRA et al., 2011; ALY; AREF; OUZZANI, 2012; SILVA et al., 2013). De acordo com esse contexto, propomos neste trabalho a extensão dos dois módulos em destaque na Figura 1, nomeadamente o Espaço de Distribuição de Dados e o Modelo de Custo. O módulo Espaço de Distribuição de Dados gera representações concisas da distribuição dos dados armazenados, denominadas sinopses

1 Um plano de execução de consulta pode ser visto como uma forma ordenada (sequencial ou paralela) de resolução de uma consulta por meio de um conjunto pré-definido de algoritmos que implementam o comportamento dos operadores relacionais. 


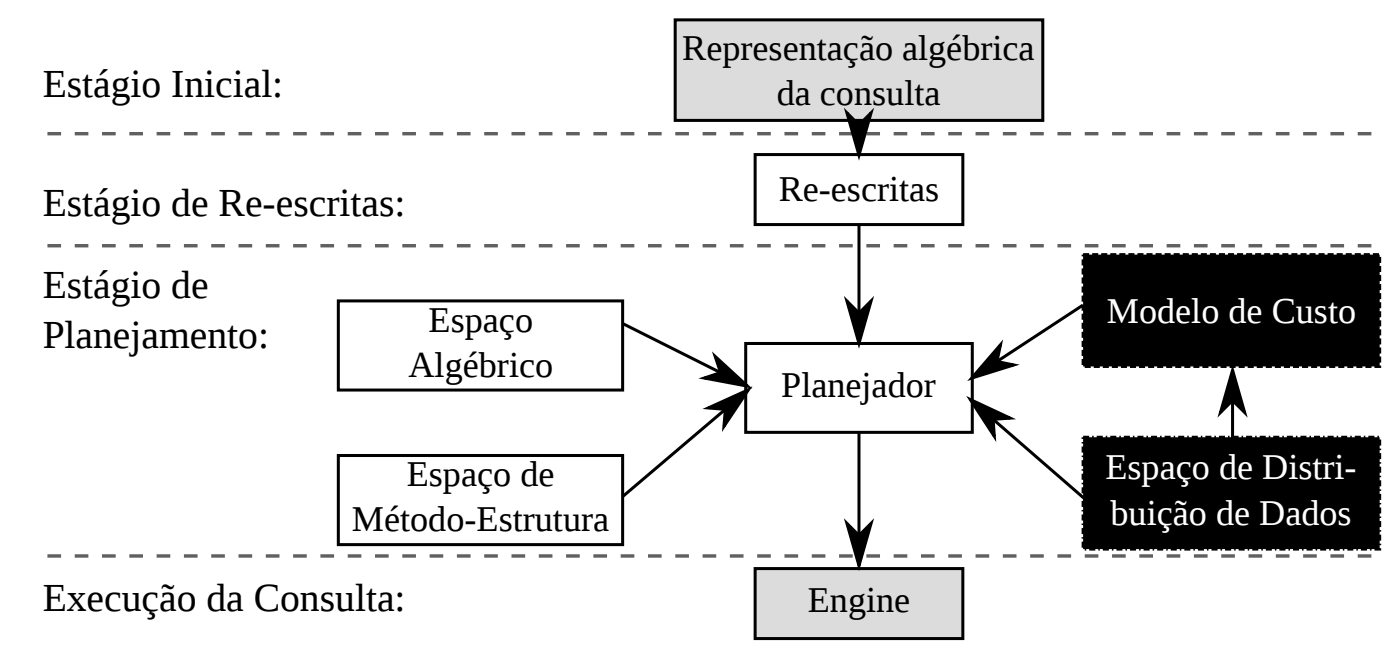

Figura 1 - Sequência de passos típica de otimização em um SGBD com relação aos módulos internos do otimizador de consultas. Os dois módulos Modelos de Custo e Espaço de Distribuição de Dados em destaque são os responsáveis por disponibilizar as sinopses e calcular o custo da execução de cada um dos operadores relacionais. Adaptado de Ioannidis (1996).

(KÖNIG; WEIKUM, 2002; CORMODE et al., 2012). No cenário específico tratado nesta tese, e conforme detalhado no Capítulo 3, verifica-se que, isoladamente, as distribuições de dados não são suficientes para obter uma estimativa adequada dos custos de consultas por similaridade, de maneira que este módulo precisa ser estendido para contemplar as chamadas distribuições de distância (e variações) (CIACCIA; PATELLA; ZEZULA, 1998; PESTOV, 2000; TASAN; OZSOYOGLU, 2004; ZEZULA et al., 2006; FRANCOIS; WERTZ; VERLEYSEN, 2007; DURRANT; KABÁN, 2009). Consequentemente, se faz necessária a definição de novas sinopses para representar essas distribuições, bem como a definição de novas regras sobre como usar estas sinopses, levando em conta o erro inerente de aproximação e o tipo de consulta por similaridade. O módulo que gerencia as distribuições de dados deve, portanto, ser ampliado para um Espaço de Distribuição de Dados e Distâncias. Destacamos que as sinopses somadas às meta-informações numéricas sobre os índices e registros contidos no Espaço de Método-Estrutura, constituem o chamado Catálogo de Estatísticas (GRAEFE; MCKENNA, 1993; IOANNIDIS, 1996) e que, nesse sentido, a criação de novas sinopses amplia o Catálogo de Estatísticas de um SGBD.

A definição e instanciação de novas sinopses que dão suporte à distribuição de distâncias no Catálogo de Estatísticas ampliado permite atacar problemas de otimização de consultas em dois cenários distintos. No primeiro cenário, o Planejador pode empregar as sinopses para estimar o custo de consultas que envolvem comparações por similaridade. Dessa forma, o Planejador deve adotar um modelo de custo sendo, por vezes, facultativa a escolha das sinopses que serão empregadas na estimativa de custo final e o uso de outras meta-informações presentes no Espaço de Método-Estrutura. Este cenário está ligado a otimização lógica da consulta, exemplificada na Seção 1.1.1. Por outro lado, em um segundo cenário, o Planejador pode empregar as sinopses do Catálogo de Estatísticas ampliado para refinar ou parametrizar as estruturas de indexação e algoritmos de busca no módulo Espaço de Método-Estrutura, de maneira que o operador físico 
que depende dessas estruturas seja executado de forma mais eficiente. Esse segundo contexto está ligado a otimização física, como é exemplificado na Seção 1.1.2.

\subsubsection{Otimização Lógica}

Para ilustrar a importância da otimização lógica por meio do Planejador de consultas, considere a consulta $\mathbf{C 1}$ a seguir: "Recupere todas as palavras mais similares a 'Quadro' tal que as palavras recuperadas não variem em mais de 3 letras e que sejam apenas substantivos”. Essa consulta envolve dois operadores de comparação, um por identidade (classe gramatical = 'substantivo') e um por similaridade (palavras mais similares a 'Quadro' em até 3 letras) (LEVENSHTEIN, 1966). Uma vez que esses operadores de comparação possam ser adequadamente representados por meio de operadores da álgebra relacional (SILVA; AREF; ALI, 2010b), o otimizador precisa decidir qual a ordem de execução dos operadores algébricos.

Por exemplo, o otimizador pode selecionar um plano PC1, onde filtra todas as palavras que estejam dentro da variação de três letras e depois escolhe dentre elas as que são substantivos, ou empregar um plano PC2, onde filtra todos os substantivos e depois verifica quais são as palavras que estão dentro da faixa da distância fixada de letras. Essa decisão é feita no nível de otimização lógica e leva em consideração $(i)$ a seletividade (proporção de elementos filtrados) do operador algébrico que é dada usando-se um cálculo direto sobre a sinopse e (ii) o custo da execução do operador físico que é dado pelo custo estimado da seletividade aplicado à relação em análise considerando-se as meta-informações disponíveis no Espaço de Método-Estrutura. O Planejador da consulta emprega um modelo de custo para considerar o custo de todos os operadores envolvidos na execução e determina o custo total de cada um dos possíveis planos de execução avaliados (GRAEFE, 1995; IOANNIDIS, 1996; KORTH; SUDARSHAN; SILBERSCHATZ, 2010). Finalmente, a Engine do SGBD, no nível físico, irá executar um determinado algoritmo descrito no Espaço de Método-Estrutura (possivelmente usando um índice) para realizar a primeira filtragem sobre similaridade se PC1 for escolhido pelo Planejador, ou um segundo algoritmo (possivelmente usando outro índice) para realizar a primeira filtragem sobre a categoria gramatical se PC2 for o plano escolhido.

$\mathrm{Na}$ literatura existem poucos modelos de custo para consultas por similaridade (BELUSSI; FALOUTSOS, 1995; CIACCIA; PATELLA; ZEZULA, 1998; TAO et al., 2004; ALY; AREF; OUZZANI, 2015). Além disso, estes modelos são frequentemente enviesados pela adoção de uma única sinopse fixa ou são baseados na adoção de uma função de probabilidade adotada de antemão o que tende a enrijecer tanto a flexibilidade do modelo (CHRISTODOULAKIS, 1984; IOANNIDIS; CHRISTODOULAKIS, 1993) quanto a acurácia do custo predito (TASAN; OZSOYOGLU, 2004). Por outro lado, algumas das estratégias para otimização física (abordadas na Seção 1.1.2) incluem sugestões de sinopses (JIN; KOUDAS; LI, 2004; VIEIRA et al., 2007) que: ou poderiam melhorar o desempenho de algum modelo de custo; ou, poderiam ser combinadas para obtenção de uma estimativa mais precisa. $\mathrm{O}$ uso eficiente de novas sinopses, bem como a parametrização dos 
modelos de custos, nos moldes existentes em SGBD tradicionais, e tal qual ilustrado na Figura 1, depende da unificação do conceito de distribuição de distância. Com isso, as estimativas previstas sobre as sinopses podem ser tratadas de forma separada dos modelos de custo. Mais do que isso, uma vez que as sinopses estejam isoladas, elas podem ser usadas para quaisquer novos tipos de consultas por similaridade.

A adoção deste fluxo hierárquico na perspectiva de um otimizador de consultas desvela, com maior clareza, tanto a necessidade de novas sinopses quanto o fato que modelos de custos para consultas por similaridade devem ser paramétricos. Finalmente, um último tópico a ser tratado em relação à otimização lógica é referente à definição de quando não é possível otimizar consultas que envolvem comparações por similaridade, um cenário que é particularmente esperado quando certas condições de concentração de distância são satisfeitas (FRANCOIS; WERTZ; VERLEYSEN, 2007; DURRANT; KABÁN, 2009; KABÁN, 2012). Nesse cenário, evitar a fase de otimização lógica leva a redução de custos no processo de execução da consulta e o desafio se torna determinar quando empregar ou não o processo de otimização.

\subsubsection{Otimização Física}

Os algoritmos contidos no módulo Espaço de Método-Estrutura muitas vezes são paramétricos e também podem se beneficiar de informações obtidas pelas sinopses no estágio de otimização (JIN; KOUDAS; LI, 2004; TASAN; OZSOYOGLU, 2004; VIEIRA et al., 2007). Por exemplo, considere a seguinte consulta $\mathbf{C 2}$ "Recupere as cinco pinturas mais similares à 'Monalisa' de Da Vinci”. Supondo que usar um índice seja a técnica escolhida para resolver a consulta, temos que nenhum limite de distância foi definido a priori para essa consulta (ao contrário da busca C1 onde este limite foi explicitamente marcado em 3 unidades), de forma que não é possível, inicialmente, parametrizar a busca no índice por meio do uso do valor máximo de distância tolerável (ZEZULA et al., 2006; CHEN et al., 2017b).

$\mathrm{Na}$ literatura da área, o algoritmo base para pesquisar o índice neste tipo de consulta segue uma premissa de otimização branch-and-bound, onde começa com um limite teórico de distância infinito que é reduzido à medida que o índice é escrutinado (CIACCIA; PATELLA; ZEZULA, 1997). Nesse sentido, muitos candidatos falso-positivos são incluídos e depois descartados enquanto o conjunto resposta vai sendo montado. Uma variação deste algoritmo-base é começar com um valor de distância inferido por alguma sinopse, para evitar avaliações de distância e inserções e remoções na lista de resposta que depois se revelem ser desnecessárias (TASAN; OZSOYOGLU, 2004; VIEIRA et al., 2007). Essa variação é capaz de aumentar substancialmente o desempenho do algoritmo e consiste no que denominados de otimização física, pois otimiza a estratégia que executa o operador da consulta. Outros algoritmos para a resolução desse tipo de consultas são variações do chamado algoritmo incremental (HJALTASON; SAMET, 1999; HJALTASON; SAMET, 2003), sendo que estes, potencialmente, também podem se beneficiar da otimização física para aumentar seu desempenho (TAO et al., 2004; SAMET, 2008). Logo, além 
do uso na otimização lógica como visto na Seção 1.1.1, boas sinopses também podem ter papel importante na otimização dos operadores físicos de consultas por similaridade.

\subsection{Hipótese e Proposta}

Dada a estrutura de um SGBD e os recentes avanços na inclusão de consultas por similaridade nestes ambientes (BATKO; NOVAK; ZEZULA, 2007; SILVA et al., 2010; LOKOČ; GROŠUP; SKOPAL, 2012), podemos perceber que a extensão do Catálogo de Estatísticas e a definição de Modelos de Custo para este tipo de consultas é mais uma etapa que deve ser cumprida para que SGBDs possam efetivamente tratar comparações por similaridade. Não obstante, essa extensão deve ser transparente e flexível para que o Planejador de consultas possa escolher as opções mais convenientes para cada consulta e cada base de dados. Diante desse cenário, a Hipótese da Extensão corresponde à tese defendida neste trabalho.

Hipótese da Extensão
O Catálogo de Estatísticas e os Modelos de Custos dos otimizadores de consultas de Sistemas
de Gerenciamento de Bases de Dados do paradigma relacional podem ser estendidos, de
maneira transparente, para contemplar informações sobre distribuição de distâncias, de forma
a auxiliar o otimizador de consultas tanto no processo de otimização lógica quanto no processo
de otimização física.

Particularmente, dividimos a investigação da Hipótese da Extensão em cinco frentes de trabalho, com o objetivo final de criar uma coleção de sinopses e um conjunto de modelos de custo que possam vir a ser úteis para diversos domínios que requeiram o uso de consultas por similaridade. Portanto, a investigação conduzida neste trabalho concentra-se nos seguintes objetivos, dispostos na ordem em que se conectam a um ambiente de otimização de consultas:

1. Formalização do conceito de distribuição de distâncias e criação/adoção de sinopses unidimensionais para dar suporte apenas a operadores de comparação por similaridade Extensão do módulo de ‘Espaço de Distribuição de Dados' do otimizador de consultas.

2. Criação/adoção de modelos de custo para dar suporte à otimização lógica de consultas que envolvam ao menos uma comparação por similaridade - Extensão do módulo 'Modelo de Custo' do otimizador de consultas.

3. Criação de sinopses multidimensionais para dar suporte à operadores de comparação por similaridade, identidade e ordem na otimização lógica e física - Extensão dos módulos 'Espaço de Distribuição de Dados' e 'Método-Estrutura' do otimizador de consultas.

4. Criação de um modelo de custo para definir quando a otimização física é possível ou factível - Extensão do módulo 'Modelo de Custo' do otimizador de consultas. 
5. Integração das novas sinopses e modelos de custo sob uma sintaxe transparente de alto nível que possa ser facilmente incorporada em um otimizador de consultas - Avaliação da Hipótese da Extensão.

Para alcançar esses objetivos, foi conduzida uma revisão bibliográfica ao longo de toda a duração do trabalho, implementação usando tanto codificação própria quanto adaptação de software de terceiros e aplicação dos métodos propostos em conjuntos de dados reais e públicos, sempre fazendo a comparação dos resultados com referências importantes na área para a validação dos resultados obtidos.

\subsection{Contribuições}

As principais contribuições desta tese foram obtidas a partir dos cinco objetivos traçados para este trabalho. A primeira contribuição compreende o estudo de distribuição de distâncias sobre a perspectiva de estatística frequentista e a implementação de uma nova sinopse, denominada Histograma Compactado de Distância (Compact-Distance Histogram - CDH) para a representação dessas distribuições como uma spline, de forma que restrições de construção bem definidas possam ser observadas e o erro de aproximação possa ser conhecido. A nova sinopse proposta é embasada em critérios de construção de histogramas que minimizam o espaço ocupado em memória principal, e portanto sua construção é feita por um algoritmo incremental. É possível usar as frequências armazenadas em um $\mathrm{CDH}$ para estimar um limite máximo de distância, de modo que sua aplicabilidade na otimização de operadores físicos é imediata. A mesma sinopse também pode ser empregada para estimativas de seletividade, o que possibilita seu uso também para a otimização lógica. No sentido de reduzir o erro de aproximação quando apenas um CDH é usado, foi proposto o uso de vários CDH's que são usados independentemente, de maneira que mais de uma sugestão de seletividade/distância pode ser obtida ao mesmo tempo pelo Planejador. Essa estratégia se mostrou eficaz no aumento da precisão das estimativas fornecidas tanto para otimização lógica quanto para otimização física.

A segunda contribuição deste trabalho é a definição de um modelo de custo para árvores métricas baseado em CDH's que denominamos Stockpile. Esse modelo utiliza um grupo de CDH's independentes e informações sobre os índices envolvidos na execução de cada consulta por similaridade para predizer o custo da execução em termos de tempo de processamento (números de cálculos de distância) e memória (quantidade de nós da árvore visitados). Cada instância do modelo Stockpile depende de cada conjunto de dados, da quantidade de CDH's empregados e das restrições de memória no ambiente do otimizador. Por usar diversos CDH's, o modelo de custo é capaz de capturar densidades locais, próximas ao elemento de referência da consulta, e entregar previsões mais precisas do que a dos modelos de custo existentes na literatura.

Uma vez que as restrições de memória são fixadas de antemão, de acordo com a disponibilidade do $\mathrm{SGBD}$, propusemos uma variação no uso de múltiplos $\mathrm{CDH}$, de forma que 
seu particionamento não seja independente para cada distribuição de distância. $\mathrm{O}$ uso nãoindependente e coordenado de histogramas de distância é a terceira contribuição deste trabalho, que denominamos Histogramas-Omni (Omni-Histograms). Basicamente, Histogramas-Omni empregam restrições de particionamento de histogramas que são capazes de dividir o espaço de busca em hiper-regiões, que constituem o que denominamos Omni-faixas. A frequência de distâncias dentro de cada Omni-faixa pode ser determinada por um outro histograma sobre qualquer distribuição de dados ortogonal. Os Histogramas-Omni são uma representação multidimensional, que permitem estimar a seletividade de critérios envolvendo comparações por Relações de Identidade, Ordem e Similaridade. Mais do que isso, ao combinar distribuições de distância e dados de modo simultâneo, Histogramas-Omni permitem a geração de estatísticas personalizadas para cada consulta.

Quando adicionamos uma camada para o armazenamento dos elementos dentro de cada Omni-faixa (em um raciocínio análogo a um índice não-clusterizado) (GARCIA-MOLINA; ULLMAN; WIDOM, 2000; KORTH; SUDARSHAN; SILBERSCHATZ, 2010), obtém-se um índice construído a partir de uma sinopse. No melhor do nosso conhecimento, esta é a primeira estrutura de indexação para consultas por similaridade construída a partir de um histograma. A realização de consultas sobre este índice permite melhorar a eficiência, pois todas as frequências dos Omni-faixa estão disponíveis de antemão e diversas otimizações podem ser realizadas pelos algoritmos de busca por similaridade. Essa característica foi mostrada empiricamente na comparação com outras estratégias de indexação da literatura.

A quarta contribuição deste trabalho é estabelecer um limite teórico para a otimização física que pode ser obtida por índices na execução de consultas por similaridade. Partindo da premissa que as sinopses implementadas são também capazes de capturar o fenômeno de concentração de distâncias (FRANCOIS; WERTZ; VERLEYSEN, 2007; DURRANT; KABÁN, 2009; PESTOV, 2013) com relação à dimensão de imersão do conjunto de dados original, propusemos o modelo denominado Modelo de Concentração da Variância Relativa (Relative Variance Concentration Model - RVRM), o qual possibilita prever quando é vantajoso utilizar um índice para resolver uma consulta ou quando este uso apenas gera sobrecarga.

Dado um redutor de dimensionalidade e um nível de confiança, nosso modelo é capaz de identificar o número máximo de dimensões para as quais o uso de um índice é útil. Caso um índice não exista, o modelo é capaz de predizer se a construção do índice (e, consequentemente sinopses) é realmente vantajosa para o processo de otimização. Em outras palavras, o modelo proposto usa as informações das sinopses para identificar quando sinopses devem ou não ser usadas para otimização. Adicionalmente, o modelo mostrou resultados interessantes também para a definição do número de dimensões relevantes que maximizem a precisão de tarefas de classificação em algoritmos que envolvem usar funções de distância. Nós avaliamos o modelo proposto sobre diversos conjuntos de dados e redutores de dimensionalidade, sendo que os resultados mostraram que os comportamentos nas tarefas de indexação e classificação são 
diferentes para conjuntos de dados reduzidos à chamada "dimensão intrínseca" (NAVARRO et al., 2017) e os reduzidos de acordo com um valor limite de dimensionalidade indicado pelo modelo RVRM para cada uma das estratégias de redução testadas.

Finalmente, a quinta contribuição deste trabalho é referente à ferramenta de integração que desenvolvemos para as sinopses e modelos propostos em otimizadores de consulta de SGBDs, adotando uma sintaxe de alto nível para seu controle. Nossa ferramenta, denominada Merkurion, é capaz de construir uma grande quantidade de sinopses para descrever as distribuições de distâncias e empregá-las tanto para a previsão de seletividade quanto para a previsão de distâncias, as quais podem ser usadas para a otimização física de algumas estruturas de índice. A sintaxe proposta inclui os comandos CREATE SYNOPSIS e ESTIMATE. O primeiro comando permite a construção paramétrica de diversas sinopses, incluindo histogramas, sinopses híbridas e funções de densidade de probabilidade. Já o segundo comando permite obter estimativas de seletividade e distâncias que podem ser diretamente usadas para otimizações lógicas e físicas. Usando uma interface em linha de comando, o protótipo permite a integração da ferramenta com qualquer SGBD com suporte à consultas por similaridade, seja ele um middleware ou uma API.

As contribuições deste trabalho de doutorado permitem avançar o tópico de otimização lógica e física de consultas por similaridade por meio da formalização de uma base teórica comum para distribuições de distância, da definição de novas sinopses, do desenvolvimento de algoritmos paramétricos para buscas por similaridade em índices, da definição de modelos de custos, além do desenvolvimento de um protótipo de módulo de otimizador de consultas com sintaxe própria. Todas as contribuições foram desenvolvidas com o propósito de manter a otimização de consultas por similaridade como um processo "caixa-branca", i.e. um conjunto de passos bem definidos e modulares, bem como propiciar a integração destes resultados em um SGBD com capacidade de processar esse tipo de consultas da forma mais transparente possível.

A partir dos resultados obtidos, espera-se que seja possível ao analista de bancos de dados, no futuro, projetar e testar diversas configurações de otimização de planos de consulta que envolvam Relações de Similaridade, ou investigar estratégias de auto-refinamento e tuning de consultas por similaridade como já ocorre com os SGBDs tradicionais quando Relações de Identidade e Ordem são usadas nas consultas (CHAUDHURI; NARASAYYA, 2007; KORTH; SUDARSHAN; SILBERSCHATZ, 2010).

\subsection{Estrutura do documento}

Além deste capítulo inicial, o texto desta tese está organizado em outros sete capítulos, como descrito a seguir:

- O Capítulo 2 mostra como consultas por similaridade são modeladas com o uso da teoria de Espaços Métricos, inclui a base teórica e notação para o restante do texto e ilustra alguns 
dos principais tipos de comparação por similaridade e suas variações. Além disso, esse capítulo apresenta uma breve revisão de estratégias de indexação para espaços métricos e quais são as consultas e algoritmos que se beneficiam com tais estratégias. Em sua conclusão, este capítulo discute como a literatura cataloga as estruturas de indexação em espaços métricos, cita exemplos e discute quais são os princípios dos algoritmos que executam buscas por similaridades sobre os índices.

- O Capítulo 3 apresenta uma categorização de tipos de sinopses e aborda com detalhes a construção de histogramas para a representação de distribuição de dados. Na sequência, é apresentada a notação que empregamos para a representação de distribuição de distâncias e são mostradas algumas das principais sinopses já existentes para a representação de distâncias. Além disso, é discutido como estas sinopses são usadas em modelos de custo da literatura e na otimização lógica e física.

- O Capítulo 4 apresenta as duas primeiras contribuições desta tese. Nele é apresentado uma nova sinopse, denominada $\mathrm{CDH}$, para distribuições de distâncias baseadas em pivôs que são construídas como splines que obedecem critérios fixados pelo usuário em termos de memória empregada. Também é discutida a premissa da densidade uniforme e como CDH's podem ser usados para otimização lógica e física de consultas por similaridade. Ao final do capítulo é apresentado um novo modelo de custo, denominado Stockpile, que emprega CDH's no tratamento de dois tipos de consultas por similaridade com o objetivo de predizer os custos de processamento e memória - Esse capítulo foi escrito com base em duas publicações em conferências.

- O Capítulo 5 descreve a terceira contribuição deste trabalho, os Histogramas-Omni, apresentando-os como uma sinopse multidimensional para distribuições de distância baseadas em pivô. Também é descrito como essa sinopse pode fornecer estimativas para otimização lógica de consultas que envolvam, simultaneamente, Relação de Similaridade, de Identidade ou de Ordem. Por fim, é detalhado como os Histogramas-Omni podem ser empregados na construção de uma estrutura de indexação que permita a execução otimizada de consultas por similaridade - Esse capítulo foi escrito com base em um artigo a ser submetido em conferência no segundo semestre de 2017.

- O Capítulo 6 detalha uma sintaxe para a integração das sinopses e modelos de custo desenvolvidos nos capítulos anteriores em um ambiente de SGBD com suporte à consultas por similaridade. Nesse capítulo também são descritas as implementações das sinopses e é apresentada a arquitetura de um middleware-protótipo, que inclui uma interface em linha de comando que permite que as contribuições desta tese sejam diretamente incorporadas por outras iniciativas da literatura - Esse capítulo foi escrito com base em um artigo submetido à revista e atualmente em fase de publicação. 
- O Capítulo 7 apresenta a última contribuição desta tese. Nele é descrito o modelo (RVRM) para a detecção da chamada "dimensão de concentração", que atua como dimensão limite para o uso de técnicas de indexação e previne o fenômeno de concentração de distâncias. O modelo é descrito como uma ferramenta do tipo wrapper que utiliza qualquer técnica de redução de dimensionalidade fornecida pelo usuário para determinar a dimensão de concentração. A dimensão obtida pelo modelo também é interessante para outras tarefas, e.g. classificação - Esse capítulo foi escrito com base em um artigo a ser submetido em revista no segundo semestre de 2017.

- O Capítulo 8 traz as conclusões deste trabalho, incluindo as dificuldades encontradas, as publicações geradas durante a avaliação da Hipótese da Extensão, além de propostas de trabalhos futuros. 


\section{Consultas por Similaridade}

“...then he added, as if requiring a response to his own remark, 'Probably the greater the difference, the greater the similarity, and the greater the similarity, the greater the difference,' at that moment he did not yet know how right he was."

José Saramago - All the Names ${ }^{1}$

O termo consulta por similaridade é usado nesta tese para identificar o processo de recuperação de informação que leva em consideração o conteúdo dos dados em análise, sejam eles multimídia, textos longos, sequências químicas ou, até mesmo, números reais. Dois tipos de abordagem são amplamente utilizados na literatura para a execução de uma consulta por similaridade, as comparações por contexto e as comparações por distância (LIU et al., 2007; SILVA et al., 2013). As comparações por contexto se valem de uma meta-descrição dos dados a serem comparados. Por exemplo, essas descrições podem ser na forma de tags, palavraschave, ontologias ou rótulos que são associados aos dados comparados tanto por meio de especialistas humanos quanto por estratégias que envolvam processos de rotulação, incluindo tarefas de aprendizado supervisionado, semi-supervisionado ou aprendizado ativo (SIDDIQUIE; GUPTA, 2010; VINYALS et al., 2015). Exemplos dessa abordagem incluem diversas aplicações de recomendação de conteúdo na $w e b$, processamento de língua natural e busca em dados não-estruturados (DESCHACHT; MOENS, 2009; SAPPELLI; VERBERNE; KRAAIJ, 2017).

Por outro lado, as comparações por distância são capazes de expressar a similaridade entre pares de elementos levando em conta apenas a proximidade entre eles. Essa abordagem tem como motivação a lógica na qual "a redução de similaridade a uma comparação por distância

1 No livro de José Saramago, o personagem vive o dilema de encontrar diferenças e similaridades entre personagens de recortes de revista, uma dificuldade compartilhada com muitas estratégias e algoritmos de recuperação de informação por conteúdo. 
permite encontrar o número mínimo de características para algoritmos eficientes que resolverão o problema da busca" (CLARKSON, 1997). Dessa forma, os algoritmos para comparação por distância são projetados para serem escaláveis ao tratamento de grandes bases de dados (ZEZULA et al., 2006). Do ponto de vista formal, o problema de comparações por distância pode ser adequadamente modelado pela teoria de Espaços Métricos (O'SEARCOID, 2006). Um espaço métrico $\mathcal{M}$ é composto de um $\operatorname{par} \mathcal{M}=\langle\mathbb{S}, \delta\rangle$, onde $\mathbb{S}$ é o domínio de dados e $\delta$ é uma função, denominada função de distância métrica, ou simplesmente métrica. Uma função de distância métrica $\delta: \mathbb{S} \times \mathbb{S} \rightarrow \mathbb{R}_{+}$deve satisfazer as cinco propriedades métricas, como se segue:

(1) $\forall s_{i}, s_{j} \in \mathbb{S}, \quad \delta\left(s_{i}, s_{j}\right) \geq 0$

(2) $\forall s_{i}, s_{j} \in \mathbb{S}, \quad \delta\left(s_{i}, s_{j}\right)=\delta\left(s_{j}, s_{i}\right)$

(3) $\forall s_{i} \in \mathbb{S}, \quad \delta\left(s_{i}, s_{i}\right)=0$

(4) $\forall s_{i}, s_{j} \in \mathbb{S}, \quad s_{i} \neq s_{j}, \delta\left(s_{i}, s_{j}\right)>0$

(5) $\forall s_{i}, s_{j}, s_{k} \in \mathbb{S}, \quad \delta\left(s_{i}, s_{k}\right) \leq \boldsymbol{\delta}\left(s_{i}, s_{j}\right)+\delta\left(s_{j}, s_{k}\right)$
Não-negatividade, Simetria, Identidade dos Indiscerníveis, Positividade, Desigualdade Triangular

Se a função de distância não satisfizer concomitantemente às cinco propriedades, ainda assim poderá ser usada em alguma aplicação específica como função de avaliação do tipo $\delta$ : $\mathbb{S} \times \mathbb{S} \rightarrow \mathbb{R}$. Diversas funções não-métricas, por exemplo a distância Time-Warp para comparação de séries temporais (KEOGH; RATANAMAHATANA, 2005), são úteis em tarefas que requerem medidas de proximidade em domínios específicos. Divergências, tais como as divergências de Jeffrey, Kullback-Leibler e Jensen-Shannon, em geral também podem ser transformadas em funções de distância e são usadas em problemas específicos (DAGAN; LEE; PEREIRA, 1997; CSISZÁR; SHIELDS, 2004). No entanto, a otimização de buscas em espaços métricos está ligada às cinco propriedades métricas listadas e o uso de funções não-métricas pode inviabilizar computacionalmente consultas em grandes bases de dados (JACOBS; WEINSHALL; GDALYAHU, 2000; BUSTOS; SKOPAL, 2011). Por esta razão, há um esforço de pesquisa considerável voltado à transformação de funções não-métricas em métricas (LIPKUS, 1999; RUBNER; TOMASI; GUIBAS, 2000; KEOGH; RATANAMAHATANA, 2005).

Uma grande quantidade de métricas diferentes pode ser encontrada na literatura, sendo que algumas são mais adequadas para um domínio de problemas do que outras (BUGATTI; TRAINA; TRAINA JR., 2008; BATISTA; SILVA, 2009). Dentre as funções mais genéricas, destaca-se a família das normas $L_{p}$, conhecida também como a família Minkowski (MINKOWSKI, 1910) de funções de distância. Essas métricas têm a mesma estrutura base, sendo que a variação do parâmetro $p, p \in \mathbb{N}_{*}$, define métricas diferentes. Dados dois vetores $d$-dimensionais, uma métrica $L_{p}$ é dada pela Equação 2.1 .

$$
\forall s_{i}, s_{j} \in \mathbb{R}^{d}, L_{p}\left(s_{i}, s_{j}\right)=\left(\sum_{k=1}^{d}\left(s_{i k}-s_{j k}\right)^{p}\right)^{\frac{1}{p}}
$$

onde $k$ corresponde as dimensões de $s_{i}$ e $s_{j}$ avaliadas. As métricas Minkowski mais comumente empregadas são as funções $L_{1}$, também conhecida como City-Block, $L_{2}$, a distância Euclideana ligada ao conceito da norma cartesiana, e a função $L_{\infty}$, conhecida como distância de Chebyshev 
(O'SEARCOID, 2006; SCHWEIZER; SKLAR, 2011). Também é possível encontrar na literatura outras métricas que foram construídas como variações da família $L_{p}$, tais como as funções de distância Canberra, Bray-Curtis e a métrica de Distância Quadrática, que é capaz de capturar correlações entre dimensões (HAFNER et al., 1995; CHA, 2007).

Quando se considera outros domínios que não os espaços multidimensionais, existe ainda uma ampla gama de métricas. Por exemplo, a distância de Levenshtein é projetada para tratar a similaridade entre cadeias de caracteres (LEVENSHTEIN, 1966) e considera o número de inserções, remoções e alterações como o valor de distância. A função de distância de Hamming usa princípios similares para calcular a distância entre duas palavras binárias de mesmo comprimento (HAMMING, 1950). Outras métricas também são definidas para domínios de problemas específicos, tais como a distância entre conjuntos de Jaccard (JACCARD, 1912), as métricas do tipo wrapper de Haussdorf (HUTTENLOCHER; KLANDERMAN; RUCKLIDGE, 1993) e a métrica do cosseno, que é limitada ao intervalo real [0,1] (CHA, 2007).

Métricas são definidas para um domínio específico e, portanto, nem sempre é possível empregá-las diretamente sobre o domínio original dos dados. Por exemplo, não é possível aplicar a distância $L_{2}$ diretamente sobre duas imagens e, tampouco, usar a métrica de Jaccard diretamente sobre duas músicas. Nesse sentido, é necessário empregar uma transformação do domínio original dos dados para o domínio da função de distância. Tal transformação pode ser modelada como a aplicação de uma função de "extração de características" para representar somente propriedades importantes dos dados em análise (NIXON; AGUADO, 2012; HINTON; KRIZHEVSKY; WANG, 2011). Portanto, o uso de estratégias de busca sobre espaços métricos requer, como primeiro passo, a aplicação de um método extrator de características sobre os dados de forma que estejam devidamente representados no domínio onde a métrica possa ser aplicada. Formalmente, um método extrator de características é dado pela Definição 2.0.1.

Definição 2.0.1 (Método extrator de características $-\varepsilon$ ). Dado o domínio original dos dados em análise $\mathbb{D}$ e o domínio da função de distância $\mathbb{S}$, um método extrator de características é qualquer função $\varepsilon$ com domínio em $\mathbb{D}$ e contradomínio em $\mathbb{S}$.

sendo que $\varepsilon$ pode ser uma função espelho, i.e. $\mathbb{D}=\mathbb{S}$, mas não existe nenhuma restrição para que $\varepsilon$ seja uma função bijetora. Para não sobrecarregar a notação neste trabalho, assumimos que, quando nos referimos a um elemento em $\mathbb{S}$, temos implicitamente convencionado o uso de um método extrator de características para transformar o dado original.

De forma geral, extratores de características são desenvolvidos para aspectos de cada domínio $\mathbb{D}$ específico. Por exemplo, para o domínio de imagens, extratores clássicos são os relacionados à cor, tais como os métodos Color-Histogram, Color-Layout e Color-Strucuture (MANJUNATH; SALEMBIER; SIKORA, 2002; LIU et al., 2007); à textura, tais como as estratégias de Haralick, Wavelets, Texture-Browsing e Texture Spectrum (REED; DUBUF, 1993; SHARMA; SINGH, 2001); e os relacionados à forma, tais como momentos de Zernike ou transformadas 
Radon para mamografias (KINOSHITA et al., 2007; TANG et al., 2009).

Além dos extratores clássicos orientados a aspectos de domínios específicos, podemos encontrar na literatura extratores genéricos, com desempenho igual ou superior aos extratores clássicos (MIKOLAJCZYK; SCHMID, 2005), mas que utilizam pontos-chave para a representação de objetos no domínio original dos dados. Por exemplo, para o domínio de imagens temos os extratores SIFT e SURF, que são capazes de representar imagens usando pontos-chave (LOWE, 2004; BAY et al., 2008; DESELAERS; KEYSERS; NEY, 2008). O extrator SIFT captura pontos-chave, invariantes à translação escala e rotação por meio de pontos de disrupção, tais como arestas e bordas, e os associa a valores de contrastes relevantes. Estes contrastes são avaliados em uma série de transformações contra contrastes de outros pontos da imagem e sintéticos, sendo que os contrastes menos relevantes são descartados. Pontos não descartados recebem uma orientação definida pelo extrator e são usados para compor a representação no novo domínio.

Recentemente, diversas iniciativas têm proposto substituir os extratores clássicos por uma abordagem única de extração de características e potencialmente aplicável a qualquer domínios de dados indistintamente (LECUN; BENGIO; HINTON, 2015; AMATO et al., 2016). Tais iniciativas são baseadas na premissa de aprender características (feature learning) por meio de um algoritmo supervisionado. A ideia é inferir quais são as características mais relevantes a partir de um amplo conjunto de dados rotulados e com o uso combinado e ordenado de técnicas que envolvem o aumento artificial de dados, redução e limpeza de dimensões e a indução de redes neurais por convolução (VINYALS et al., 2015; HINTON; KRIZHEVSKY; WANG, 2011). Para o domínio de imagens, a qualidade das características extraídas por técnicas de feature learning tem demonstrado, em alguns casos, ser superior as das encontradas pelo uso de extratores clássicos ou genéricos como SIFT e SURF (RAZAVIAN et al., 2014; AFFONSO et al., 2017).

O uso do método extrator é completamente transparente, sendo que a métrica, a primeira vista, é quem avalia a comparação entre os pares de elementos. No entanto, a semântica da comparação por similaridade depende fundamentalmente dos dois parâmetros: o método extrator de características e a função de distância (LIU et al., 2007; BUGATTI; TRAINA; TRAINA JR., 2008). Se o extrator não capturar características relevantes para a comparação, o resultado da busca pode ser insatisfatório. Da mesma forma, se a função de distância não definir adequadamente a relação de proximidade, o resultado da consulta pode ser insuficiente para atender às perspectivas do usuário. Dessa forma, a vinculação destes dois parâmetros constitui o descritor da consulta por similaridade, tal como explícito na Observação 2.0.1.

Observação 2.0.1 (Descritor da consulta por similaridade). Um descritor de consulta por similaridade é composto pelo par 〈extrator de características $\varepsilon$, métrica empregada $\delta$.

A quantidade de possíveis descritores aplicáveis a uma mesma busca aumenta exponencialmente à medida que novos extratores e funções de distância estejam disponíveis para serem usados. Portanto, a escolha do descritor adequado para cada domínio de aplicação normalmente é 
feita por um especialista do domínio (AKGÜL et al., 2011), embora também seja possível empregar estratégias supervisionadas para automatizar esse processo (BUGATTI; TRAINA; TRAINA JR., 2008; KULIS, 2013). Para evitar a sobrecarga da notação, assumimos no restante deste trabalho que apenas um descritor está vinculado a cada consulta por similaridade a ser executada.

\subsection{Critérios empregados em consultas por similaridade}

As consultas por similaridade recuperam elementos cujas distâncias estejam de acordo com algum critério definido de antemão. Dois dos mais comuns critérios de comparação por similaridade são os usados nas buscas por abrangência $(R q)$ e na busca aos $k$-vizinhos mais próximos (k-NN), embora outros critérios também existam (DROSOU; PITOURA, 2010; RADOVANOVIĆ; NANOPOULOS; IVANOVIĆ, 2010; CASANOVA et al., 2017). As próximas seções apresentam uma revisão sobre critérios empregados em consultas por similaridade e discutem a sua adequação como extensão ao conjunto de operadores de comparação (CODD, 1970; DATE, 2011).

\subsubsection{Consultas por Abrangência}

Uma consulta por abrangência permite recuperar todos os elementos de um conjunto de dados que estejam dentro de um raio de cobertura com relação à um elemento de consulta fornecido pelo usuário como referência (CHÁVEZ et al., 2001; SAMET, 2006). Formalmente, uma consulta por abrangência $R q$ é o conjunto de elementos que satisfaz a Definição 2.1.1.

Definição 2.1.1 (Consulta por abrangência - $R q\left(\mathcal{S}, s_{q}, \xi\right)$ ). Dado um espaço métrico $\mathcal{M}=\langle\mathbb{S}, \boldsymbol{\delta}\rangle$, um conjunto de dados $\mathcal{S} \subset \mathbb{S}$, um elemento de consulta $s_{q} \in \mathbb{S}$, e uma distância máxima de busca $\xi \in \mathbb{R}_{+}$, a consulta $R q\left(\mathcal{S}, s_{q}, \xi\right)$ recupera todos os elementos de $\mathcal{S}$ que estão à uma distância de, no máximo, $\xi$ de $s_{q}$ de tal forma que $R q\left(\mathcal{S}, s_{q}, \xi\right)=\left\{s_{i} \in \mathcal{S} \mid \delta\left(s_{i}, s_{q}\right) \leq \xi\right\}$.

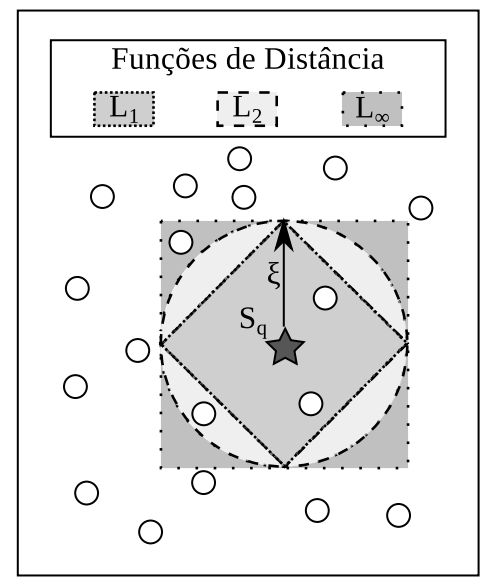

(a)

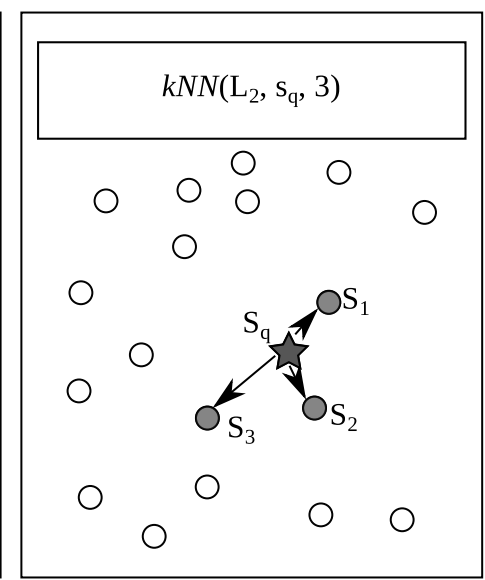

(b)

Figura 2 - Exemplos de consultas por similaridade considerando critérios de abrangência e vizinhança em um espaço de duas dimensões. (a) Consulta por abrangência para métricas $L_{1}, L_{2}$ e $L_{\infty}$ com raio $\xi$. (b) Consulta por vizinhança para três vizinhos considerando a métrica $L_{2}$. Elaborado pelo autor. 
Um exemplo de consulta por abrangência é ilustrado na Figura 2(a). No exemplo, temos o elemento de consulta $s_{q}$ em um espaço de duas dimensões junto ao conjunto-resposta, sendo que este conjunto varia de acordo com as três diferentes métricas da família $L_{p}$ para um mesmo raio. Um exemplo prático da aplicação de uma consulta por abrangência é $\mathbf{C 3}$ "Localize todas as cidades que não distem mais do que 100 unidades de distância de São Carlos”, sendo que o resultado depende da métrica empregada para medir a distância. Embora a consulta por abrangência seja executada sobre um conjunto fixo de dados $\mathcal{S} \in \mathbb{S}$, não existe restrição para que o elemento de consulta $s_{q}$, também denominado centro da consulta, esteja no conjunto consultado. No entanto, é fácil verificar se $s_{q} \in S$ por meio da execução de uma consulta $R q\left(\mathcal{S}, s_{q}, 0.0\right)$ e usando a propriedade métrica da identidade dos indiscerníveis. Esse tipo de consulta, em particular, é também chamado de consulta pontual, e pode ser usada para a coleta de informações sobre o conjunto de dados como detalhado na Seção 2.3.1.2.

Do ponto de vista estrito de um critério de comparação por similaridade, uma consulta por abrangência pode ser entendida como um operador que retorna a admissibilidade de cada elemento do conjunto de dados no conjunto-resposta quando comparados com o elemento de consulta $s_{q}$. De forma geral, o critério por abrangência dá origem ao operador de comparação por abrangência como formalizado na Definição 2.1.2.

Definição 2.1.2 (Operador de comparação por abrangência - $\operatorname{Rng}(\delta, \xi)$ ). Dado um espaço métrico $\mathcal{M}=\langle\mathbb{S}, \delta\rangle$, dois elementos quaisquer $s_{i}$ e $s_{j} \in \mathbb{S}$, e uma distância máxima de busca $\xi \in$ $\mathbb{R}_{+}$, o operador de comparação $\operatorname{Rng}(\delta, \xi)$ retorna verdade para a comparação $s_{i} \operatorname{Rng}(\delta, \xi) s_{j}$ se, e somente se, $s_{i}$ estiver, no máximo, a uma distância de $\xi$ de $s_{j}$.

onde $s_{j}$ pode ser fixado como o centro de consulta comparado com todo $s_{i} \in \mathcal{S}$. Note que o conjunto complementar ao conjunto $R q\left(\mathcal{S}, s_{q}, \xi\right)$ com relação ao o conjunto de dados $\mathcal{S}$ é dado por $\mathcal{S} \backslash R q\left(\mathcal{S}, s_{q}, \xi\right)$ e pode ser obtido por um critério de consulta que denominados consulta por abrangência reversa. Assim como na Definição 2.1.2, é possível definir um novo operador de comparação para a consulta por abrangência reversa bastando usar a condição lógica inversa $\neg R n g(\boldsymbol{\delta}, \xi)$ (FERREIRA et al., 2011; SILVA et al., 2013).

\subsubsection{Consultas por Vizinhança}

Consultas por abrangência podem ser semanticamente insuficientes, pois nem sempre é possível precisar um valor de limite de distância para o conjunto-resposta. Além disso, é interessante ter a expectativa de recuperar um número pré-definido de elementos (limitar a cardinalidade) no conjunto-resposta, o que é trabalhoso quando apenas o valor de distância é usado. Repare que o par $\left\langle s_{q}, \xi\right\rangle$ define uma bola no espaço métrico, usada para modelar a consulta, tal que esta bola pode cobrir mais ou menos elementos a depender do raio limite $\xi$. Valores de $\xi$ muito pequenos podem gerar conjuntos-respostas vazios, ao passo que se $\xi$ for aumentado indiscriminadamente, todos os elementos do conjunto de dados podem ser retornados 
(BöHM; KREBS, 2004; YAO; LI; KUMAR, 2010). Nesse cenário, o mais adequado é a realização de uma consulta por vizinhança para recuperar o equivalente aos $k$-elementos mais próximos do elemento de consulta. Formalmente, uma consulta desse tipo segue a Definição 2.1.3.

Definição 2.1.3 (Consulta por vizinhança - k-NN(S, $\left.s_{q}, k\right)$ ). Dado um espaço métrico $\mathcal{M}=$ $\langle\mathbb{S}, \boldsymbol{\delta}\rangle$, um conjunto de dados $\mathcal{S} \subset \mathbb{S}$, um centro de consulta $s_{q} \in \mathbb{S}$ e uma quantidade de vizinhos $k \in \mathbb{N}$, a consulta k-NN $\left(\mathcal{S}, s_{q}, k\right)$ recupera os elementos de $\mathcal{S}$ que estão entre os $k$ mais próximos de $s_{q}$. Dessa forma, $\mathrm{k}-N N\left(\mathcal{S}, s_{q}, k\right)=\left\{s_{1}, s_{2}, \ldots, s_{k}\right\}$ onde:

$$
\begin{gathered}
s_{1}=\left\{s_{i} \in \mathcal{S} \mid \forall s_{j} \in \mathcal{S}, \boldsymbol{\delta}\left(s_{i}, s_{q}\right) \leq \boldsymbol{\delta}\left(s_{j}, s_{q}\right)\right\} ; \\
s_{2}=\left\{s_{i} \in \mathcal{S} \backslash\left\{s_{1}\right\} \mid \forall s_{j} \in \mathcal{S} \backslash\left\{s_{1}\right\}, \delta\left(s_{i}, s_{q}\right) \leq \delta\left(s_{j}, s_{q}\right)\right\}, \\
\ldots \\
s_{k}=\left\{s_{i} \in \mathcal{S} \backslash\left\{s_{1}, s_{2}, \ldots, s_{k-1}\right\} \mid \forall s_{j} \in \mathcal{S} \backslash\left\{s_{1}, s_{2}, \ldots, s_{k-1}\right\}, \delta\left(s_{i}, s_{q}\right) \leq \delta\left(s_{j}, s_{q}\right)\right\} .
\end{gathered}
$$

A Definição 2.1.3 implica que uma consulta por vizinhança também pode ser vista como uma variação da consulta por abrangência. Em outras palavras, uma consulta por vizinhança é uma consulta por abrangência com um raio máximo fixo com a condição $|R q|=k$ sempre que houver um único $k$-ésimo vizinho (CIACCIA; PATELLA; ZEZULA, 1998; TASAN; OZSOYOGLU, 2004; ZEZULA et al., 2006). Neste trabalho, denotamos essa distância máxima fixada como $\xi_{s_{q} s_{k}}$ de forma que ela é calculada como a maior distância entre $s_{q}$ e os elementos em k-NN $\left(\mathcal{S}, s_{q}, k\right)$. A Figura 2(b) ilustra uma consulta k- $N N$ usando a métrica $L_{2}$ e um valor solicitado de $k=3$. Um exemplo prático da aplicação de uma consulta por vizinhança é a consulta C2 sobre as cinco pinturas mais similares à Monalisa de Da Vinci.

Um aspecto interessante a ser considerado é que empates podem ocorrer no $k$-ésimo elemento, i. e., podem existir vários elementos que estejam à mesma distância do vizinho mais afastado selecionado como parte do conjunto-resposta. Esse tipo de "empate" é tratado de duas formas, a saber, $(i)$ incluir os elementos equidistantes, ou (ii) selecionar arbitrariamente um elemento como representativo e descartar o restante (BEZDEK; CHUAH; LEEP, 1986; PIERRO et al., 2014). Adotar o primeiro tratamento, tal qual na Definição 2.1.3, implica na equivalência estrita entre vizinhança e abrangência, i.e. $\mathrm{k}-N N\left(\mathcal{S}, s_{q}, k\right) \equiv R q\left(\mathcal{S}, s_{q}, \xi_{s_{q} s_{k}}\right)$. Portanto, dado que uma consulta por vizinhança pode ser expressa como uma consulta por abrangência não se faz necessário definir um novo operador de comparação, bastando usar o operador $\operatorname{Rng}\left(\delta, \xi_{s_{q} s_{k}}\right)$ para realizar a operação lógica entre os pares de elementos.

As consultas do tipo k-NN também constituem a base do funcionamento das estratégias supervisionadas do tipo de Aprendizado Baseado em Instâncias. Basicamente, estas estratégias recebem a saída da consulta k-NN e verificam a classe de cada elemento. Dessa forma, dado um elemento não rotulado, é possível inferir seu rótulo usando a classe da maioria dos elementos retornados (AHA; KIBLER; ALBERT, 1991; BATISTA; SILVA, 2009). 


\subsubsection{Outros critérios para consultas por similaridade}

Além dos critérios por vizinhança e abrangência, outros critérios são encontrados na literatura para a execução de consultas por similaridade. Alguns deles fazem referência a possíveis complementos da consulta por vizinhança. Por exemplo, o critério de consulta aos $k$ vizinhos mais distantes permite recuperar, dentre os elementos armazenados, os $k$ elementos mais afastados do centro de consulta (ROUSSOPOULOS; KELLEY; VINCENT, 1995). Outra possibilidade para este complemento é a chamada consulta por vizinhança reversa, que permite recuperar todos os elementos armazenados cuja lista de $k$-vizinhos mais próximos inclua o elemento de consulta.

Essa operação é interessante para determinar quais elementos têm o centro de consulta como um de seus $k$-vizinhos mais próximos (KORN; MUTHUKRISHNAN, 2000; CASANOVA et al., 2017). Um exemplo prático da aplicação de uma consulta envolvendo esse critério é a consulta $\mathbf{C 4}$ "Retorne as imagens de mamografia que incluam esta imagem dada como uma de suas 15 mais similares". A Figura 3 ilustra as diferenças entre uma consulta por vizinhança e uma consulta por vizinhança reversa. Na Figura 3(a) temos que $s_{q}$ é parte do conjunto-resposta para consultas por vizinhança com $k=2$ e centros de consulta $s_{3}$ e $s_{5}$. No entanto, a consulta por vizinhança recupera apenas um dos elementos incluídos na resposta reversa $\left(s_{3}\right)$, como mostrado na Figura 3(b). Esse exemplo ilustra que as consultas por vizinhança e vizinhança reversa são assimétricas, i. e., mesmo que um elemento $s_{i} \in \mathrm{k}-N N\left(\mathcal{S}, s_{q}, k\right)$ não se exclui que $s_{i}$ também faça parte da consulta por vizinhança reversa.

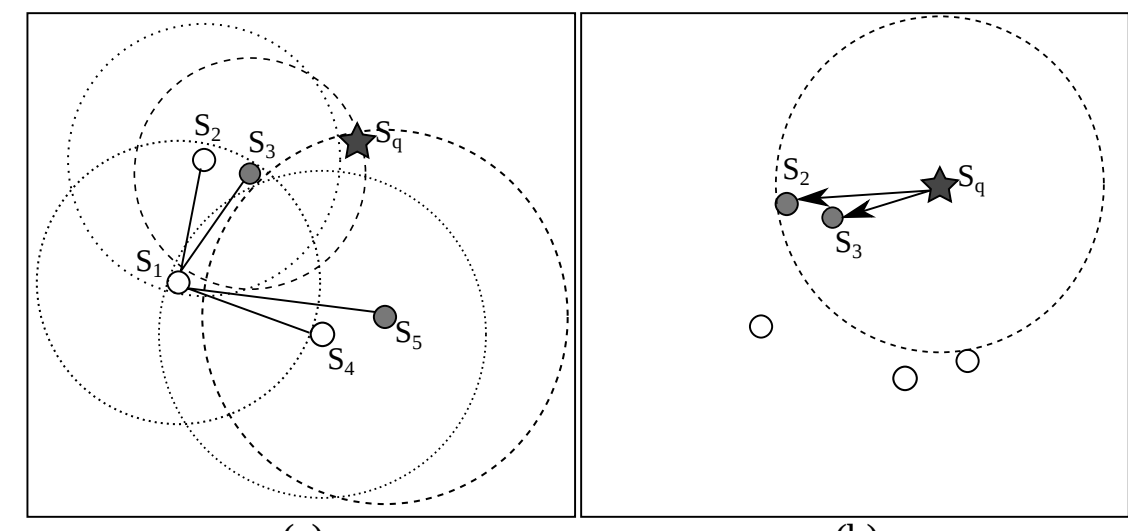

(a)

(b)

Figura 3 - Comparação de uma consulta por vizinhança e uma consulta por vizinhança reversa. (a) A consulta por vizinhança reversa para $s_{q} \operatorname{com} \delta=L_{2}$ e $k=2$, e (b) a consulta k-NN para $s_{q} \operatorname{com} \delta=L_{2}$ e $k=2$. Elaborado pelo autor.

Especificamente para o caso de busca por vizinhança reversa em espaços multidimensionais de alta dimensão é comum a ocorrência do fenômeno conhecido como hubness. Esse fenômeno é a tendência de que conjuntos de dados de alta dimensionalidade tenham elementos que apareçam com muita frequência em quaisquer conjuntos-resposta de $k$-vizinhos mais próximos de centros de consulta aleatórios, sendo que estes elementos que ocorrem com frequência são denominados hubs. Trabalhos recentes têm procurado caracterizar hubs como elementos que residem em regiões de baixa dimensão em espaços de alta dimensionalidade e com isso 
justificar porquê estes elementos são simultaneamente os mais próximos aos demais elementos do conjunto de dados (RADOVANOVIĆ; NANOPOULOS; IVANOVIĆ, 2010). Nesse cenário de alta dimensionalidade, a busca por hubs pode ser mais adequada que a busca por vizinhança ou vizinhança reversa, tanto para encontrar os elementos mais próximos quanto os elementos que sejam centróides do conjunto de dados (TOMAŠEV et al., 2014).

Além do caso específico de busca por vizinhança reversa em espaços de alta dimensionalidade, outro problema pode inviabilizar consultas por vizinhança em bases de dados massivas e com vários elementos muito próximos entre si. Nesse caso, a recuperação dos $k$-vizinhos mais próximos pode retornar um conjunto-resposta cujos elementos sejam também muito parecidos entre eles mesmos, limitando a usabilidade da busca. Para superar este problema, é interessante recuperar elementos que estejam próximos do centro de consulta e, ao mesmo tempo, garantir que elementos não muito próximos entre si também sejam retornados (DROSOU et al., 2017). Este tipo de critério pode ser compreendido como um problema de otimização, cujo objetivo é encontrar um equilíbrio entre um fator de proximidade e afastamento, ou ainda similaridade e diversidade, tal que os elementos retornados sejam similares ao centro de consulta, porém diversificados entre si (DROSOU; PITOURA, 2010; VIEIRA et al., 2011).

Dentre as soluções para este problema de otimização, destacam-se aquelas baseadas no uso da proporção entre distâncias e as que usam técnicas de agrupamento por distância (DROSOU; PITOURA, 2010; SANTOS et al., 2013) para evitar qualquer intervenção externa/humana durante o processo de busca. Estes critérios também podem ser usados como critérios de consultas por similaridade, o que resulta no que aqui denominamos consultas por similaridade com diversidade. Uma abordagem que considera apenas o relacionamento entre distâncias de elementos é a proposta de diversificação de resultados baseada na influência de distâncias entre os elementos do conjunto de dados com relação à um centro consulta (SANTOS et al., 2013). Formalmente, dado um espaço métrico $\mathcal{M}=\langle\mathbb{S}, \boldsymbol{\delta}\rangle$, três elementos $s_{i}, s_{j}$ e $s_{k} \in \mathbb{S}$, o elemento $s_{j}$ é dito ser mais influenciado pelo elemento $s_{i}$ que por $s_{k}$, se $\delta\left(s_{i}, s_{j}\right)<\delta\left(s_{k}, s_{j}\right)$.

O uso da influência como uma medida de distância entre ternas de elementos, possibilita "cortar" elementos do espaço de busca a depender do centro de consulta. A ideia é encontrar conjuntos de influência, tal que seja possível retornar os conjuntos influenciados mais similares ou, em casos simplificados, apenas o elemento com maior influência dentro de cada conjunto. Dessa forma, o conjunto de dados pesquisado é particionado em um grupo de conjuntos de influências, sendo que um conjunto de influência $\hat{S}\left(s_{q}, s_{i}\right)$ é dado pela Definição 2.1.4.

Definição 2.1.4 (Conjunto de influência $-\hat{S}\left(s_{q}, s_{i}\right)$ ). Dado um espaço métrico $\mathcal{M}=\langle\mathbb{S}, \boldsymbol{\delta}\rangle$, um conjunto de dados $\mathcal{S}$, um centro de consulta $s_{q} \in \mathbb{S}$ e um elemento de influência $s_{i} \in \mathcal{S}$, o conjunto de influência é dado por $\hat{S}\left(s_{q}, s_{i}\right)=\left\{s_{j} \in \mathcal{S} \mid\left(\delta\left(s_{i}, s_{j}\right) \geq \delta\left(s_{i}, s_{q}\right)\right) \wedge\left(\delta\left(s_{i}, s_{j}\right) \geq \delta\left(s_{j}, s_{q}\right)\right)\right\}$.

Ao substituirmos o uso direto da função de distância $\delta$ pela avaliação da distância em termos de conjuntos de influência, podemos redefinir as consultas por abrangência (Definição 
2.1.1) e vizinhança (Definição 2.1.3) para contemplar o suporte à busca por diversidade. Uma consulta por abrangência diversificada retorna apenas os elementos mais influentes (que definem os conjuntos de influência) dentro de um dado limite de distância, enquanto que uma consulta por vizinhança diversificada recupera apenas os $k$-elementos mais influentes.

Alternativamente, as consultas por diversidade permitem agrupar os elementos influenciados dentro dos conjuntos de influência que podem ser associados aos respectivos elementos influentes e retornados de forma hierárquica como resposta da consulta. Uma possibilidade de execução para essa categoria de consultas é por meio do algoritmo BridGE (Better result with influence diversification to Group Elements) (SANTOS et al., 2014). Basicamente, a estratégia do algoritmo é construir iterativamente as regiões de influência para cada elemento do conjunto-resposta, quer seja uma consulta por abrangência, quer seja por vizinhança.

A Figura 4 ilustra uma busca por vizinhança diversificada para $k=3$ usando a estratégia BridGE em um espaço de duas dimensões e considerando a métrica $L_{2}$. A resposta da consulta é a identificação de quais são os três elementos mais influentes (que são usados como os três vizinhos mais próximos) e agrupar os demais elementos consultados considerando as regiões de influência encontradas. O primeiro passo da solução é encontrar o primeiro elemento mais próximo que irá definir a primeira região de influência. No exemplo da Figura 4(a) temos o primeiro elemento mais similar $\left(s_{1}\right)$ ao centro de consulta $s_{q}$ e a região de influência definida por ambos. Os elementos $s_{2}$ e $s_{3}$ estão dentro dessa região e são agrupados sob $s_{1}$. No passo seguinte, ilustrado na Figura 4(b), a estratégia continua a procurar pelo próximo elemento fora do primeiro conjunto de influência que definirá uma segunda área de influência. Os elementos dentro da segunda região são agrupados sob $s_{4}$. Como último passo, ilustrado na Figura 4(c), o algoritmo encontra $s_{5}$ como o terceiro elemento mais similar e não influenciado por nenhum dos elementos que definem os dois conjuntos de influência prévios para definir uma nova região

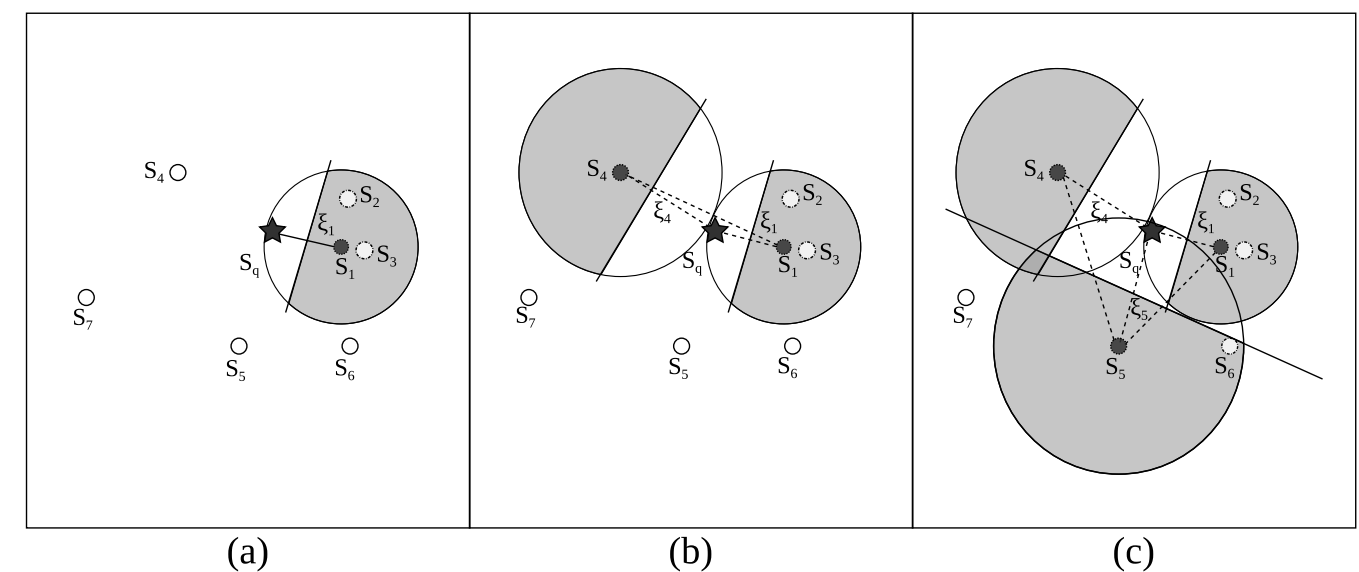

Figura 4 - Exemplo de uma consulta por vizinhança diversificada para $k=3$ usando a métrica $L_{2}$ em um espaço bidimensional. As regiões demarcadas são áreas de influência de um dos elementos do conjunto-resposta. (a) O primeiro conjunto de influência é definido por $s_{q}$ e $s_{1}$, possui cobertura $\xi_{1}$ e inclui os elementos $s_{2}$ e $s_{3}$. (b) O segundo conjunto de influência é definido por $s_{q}$ e $s_{4}$, com cobertura $\xi_{4}$. (c) O terceiro conjunto de influência é definido por $s_{q}$ e $s_{5}$, com cobertura $\xi_{5}$. Adaptado de Santos et al. (2013). 
para o agrupamento. Os elementos na intersecção entre regiões de influência são arbitrariamente incluídos em apenas um único conjunto de influência.

\subsection{Operadores relacionais e consultas por similaridade}

Os critérios de busca por similaridade apresentados nas seções anteriores podem constituir extensões dos operadores de comparação que, caso façam a comparação apenas sobre um par de elementos de cada vez, podem ser diretamente incorporados por operadores relacionais (CODD, 1970; DATE, 2011). A incorporação e a adequabilidade dos operadores de comparação por similaridade é o objeto dos estudos de Li et al. (2005), Ferreira et al. (2011), Silva et al. (2013). As propriedades dos operadores algébricos devem continuar inalteradas de forma que seja possível incluir as consultas por similaridade no modelo relacional sem alterar o funcionamento dos operadores que já suportam as comparações por identidade e ordem.

Neste trabalho, consideramos a incorporação dos operadores de comparação por similaridade no operador relacional unário de Seleção $(\sigma)$ o qual deve continuar a ser capaz de realizar filtragens por similaridade, identidade e ordem sem que haja a necessidade de alterar as propriedades já definidas para este operador com relação aos demais operadores algébricos (comutabilidade, precedência, etc.) (CODD, 1970; KANELLAKIS, 1989). Tradicionalmente, um operador de seleção é representado como $\sigma_{(\mathrm{A} \theta \text { constante })}^{\top}$, onde A é um atributo da relação $T$ que é comparado com o valor constante constante pelo operador de comparação $\theta$. De acordo com o critério do operador de comparação, uma tupla $t$ da relação T é selecionada como parte da relação resposta se a comparação do valor $t[\mathrm{~A}]$ com o valor constante resulta verdade.

Ao incluirmos os critérios de consultas por similaridade como operadores de comparação, o operador $\theta$ é estendido como $\ddot{\theta}$ para que possa também contemplar consultas por abrangência, de forma que $\ddot{\theta} \in\{=, \neq,<, \leq,>, \geq, \operatorname{Rng}(\delta, \xi), \neg \operatorname{Rng}(\delta, \xi)\}$. Portanto, o operador de Seleção pode usar o comparador $\ddot{\theta}$ sem que haja a necessidade de modificar o operador em relacional em si ou redefinir quaisquer de suas propriedades algébricas. A incorporação de $\ddot{\theta}$ pode ser feita diretamente por $\sigma$ tal que a notação $\sigma_{\left(\mathrm{A} \ddot{\theta} s_{q}\right)}^{\top}$ refere-se a um operador de Seleção, onde o operador de comparação empregado $\ddot{\theta}$ é usado na comparação dos valores $t[\mathrm{~A}]$ do atributo $A$ de cada tupla $t$ da relação $T$ contra o valor constante $s_{q}$ que é usado como centro da consulta. Repare que a sintaxe é transparente com o uso do descritor da consulta por similaridade embutida no operador de comparação $\ddot{\theta}$, com a única restrição de que $s_{q}$ deve ter o mesmo domínio do atributo A. Essa restrição é a mesma encontrada nos comparadores já existentes.

Ao seguirmos essa abordagem, somos forçados a desconsiderar quaisquer critérios de consulta por similaridade que requeiram o uso de ordenação para compor o conjunto-resposta da busca por similaridade. Isso fica claro quando percebemos que, da forma como estendemos o operador de comparação, não se faz necessário acessar o domínio ativo inteiro do atributo ao se processar a filtragem de cada tupla. No entanto, para alguns critérios de consultas por 
similaridade, tais como os $k$-vizinhos reversos ou as consultas com diversidade, ter acesso à totalidade do domínio ativo é a única forma de garantir a ordenação por distâncias (KORN; MUTHUKRISHNAN, 2000; SILVA et al., 2013). Para estas consultas podem ser traçadas duas alternativas, a saber, a extensão de outro operador que dê suporte à ordenação considerando um novo critério (GARCIA-MOLINA; ULLMAN; WIDOM, 2000; DATE, 2011); ou, a extensão do operador de Seleção para que este realize a filtragem e a ordenação dos elementos filtrados (CARVALHO et al., 2014; TANG et al., 2016). Em ambas as alternativas, é necessário explorar as consequências sobre os operadores relacionais já existentes, quais propriedades algébricas permanecem inalteradas e como isso afeta a otimização lógica de consultas, como discutido em Ferreira et al. (2011), Aly, Aref e Ouzzani (2015). De acordo com as definições adotadas até o momento nesta tese, trataremos da otimização lógica apenas dos critérios de consultas por similaridade que requeiram a extensão do operador de comparação mas não a extensão do operador de Seleção. Para os critérios que requeiram o uso de ordenação, investigaremos formas de realizar a otimização física, uma vez que o suporte algébrico mais adequado ainda é objeto de investigação conforme será ilustrado na sequência.

Além do operador de Seleção, outros operadores relacionais podem incluir os operadores de comparação por similaridade para executar consultas, tais como Agrupamento e Junção (SILVA; AREF; ALI, 2010b; TANG et al., 2016). O operador de Junção pode incorporar os operadores de comparação por similaridade para comparar dados de duas relações (BöHM; KREBS, 2004; SILVA et al., 2013). Neste caso, porém, não é necessário usar uma notação diferenciada para o operador de comparação usado, uma vez que o critério de junção é explícito (teta-junção, etc.). Idealmente, o operador por comparação não deve alterar as propriedades algébricas do operador relacional e, com isso, junções por similaridade se somam naturalmente àquelas já existentes.

Um operador de Junção combina tuplas de duas relações $T_{1}$ e $T_{2}$, considerando um atributo de cada relação $A \in T_{1}$ e $B \in T_{2}$, na forma de produto cartesiano seguido por uma filtragem por Seleção considerando um operador de comparação sobre A e B. Repare que os operadores por abrangência e por vizinhança são candidatos naturais a atuarem como operadores de comparação também nos critérios de Junção. Supondo o uso de um comparador por abrangência, o operador de Junção corresponde ao operador de Junção por Abrangência de acordo com a Definição 2.2.1.

\section{$(\operatorname{Rng}(\delta, \xi))$}

Definição 2.2.1 (Junção por Abrangência - $\aleph^{3}$ ). Dado um espaço métrico $\mathcal{M}=\langle\mathbb{S}, \delta\rangle$ e uma distância máxima $\xi \in \mathbb{R}_{+}$uma junção por abrangência sobre os atributos $A$ de $T_{1}$ e $B$ de $T_{2}$ denotada por $\mathrm{T}_{1} \stackrel{(\mathrm{R} g(\delta, \xi) \mathrm{B})}{\bowtie} \mathrm{T}_{2}$ combina todas as tuplas de $\mathrm{T}_{1}$ e $\mathrm{T}_{2}$ cuja distância entre os valores dos atributos $A$ e $B$ seja menor ou igual à distância $\xi$ dada. Dessa forma, a Junção retorna $o$ conjunto de tuplas $\mathrm{T}_{R}$, tal que $\mathrm{T}_{R}=\left\{\left\langle t_{i}[\mathrm{~A}], t_{j}[\mathrm{~B}]\right\rangle \in\left(\mathrm{T}_{1} \times \mathrm{T}_{2}\right) \mid \delta\left(t_{i}[\mathrm{~A}], t_{j}[\mathrm{~B}] \leq \xi\right\}\right.$.

Um consulta exemplo que envolve uma Junção por Abrangência é C5 "Recupere todos os pares sorveteria-cinema de São Carlos que estão próximos entre si em até 10 unidades de distância.”. O comparador usado na Junção por Abrangência não faz uso de ordenação e, 
portanto, pode ser integrado sem emendas com os demais operadores de comparação por ordem e identidade no operador Junção da álgebra relacional. Já para o critério de vizinhança, não é possível manter a semântica da busca ao realizarmos a redução da comparação por vizinhança a uma comparação por abrangência tal como fizemos para os operadores de comparação incorporados no operador relacional de Seleção.

Para ilustrar esse problema, considere a seguinte consulta exemplo C6 "Recupere a lista de pares de cinemas e suas duas sorveterias mais próximas e, dessa lista, encontre os dois pares de cinemas e sorveterias mais próximas da universidade”. Essa consulta envolve uma Seleção por Vizinhança e uma Junção por Vizinhança, sendo que as Figuras 5(a) e (b) exibem dois possíveis planos de execução para esta consulta. Na Figura 5(c) pontos pretos representam cinemas e pontos brancos representam sorveterias, enquanto que a estrela ao centro representa a universidade. O plano da Figura 5(a) executa a Seleção por Vizinhança após a operação de Junção por Vizinhança, enquanto que na 5(b) a Seleção por Vizinhança é realizada antes da operação de Junção. De acordo com os resultados dos dois planos de consulta constata-se que ambos os planos não são equivalentes, pois não produzem o mesmo resultado.

A Álgebra Relacional identifica uma propriedade que garante a equivalência entre dois planos de consulta diferentes apenas pela troca da ordem entre os operadores de Junção e Seleção relacionais (GARCIA-MOLINA; ULLMAN; WIDOM, 2000; DATE, 2011). Portanto, esse exemplo mostra que as propriedades da Álgebra Relacional para as junções tradicionais não são atendidas para junções por vizinhança. Dessa maneira, se uma junção por vizinhança for expressa sem indicar a ordem de execução, haverá ambiguidade na interpretação de seu significado. $\mathrm{Na}$ literatura, alguns autores defendem o primeiro plano como o mais adequado, enquanto outros indicam que o segundo pode conter a semântica correta e há ainda aqueles que afirmam que

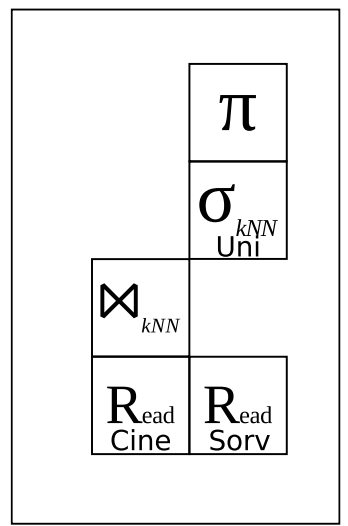

(a)

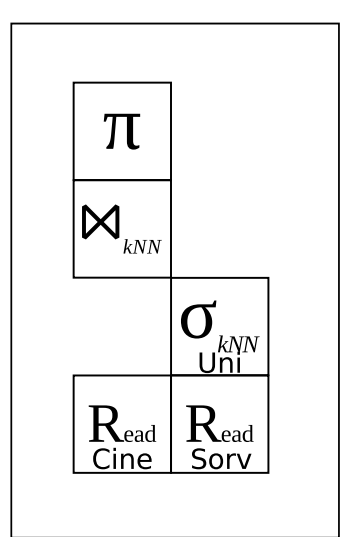

(b)

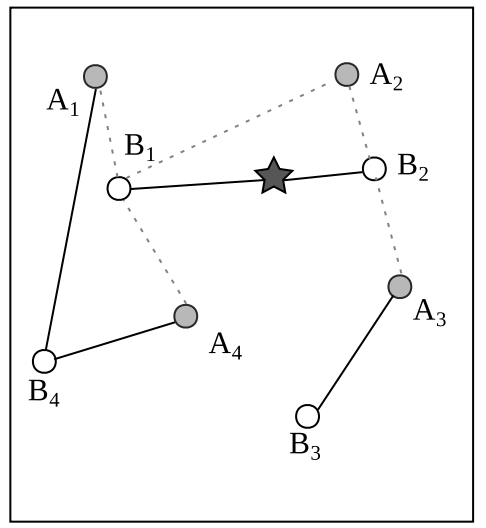

(c)

Figura 5 - Dois planos de execução válidos, porém não equivalentes, para uma consulta envolvendo Seleção e Junção por Vizinhança para $k=2$ em todas as comparações e considerando a métrica $L_{2}$. (a) Plano de execução que executa primeiro a Junção por Vizinhança e depois Seleção, e (b) plano alternativo que executa os operadores de Junção e Seleção na ordem inversa. (c) A execução em (a) recupera os pares $\left\langle A_{1}, B_{1}\right\rangle,\left\langle A_{2}, B_{1}\right\rangle,\left\langle A_{2}, B_{2}\right\rangle,\left\langle A_{3}, B_{2}\right\rangle$ e $\left\langle A_{4}, B_{1}\right\rangle$, enquanto a execução em (b) recupera os pares $\left\langle A_{1}, B_{1}\right\rangle$, $\left\langle A_{1}, B_{2}\right\rangle,\left\langle A_{2}, B_{1}\right\rangle,\left\langle A_{2}, B_{2}\right\rangle,\left\langle A_{3}, B_{1}\right\rangle,\left\langle A_{3}, B_{2}\right\rangle,\left\langle A_{4}, B_{1}\right\rangle$ e $\left\langle A_{4}, B_{2}\right\rangle$. Conjunto de dados de Aly, Aref e Ouzzani (2015). Planos de consulta gerados na ferramenta SHRuB (BEDO et al., 2014). 
ambos são adequados, mas que constituem dois novos operadores relacionais (SILVA et al., 2010; ALY; AREF; OUZZANI, 2015).

Podemos ver que a incorporação da comparação por vizinhança em um operador de Junção, ao contrário do operador de abrangência, requer o tratamento da ordenação por distâncias já no critério de comparação, o que implica que o operador em questão deve ser implementado como uma extensão do operador de Junção ou como um novo operador relacional. Dado o escopo e as definições desta tese, consideramos que a otimização lógica envolvendo o operador de Junção só pode ser realizada quando o operador de comparação empregado é por abrangência. Por outro lado, é possível otimizar fisicamente consultas envolvendo quaisquer comparações por similaridade por meio do desenvolvimento de algoritmos específicos ou estruturas de indexação. A Tabela 1 resume os critérios de busca por similaridade e os operadores de comparação do ponto de vista dos operadores relacionais revisados nesta seção e os tipos de otimização aplicáveis, dadas as restrições algébricas e semânticas de cada consulta.

Tabela 1 - Tipos de otimização empregados para os operadores por similaridade revisados.

\begin{tabular}{|l|l||}
\hline \hline Nome do Operador & Tipo de Otimização \\
\hline \hline Seleção por Abrangência & Lógica \& Algébrica \\
\hline Seleção por Vizinhança & Física \\
\hline Seleção por Vizinhança Reversa & Física \\
\hline Seleção por Abrangência Diversificada & Física \\
\hline Seleção por Vizinhança Diversificada & Física \\
\hline Junção por Abrangência & Lógica \& Algébrica \\
\hline Junção por Vizinhança & Física \\
\hline
\end{tabular}

\subsection{Estratégias de indexação}

Quaisquer dos operadores unários ou binários que envolvem filtragem da álgebra relacional podem ser executados sobre as relações de um SGBD por meio da comparação direta entre os elementos armazenados. Essa estratégia requer o uso de um método de acesso sequencial (STONEBRAKER; ROWE, 1986; KORTH; SUDARSHAN; SILBERSCHATZ, 2010), que denotamos por SeqScan. No entanto, essa estratégia pode ser pouco eficiente do ponto de vista computacional e inviabilizar consultas sobre grandes bases de dados. Considerando-se apenas os operadores de busca por similaridade, evitar a comparação de "todos-contra-todos" ou "todos-contra-um" leva à diminuição do número de cálculos de distância e acessos a disco necessários para a obtenção dos conjuntos-resposta, o que pode melhorar o tempo de execução em ordens de magnitude (CIACCIA; PATELLA; ZEZULA, 1997; CHÁVEZ; MARROQUÍN; BAEZA-YATES, 1999; TRAINA JR. et al., 2000; SKOPAL; POKORNỲ; SNASEL, 2004; TRAINA JR. et al., 2007; MOŠKO; LOKOČ; SKOPAL, 2011; CHEN et al., 2015). Estratégias de indexação são potencialmente capazes de alcançar esse objetivo. Embora uma grande quantidade de técnicas para resolução aproximada de consultas possa ser encontradas na literatura (SKOPAL, 2007), é importante destacar que apenas as estratégias de 
indexação com resultados exatos são candidatas a serem empregadas no contexto relacional. A ideia por trás de índices exatos para dados sujeitos à comparação por similaridade é dividir o espaço de busca tendo por base as propriedades das funções de distância métricas.

De acordo com a classificação proposta em Zezula et al. (2006), as técnicas de indexação podem ser catalogadas de acordo com sua estratégia de particionamento em três grandes grupos $(i)$ Particionamento por bola, (ii) Particionamento generalizado por hiperplanos, ou ainda (iii) Particionamento por exclusão do meio. Índices da primeira categoria particionam o conjunto original dos dados $\mathcal{S} \subseteq \mathbb{S}$ em subconjuntos $S_{1}$ (partição 1) e $S_{2}$ (partição 2) usando uma bola no espaço métrico com relação à um elemento de referência, denominado pivô e denotado por $p_{i}, p_{i} \in \mathcal{S}$, escolhido de acordo com critérios convenientes para cada estrutura. Portanto, fixado um pivô $p_{i}$ e um raio $\xi$ que definem uma bola no espaço, todos os elementos de $\mathcal{S}$ devem ser colocados dentro ou fora da partição definida pela bola. A Figura 6(a) mostra um exemplo de duas partições geradas pelo princípio de particionamento por bola em um conjunto bi-dimensional com métrica $L_{2}$.

Índices da segunda categoria usam um princípio ortogonal ao particionamento por bola, que também divide o conjunto original de dados em dois subconjuntos. Essas estratégias, porém, usam dois pivôs $p_{1}, p_{2} \in \mathcal{S}$ ao invés de um único pivô como no particionamento por bola. Assim, um elemento $s_{i} \in \mathcal{S}$ é colocado na partição $S_{1}$ se $\delta\left(s_{i}, p_{1}\right) \leq \delta\left(s_{i}, p_{2}\right)$, ou na partição $S_{2}$, caso contrário. A Figura 6(b) ilustra um exemplo de particionamento generalizado por hiperplanos para o mesmo conjunto e condições da Figura 6(a). Finalmente, índices da terceira categoria procuram dividir o conjunto de dados, não em dois, mas em três subconjuntos, com o objetivo de colocar os pontos mais próximos do limite $\xi$ que particiona a bola em um terceiro grupo. Dessa forma, os pontos excluídos por estarem próximos à fronteira da bola, formam o terceiro conjunto. A "proximidade" da fronteira é um parâmetro $t$, cuja estimativa depende da estratégia do índice. A Figura 6(c) mostra um exemplo de particionamento por exclusão do meio com as mesmas condições da Figura 6(a) e considerando-se um parâmetro $t$ arbitrário.

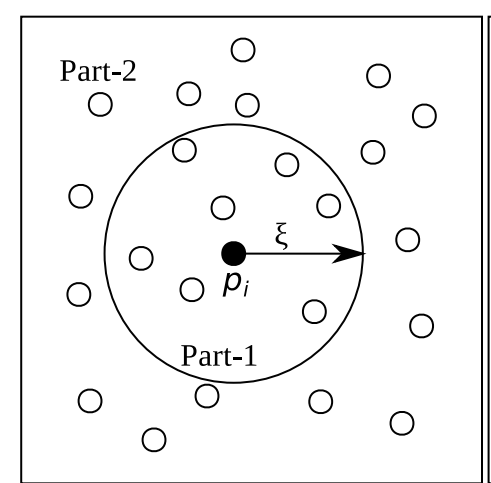

(a)

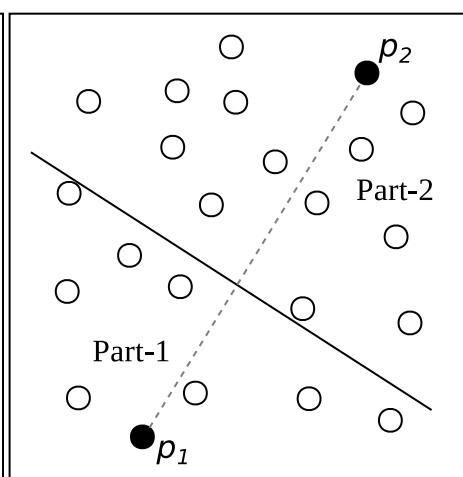

(b)

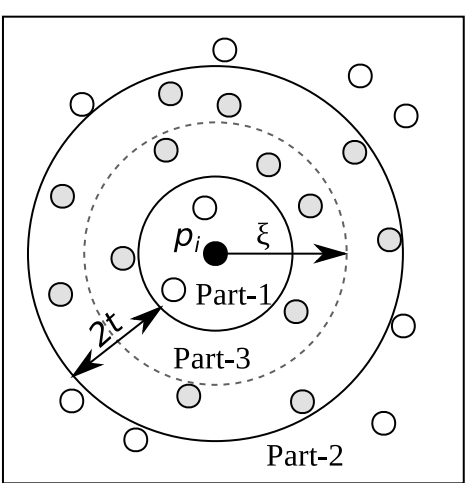

(c)

Figura 6 - Tipos de particionamento adotados por estratégias de indexação métricas para o mesmo conjunto de dados. "Part-" é usado para partição. (a) Particionamento por bola, (b) Particionamento generalizado por hiperplanos e (c) Particionamento por exclusão do meio. Adaptado de Zezula et al. (2006).

Outra possível, e mais recente, taxonomia para os índices métricos é a proposta de Chen 
et al. (2017b). De acordo com essa proposta, os índices também podem ser divididos em dois grupos pela forma em que processam as consultas por similaridade. O primeiro grupo, denominado técnicas de particionamento compactadas, tem o objetivo de descartar regiões de busca, computando distâncias de modo dinâmico, enquanto o segundo grupo, denominado técnicas baseadas em pivô, tem por objetivo cortar elementos usando distâncias pré-computadas. Além disso, essa taxonomia ainda divide o segundo grupo em três partes, denominadas Tabelas baseadas em pivôs, Árvores baseadas em pivôs e Índices externos baseados em pivôs. Tanto a taxonomia em Zezula et al. (2006) quanto a em Chen et al. (2017b) não implicam, necessariamente, que um índice pertença a apenas um grupo taxonômico, pois não é incomum que a estratégia de indexação combine premissas para melhorar sua eficiência.

Uma característica comum a todas as técnicas de indexação é que elas têm por objetivo tirar proveito do princípio do limite inferior, detalhado na Observação 2.3.1, para evitar ao máximo a comparação por distâncias com objetos armazenados na base de dados. Esse principio permite descartar o elemento $s_{j}$ sem que haja a comparação entre o centro de consulta $s_{q}$ e um elemento $s_{j}$. A Figura 7 ilustra como o princípio do limite inferior pode ser usado para cortar bolas inteiras da avaliação de proximidade com relação à uma consulta por abrangência.

Observação 2.3.1 (Princípio do limite inferior). Dado um centro de consulta $s_{q} \in \mathbb{S}$, um elemento $s_{j} \in \mathcal{S}$ dentro de uma bola definida pelo pivô $p_{i}$ e raio $\xi_{p_{i}}$, a distância $\delta\left(s_{q}, s_{j}\right)$ não pode ser menor que $\left|\delta\left(s_{q}, p_{i}\right)-\delta\left(s_{j}, p_{i}\right)\right|$ de acordo com a propriedade da desigualdade triangular.

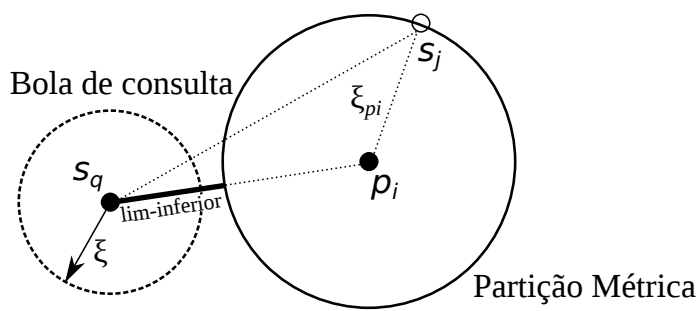

Figura 7 - Exemplo do princípio do limite inferior ilustrado com a métrica $L_{2}$, que possibilita o descarte de bolas pré-particionadas em espaços métricos. Adaptado de Moško, Lokoč e Skopal (2011).

\subsubsection{Técnicas de particionamento compactadas}

Técnicas de particionamento compactadas têm o foco na redução de acessos a disco (CHÁVEZ et al., 2001; ZEZULA et al., 2006). Majoritariamente, essas técnicas aplicam o particionamento por bolas com o objetivo de gerar partições não-mutuamente exclusivas, porém balanceadas, com o uso de poucos pivôs de forma que a redundância da informação armazenada seja controlada (SKOPAL; POKORNỲ; SNÁSEL, 2005). A seguir, apresentamos duas estratégias dessa categoria que são adequadas para o gerenciamento eficiente de espaço em memória e disco.

\subsubsection{M-Tree}

A M-Tree (CIACCIA; PATELLA; ZEZULA, 1997) é uma estrutura de indexação que organiza dinamicamente os elementos de um espaço métrico em bolas fechadas, armazenando-os em nós. 
Basicamente, a M-Tree emprega dois tipos de nós, os chamados nós diretórios ( $\mathrm{N}_{d}$ ) e os nós-folha $\left(\mathrm{N}_{l}\right)$. Nós diretório são armazenados como um conjunto de bolas, enquanto os nós folhas incluem os próprios elementos e, alternativamente, um ponteiro para a tupla da relação indexada pelo elemento ou a própria tupla diretamente. Considerando que tão somente o ponteiro para a tupla seja armazenado, um nó folha tem o seguinte formato $\mathrm{N}_{l}\left(s_{j}\right)=\left\{\left\langle s_{i}, d_{i j}, p \operatorname{tr}\left(s_{i}\right)\right\rangle\right\}$, onde $s_{i} \in \mathcal{S}$ é um elemento comparável por similaridade, $\operatorname{ptr}\left(s_{i}\right)$ é o ponteiro para $s_{i}, d_{i j}$ é a distância de $s_{i}$ para o elemento representante do nó $s_{j}$, o qual é armazenado no nó pai dessa folha. Um nó diretório $\mathrm{N}_{d}$ tem o formato $\mathrm{N}_{d}\left(s_{j}\right)=\left\{\left\langle s_{i}, \xi_{i}, \mathrm{~N}\left(s_{i}\right), d_{i j}\right\rangle\right\}$, onde $s_{i} \in S$ é a raiz da sub-árvore $\mathrm{N}\left(s_{i}\right)$, $\xi_{i}$ é o raio de cobertura do nó $\mathrm{N}\left(s_{i}\right)$ e $d_{i j}$ é a distância de $s_{i}$ para o elemento representante $s_{j}$ do nó diretório. As distâncias pré-computadas $d_{i j}$ são empregadas para a poda de nós (ou elementos) quando uma consulta por similaridade é executada. O nó diretório que corresponde ao topo da árvore é o nó raiz da M-tree: um nó sem pai que cobre todos os elementos indexados. A Figura 8 mostra o mesmo conjunto de dados indexado por duas M-trees diferentes sob a métrica $L_{2}$.

Diferentes escolhas de particionamento (políticas de construção da estrutura) podem ser empregadas na construção de uma M-Tree válida. Em todos os casos, os nós que definem uma partição podem se sobrepor, contanto que todos os elementos enraizados em $s_{j}$ estejam dentro do raio de cobertura do nó $\mathrm{N}\left(s_{j}\right)$. Não obstante, quanto maior o "volume"2 da árvore, maior será a probabilidade de ocorrer intersecção entre os nós, o que potencialmente pode inibir a poda de nós quando o princípio do limite inferior é empregado. Por exemplo, embora ambas as partições nas Figura 8(a) e (b) sejam M-Trees válidas, a árvore da Figura 8(b) tem um menor volume em comparação com a árvore da Figura 8(a).

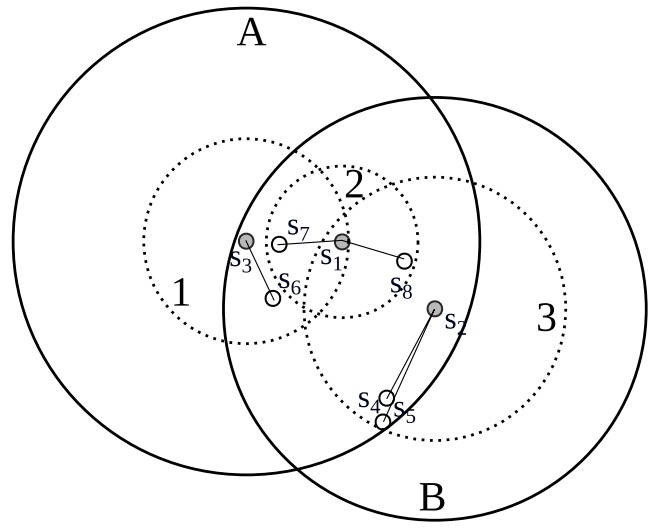

(a)

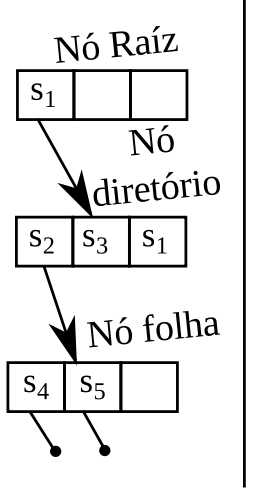

Figura 8 - Um mesmo conjunto de dados indexado por duas M-Trees. (a) Uma M-Tree com maior sobreposição e (b) Uma M-Tree com menor sobreposição. Adaptado de Skopal, Pokornỳ e Snasel (2004).

\subsubsection{O método de acesso métrico Slim-Tree}

O método Slim-Tree melhora os algoritmos de particionamento da M-Tree com o objetivo de minimizar as sobreposições das partições geradas (TRAINA JR. et al., 2000). Basicamente, é

2 Nós colocamos o termo "volume” entre aspas, pois não existe noção formal de volume em espaços métricos. Na prática, usamos a quantidade de elementos cobertos pela bola como uma sugestão de volume. 
empregado um conjunto de algoritmos para garantir um balanceamento adequado, alterandose a política de divisão de nós e escolha de elementos como pivôs através de uma estratégia bottom-up. Da mesma forma como em uma M-Tree, a estratégia usa uma estrutura composta de nós diretórios e folhas, sendo que cada nó armazena um número fixo e pré-definido de elementos. A Figura 9 mostra a representação de uma Slim-Tree com capacidade máxima para três elementos por nó, considerando um espaço bidimensional e a métrica $L_{2}$. Os pivôs para cada nó (elementos mais escuros) são os responsáveis por identificar uma região de cobertura para elementos inseridos dentro da região.

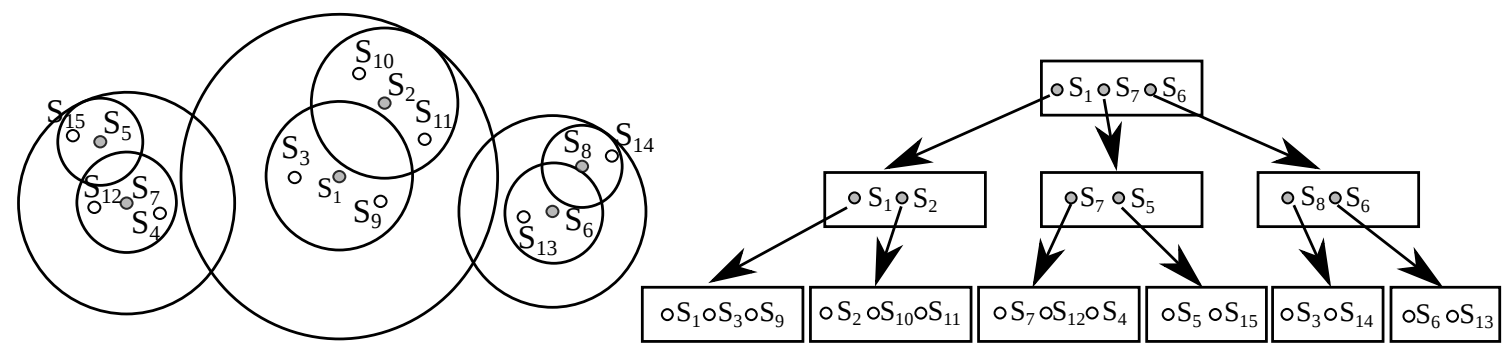

(a)

(b)

Figura 9 - Particionamento via Slim-Tree de 15 elementos. (a) Estrutura lógica do particionamento. (b) Organização da estrutura de dados equivalente. Adaptado de Traina et al. (2002).

Considerando-se as políticas de construção da Slim-Tree, para cada novo elemento a ser inserido, percorre-se a árvore desde a raiz para encontrar o nó folha que pode incluir o elemento. Como pode existir sobreposição entre os nós, pode ser necessário percorrer mais de um caminho até localizar o nó adequado para a inserção. Neste caso, a escolha da sub-árvore a ser percorrida é dada por uma política pré-definida que pode ser escolhida dentre três possibilidades, a saber $(i)$ aleatória, que seleciona aleatoriamente um dos nós qualificados; (ii) MinDist, que escolhe o nó cuja distância ao representante é o mais próximo possível do novo objeto; ou ainda (iii) Min0ccup, que verifica o número de elementos em cada sub-árvore para escolha da menos populosa (TRAINA et al., 2002).

Na medida em que a estrutura de árvore cresce, os nós são criados e os nós-folhas podem atingir a sua capacidade máxima de armazenamento, já que são de tamanho fixo. Quando isso acontece, os elementos inseridos naquele nó precisam ser redistribuídos, de acordo com um critério de divisão dos nós. Dessa forma, novos elementos representantes são escolhidos e novos raios de cobertura definidos. A Slim-Tree permite a adoção de três políticas possíveis para a divisão de nós: $(i)$ aleatória, que escolhe dois representantes aleatórios e distribui os demais elementos existentes entre eles; (ii) MinMax, que utiliza todas as combinações de pares de elementos como potenciais representativos e escolhe aquele que minimiza o raio de cobertura; ou finalmente (iii) MST, que constrói uma árvore de geradora mínima (minimum spanning tree) entre os elementos considerando a distância entre eles como os pesos de uma aresta em um grafo que representa as distâncias entre todos os elementos de um nó. Uma vez construída a MST, a aresta mais longa é removida e os elementos mais centrais de cada uma das duas componentes conexas resultantes são escolhidos como representantes dos novos nós. A construção que gera 
uma Slim-Tree balanceada e potencialmente com menor volume é a que usa MinDist e MinMax como políticas de escolha e divisão do nó, respectivamente.

É possível executar uma fase de pós-processamento após a construção de uma Slim-Tree, com o objetivo de minimizar o volume da árvore, usando o algoritmo Slim-Down (TRAINA et al., 2002). A ideia central desse algoritmo é resolver o problema de otimização que diminui ao máximo a sobreposição levando em consideração uma medida da qualidade da árvore construída. A medida de qualidade usada pelo algoritmo Slim-Down é denominada fator de gordura e é obtido de acordo com a Definição 2.3.1.

Definição 2.3.1 (Fator de gordura - $f a t(T, \mathcal{S})$ ). Dado um espaço métrico $\mathcal{M}=\langle\mathbb{S}, \delta\rangle$, o fator de gordura de uma dada árvore $T$ com relação à um conjunto de dados $\mathcal{S}$ é calculado como:

$$
f a t(T, \mathcal{S})=\frac{I_{C}-|\mathcal{S}| \cdot h}{|\mathcal{S}|} \cdot \frac{1}{|\mathrm{~N}|-h}
$$

onde $I_{C}$ é a soma de todos os nós acessados para a realização de todas as consultas pontuais possíveis, i.e. a execução da consulta $R q\left(\mathcal{S}, s_{i}, 0.0\right)$ para todo $s_{i} \in \mathcal{S}, h$ é a altura da estrutura e IN é a quantidade de nós da árvore $T$.

O fator de gordura expressa "quão bom" é o particionamento de $\mathcal{S}$ em uma escala $[0,1]$ considerando a sobreposição dos elementos na árvore. Por exemplo, o fator de gordura da árvore da Figura 8(a) é 0.5, enquanto que para a árvore na Figure 8 (b) é de apenas $\approx 0.04$. Nesse contexto, a árvore na Figura 8(b) tem maiores chances de evitar varrer a mesma região do espaço duas vezes em comparação com a árvore na Figura 8(a) ao executar uma consulta por abrangência com centro de consulta aleatório.

\subsubsection{Algoritmos de busca por vizinhança em árvores métricas}

Consultas por abrangência sobre árvores métricas são executadas de forma tão direta quanto possível. Dada uma consulta $R q\left(\mathcal{S}, s_{q}, \xi\right)$, verifica-se quais são os nós que interceptam a bola de consulta dada por $\left\langle s_{q}, \xi\right\rangle$ por meio da desigualdade triangular e descartam-se os demais nós. Para cada um dos elementos $s_{i}$ nos nós-folhas não descartados é necessário verificar se a distância $\delta\left(s_{q}, s_{i}\right)$ é menor ou igual ao limite $\xi$ da consulta. Caso a condição dessa desigualdade seja satisfeita, o elemento é inserido no conjunto-resposta. Note que tanto faz visitar os nós em largura ou profundidade, pois todos os nós interceptados pela bola da consulta precisam ser analisados (CHÁVEZ et al., 2001; SAMET, 2006).

No entanto, para consultas por vizinhança não se conhece o raio da consulta de antemão. Dessa forma, não é possível traçar a bola de consulta para limitar o escopo (e, consequentemente, os nós visitados) para resolver a consulta. Nesse caso, o algoritmo-base para resolver consulta por vizinhança emprega uma estratégia do tipo branch-and-bound para podar nós e elementos durante a consulta (ROUSSOPOULOS; KELLEY; VINCENT, 1995). O algoritmo inicialmente define o raio da consulta como infinito $(\xi=\infty)$ e o reduz dinamicamente até que os $k$-vizinhos mais 
próximos tenham sido encontrados. Essa redução dinâmica implica em manter uma lista de $k$-candidatos ordenada por distância e usar a distância do $k$-ésimo elemento para o ajuste do raio. Portanto, para cada elemento inserido na lista o raio é atualizado. Ainda nesse sentido, os nós da árvore são percorridos em profundidade com relação à primeira entrada do nó-raiz, uma estratégia conhecido como "profundidade primeiro" (depth-first search), denotado neste trabalho por depth-kNN. Uma variação desse algoritmo é avaliar as regiões por ordem de proximidade ao elemento de consulta ao invés de usar a busca em profundidade. Esse algoritmo é conhecido como "melhor primeiro" (best-first search) e denotado nesta tese como bf-kNN (CIACCIA; PATELLA; ZEZULA, 1997; ZEZULA et al., 2006).

Uma terceira abordagem para a execução de consultas por vizinhança é o algoritmo de busca incremental (distance-browsing) (HJALTASON; SAMET, 1998; HJALTASON; SAMET, 2003), um procedimento que aqui denotamos como inc-kNN. Esta estratégia limita o número de cálculos de distância baseados em um princípio de otimalidade. Basicamente, a ideia é recuperar, incrementalmente, os elementos mais próximos usando duas filas de prioridade. A primeira fila ordena os nós que ainda não foram avaliados, enquanto a segunda ordena os elementos das regiões que já foram avaliadas, mas que ainda não foram descartados como potenciais próximos vizinhos. Os elementos na segunda fila de prioridades são ordenados com relação à distância para o centro de consulta, enquanto os nós da primeira fila são ordenados de acordo com a menor e, em caso de empate, maior distância possíveis para o centro de consulta considerando a desigualdade triangular e o raio de cobertura do nó. O algoritmo escolhe o próximo vizinho mais próximo avaliando as duas filas de prioridades. Se o primeiro elemento da segunda fila está mais próximo de $s_{q}$ que o primeiro elemento da primeira fila, o primeiro elemento da segunda fila é inserido como o próximo vizinho mais próximo. Caso o primeiro nó da primeira fila seja mais próximo, os elementos do nó são carregados na memória e a distância deles ao centro de consulta é usada para inseri-los por prioridade na segunda fila.

O algoritmo inc-kNN executa o número mínimo possível de cálculos por distância, mas o preço para que esse resultado seja alcançado é a manutenção de duas (custosas) filas de prioridade em memória principal (especialmente a segunda) que faz a ordenação de grande parte dos elementos consultados. Portanto, se considerarmos como métrica de desempenho o tempo necessário para a execução da consulta, existem casos onde o algoritmo bf-kNN pode ter melhor desempenho em comparação com o método inc-kNN (TAO et al., 2004; VIEIRA et al., 2007).

\subsubsection{Técnicas baseadas em pivôs}

Diferentemente das técnicas de particionamento compactado, técnicas baseadas em pivô não se importam em adicionar uma sobrecarga de armazenamento de disco/memória para evitar cálculos de distância e partem do princípio que usar pivôs extras podem melhorar este aspecto. Vale ressaltar que as técnicas não são do tipo "quanto mais pivôs, melhor", pois o uso de um número inadequado de pivôs pode levar a uma sobrecarga no número de comparações (YIANILOS, 
1993; CHÁVEZ; MARROQUÍN; BAEZA-YATES, 1999). A ideia comum a todos estes métodos é o armazenamento das distâncias pré-computadas de todos os elementos para um conjunto de pivôs e empregá-las para maximizar o princípio do limite inferior quando vários pivôs são usados. Se considerarmos a forma como as distâncias pré-calculadas são tratadas, as técnicas baseadas em pivôs podem ser divididas entre Tabelas baseadas em pivôs, Árvores baseadas em pivôs e Índices externos baseados em pivôs.

\subsubsection{Tabelas baseadas em pivôs}

As estratégias dessa categoria usam tabelas para armazenar as distâncias pré-computadas, o que pode ser muito adequado quando se quer realizar consultas sobre um conjunto de dados que não sofrerá alteração (atualização ou remoção). Dois grandes métodos são os principais representantes dessa classe, os métodos Algoritmo de Busca por Eliminação por Proximidade (AESA -Approximating Eliminating Search Algorithm) e AESA linear (LAESA) (MICÓ; ONCINA; CARRASCO, 1996; RUIZ et al., 2013). O método AESA depende de uma tabela para armazenar as distâncias de todos para todos os elementos do conjunto de dados, o que também pode ser visto como uma matriz de distâncias. Basicamente, esse método usa $\mathcal{P}=\mathcal{S}$, o que implica em uma alta complexidade de espaço (quadrática em número de elementos do conjunto de dados) e rapidamente pode ocupar toda a memória principal. O método LAESA reduz a complexidade de espaço do AESA ao calcular apenas as distâncias dos elementos de consulta para um conjunto pequeno de pivôs, fazendo com que o custo de armazenamento da tabela se torne linear com a quantidade de elementos do conjunto de dados.

Ao contrário do AESA, o método LAESA depende de duas tabelas, uma para armazenar as distâncias pré-computadas e outra para armazenar os pivôs. Essas duas tabelas são usadas para cortar comparações por distância quando uma consulta por abrangência ou vizinhança é executada. Por exemplo, para uma consulta por abrangência, o método LAESA calcula a distância do centro de consulta para todos os pivôs da segunda tabela e combina as distâncias entre os pivôs e as distâncias da primeira tabela para obter os elementos que não podem ser descartados pelo princípio do limite inferior. Cada elemento que passa pelo filtro é comparado com o centro de consulta e inserido no conjunto-resposta não ordenado. Para uma consulta por vizinhança, a técnica LAESA usa uma variação do algoritmo depth-kNN, iniciando a bola de consulta como raio infinito e aplica o princípio do limite inferior para cada elemento do conjunto de dados, para tentar evitar o cálculo da distância. Quando, ao menos, $k$ elementos são inseridos no conjuntoresposta, o raio de consulta pode ser atualizado. Nesse caso, o conjunto-resposta é mantido ordenado. Repare que vários falso-positivos são inseridos e removidos do conjunto-resposta a medida em que ele é construído.

Uma limitação tanto do AESA quanto do LAESA é que o espaço disponível em memória principal é rapidamente preenchido, pois além das tabelas de distância eles também trabalham com o conjunto de dados em memória principal (ZEZULA et al., 2006). Uma alternativa interessante 
é usar uma M-Tree para agrupar o conjunto de dados e manter apenas as tabelas do LAESA em memória para otimizar o uso do acesso a disco. Dessa forma, os dados são particionados por uma M-Tree, que é guardada em separado, e resulta em um método conhecido como Clustered-Pivot Tables (CPT) (MOŠKO; LOKOČ; SKOPAL, 2011). A Figura 10 apresenta um exemplo do CPT que inclui uma M-Tree com ponteiros para os elementos de dados, uma tabela de pivôs e uma tabela de distâncias. Ambas as tabelas ficam em memória principal, enquanto a M-Tree se encarrega de fazer o gerenciamento dos dados em disco, sendo que os dados estão clusterizados no sentido de estarem armazenados integralmente nos nós folha. O método CPT adota o mesmo algoritmo de consulta por abrangência e vizinhança do método LAESA e pode incorrer em vários cálculos de distância não necessários em princípio.

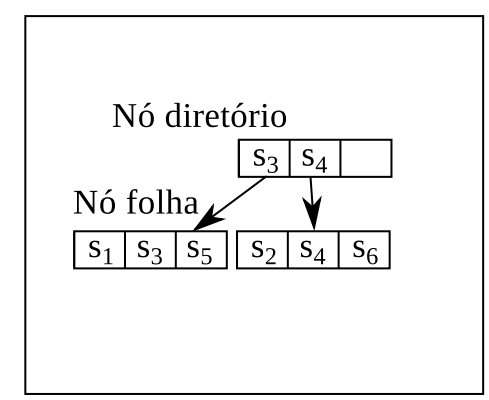

(a)

\begin{tabular}{|c|c|c|c|}
\hline$P$ & Ptr & $\delta\left(s_{i}, p_{1}\right)$ & $\delta\left(\mathrm{s}_{\mathrm{i}}, \mathrm{p}_{2}\right)$ \\
\hline $\mathrm{p}_{1}=\mathrm{s}_{1}$ & $\mathrm{~s}_{1}$ & 0 & 6 \\
\hline \multirow[t]{5}{*}{$\mathrm{p}_{2}=\mathrm{s}_{6}$} & $\mathrm{~S}_{2}$ & 1.42 & 5.09 \\
\hline & $\mathrm{S}_{3}$ & 2.23 & 5.38 \\
\hline & $\mathrm{S}_{4}$ & 3.16 & 3.16 \\
\hline & $\mathrm{S}_{5}$ & 2 & 4 \\
\hline & $\mathrm{s}_{6}$ & 6 & 0 \\
\hline
\end{tabular}

(b)

Figura 10 - Clustered-Pivot Table para um conjunto de seis elementos. (a) M-Tree para o conjunto de dados. (b) Tabelas de distâncias LAESA. Adaptado de Moško, Lokoč e Skopal (2011).

\subsubsection{2 Árvores baseadas em pivôs}

Diferentemente de árvores com crescimento balanceado, como a M-Tree e a Slim-Tree, as árvores baseadas em pivôs podem ser parametrizadas com relação ao número de partições empregadas. Duas técnicas de árvore mais empregadas são a VP-Tree (Vantage-Point Tree) e a MVP-Tree (Multi Vantage-Point Tree), que usam particionamento por exclusão do meio (BOZKAYA; OZSOYOGLU, 1997). No caso da VP-Tree, a ideia é escolher um pivô raiz (chamado vantage point - VP) e um raio de corte com o valor da mediana das distancias entre esse elemento e os demais, tal que os elementos mais próximos do pivô do que a mediana são colocados do lado esquerdo do pivô e os demais do lado direto. Se o número de objetos em qualquer das sub-árvores esquerda ou direita geradas excede um valor pré-definido, a sub-árvore é, por sua vez, particionada. Se várias medianas e pivôs forem usados, a estrutura resultante é conhecida como MVP-Tree. Nesse sentido, se o valor da distância entre o elemento e os pivôs estiver no intervalo $\left[0,1^{a}\right.$. mediana) ele é incluído na primeira sub-árvore, e assim sucessivamente, considerando-se todas as partições geradas pelas medianas usadas.

Para resolver uma consulta por abrangência, o método MVP-Tree atravessa todas as sub-árvores incluídas no limite inferior na forma de uma busca em profundidade. Já para uma consulta por vizinhança, as sub-árvores são avaliadas em uma estratégia similar ao bf-kNN, de forma que a sub-árvore mais próxima é a primeira a ser avaliada e, para cada elemento inserido como $k$-ésimo candidato, o valor do raio da consulta é atualizado. A MVP-Tree pode ser 
construída como uma árvore balanceada (para a escolha adequada de valores de medianas), sendo que a capacidade de poda inicialmente aumenta à medida que o número de medianas também aumenta. $\mathrm{O}$ ponto de equilíbrio de capacidade de poda vs. número de medianas é usualmente determinado empiricamente (CHEN et al., 2017b).

\subsubsection{3 Índices externos baseados em pivôs}

Uma variação ao CPT é a estratégia em Skopal, Pokornỳ e Snasel (2004) que propõe o método Pivoting M-Tree (PM-Tree) para o armazenamento tanto dos elementos de dados quanto da tabela de pivôs dentro dos nós de uma M-Tree. Assim como no CPT, a M-Tree tem a principal atribuição de cuidar do armazenamento dos elementos, enquanto a tabela de pivôs é usada para evitar cálculos de distância. A ideia básica do método é incluir, já em cada região armazenada em um nó diretório, a tabela de pivôs dos elementos dentro da região de forma a poder processar rapidamente cada entrada do nó descendente. Para evitar a sobrecarga do armazenamento redundante de parte da tabela de pivôs que aparece em todos elementos de uma dada hierarquia é usada uma referência externa para indicar as regiões abaixo na estrutura da árvore. A sobrecarga fica, portanto, restrita as referências à tabela de pivôs.

O processamento de uma consulta por abrangência é realizado como um procedimento em profundidade similar à M-Tree original, sendo que é possível proceder diretamente com a poda dos elementos contidos nos nós-folhas usando as distâncias pré-calculadas da tabela de pivôs. Já para uma consulta por vizinhança, os nós da PM-Tree são consultados usando o procedimento $\mathrm{bf}-\mathrm{kNN}$, onde o princípio do limite inferior permite aumentar a capacidade de poda, já que mais pivôs estão disponíveis em cada nível na comparação com o único pivô por nó da M-Tree padrão (SKOPAL; POKORNỲ; SNÁSEL, 2005). Por modificar a estrutura da M-Tree, a estrutura em árvore PM-Tree requer mais espaço de armazenamento em disco, uma vez que os nós gerados são, proporcionalmente, maiores do que os da M-Tree padrão.

Outro eficiente índice externo baseado em pivô é o método SPB-Tree (Space Filling curve and Pivot-based $B^{+}$-tree) (CHEN et al., 2015). Essa estratégia combina a ideia de redução de dimensionalidade ligada ao conceito da representação via pivôs (MAO; MIRANKER; MIRANKER, 2012) para usar curvas de preenchimento de espaço (curvas de Hilbert) e mapear os valores da tabela de pivôs em inteiros, com o objetivo de preservar a relação de proximidade. Além disso, a técnica emprega a árvore $B^{+}$(GRAEFE, 2011) para armazenar os valores obtidos das curvas de preenchimento e evitar sobrecarga na memória principal. Cada nó da árvore $B^{+}$armazena os valores de máximo e mínimo das distâncias das regiões definidas pelas curvas de Hilbert, sendo que os elementos do conjunto de dados são mantidos em um arquivo à parte. A Figura 11 ilustra a estrutura de dados usada para armazenar a estratégia SPB-Tree.

Para executar uma consulta por abrangência, as entradas da árvore $B^{+}$são percorridas em profundidade usando o princípio do limite inferior para podar regiões que mapeiam parte da tabela de pivôs. Elementos da tabela não podados por esse limite são recuperados e a validação 


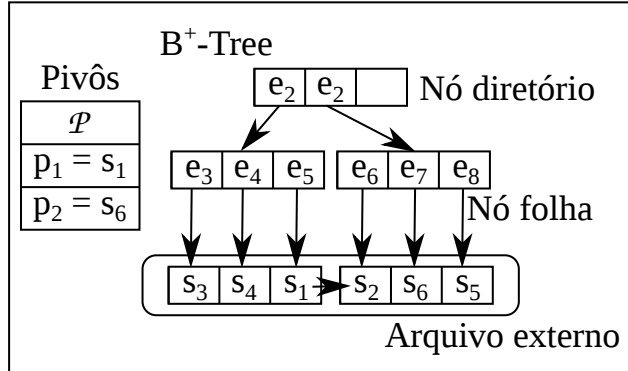

(a)

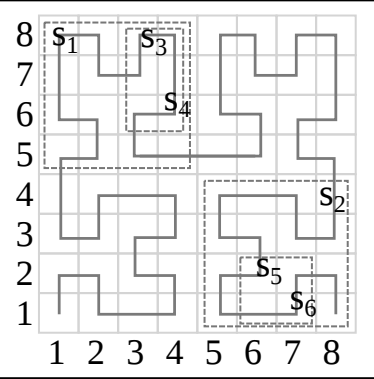

(b)

Figura 11 - Estrutura de dados de uma SPB-Tree. (a) Lista de pivôs e entradas mapeadas de Hilbert em uma $B^{+}$-Tree que inclui a lista de elementos do conjunto de dados. (b) Mapeamento de Hilbert das coordenadas para os pivôs para um valor inteiro. Adaptado de Chen et al. (2017a).

comparando cada elementos é então realizada. Já no caso de uma consulta por vizinhança, uma estratégia do tipo bf-kNN é empregada com redução dinâmica do raio. Nesse caso, um mapeamento em três níveis é usado. No primeiro nível estão os elementos de dados, no segundo estão as tabelas de pivôs e acima destas se encontra a curva de Hilbert. O uso da árvore $B^{+}$ para o armazenamento das curvas de Hilbert é particularmente adequado, pois permite reduzir a sobrecarga gerada no segundo mapeamento (CHEN et al., 2017a).

Os métodos da Família Omni (TRAINA JR. et al., 2007) também usam um mapeamento em níveis. A ideia dos métodos Omni é indexar as tabelas de distâncias de cada elemento aos pivôs por um método de indexação já existente, o que cria uma segunda camada que pode aumentar a capacidade de poda para resolver uma consulta por vizinhança. A abordagem Omni se refere ao conjunto de distâncias entre um elemento e $\mathcal{P}$ como as coodenadas Omni, sendo que uma estrutura secundária é usada para armazenar estas estruturas. Esses métodos secundários geram as variações das Omni estruturas e constituem a chamada "família Omni". Por exemplo, pode-se empregar uma árvore $B^{+}$, uma estrutura espacial do tipo R-Tree (GUTTMAN, 1984) ou uma SlimTree para o particionamento das coordenadas Omni, o que irá gerar a Omni- $B^{+}$Tree, Omni-R Tree e Omni Slim-Tree, respectivamente. Se a estratégia SeqScan for usada, as coordenadas Omni são lidas de forma sequencial, gerando um índice denominado como Omni-Sequencial que implementa a estratégia LAESA com suporte à paginação em disco e memória.

Para os métodos da família Omni, a construção do conjunto-resposta para consultas por abrangência e vizinhança é realizado como um procedimento em duas etapas: filtragem e refinamento. Na primeira etapa, as Coordenadas-Omni são calculadas para o elemento de consulta dado, definindo a região afetada. Na etapa de refinamento, a consulta por similaridade é repassada para as estruturas secundárias associadas à região afetada pelas coordenadas calculadas, de modo a minimizar a quantidade de elementos candidatos ao conjunto-resposta. A região afetada final é chamada de região de fronteira mínima (mbOr - minimal bounding Omni region).

A Figura 12 mostra um exemplo de uma consulta por abrangência com métrica $L_{2} \mathrm{em}$ um espaço bi-dimensional usando o método Omni-Sequencial. Cada pivô gera um hiper-anel no espaço métrico que cobre a resposta de uma consulta por abrangência. A mbOr corresponde 
à intersecção dos hiper-anéis gerados por todos os pivôs. No exemplo, a Figura 12(c) mostra a região da intersecção dos anéis em relação ao raio de consulta. Repare que a mbOr inclui todos os objetos do conjunto-resposta. Nesse caso, o refinamento pode ser feito com o cálculo de distâncias, uma vez que já foi possível descartar a maior parte do conjunto de dados no passo anterior. Para consultas por vizinhança, a mbOr é obtida por uma variação do algoritmo bf-kNN sobre a estrutura que indexa as Coordenadas-Omni.

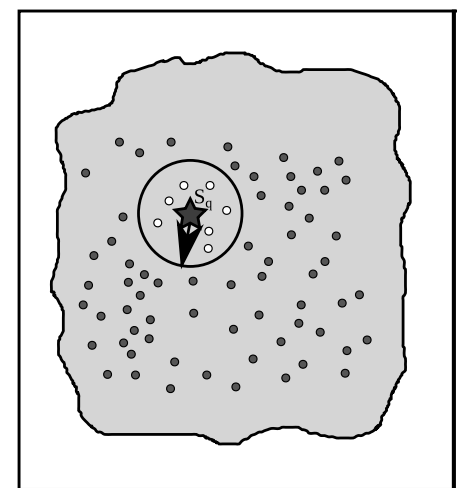

(a)

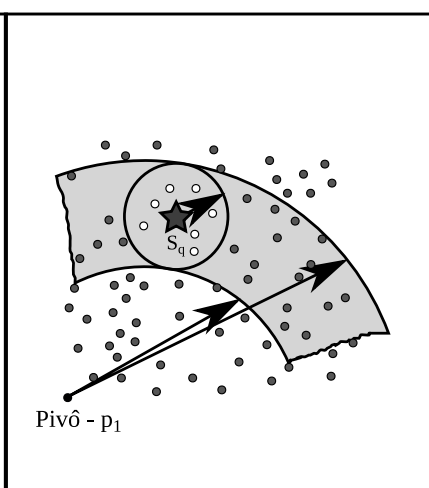

(b)

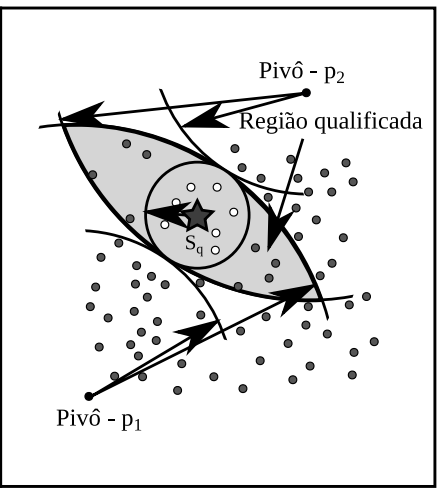

(c)

Figura 12 - Uma consulta por abrangência com centro $s_{q}$ e raio $\xi$ para métrica $L_{2}$. A área em cinza ilustra a definição da mbOr na etapa de filtragem, contendo os elementos candidatos à resposta. (a) Sem a utilização de nenhum pivô, todos os elementos são candidatos potenciais. (b) Com um pivô, os elementos do hiper-anel são os candidatos possíveis. (c) Com dois pivôs ( $p_{1}$ e $\left.p_{2}\right)$, a mbOr circunscreve uma região menor, que contém o conjunto-resposta. Adaptado de Traina Jr. et al. (2007).

\subsection{Considerações Finais}

Neste capítulo foram introduzidos os conceitos necessários para o entendimento de consultas por similaridade, como elas podem ser vistas como operadores por comparação e como estes, por sua vez, podem ser incorporados aos operadores algébricos de Seleção e Junção. Essa incorporação é fundamental para permitir executar a otimização lógica, sendo que os operadores que ainda não têm suporte algébrico adequado, ou que requeiram a extensão dos operadores relacionais, estão situados fora do escopo dessa classe de otimização. Nossa premissa é que representar uma consulta por similaridade como um operador de comparação permite desenvolver algoritmos mais eficientes para cada critério individualmente, enquanto que representá-la como um operador relacional permite usar a álgebra relacional para encontrar planos de execuções em consultas que envolvem mais de um critério de busca.

Mais abrangente, no entanto, é a possibilidade de realizar a otimização física para os critérios de consultas por similaridade revisados neste capítulo e que, eventualmente, possam constituir novos operadores algébricos. Foram apresentadas estruturas de dados e métodos de indexação desenvolvidos para viabilizar essa classe de otimização e capazes de acelerar a execução de consultas por similaridade. É importante ressaltar que para o uso de índices não vale a máxima de "uma mesma estratégia para todas as consultas" - one size fits all - (Stonebraker e Cetintemel (2005)), uma vez que não há um método de indexação que sempre seja superior a todos os demais em todos os quesitos envolvidos no contexto de um SGBD. 
Por exemplo, para ambientes com atualização ou remoção de dados, tais como em ambientes transacionais, técnicas de particionamento compactado como a M-Tree e a Slim-Tree, se destacam. Por outro lado, para tarefas que envolvem dados consolidados, tais como em ambientes de processamento analítico, técnicas baseadas em pivô são mais adequadas. Além disso, a depender do tipo da consulta a ser resolvida e do tamanho do conjunto de dados, um índice pode ser mais adequado que outro. Dessa forma, não é incomum indexar o mesmo conjunto de dados por dois ou mais métodos diferentes, sendo que caberá a otimização lógica escolher qual será o mais indicado para cada consulta em particular.

Além disso, as revisões realizadas permitiram destacar que a otimização física de consultas por similaridade depende de três fatores, a saber:

- Redução do número de acessos a disco - Foco de algumas estruturas de indexação revisadas, tais como M-Tree e Slim-Tree.

- Redução do número de cálculos de distância - Foco de algumas das estruturas revisadas, tais como CPT, VP-Tree, SPB-Tree e Família Omni.

- Uso do algoritmo de consulta mais eficiente - Estruturas diferentes usam algoritmos diferentes; em particular, para consultas por vizinhança foram revisados os algoritmos SeqScan, depth-kNN, bf-kNN e inc-kNN.

Para otimizar consultas por similaridade, tanto física quanto logicamente, é necessário coletar e utilizar estatísticas sobre o comportamento das distâncias nos conjuntos de dados armazenados. Dispensar um tratamento adequado às informações sobre distâncias pode permitir tanto a escolha conveniente da ordem de execução das filtragens como a definição dos índices que irão realizar as consultas por similaridade. Além disso, essas informações podem ser usadas para configurar as estruturas de indexação para melhorar o seu desempenho na execução das consultas. Nos próximos capítulos serão discutidas estratégias para possibilitar tanto a otimização lógica quanto a otimização física de consultas por similaridade. 


\title{
Sinopses e distribuições de distâncias em espaços métricos
}

\author{
"For the things we have to learn \\ before we can do them, we learn by \\ doing."
}

Aristotle - The Nicomachean Ethics $^{1}$

Os conceitos revistos na seção anterior mostram como buscas por similaridade podem ser incorporadas ao ambiente relacional de execução de consultas. Com esse objetivo, mostrou-se como os critérios de similaridade podem ser usados para definir operadores de comparação por similaridade que podem ser incorporados aos operadores relacionais de Seleção e Junção. Os dois operadores de comparação permitem filtrar tuplas (ou pares de tuplas) de acordo com o critério de comparação usado. Da mesma maneira que para os operadores baseados em identidade e relações de ordem, cada tupla irá fazer parte do conjunto-resposta apenas se satisfizer as condições impostas pelo operador de comparação. A razão entre a quantidade de tuplas selecionadas pelo total de tuplas analisadas é denominada fator de seletividade da comparação, ou simplesmente seletividade (IOANNIDIS; CHRISTODOULAKIS, 1993; GARCIA-MOLINA; ULLMAN; WIDOM, 2000; KORTH; SUDARSHAN; SILBERSCHATZ, 2010).

Obter o valor esperado de seletividade para todas as operações de comparação antes da execução da consulta em si é o primeiro passo para que planos de consultas equivalentes possam ter seu custo de execução avaliado. Repare que realizar essa estimativa não pode requerer mais recursos do que processar a consulta usando aleatoriamente um dos planos candidatos, o que implica que a estimativa tem que ser calculada rapidamente e a representação usada no cálculo deve ser bastante concisa para não ocupar um espaço em memória principal que poderia ser melhor usado no processamento da consulta (GRAEFE, 1995; STONEBRAKER; WEISBERG, 2013).

1 As abordagens baseadas em sinopses se valem desta premissa para antecipar o funcionamento de consultas em SGBDs. Em outras palavras, a construção de sinopses captura estatísticas referentes à distribuição dos dados, sumarizando o comportamento de todos os possíveis conjuntos-resposta. 
Como ilustrado na Figura 1, as representações concisas usadas para representar os dados (as sinopses) ficam armazenadas no módulo de Espaço de Distribuição de Dados do otimizador de consultas. A combinação das sinopses e meta-informações do módulo Espaço de MétodoEstrutura constituem o Catálogo de Estatísticas usado na avaliação de planos de consultas.

Para operadores de comparação, que envolvem apenas identidade e ordem, as sinopses representam as distribuições de dados do domínio ativo do atributo. Entretanto, para operadores de comparação por similaridade, as sinopses deveriam caracterizar a distribuição de distâncias entre os elementos armazenados (TASAN; OZSOYOGLU, 2004; ZEZULA et al., 2006). O desafio, então, consiste em como coletar e manter sinopses sobre distribuição de distâncias e como combiná-las com informações no módulo Espaço de Método-Estrutura para calcular o custo da execução de cada operador relacional por similaridade. Este capítulo apresenta uma revisão sobre sinopses para distribuição de dados, uma notação estendida para distribuições de distâncias, além de uma discussão sobre sinopses e modelos de custo existentes na literatura.

\subsection{Sinopses e seu uso no contexto de um SGBD}

Dada uma consulta envolvendo apenas operadores de comparação por identidade e ordem, o otimizador de consultas escolhe quais são os planos de consulta candidatos a serem executados. Os planos candidatos são submetidos a uma avaliação de custo, que totaliza o custo estimado para cada operador relacional usado no plano, de forma individual ou em conjunto, a depender do critério de otimização (TRAINA JR. et al., 2006; SILVA et al., 2013). Por exemplo, o custo do operador de Seleção depende da estimativa da seletividade de acordo com o critério empregado na comparação, sendo que esta estimativa pode ser realizada sobre a distribuição de dados do domínio ativo do atributo envolvido na comparação. Entretanto, também é possível combinar atributos por meio de conectivos lógicos $(\wedge, \vee, \neg)$ na execução do operador de Seleção ou combinar dois atributos quando a operação de Junção é realizada (KASTRATI; MOERKOTTE, 2016). Nos casos onde há mais de um atributo envolvido na comparação, a previsão da seletividade deveria levar em consideração uma distribuição de dados multidimensional, sendo que uma dimensão é adicionada sempre que um novo atributo passa a fazer parte da comparação. O grande problema é que a construção e manutenção dessas estruturas é computacionalmente cara e, pior do que o custo de construção, a quantidade de combinações para relações com muitos atributos é praticamente ilimitada, ocupando tanto espaço quanto disponível (JAGADISH et al., 2001; BRUNO; CHAUDHURI; GRAVANO, 2001; PHAM; SEVCIK, 2004).

Diante dessa limitação prática, muitos dos otimizadores tradicionais tratam a distribuição de dados uma de cada vez, assumindo a independência entre os atributos (GRAEFE; MCKENNA, 1993; KIM et al., 2017). Para alguns casos, quando pares de atributos são frequentemente comparados, alguns otimizadores podem usar estratégias multidimensionais (ACHARYA; GIBBONS; POOSALA, 1999; HELLERSTEIN et al., 2012), mas diversos estudos indicam que o uso da suposição 
de independência entre atributos é, em geral, suficiente para alcançar resultados próximos ao caso multidimensional (DESHPANDE; GAROFALAKIS; RASTOGI, 2001; WU; NAUGHTON; SINGH, 2016). Dessa forma, a regra é encontrar a melhor associação entre uma distribuição de dados e um único atributo de uma relação. A distribuição de dados captura em minúcias o domínio ativo do atributo e pode ocupar uma grande quantidade de memória principal apenas para detalhar as frequências calculadas. Portanto, é necessário, de alguma forma, "comprimir" a distribuição de dados em uma representação conveniente. As representações geradas são as denominadas sinopses, sendo que sinopses diferentes têm custo de construção distintos e podem ser usadas para vários objetivos. O estudo em Cormode et al. (2012) propõe a classificação das sinopses em quatro grandes grupos, da forma como se segue:

1. Amostragem Aleatória - Uma amostragem sobre o conjunto de dados pode ser rapidamente obtida usando um método aleatório ou estocástico (DEVROYE, 1986), sendo comum o uso do conjunto amostrado para responder perguntas sobre o conjunto de dados original (COHEN; GROSSAUG; KAPLAN, 2006). Após a coleta dos dados, é possível comprimi-los para escolher um subconjunto de valores de interesse ou usá-los para parametrizar uma função de densidade de probabilidade como representante do comportamento do conjunto de dados em análise (KORN; PAGEL; FALOUTSOS, 2001).

2. Histogramas - Um histograma representa uma distribuição de dados ao agrupar os valores de dados em subconjuntos, ou faixas ${ }^{2}$, de valores. Um conjunto de medidas, usualmente apenas a frequência, é usado para representação dos dados incluídos no intervalo de cada faixa. Histogramas constituem as principais estruturas de dados usadas como sinopses em ambientes de otimização de um SGBD (IOANNIDIS; CHRISTODOULAKIS, 1993; GARCIAMOLINA; ULLMAN; WIDOM, 2000).

3. Wavelets - Sinopses do tipo wavelets são baseadas nas estratégias de extração de características para representação de pontos importantes de uma distribuição de dados. A ideia é que o conjunto de dados seja visto como um vetor $n$-dimensional, sendo $n$ a cardinalidade do domínio ativo. Uma transformada wavelet pode ser diretamente empregada para encontrar os pesos (coeficientes) com relação à uma determinada aproximação do vetor por uma função wavelet base (PANG et al., 2013). Após a definição dos pesos, aplica-se uma abordagem com supervisão humana para eliminar os coeficientes mais baixos de acordo com sua magnitude. O conjunto final de pesos captura as propriedades do conjunto de dados em várias escalas e constitui a sinopse.

4. Sketches - Sinopses do tipo sketch (esboço de dados) são adequadas para fluxos de dados (streaming). A ideia é constituir uma representação enxuta do tipo matriz ou vetor, tal que

2 Os termos originais usados para nomear um subconjunto dividido um histograma são bucket ou bin com tradução para 'balde' e 'caixa', respectivamente. Neste trabalho preferimos usar o termo 'faixa' como tradução pois a sonoridade fica mais adequada quando combinada aos parâmetros do histograma, e.g. um 'balde de valores' vs. uma 'faixa de valores'. 
a análise do conjunto de dados possa ser rapidamente executada através de uma operação de soma ou multiplicação vetorial. Uma aplicação muito usada para sketches é o uso de vetores binários para consultas aproximadas (MIC; NOVAK; ZEZULA, 2016). Embora não tão precisas quanto os histogramas para alguns domínios, as estimativas por sketches permitem escalabilidade natural para processamento paralelo.

Uma vez que o foco deste trabalho é a representação de distâncias no contexto de um SGBD, nossa investigação se concentra sobre os dois primeiros tipos de sinopses, com o objetivo de investigar a adequabilidade de funções clássicas de densidade de probabilidade e histogramas para o problema de estimativa de seletividade em comparações por similaridade.

\subsection{Distribuição de Dados}

Os trabalhos em Ioannidis (2003) e em Buccafurri et al. (2008) procuram categorizar uma distribuição de dados do ponto de vista estrito da coleta de informações sobre os dados armazenados sem assumir previamente nenhuma modelagem por variável aleatória ou algum processo estocástico (DEVROYE, 1986; YI; WANG; WEI, 2014). Nesse cenário, uma distribuição de dados é formalizada pela Definição 3.2.1.

Definição 3.2.1 (Distribuição de Dados $-\mathcal{T}_{d}$ ). Dado um atributo numérico $A$ de uma relação $T$ cujo conjunto dos valores do atributo seja o conjunto de dados $\mathcal{S}$, a distribuição de dados $\mathcal{T}_{d}$ captura o conjunto ordenado de pares de valor e frequência. Seja $\mathcal{V}$ o conjunto ordenado de valores distintos assumidos por um atributo $\mathrm{A}$ em qualquer tupla $t$ de $\mathrm{T}$, tal que $\mathcal{V}=\{v(j): 1 \leq j \leq M\}$, $v(j)<v(k)$, para qualquer $j<k$ e sendo $M$ a quantidade de valores distintos em A. A frequência $f_{\text {req }}(j)$ de $v(j)$ é o número de tuplas de $\mathrm{T}$ onde $t[\mathrm{~A}]=v(j)$, de forma que a distribuição de dados é constituída por $\mathcal{T}_{d}=\left\{\left\langle v(1), f_{\text {req }}(1)\right\rangle, \ldots,\left\langle v(M), f_{\text {req }}(M)\right\rangle\right\}$.

Dada uma distribuição de dados $\mathcal{T}_{d}$, também são definidos:

1. A abertura $a_{b}(j)$ de cada valor $v(j)$, expressa como $a_{b}(j)=v(j)-v(j-1)$ e $a_{b}(1)=1$.

2. A área $a_{r}(j)$ para cada ponto de $\mathcal{T}_{d}$, calculada como $a_{r}(j)=f_{\text {req }}(j) \times a_{b}(j)$.

3. A frequência acumulada $c(j)$, dada pelo número de tuplas da relação $\mathrm{T}$ cujo atributo $\mathrm{A}$ toma valores entre $[v(1), v(j)]$, i.e. $c(j)=\sum_{k=1}^{j} f_{\text {req }}(k)$.

4. A distribuição acumulada de dados $\mathcal{T}_{d}^{\mathcal{C}}, \mathcal{T}_{d}^{\mathcal{C}}=\{\langle v(1), c(1)\rangle, \ldots,\langle v(M), c(M)\rangle\}$.

\subsection{Histogramas}

Um histograma sobre um atributo A se aproxima da distribuição de dados ou da distribuição acumulada de dados. Basicamente, um histograma é construído particionando-se a 
distribuição de dados de $\mathrm{A}$ em $\beta,(\beta \geq 1)$ subconjuntos mutuamente disjuntos, denominados faixas. Os conjuntos de valores e frequências são aproximados em cada faixa seguindo um critério específico. É possível construir diversos histogramas para um mesmo atributo ou combinação de atributos seguindo diferentes critérios, sendo que novos valores de abertura e área são calculados de acordo com a aproximação de cada faixa. De forma geral, qualquer histograma pode ser catalogado de acordo com a taxonomia proposta em Ioannidis (2003) cujos critérios estão listados a seguir.

- Regra de particionamento: A regra que define o particionamento dos valores de um histograma pode ser expressa em função de quatro características:

1. Classe do particionamento: Este parâmetro identifica se existem restrições para a definição de alguma faixa com relação às demais. Exemplos de faixas que são construídas utilizando este parâmetro são os histogramas com diversidade (KANNE; MOERKOTTE, 2010), histogramas equi-algo, histogramas seriados e histogramas de extremos detalhados (IOANNIDIS, 1993b).

2. Parâmetro de ordenação: Este parâmetro caracteriza qual é o atributo dos dados usado para gerar o histograma. Para dados que cobrem a faixa de maneira contínua e sem intercalação, assume-se que os valores em cada faixa são constantes, onde é possível ter:

- Suposição do Valor Contínuo - Equivalente à distribuição constante do parâmetro de ordenação por faixa, ou

- Suposição da Abertura Uniforme - Equivalente a uma distribuição uniforme do parâmetro de ordenação por faixa.

Para dados discretos, em que a ordem pode não existir (ou não é explícita), deve ser usada uma função de mapeamento que indica a faixa correspondente ao valor consultado. Exemplos de parâmetros de ordenação que podem ser usados na construção de um histograma são o conjunto de valores, frequência e área.

3. Parâmetro fonte: Este parâmetro captura a distribuição dos dados em relação ao parâmetro de ordenação, i.e. o parâmetro que será usado como alvo na geração das estimativas. A frequência é tipicamente o parâmetro fonte, mas a abertura ou a área também podem ser usadas como parâmetros fonte.

4. Restrição de particionamento: Esse parâmetro é a restrição lógica aplicada sobre o particionamento da distribuição de dados que identifica univocamente um histograma construído para uma dada classe de particionamento. Diversas restrições de particionamento, tais como Equi-Width e V-Optimal, são examinadas na sequência.

- Algoritmo de construção: De acordo com cada regra de particionamento, o algoritmo de construção monta um histograma que satisfaz os critérios de formação das faixas. Usual- 
mente, existem diversos algoritmos de construção para a mesma regra de particionamento, podendo ser as soluções ótimas ou aproximadas (JAGADISH et al., 2001).

- Aproximação de valor: Esta característica captura como o conjunto de valores do domínio ativo é aproximado em cada faixa, independentemente da regra de particionamento do histograma. A maioria dos histogramas assume a distribuição uniforme dentro de cada faixa, bem como em todo o parâmetro fonte.

- Aproximação de frequências: Esta característica define como as frequências em uma faixa são aproximadas. Exemplos de aproximação são usar uma distribuição uniforme, uma distribuição constante ou usar uma spline (KÖNIG; WEIKUM, 2002).

- Garantia de erro: As aproximações de valores e frequências geram erros que podem ser expressos de acordo com cada restrição de particionamento. A garantia de erro é o erro máximo da aproximação de acordo com a respectiva restrição.

Histogramas constituem o tipo de sinopse mais básica empregada por otimizadores de consultas em contextos relacionais (GARCIA-MOLINA; ULLMAN; WIDOM, 2000). Além disso, histogramas nesses ambientes são quase sempre empregados para sumarizar a frequência como parâmetro fonte em relação ao atributo de dados em análise como parâmetro de ordenação. Os tipos mais básicos de restrições de particionamento geram os chamados histogramas equi-algo. De forma geral, histogramas equi-algo possuem como restrição de particionamento manter a uniformidade (tanto quanto possível) do parâmetro fonte, sendo que este pode incluir o conjunto de valores, a frequência ou até mesmo a área. A Figura 13 exemplifica esses conceitos. Na Figura 13(a) há um conjunto de dados base, enquanto na Figura 13(b) a distribuição de dados é representada. Um histograma Equi-Width, que espaça igualmente o parâmetro de ordenação em faixas com valor de abertura fixa de acordo com a restrição de $\beta=3$ é mostrado na Figura 13(c). Note que a Figura 13(b) também é um histograma Equi-Width ordenado pelo valor do atributo mas com $\beta=|\mathcal{V}|-1$. Um histograma Equi-Depth, que agrupa o parâmetro de ordenação de acordo com um valor fixado para o parâmetro fonte, é mostrado na Figura 13(d). Para consultas por abrangência, os histogramas do tipo Equi-Depth tendem a gerar um erro máximo de aproximação menor do que o Equi-Width (CORMODE et al., 2012).

Diferentemente dos histogramas equi-algo, alguns histogramas seriados constroem as faixas preservando apenas parâmetros de ordenação, mas não os valores que estão inseridos em cada faixa, sendo estes particularmente úteis para atributos discretos. Destaca-se que esses histogramas podem incluir o particionamento das faixas por valores fixos de área, frequência ou abertura. Um caso particular de histogramas seriados são os histogramas de extremos detalhados (IOANNIDIS, 1993b). Esses histogramas separam os parâmetros fonte de frequências mais altas e mais baixas em faixas individuais, denominadas extremos detalhados (end biased), enquanto os demais valores são aproximados em uma única faixa central. A Figura 13(e) mostra o exemplo de um histograma de extremos detalhados para 1 extremo inicial e 1 extremo final, considerando 


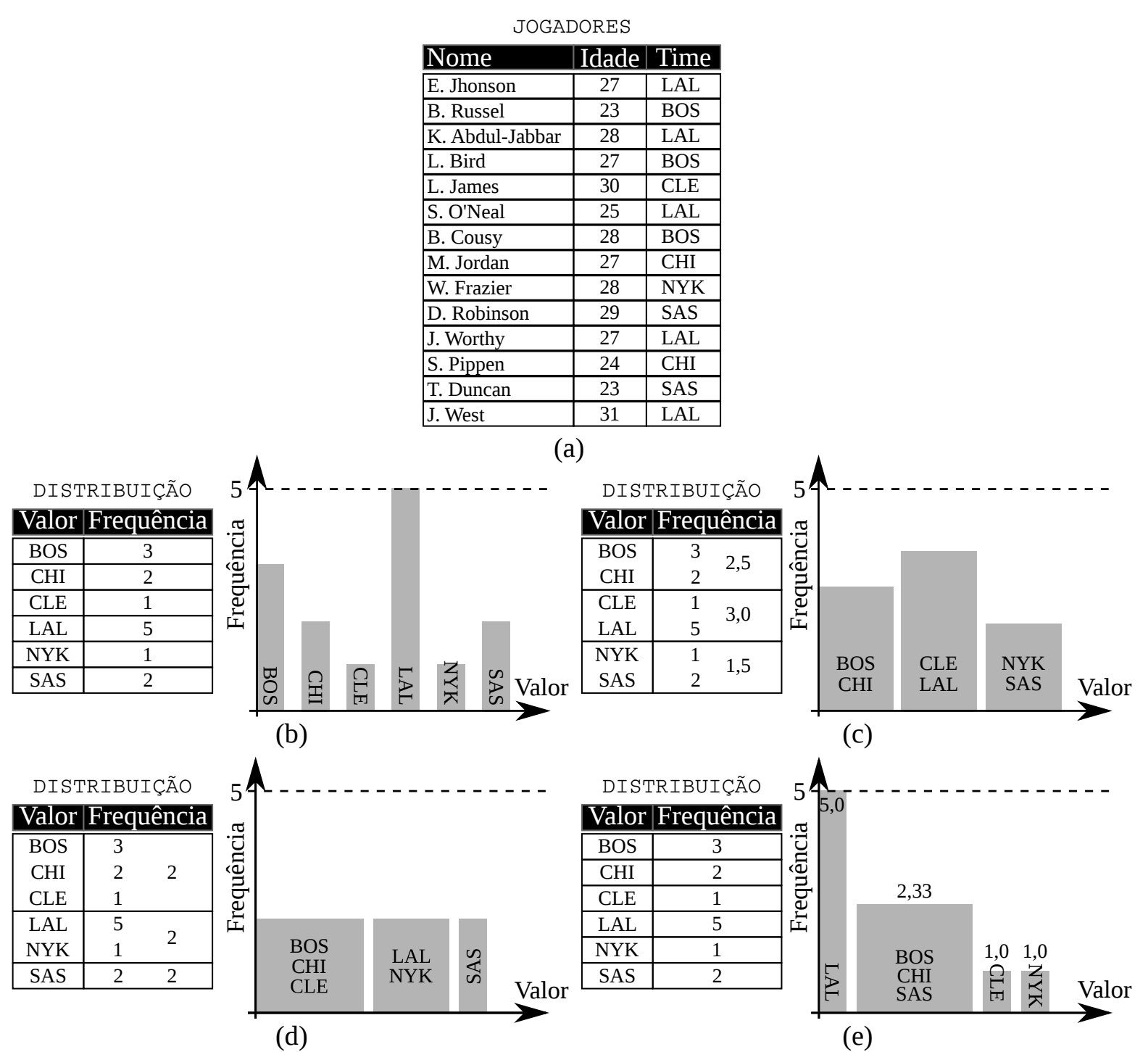

Figura 13 - Classes de histogramas por restrições de particionamento. (a) Relação original dos dados sobre jogadores de basquete, incluindo, nome, idade e time de quando se tornaram campeões de um torneio. (b) Distribuição para o atributo Time, (c) histograma Equi-Width com três faixas, (d) histograma Equi-Depth com três faixas, e (e) histograma de extremos detalhados com quatro faixas. Elaborado pelo autor.

a distribuição do atributo Time da relação na Figura 13(a). De forma geral, histogramas de extremos detalhados têm desempenho não diferente de histogramas Equi-Width e inferior aos Equi-Depth, mas essa classe de histogramas é útil para domínios com dados discretizados (ESTAN; NAUGHTON, 2006).

Considerando os exemplos das Figuras 13(c), (d) e (e) e considerando o erro de aproximação como o erro quadrático entre a média e a frequência observada, o histograma de extremo detalhados foi o que apresentou o menor erro de aproximação em comparação com os demais. Não obstante, nessa representação foram usadas quatro faixas, enquanto os demais histogramas foram representados com apenas três faixas. Nesse caso, o equilíbrio entre o espaço de memória usado e o erro da aproximação prejudicou a classe de histogramas equi-algo, visto que o erro de aproximação depende, em última instância, do número de faixas (ou do espaço em memória) 
disponibilizado no ambiente de otimização. Nesse sentido, restrições de particionamento mais complexas foram propostas com o objetivo de reduzir o erro da aproximação da representação de um histograma, sempre levando em consideração uma quantidade máxima de faixas disponibilizadas pelo SGBD. Essas restrições diferem na forma como as faixas são escolhidas, quais valores são usados como parâmetro fonte e para quais tipos de consultas elas são mais adequadas (IOANNIDIS, 1996; GUHA; SHIM, 2007). No entanto, todas essas restrições de particionamento são capazes de quantificar o erro da aproximação e com isso é possível ter a garantia do valor aproximado em cada faixa.

\subsection{Histogramas com erro controlado}

As regras de particionamento mais complexas para histogramas são basicamente as que têm funções objetivo a serem minimizadas/maximizadas em termos da função de erro e da quantidade de faixas disponíveis. Repare que diversas funções de erro podem ser usadas, incluindo as normas geométricas derivadas da família de Minkowski $L_{1}, L_{2}$ e $L_{\infty}$ que são calculadas com relação à aproximação da frequência em cada faixa em função dos valores reais do parâmetro fonte. Também são possíveis outras formas de cálculo do erro, tal como usar a divergência de Kullback-Leibler para medir a qualidade da aproximação (GIANNELLA; SAYRAFI, 2005). Na prática, a função de erro é normalmente calculada usando a premissa geométrica da norma $L_{2}$ como nos estudos em Poosala e Ioannidis (1997), Jagadish et al. (2001).

Uma restrição que usa o erro calculado pela norma $L_{2}$ com o objetivo de minimizar a variância dentro de cada faixa é a restrição que gera histogramas do tipo V-Optimal (IOANNIDIS; CHRISTODOULAKIS, 1993). Histogramas V-Optimal são construídos de forma que suas faixas minimizem a função objetivo do tipo $\sum_{k=1}^{\beta}\left|b_{k}\right| \sigma_{k}^{2}$, onde $\left|b_{k}\right|$ é o número de tuplas com valores contabilizados na faixa $b_{k}$ e $\sigma_{k}^{2}$ é a variância de todos os valores incluídos dentro dessa faixa. Diferentemente dos histogramas revisados na Seção 3.3 que podem ser construídos após uma única passada nos dados, a solução "força-bruta" para histogramas V-Optimal é de custo exponencial no tamanho da distribuição de dados $\mathcal{T}_{d}$ pela quantidade máxima de faixas (IOANNIDIS, 1996).

Uma alternativa é a proposta em Jagadish et al. (2001) para a construção de histogramas V-Optimal usando programação dinâmica. Essa proposta encontra um histograma V-Optimal com custo quadrático com relação ao tamanho de $\mathcal{T}_{d}$ e o número de faixas dado, i.e. possui custo de construção $\mathcal{O}\left(|\beta| \cdot\left|\mathcal{T}_{d}\right|^{2}\right)$. O estudo de Jagadish et al. (2001) também mostrou que esse é o menor custo possível para a obtenção de uma das soluções ótimas para essa restrição de partição e que a solução encontrada pode não ser única, i.e. podem existir mais de uma configuração distinta de faixas tal que a restrição V-Optimal atinge o menor erro global.

Soluções alternativas à proposta ótima baseada em programação dinâmica são as obtidas por estratégias aproximadas que incluem heurísticas gulosas (com ou sem backtracking) que são suscetíveis ao problema de ficarem presas a uma solução intermediária de erro mínimo local. 
Uma implementação interessante dessa categoria é a variação da restrição V-Optimal que gera a regra de particionamento maxdiff (POOSALA et al., 1996). Essa regra obtém um histograma cujo particionamento das faixas se dá nos pontos de maior diferença entre o final de uma faixa e o começo de outra. A complexidade média de construção de um histograma maxdiff é menor do que um histograma V-Optimal, sendo que experimentos indicam que o erro de ambas são razoavelmente semelhantes (POOSALA et al., 1996; IOANNIDIS, 2003; GUHA; SHIM, 2007).

Tanto os histogramas discutidos na Seção 3.3 quanto os histogramas V-Optimal e maxdiff têm uma polarização estatística no sentido de aproximarem o parâmetro fonte apenas pela distribuição uniforme. Essa suposição é particularmente inadequada quando o parâmetro de ordenação é esparso, i.e. quando alguns valores apresentam frequência igual a zero. Nesse caso, esses valores influenciam a distribuição uniforme, uma vez que esta é calculada como a média das frequências dos valores da faixa e a medida média é bastante sensível a valores extremos (OSBORNE; OVERBAY, 2004). Uma alternativa interessante é evitar a aproximação dos valores dentro da faixa pela distribuição uniforme, usando algum método numérico de aproximação ou interpolação para representar a distribuição das frequências da forma mais adequada.

A proposta em König e Weikum (1999) se vale desse raciocínio para apresentar uma estratégia capaz de minimizar a variância de valores contabilizados em cada faixa por meio de uma aproximação das frequências como uma spline de funções polinomiais. Essa estratégia, denominada Parametric Curve-Fitting, propõe o uso de splines implementadas como funções lineares para aproximar a frequência de cada faixa de um histograma. De acordo com essa restrição, cada faixa é construída usando-se o intervalo do parâmetro de ordenação $\left[v(j), v\left(j^{\prime}\right)\right), j^{\prime}>j$ e o parâmetro fonte é expresso como uma função linear, construída como a aproximação por mínimos quadrados dos valores que caem na faixa especificada (KÖNIG; WEIKUM, 2002).

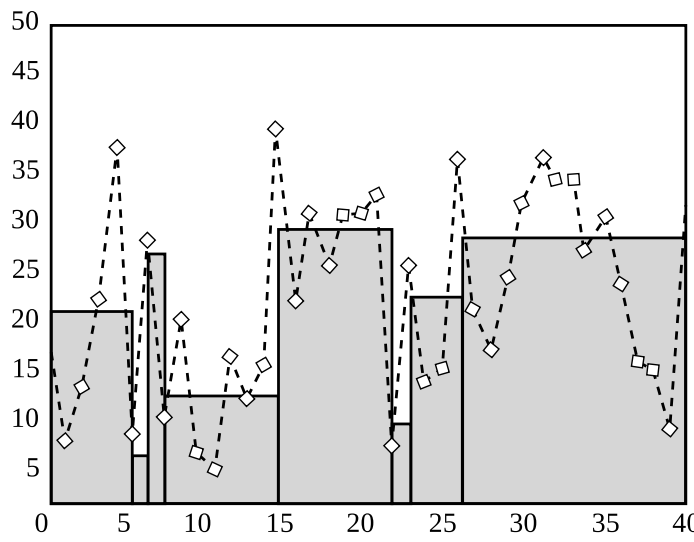

(a)

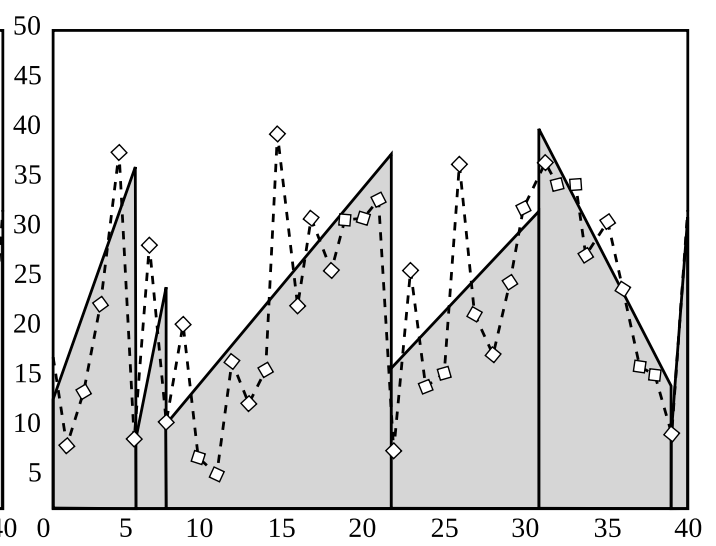

(b)

Figura 14 - Diferentes aproximações de parâmetro-fonte usando particionamento ótimo com o mesmo valor de erro de aproximação. (a) Histograma V-Optimal e (b) Histograma Parametric Curve-Fitting. Adaptado de König e Weikum (1999).

Assim como na proposta de Ioannidis e Christodoulakis (1993) para histogramas V-Optimal, os histogramas Parametric Curve-Fitting usam o erro por norma $L_{2}$ entre as frequências reais de $\mathcal{T}_{d}$ e as aproximações lineares como uma função a ser minimizada. Com esse raciocínio, 
uma aproximação por mínimos quadrados pode ser usada diretamente para minimizar a função de erro e, consequentemente, a variância. Ainda que os resultados indiquem que o uso de splines encareça bastante a construção de histogramas Parametric Curve-Fitting, o erro máximo atingido é, potencialmente, menor do que em histogramas V-Optimal. Alternativamente, é possível usar uma construção aproximada para histogramas Parametric Curve-Fitting por meio de um algoritmo guloso que divide uma faixa em duas a cada momento dessa tomada de decisão, usando como erro calculado a solução de um sistema linear (KÖNIG; WEIKUM, 2002). A Figura 14 apresenta uma distribuição de dados aproximada por um histograma V-Optimal e por um histograma Parametric Curve-Fitting. Note que a restrição de partição por splines requer uma quantidade menor de faixas para alcançar o mesmo erro de aproximação.

\subsection{Histogramas multidimensionais}

Os histogramas implementados em SGBD tradicionais são histogramas unidimensionais (para um único atributo), embora também existam histogramas multidimensionais (para tratar dois atributos dependentes) como extensões das abordagens unidimensionais. Essa extensão adiciona complexidade de processamento e aumenta o uso de memória (BUCCAFURRI et al., 2008; HE; LEE; WANG, 2008), sendo que o aumento da precisão das estimativas nem sempre é proporcional (PHAM; SEVCIK, 2004). No caso multidimensional, as restrições de particionamento podem ser mais variadas e o custo de construção costuma aumentar exponencialmente com o número de dimensões (GUHA; SHIM, 2007). Basicamente, histogramas multidimensionais podem ser divididos pelos algoritmos que são usados para construí-los, os quais podem requerer (i) múltiplas passadas sobre os dados ou (ii) uma única passada sobre os dados.

As estratégias de múltiplas passadas mais usadas são variações do método em Muralikrishna e DeWitt (1988). Esse método usa uma estratégia top-down que inicia o processamento com uma única faixa que inclui todos os dados $d$-dimensionais e escolhe uma partição arbitrária para dividir a faixa em duas, considerando uma restrição similar a histogramas Equi-Depth. Por turnos, cada faixa é dividida recursivamente considerando as dimensões restantes, levando em consideração uma quantidade pré-fixada de faixas para cada dimensão e de forma que a quantidade de faixas não exceda um número total. A estrutura do histograma resultante é armazenada

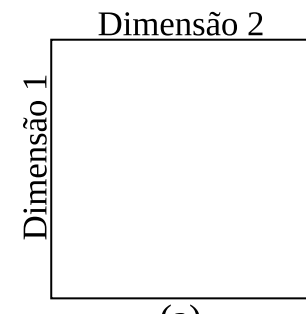

(a)

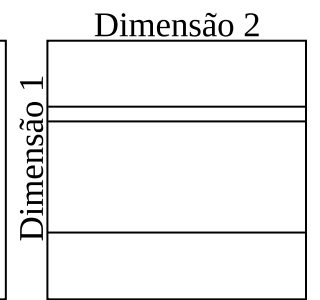

(b)

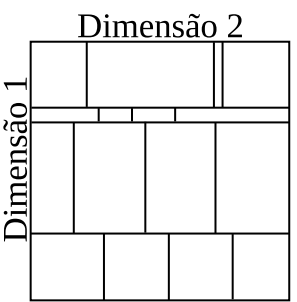

(c)

Figura 15 - Histograma de Muralikrishna e DeWitt (1988). (a) Distribuição uniforme. (b) Divisão das faixas em uma dimensão. (c) Divisão das faixas em duas dimensões. Adaptado de Cormode et al. (2012). 
em uma estrutura similar à estrutura de indexação espacial R-Tree (GUTTMAN, 1984), onde a altura da árvore corresponde ao número de dimensões e os níveis são construídos com relação à divisão das dimensões. Nessa estrutura, cada nó corresponde a um intervalo, sendo que os nós folhas incluem os limites da faixa multidimensional. A Figura 15 mostra o exemplo de um caso de duas dimensões com número máximo de faixas igual a quatro em cada dimensão. Esse histograma é particularmente interessante, pois indica a possibilidade de ligação da restrição de particionamento com a estratégia usada na indexação (BUCCAFURRI et al., 2008).

Alternativas à abordagem de Muralikrishna e DeWitt (1988) são variações da proposta multidimensional em Poosala e Ioannidis (1997), tais como as de Gunopulos et al. (2000), Bruno, Chaudhuri e Gravano (2001) e Baltrunas, Mazeika e Bohlen (2006), onde a escolha de cada dimensão a ser dividida ocorre de forma idêntica ao caso unidimensional como, por exemplo, com as restrições maxdiff e V-Optimal. Essa abordagem geral, denominada MHIST, também é uma estratégia top-down que em cada passo divide uma faixa em uma das dimensões.

Diferentemente da abordagem apresentada em Muralikrishna e DeWitt (1988), a abordagem MHIST escolhe tanto a faixa quanto a dimensão da faixa de modo guloso e faz o particionamento da faixa usando quaisquer das restrições unidimensionais. Por exemplo, para uma restrição do tipo V-Optimal, a dimensão e a faixa com a maior variância são escolhidas para a divisão. $\mathrm{O}$ algoritmo finaliza quando o número máximo pré-fixado de faixas são encontradas. A Figura 16 mostra um exemplo de partição para o histograma MHIST com a restrição V-Optimal.

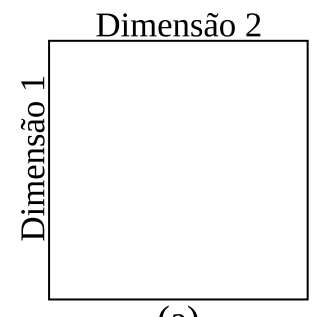

(a)

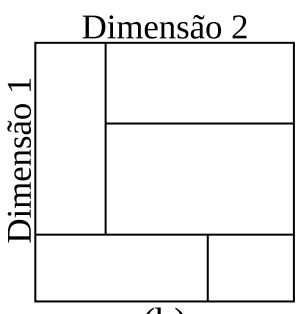

(b)

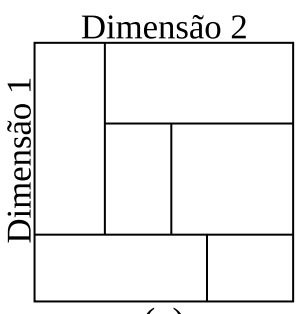

(c)

Figura 16 - Histograma multidimensional com restrição MHIST. (a) Distribuição uniforme. (b) Divisão do histograma para cinco faixas. (c) Divisão do histograma para seis faixas. Adaptado de Poosala e Ioannidis (1997).

\subsection{Distribuição de distâncias}

Distribuições de dados podem ser capturadas sempre que os valores estejam sujeitos à comparação por identidade e ordem. No entanto, não é possível coletar distribuições de dados em espaços métricos, uma vez que nem sempre existem coordenadas e não é possível definir a ordenação entre os elementos no espaço de dados. Dessa forma, a única forma possível de caracterização desse tipo de dados depende da definição de distribuições de distâncias. Diversos trabalhos empregam distribuições de distâncias, sendo que, a forma como elas são definidas variam caso a caso. Por exemplo, os estudos de Pestov (2013), Agarwal et al. (2016) modelam a 
distribuição em termos de uma variável aleatória, enquanto o trabalho em Korn, Pagel e Faloutsos (2001) faz uso de contagem de pares de distância.

Nesta tese, estendemos a definição da distribuição de dados (Definição 3.2.1) para separar as distribuições de distâncias em duas classes (que abrangem os trabalhos revisados sob uma única notação), a saber ( $i$ ) a distribuição de distâncias baseadas em pivô e a (ii) distribuição de pares de distância. Dado um atributo $A$ de uma relação $T$ sujeito à comparação por similaridade em um espaço métrico $\mathcal{M}=\langle\mathbb{S}, \delta\rangle$, o domínio ativo de $\mathrm{A}$ é dado por $\mathcal{S}$, tal que $\mathcal{S}=\left\{s_{1}, \ldots, s_{n}\right\}$ e todo $s_{i}$ é o valor em do atributo $\mathrm{A}$ em ao menos uma tupla $t[\mathrm{~A}]$ da relação $\mathrm{T}$. De acordo com essas premissas, as distribuições baseados em pivô e pares de distância, são dados pelas Definições 3.6.1 e 3.6.2, respectivamente.

Definição 3.6.1 (Distribuição de distâncias baseadas em pivô - $\mathcal{T}_{p}$ ). Dado um atributo $A$ de uma relação $\mathrm{T}$ sujeito à comparação por similaridade em $\mathcal{M}=\langle\mathbb{S}, \delta\rangle$, a distribuição de distâncias baseadas em pivô $\mathcal{T}_{p}$ captura o conjunto ordenado de distâncias a um dado pivô $p \in \mathcal{P} \subseteq \mathcal{S}$ e suas frequências. O conjunto de distâncias inclui todos os valores distintos de distâncias $\delta\left(s_{i}, p\right)$ considerando todos elementos $s_{i} \in \mathcal{S}$, tal que $\mathcal{V}_{p}=\left\{v_{p}(j): 1 \leq j \leq m_{p}\right\}, m_{p} \leq|\mathcal{S}|$. A frequência $f_{\text {reqp }}(j)$ de $v_{p}(j)$ é a quantidade de tuplas $t_{i} \in \mathrm{T}$, tal que $\delta\left(s_{i}, p\right)=v_{p}(j)$ e a frequência acumulada $c_{p}(j)$ de $v_{p}(j)$ é a quantidade de tuplas $t \in \mathrm{T}$, tal que $\delta\left(s_{i}, p\right) \leq v_{p}(j)$, de forma que a distribuição de distâncias baseadas em pivô $\mathcal{T}_{p}$ é dada por $\mathcal{T}_{p}=\left\{\left\langle v_{p}(1), f_{\text {reqp }}(1)\right\rangle, \ldots,\left\langle v_{p}\left(m_{p}\right), f_{\text {reqp }}\left(m_{p}\right)\right\rangle\right\}$, onde $v_{p}\left(m_{p}\right)$ é a maior distância entre $p$ e qualquer elemento $s_{i} \in \mathcal{S}$. De forma análoga, $\mathcal{T}_{p}^{\mathcal{C}}=$ $\left\langle v_{p}(1), c_{p}(1)\right\rangle, \ldots,\left\langle v_{p}\left(m_{p}\right), c_{p}\left(m_{p}\right)\right\rangle$ é a distribuição acumulada de $\mathcal{T}_{p}$.

Definição 3.6.2 (Distribuição de pares de distância $-\mathcal{T}$ ). Dado um atributo $A$ de uma relação $\mathrm{T}$ sujeito à comparação por similaridade em $\mathcal{M}=\langle\mathbb{S}, \delta\rangle$, a distribuição de pares de distâncias $\mathcal{T}$ captura o conjunto ordenado de distâncias entre todos os pares de elementos em $\mathcal{S}$ e suas frequências. O conjunto de distâncias contém os valores distintos de distância $\delta\left(s_{i}, s_{h}\right)$ entre todos pares de elementos $\left\langle s_{i}, s_{h}\right\rangle \in \mathcal{S} \times \mathcal{S}$ e é dado por $\mathcal{V}=\left\{v(j): 1 \leq j \leq m_{q}\right\}$ onde $m_{q} \leq|\mathcal{S}|^{2}$. A frequência $f_{r e q}(j)$ de $v(j)$ é a quantidade de distâncias onde $\delta\left(s_{i}, s_{h}\right)=v(j)$ e a frequência acumulada $c(j)$ de $v(j)$ é quantidade de distâncias onde $\delta\left(s_{i}, s_{h}\right) \leq v(j)$, de forma que a distribuição de pares de distâncias $\mathcal{T}$ é expressa como $\mathcal{T}=\left\{\left\langle v(1), f_{\text {req }}(1)\right\rangle, \ldots,\left\langle v\left(m_{q}\right), f_{\text {req }}\left(m_{q}\right)\right\rangle\right\}$, onde $v\left(m_{q}\right)$ é a maior distância entre quaisquer dois elementos em $\mathcal{S}$. Analogamente, a distribuição de pares de distância acumulada é dada por $\mathcal{T}^{\mathcal{C}}=\left\{\langle v(1), c(1)\rangle, \ldots,\left\langle v\left(m_{q}\right), c\left(m_{q}\right)\right\rangle\right\}$.

A distribuição de pares de distância pode ser estendida para a totalidade do contradomínio da função de distância, i.e. $\mathbb{R}_{+}$quando a frequência 0 é empregada para qualquer valor $v(k) \in \mathbb{R}_{+} \backslash \mathcal{V}$, o que gera a distribuição acumulada e estendida $\mathcal{T}^{\mathcal{C}}$. O mesmo raciocínio pode ser aplicado à distribuição de distância baseada em pivôs, o que gera a distribuição acumulada e estendida $\mathcal{T}_{p}^{\mathcal{C}+}$. Ambas as distribuições de distâncias são usadas na construção de sinopses que seguem diversos critérios com o objetivo de prover a estimativa de raio para consultas por 
abrangência e, junto a outras informações no Catálogo de Estatísticas, prover estimativas de acessos a disco e cálculos de distância.

\subsection{Estimativa de abrangência para consultas por vizinhança}

Sinopses que representam distribuições de distâncias podem ser usadas para estimar a distância máxima entre um centro de consulta $s_{q}$ e seu $k$-ésimo vizinho mais próximo $s_{k}$, a distância denominada de $\xi_{s_{q} s_{k}}$. O uso dessa estimativa possibilita, em teoria, reduzir uma consulta por vizinhança em uma consulta por abrangência, a qual tende a ser executada bem mais rapidamente, pois permite a poda de elementos desde o início da sua execução. Tal redução é de particular interesse para os algoritmos de busca depth-kNN e bf-kNN, uma vez que, sendo limitado o raio de cobertura, é possível evitar comparações de distância ou visitar regiões que não interceptem a bola da consulta (TASAN; OZSOYOGLU, 2004; SAMET, 2017). Mesmo os algoritmos de busca incremental podem se beneficiar da cobertura máxima estimada de uma consulta por vizinhança, sendo que nesse caso é possível controlar o tamanho das duas filas de prioridade para evitar o fenômeno de disk thrashing como sugerido em Tao et al. (2004) e também para fazer melhor uso dos algoritmos de escalonamento de disco e escolher as regiões que devem ser carregadas em memória principal.

De fato, diversos estudos mostram que, quando o raio máximo de cobertura de uma consulta por abrangência é definido de antemão, o desempenho médio do algoritmo bf -kNN pode aumentar substancialmente (JIN; KOUDAS; LI, 2004; VIEIRA et al., 2007; BEHLEY; STEINHAGE; CREMERS, 2015). Em geral, o que se espera com a definição de um raio máximo de cobertura é construir uma variação da busca por vizinhança usando a premissa de avaliar primeiro as regiões mais próximas. Supondo que um raio máximo de cobertura $\xi^{\prime}$ para $\xi_{s_{q} s_{k}}$ tenha sido estimado para uma consulta $\mathrm{k}-N N\left(\mathcal{S}, s_{q}, k\right)$, executa-se uma rotina bf-kNN com raio $\xi^{\prime}$. A propriedade do limite inferior é usada para podar regiões de busca e os elementos avaliados são inseridos em uma fila de prioridade ordenados por distância. Repare que essa estratégia pode realizar também a poda prematura de regiões quando o raio estimado $\xi^{\prime}$ é menor do que o raio real da consulta $\xi_{s_{q} s_{k}}$. Nesse caso, uma segunda estimativa $\xi^{\prime \prime}>\xi^{\prime}$ é necessária para recuperar os elementos mais próximos que façam parte do conjunto-resposta e que estejam no intervalo de distâncias $\left(\xi^{\prime}, \xi^{\prime \prime}\right]$, e assim iterativamente. A essa estratégia que usa raios estimados para resolver consultas $\mathrm{k}-N N\left(\mathcal{S}, s_{q}, k\right)$ denominamos bf-kNN limitada.

Das rotinas do tipo bf-kNN limitada, destacamos, cronologicamente, a proposta em Jin, Koudas e Li (2004), que usa como sinopse uma estrutura denominada Histograma NN (Nearest-Neighbors Histogram - NNH). Um Histograma NN baseia-se em um conjunto de pivôs $\mathcal{P}$ escolhidos arbitrariamente, para os quais se armazena um conjunto de vetores de distância. Todos os vetores de distância têm o mesmo tamanho max_k, e por isso eles armazenam distâncias para um número máximo de vizinhos, sendo que esse parâmetro é definido baseado 
nas consultas por vizinhança mais frequentes. A quantidade de pivôs $|\mathcal{P}|$ é definida em função da quantidade de memória disponível após o parâmetro max_k ser escolhido. A escolha dos parâmetros $|\mathcal{P}|$ e max_k juntamente com o critério de escolha dos pivôs define uma instância de um Histograma NN.

De modo formal, dado um conjunto de pivôs $p_{i} \in \mathcal{P}$ e um conjunto de elementos $\mathcal{S}$ obtidos do atributo $\mathrm{A}$ de uma relação $\mathrm{T}$, calculam-se as distâncias dos pivôs $p_{i}$ aos seus $k$-vizinhos mais próximos como um vetor de distância $N N\left(p_{i}\right)$, tal que $N N\left(p_{i}\right)=\left\langle H\left(p_{i}, 1\right), \ldots, H\left(p_{i}\right.\right.$, max_k $\left.)\right\rangle$, onde $H\left(p_{i}, k\right)$ denota a distância do pivô $p_{i}$ para seu $k$-ésimo vizinho no vetor de distância NN. A Figura 17 ilustra o formato da estrutura de Histograma NN, utilizando-se $|\mathcal{P}|$ pivôs, sendo que cada pivô tem associado um vetor NN de max_k vizinhos. Por exemplo, $H\left(p_{1}, 1\right)=0.95, H\left(p_{2}, 2\right)=1.50$ e $H\left(p_{|\mathcal{P}|}\right.$, max $\left.\_k\right)=2.34$.

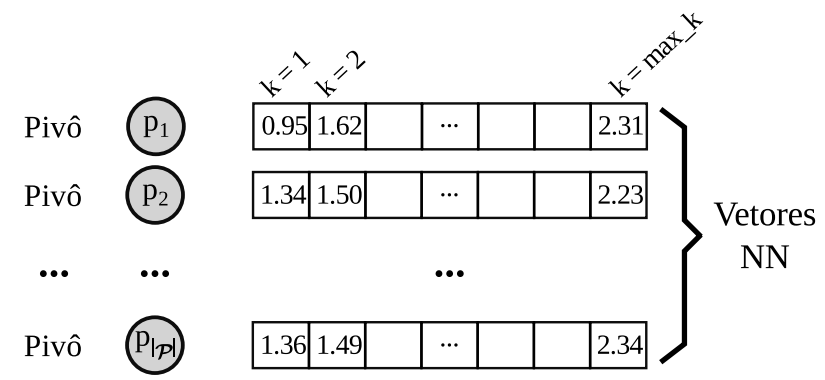

Figura 17 - Representação de um Histograma NN. Adaptado de Jin, Koudas e Li (2004).

A definição de uma rotina bf-kNN limitada usando um Histograma NN consiste em usar as distâncias armazenadas para definir um raio máximo de consulta. Quando um centro de consulta $s_{q}$ é informado pelo usuário, obtém-se a distância do elemento para cada pivô $p_{i}$ por meio do valor pré-calculado $H\left(p_{i}, k\right)$. Dessa forma, a distância entre $s_{q}$ e seu $k$-ésimo vizinho mais próximo será sempre menor ou igual à distância dada por $\xi^{\prime}=\operatorname{minimo}\left\{\xi\left(p_{i}\right)\right\} \mathrm{e}$ $\xi\left(p_{i}\right)=\delta\left(s_{q}, p_{i}\right)+H\left(p_{i}, k\right)$ considerando todos os pivôs $p_{i} \in \mathcal{P}$. Com a estimativa $\xi^{\prime}$, constróise a variação da estratégia bf-kNN limitada que denominamos, nesta tese, NNH-kNN. Repare que, no caso do NNH-kNN, $\xi^{\prime}$ sempre será uma sobre-estimativa, pois o valor calculado é sempre maior ou igual ao raio real da consulta devido a propriedade da desigualdade triangular. Portanto, garante-se que não existem falsos negativos e os falsos positivos podem ser removidos com uma filtragem final comparando os elementos recuperados diretamente com o centro da consulta. Em outras palavras, nenhuma estimativa adicional (ou mais de uma execução de busca) é necessária quando o NNH-kNN é usado como algoritmo de busca.

$\mathrm{Na}$ medida em que a quantidade de pivôs aumenta, espera-se que as estimativas usadas no NNH-kNN se tornem mais precisas. No entanto, à proporção em que cresce o número de pivôs, a quantidade de memória necessária para o armazenamento da estrutura também cresce. Portanto, a escolha de um conjunto de pivôs de boa "qualidade" é importante, sendo que a "qualidade" dos pivôs depende de uma função objetivo a ser minimizada/maximizada (BUSTOS; NAVARRO; CHáVEZ, 2003; MOŠKO; LOKOČ; SKOPAL, 2011). Pivôs de qualidade para um Histograma NN são 
aqueles que minimizam a sobre-estimativa do raio. Este problema também pode ser visto como a definição de pivôs para regiões fechadas, similar ao problema de escolha de medóides usados em técnicas clássicas de agrupamento de dados (KAUFMAN; ROUSSEEUW, 1987). De acordo com este raciocínio, o número adequado de pivôs para um NNH torna-se um problema de escolha da quantidade de grupos, para o qual os autores propõem uma solução iterativa que visa diminuir a média da sobre-estimativa do raio para uma consulta por vizinhança, considerando-se elementos aleatórios como casos de teste. Nesse procedimento, se o valor relativo da sobre-estimativa média está acima de um limite definido pelo usuário, um novo pivô é adicionado ao Histograma NN.

Ainda que o Histograma NN possa ser visto como um histograma de extremos detalhados para a distribuição de distâncias baseadas em pivô, ele também gera uma variação da estratégia de indexação LAESA detalhada na Seção 2.3.2.1. Outra estratégia baseada em restrições de histogramas clássicos é a proposta em Tasan e Ozsoyoglu (2004). No artigo original, a proposta é ilustrada sobre uma estrutura de indexação do tipo Vantage-Point Tree, embora o método dependa exclusivamente do particionamento dos elementos de dados com relação à um conjunto de pivôs $\mathcal{P}$. Basicamente, a ideia é capturar tanto as distribuições de distâncias com relação aos pivôs que definem os particionamentos quanto a distribuição de pares de distância para ponderar as estimativas oriundas das distribuições baseadas em pivô.

Todas as distribuições são compactadas de acordo com uma sinopse básica, como histogramas Equi-Width, Equi-Depth ou V-Optimal. A sinopse de distribuição acumulada e normalizada de pares de distância (chamada de representação "global" de distâncias) pode ser vista como uma função de probabilidade $H_{g}(x):[0,1]$ que expressa a possibilidade de visitar uma partição em bola definida por um pivô. Cada sinopse para uma distribuição baseada em um pivô (chamada de representação "local" de distâncias) é usada para fornecer uma estimativa média $H_{p_{i}}(x):[0, \infty)$ de quantos elementos estão cobertos por um determinado raio dentro daquela partição. A proposta original define um Evento de Busca como a probabilidade de atravessar uma (ou múltiplas) partições durante a execução de uma consulta por similaridade. Dessa forma, o raio de cobertura de uma busca por vizinhança $\mathrm{k}-N N\left(\mathcal{S}, s_{q}, k\right)$ pode ser estimado por cada pivô $p_{i} \in \mathcal{P}$ de acordo com a Equação 3.1.

$$
\int_{0}^{\xi\left(p_{i}\right)} H_{p_{i}}(x) d x=k
$$

sendo que cada estimativa para $\xi\left(p_{i}\right)$ deve ser ponderada pela distância entre $s_{q}$ e $p_{i}$ de acordo com o histograma normalizado $H_{g}(x)$, tal como na Equação 3.2,

$$
\xi^{\prime}=\sum_{i}^{|\mathcal{P}|} H_{g}\left(\delta\left(s_{q}, p_{i}\right)\right) \cdot \xi\left(p_{i}\right) \cdot \frac{1}{C_{t a s}}
$$

onde a constante $C_{t a s}$ é calculada com base na soma das distâncias de $s_{q}$ a todo $p_{i} \in \mathcal{P}$ e é usada para "espelhar" $H_{g}(x)$, i.e. quanto menor a distância entre o centro de consulta e um dado pivô $p_{i}$, maior o peso dado pela estimativa gerada pelo histograma local definido por $p_{i}$. 
Denominamos a variação bf-kNN limitada que usa o raio estimado $\xi^{\prime}$ na Equação 3.2 como Evento-Busca-kNN. Quanto menor o erro de aproximação das distribuições de distância pelos histogramas, melhor tende a ser o raio usado no algoritmo Evento-Busca-kNN.

A Figura 18 apresenta o raciocínio empregado para a estimativa de um raio para um consulta por vizinhança segundo o algoritmo Evento-Busca-kNN. Na Figura 18 (a) temos uma sinopse de um Evento de Busca, onde o espaço de busca foi particionado por três pivôs $p_{A}$, $p_{B}$ e $p_{C}$ que cobrem três regiões $A, B$ e $C$. Quatro histogramas Equi-Depth são usados para capturar a distribuição global e local de distâncias para o conjunto de dados e das partições, respectivamente. Considerando uma consulta por vizinhança com centro arbitrário $s_{q}$, os raios médios em cada região podem ser calculados como na Figura 18(b). O raio final é calculado pelos raios locais (obtidos na Equação 3.1) ponderados de acordo com o histograma global (dado por $H_{g}(x)$ ), tal como mostrado na Figura 18(c).

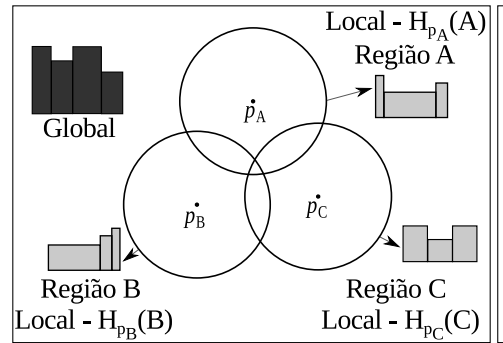

(a)

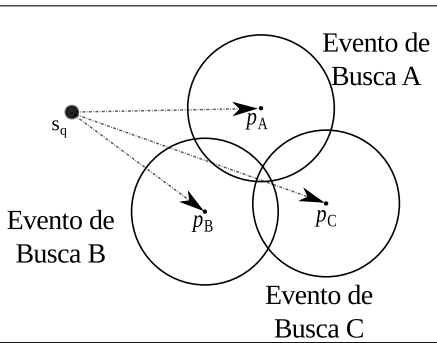

(b)

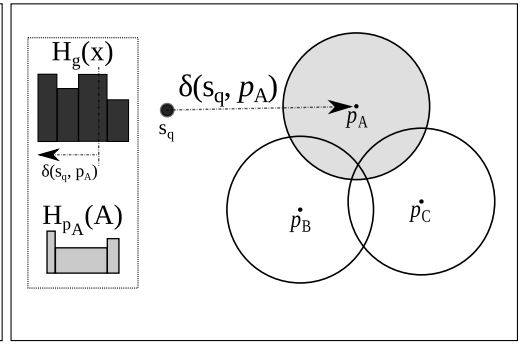

(c)

Figura 18 - Estimativa de raio usando uma sinopse Evento de Busca. (a) Regiões definidas pelos pivôs $p_{A}, p_{B}$ e $p_{C}$ e histogramas Equi-Depth associados. Um histograma também é associado à distribuição de pares de distâncias. (b) Distância das partições para um dado centro de consulta $s_{q}$. (c) Cálculo parcial de raio para a região $A$, que será ponderado de acordo $\operatorname{com} H_{g}\left(\delta\left(s_{q}, p_{A}\right)\right)$. Elaborado pelo autor.

\subsubsection{Amostragem e aproximações para distribuição de distâncias}

Além da utilização de histogramas, existem na literatura abordagens que partem do princípio de que é possível inferir uma distribuição de pares de distância a priori, considerandose a totalidade ou uma amostra arbitrária do conjunto de dados. Suposições sobre a utilização da distribuição uniforme podem ser usadas, mas os erros dessa suposição já se mostraram próximos ao limite da aleatoriedade para distribuição de dados (CHRISTODOULAKIS, 1984). Nesse sentido, alguns estudos reportam análises experimentais para determinar um método estocástico clássico mais adequado para a aproximação da distribuição de distâncias (BELUSSI; FALOUTSOS, 1995; CORMODE et al., 2012). Uma abordagem mais robusta é a relatada no trabalho em Korn, Pagel e Faloutsos (2001) para dados espaciais e, posteriormente, estendida para espaços métricos nos estudos em Vieira et al. (2007), Baioco, Traina e Traina Jr. (2007). Nestes trabalhos, os autores afirmam que a distribuição acumulada de pares de distâncias tende a apresentar um comportamento dito "fractal" ou de auto-similaridade, i.e. as propriedades das partes do conjunto de dados são similares às da totalidade do conjunto de dados (MANDELBROT, 1985). 


\subsubsection{A dimensão fractal e o expoente de distâncias}

Para conjuntos de dados que apresentam as propriedades de auto-similaridade, a distribuição de distância segue uma lei de potências, tal que dado um conjunto $\mathcal{S}$ com os valores do atributo $A$ de uma relação $T$ e um espaço métrico para representar a busca $\mathcal{M}=\langle\mathbb{S}, \delta\rangle$, a média $k$ de vizinhos em uma dada distância $\xi$ é proporcional à $\xi$ elevado à $\mathcal{D}$, onde $\mathcal{D}$ é a medida de correlação conhecida como dimensão fractal (KORN; PAGEL; FALOUTSOS, 2001). Nesse caso, a contagem de pares de elementos $P C(\xi)$ em até uma distância $\xi$ é expressa pela Equação 3.3,

$$
P C(\xi)=C_{\mathcal{D}}^{\prime} \cdot \xi^{\mathcal{D}}
$$

onde $C_{\mathcal{D}}^{\prime}$ é uma constante de proporcionalidade.

Considere a distribuição acumulada de pares de distância representada por um histograma Equi-Width com número $\beta$ de faixas arbitrário. Um gráfico que aproxima o histograma para os valores de distância e frequência acumulada pode ser desenhado em escala $\log$ - $\log$ e, caso a distribuição seja próxima a de uma distribuição exponencial, sempre será possível obter uma aproximação pela Equação 3.3. Nesta tese, denominamos esse gráfico e a sinopse correspondente de Distance Plot. A aproximação do gráfico Distance Plot pela Equação 3.3 aplicada a um conjunto de dados que exibe as propriedades de um fractal resulta em um reta, e seu coeficiente angular é uma aproximação adequada para a dimensão fractal $-\mathcal{D}$. Embora outras formas para a obtenção da dimensão fractal existam (CAMASTRA; VINCIARELLI, 2002), o uso desse método do "expoente de distância" é um dos mais comumente empregados na estimativa de raios para consultas por vizinhança e é o que usaremos em experimentos nesta tese.

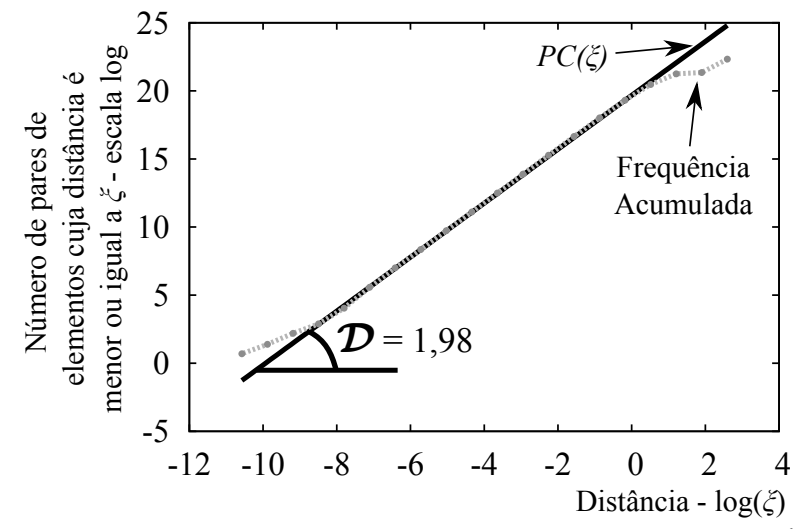

Figura 19 - Distance Plot do conjunto de dados SYNTHETIC aproximado por $P C(\xi)$ com a função de distância $L_{2}$. Ambos os eixos estão em escala logarítmica. Adaptado de Vieira et al. (2007).

A aproximação independe da escala logarítmica utilizada, embora seja usual a adoção do logaritmo natural. A Figura 19 mostra o Distance Plot para um conjunto de dados SYNTHETIC 3 que inclui 100.000 pontos em duas dimensões gerados por uma distribuição normal e comparados com a métrica $L_{2}$. Repare que a aproximação está muito próxima ao valor real da frequência acumulada na maioria dos pontos. Uma vez que o expoente de distância pode ser

\footnotetext{
3 Os detalhes sobre este conjunto de dados estão no Apêndice B.
} 
calculado como a inclinação linear da reta que aproxima a frequência acumulada, a Equação 3.3 é expressa como a Equação 3.4.

$$
\log (P C(\xi))=\mathcal{D} \cdot \log (\xi)+C_{\mathcal{D}}, C_{\mathcal{D}}=\log \left(C_{\mathcal{D}}^{\prime}\right)
$$

Uma das diversas propriedades do expoente de distância, é que $\mathcal{D}$ é invariante ao tamanho do conjunto de dados, desde que um número razoável de elementos tenha sido usado em seu cálculo (BELUSSI; FALOUTSOS, 1995) e que a amostragem não seja tendenciosa. Isso implica que, casos os dados sigam a distribuição fractal, a inclinação das retas obtidas para distintos sub-conjuntos do conjunto original com cardinalidade válida serão sempre próximas. Portanto, ao contrário do que acontece com os histogramas, se a distribuição de dados for mantida, o valor do expoente de distância permanece o mesmo, independentemente de atualizações.

\subsubsection{Expoente de distância e consultas por vizinhança}

Uma aplicação imediata do expoente de distâncias é o seu uso na estimativa de um raio inicial para otimizar a estratégia bf-kNN. Assumindo que a distribuição acumulada de pares de distância é bem aproximada por uma distribuição exponencial, é necessário obter, além do expoente de distância, o coeficiente linear da reta que aproxima as frequências acumuladas no Distance Plot. A proposta em Vieira et al. (2007) sugere utilizar um ponto conhecido da reta dado pelo tamanho do conjunto de dados $|\mathcal{S}|$ e pela maior distância entre qualquer par de elementos $-R$. Esse ponto, denominado 'Ponto 0', pode ser rapidamente obtido com o auxílio de um Catálogo de Estatísticas que armazene a quantidade de elementos inseridos na base de dados e o valor máximo de distância entre dois elementos. Para calcular a estimativa inicial do raio máximo de uma consulta por vizinhança, a estratégia emprega o expoente de distância e o 'Ponto 0' para a construção da reta.

A Figura 20(a) ilustra a ideia de como relacionar a quantidade de elementos $k$ com um raio estimado $\xi^{\prime}$. Considerando que o Ponto 0 é dado por $\langle\log (R), \log (\mathcal{S})\rangle$ e que ele define uma reta cujo coeficiente angular é dado pelo expoente de distância, a quantidade de elementos $k$ que estão à uma distância menor ou igual a $\xi$ pode ser estimada por meio da Equação 3.5.

$$
\xi^{\prime}=R \cdot \exp \left(\frac{\log (k-1)-\log (|\mathcal{S}|-1)}{\mathcal{D}}\right)
$$

Diferentemente da abordagem do Histograma NN, a estimativa de $\xi^{\prime}$ determinada pela análise da dimensão fractal pode ser subestimada. Essa estimativa depende da densidade de elementos próximos ao elemento de consulta. Caso o elemento de consulta se encontre em uma região cuja densidade média seja a mesma do conjunto de dados, a estimativa irá cobrir o conjunto-resposta. No entanto, caso a densidade de elementos próximo ao centro de consulta seja mais baixa do que a média, então é necessário realizar uma operação extra para capturar os $k^{\prime}, k^{\prime}<k$ elementos remanescentes que se encontram entre o raio estimado $\xi^{\prime}$ e $\xi^{\prime \prime}$. 


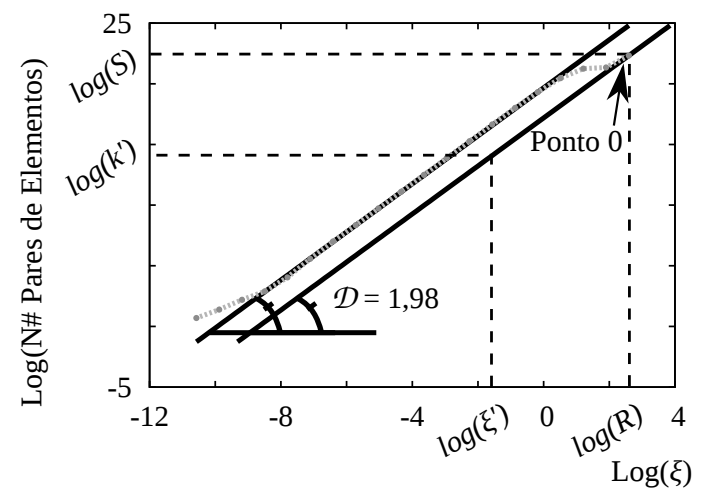

(a)

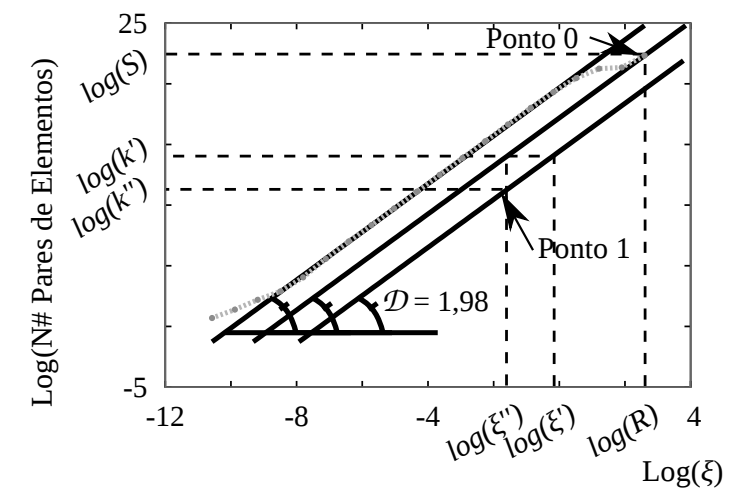

(b)

Figura 20 - Distance Plot para estimativa inicial do raio máximo de uma consulta $k$-NN. (a) Estimativa global dada pela aproximação linear. (b) Refinamento local. Adaptado de Vieira et al. (2007).

Esse ajuste pode ser calculado ao se usar novamente o Distance Plot, da maneira mostrada na Figura 20(b). Para isso, a quantidade de elementos retornados $k^{\prime}$ pode ser utilizada como uma medida da "densidade" de elementos ao redor do centro de consulta. Considerase então o 'Ponto 1', dado por $\left\langle\log \left(\xi^{\prime}\right), \log \left(k^{\prime}\right)\right\rangle$ como correspondendo à quantidade real de elementos estão próximos ao elemento de consulta limitado por $\xi^{\prime}$. De acordo com este ponto define-se uma segunda reta, com a mesma inclinação angular da primeira, mas que reflete melhor a densidade local da região onde o elemento de consulta está posicionado. O segundo valor do raio é calculado pela Equação 3.6.

$$
\xi^{\prime \prime}=\xi^{\prime} \cdot \exp \left(\frac{\log (k-1)-\log \left(k^{\prime}-1\right)}{\mathcal{D}}\right)
$$

Em casos extremos, a depender da densidade de elementos, pode ocorrer que sejam recuperados $k^{\prime \prime}$ elementos tal que $k^{\prime}+k^{\prime \prime}<k$, o que requer uma terceira aproximação e assim sucessivamente. Denominamos, neste trabalho, a variação da estratégia bf-kNN limitada que usa o expoente de distância para estimativa do raio como Fractal-kNN.

Uma variação da proposta de Vieira et al. (2007) é o estudo em Şardan (2009) que também usa uma representação única de pares de distância com apoio do expoente de distância. A interpretação, no entanto, é que o expoente de distância define uma função linear $f_{\mathcal{D}}(x)=P C(\xi)$ tal que uma função de densidade de probabilidade acumulada $F_{\mathcal{D}}(\xi):[0, R]$ é obtida sobre $f_{\mathcal{D}}(x)$ tal como na Equação 3.7.

$$
k=\left(\frac{\int_{0}^{\log \left(\xi^{\prime}\right)} f_{\mathcal{D}}(x) d x}{\int_{0}^{\log (R)} f_{\mathcal{D}}(x) d x}\right) \cdot|\mathcal{S}|=F_{\mathcal{D}}\left(\xi^{\prime}\right)
$$

sendo que basta resolver a inversa de $F_{\mathcal{D}}\left(\xi^{\prime}\right)=k$ para a obtenção de uma estimativa de distância $\xi^{\prime}$ para $\xi_{s_{q} s_{k}}$. O estudo também mostra, após análise empírica, que é comum se obter um raio subestimado para algumas execuções, sendo, portanto necessário definir um mecanismo 
eficiente de refinamento para obtenção de $\xi^{\prime \prime}$. Os autores empregam um conjunto de pivôs $\mathcal{P}$ para representar a densidade de uma determinada região de forma similar a um vetor de distâncias $\mathrm{NN}$ (ou assume-se uma distribuição uniforme caso não haja espaço na memória principal). Com isso, acrescenta-se ao raio estimado $\xi^{\prime}$ a distância entre o elemento de consulta e o pivô mais próximo considerando-se a densidade pré-estimada ao redor do centro de consulta.

\subsection{Modelos de custo}

As sinopses revisadas nas seções anteriores foram propostas com o objetivo exclusivo de executar a otimização física, mas elas também podem ser incorporadas a modelos de custo cujo objetivo é calcular os requisitos da execução de um plano de consulta. Dividimos aqui os trabalhos da literatura entre os modelos de custo para estruturas de indexação espaciais (BELUSSI; FALOUTSOS, 1995; BERCHTOLD et al., 1997; TAO et al., 2004; CORRAL et al., 2006; ALY; AREF; OUZZANI, 2015) e para estruturas de indexação métricas (CIACCIA; PATELLA; ZEZULA, 1998; CIACCIA; NANNI; PATELLA, 1999; SKOPAL; POKORNỲ; SNASEL, 2004; BAIOCO; TRAINA; TRAINA JR., 2007; CHEN et al., 2017a).

Um modelo base de custo que utiliza a distribuição de pares de distância é o modelo em Ciaccia, Patella e Zezula (1998) que denominamos nesta tese, CIA-98. A ideia é que a distribuição acumulada de pares de distância pode ser representada por qualquer tipo de histograma (e.g. Equi-Width, Equi-Depth) que, uma vez normalizado, representa uma função de densidade de probabilidade. Basicamente, o histograma é visto como uma função $H(x)$ de onde seja possível definir a densidade $\operatorname{para} \operatorname{Prob}(x \leq \xi)$, com a variável $x$ sendo um valor arbitrário de distância. Este modelo é do tipo enviesado, o que implica que as distâncias dos elementos do conjunto de dados para quaisquer centros de consultas supostamente seguem a representação $\mathcal{T}^{\mathcal{C}}$. Considerando uma árvore métrica $T$ e uma consulta por abrangência $R q\left(\mathcal{S}, s_{q}, \xi\right)$, o modelo CIA-98 expressa a probabilidade de examinar um nó enraizado por $s_{i}$ com raio de cobertura $\xi_{i}$ tal como a Equação 3.8 .

$$
\operatorname{Prob}\left\{\delta\left(s_{q}, s_{i}\right) \leq \xi+\xi_{i}\right\} \approx H\left(\xi+\xi_{i}\right)
$$

O número total de nós examinados na árvore $T$ é dado pela soma da probabilidade de acessar cada nó individualmente na estrutura, tal como disposto na Equação 3.9. De forma análoga, o número de comparações entre $s_{q}$ e os elementos indexados em $T$ é a soma dos elementos em cada nó ponderados pela probabilidade de acessar o nó como na Equação 3.10.

$$
\begin{gathered}
\text { nós_visitados } \\
\text { CIA-98 }\left(T, s_{q}, \xi\right) \approx \sum_{i}^{\mathrm{N}} H\left(\xi+\xi_{i}\right) \\
\text { distâncias_calculadas }{ }_{\mathrm{CIA}-98}\left(T, s_{q}, \xi\right) \approx \sum_{i}^{\mathrm{N}}\left|\mathrm{N}\left(s_{i}\right)\right| \cdot H\left(\xi+\xi_{i}\right)
\end{gathered}
$$


Para modelar o custo de consultas por vizinhança, é necessário, primeiramente, reduzir a consulta por vizinhança a uma consulta por abrangência. O modelo em CIA-98 usa uma função binomial para estimar a probabilidade de um elemento se encontrar em um determinado nó em função de $H(x)$, tal como detalhado na Equação 3.11 .

$$
\xi^{\prime}=R-\int_{0}^{R} 1-\left(\sum_{i=0}^{k-1}\left(\begin{array}{c}
|\mathcal{S}| \\
i
\end{array}\right) H(x)^{i}(1-H(x))^{|\mathcal{S}|-1}\right) d x
$$

A abordagem em CIA-98 alcança boa precisão sem assumir nenhuma distribuição de probabilidade a priori. No entanto, essa abordagem tem duas desvantagens, a saber, $(i)$ o valor do raio para consultas por vizinhança é computacionalmente caro para ser obtido, e (ii) a precisão das estimativas depende que a estrutura da árvore não tenha muitas sobreposições.

Com o objetivo de evitar este cálculo custoso e considerando (i) apenas o caso de espaços multidimensionais, (ii) baixos valores de $k, k \leq 10$ e (iii) que os dados espaciais estão uniformemente distribuídos, o estudo em Tao et al. (2004) propõe um modelo de custo que aqui denominaremos TA0-04. Basicamente, a ideia é calcular a intersecção entre os volumes de duas hiper-esferas espaciais: uma para a bola de consulta e outra para o nó da árvore. Com este raciocínio, o raio $\xi^{\prime}$ de uma consulta por vizinhança em um espaço $d$-dimensional para uma métrica $L_{2}$ pode ser calculado de acordo com a Equação 3.12,

$$
\begin{array}{r}
\xi^{\prime}=\frac{2}{C_{t}} \cdot\left(1-{\sqrt{\frac{k}{}^{1 / d}}}^{|\mathcal{S}|}\right), \\
C_{t}=\frac{\sqrt{\pi}}{[\Gamma(d / 2+1)]^{\frac{1}{d}}}
\end{array}
$$

onde $\Gamma(x)$ é a função gama associada à dimensionalidade $d$. Os autores combinam a estimativa de raio para a aproximação do hiper-volume como uma região de Minkowiski, de forma que é possível obter uma estimativa considerando a distribuição uniforme sob o índice espacial R-Tree (GUTTMAN, 1984), de maneira semelhante à dada pela Equação 3.9. O modelo TAO-04 tem equações baseadas no modelo CIA-98 para o cálculo de custo, mas possui ainda mais inconvenientes do que o modelo em Ciaccia, Patella e Zezula (1998). Primeiro, o modelo assume especificamente a distribuição uniforme em sua modelagem, sendo que essa premissa raramente ocorre em casos reais (CHRISTODOULAKIS, 1984). Segundo, o modelo de custo é baseado na noção de hiper-volumes em espaços multidimensionais, o que não pode ser generalizado para espaços métricos.

Uma alternativa a este modelo multidimensional é a proposta em Baioco, Traina e Traina Jr. (2007) que propõe a generalização da dimensão fractal para a estimativa de custos em consultas por similaridade sobre árvores métricas. Essa proposta estende as abordagens prévias de Belussi e Faloutsos (1995), Korn, Pagel e Faloutsos (2001) que eram originalmente de índices espaciais para árvores métricas. Os autores argumentam que a dimensão fractal é uma 
boa aproximação da dimensão intrínseca e que a primeira pode ser obtida por meio da sinopse Distance Plot (CAMASTRA; VINCIARELLI, 2002). O modelo de Baioco, Traina e Traina Jr. (2007), que denominamos BAI-07, assume que sempre que a distribuição acumulada de pares de distância $\mathcal{T}^{\mathcal{C}}$ for uma distribuição exponencial, então o expoente de distância $\mathcal{D}$ será uma aproximação boa o suficiente da dimensão intrínseca do conjunto de dados. Sob estas condições, o número de regiões examinadas e de cálculos de distância para uma consulta por abrangência $R q\left(\mathcal{S}, s_{q}, \xi\right)$ são dadas pelas Equações 3.13 e 3.14, respectivamente.

$$
\begin{gathered}
\text { nós_visitados }{ }_{\mathrm{BAI}-07}\left(T, s_{q}, \xi\right) \approx \frac{1}{R^{\mathcal{D}}} \sum_{i}^{h}|\mathcal{S}|^{\frac{i}{h}}\left(\sqrt[\mathcal{D}]{|\mathcal{S}|^{\frac{-i}{h}}}+\xi\right)^{\mathcal{D}} \\
\text { distâncias_calculadas }{ }_{\mathrm{BAI}-07}\left(T, s_{q}, \xi\right) \approx \frac{1}{R^{\mathcal{D}}} \sum_{i}^{h}|\mathcal{S}|^{\frac{i+1}{h}}\left(\sqrt[\mathcal{D}]{|\mathcal{S}|^{\frac{-i}{h}}}+\xi\right)^{\mathcal{D}}
\end{gathered}
$$

onde $h$ é a altura da árvore. Em sua proposta original, os autores argumentam que a distância entre o centro de consulta e seu $k$-ésimo vizinho pode ser calculado de acordo com a Equação 3.5. De posse do raio estimado, o modelo de custo usa as Equações 3.13 e 3.14 para obtenção dos custos finais da consulta. Como última análise, o modelo BAI-07 considera que raios sobre-estimados são preferíveis à raios subestimados, tal qual a avaliação em Vieira et al. (2007). Devido a isso, o modelo adiciona uma sobre-estimativa controlada às previsões, considerando as propriedades da árvore métrica analisada. Essa sobre-estimativa multiplica as Equações 3.13 e 3.14 pela constante do fator de gordura da árvore dada por $(1+f a t(T))$.

Outros modelos também empregam uma representação única para os pares de distâncias e assumem um modelo enviesado para predizer custos de consultas por abrangência e vizinhança. Recentemente, o estudo de Aly, Aref e Ouzzani (2015) introduziu o modelo STAIRCASE-15 para consultas por vizinhança em espaços multidimensionais. Os autores argumentam que o custo de consultas por vizinhança é estável, i.e. o custo de executar uma consulta por vizinhança com um valor de vizinhança maior do que $k$ pode ser o mesmo que executar uma consulta com um valor menor de $k$ devido ao fato que são acessados os mesmos nós do índice quando o procedimento inc-kNN é usado. Portanto, o modelo assume uma distribuição uniforme por intervalos de $k$, que resulta em uma representação compacta dos dados indexados. A Figura 21 ilustra a sinopse usada pelo modelo STAIRCASE-15 para predizer o custo de consultas por similaridade, onde o número de acessos a disco é calculado diretamente do gráfico. Restrições similares às feitas para o modelo TAO-04 também são aplicáveis ao modelo STAIRCASE-15.

Aqui nós destacamos que o viés dos modelos revisados é relacionado ao fato de adotarem uma única representação para um único tipo de distribuição de distâncias (a distribuição de pares de distância). O estudo de Tasan e Ozsoyoglu (2004), apresentado na Seção 3.7, dá uma sugestão para evitar este viés na tarefa de predizer o raio estimado de uma consulta por vizinhança. A ideia é coletar tanto a distribuição de pares de distância (global) quanto a representação de distâncias baseadas em pivôs (local) para um conjunto de pivôs selecionados arbitrariamente. Ao contrário 


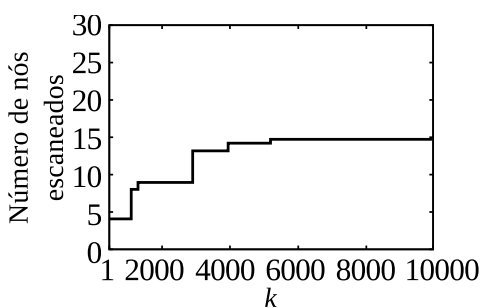

(a)

\begin{tabular}{|l|c|}
\hline Intervalo - $\boldsymbol{k}$ & Custo \\
\hline \hline$[1,520]$ & 3 \\
\hline$[521,675]$ & 7 \\
\hline$[676,3496]$ & 8 \\
\hline$[3497,4699]$ & 12 \\
\hline$[4700,5837]$ & 13 \\
\hline$[5838,10000]$ & 14 \\
\hline
\end{tabular}

(b)

Figura 21 - Sinopse do modelo de custo STAIRCASE-15. (a) Representação visual da sinopse. (b) Mapeamento do número médio de blocos visitados para um dado valor de $k$. Adaptado de Aly, Aref e Ouzzani (2015).

da convergência sugerida pela propriedade de "Homogeneidade de Pivôs" discutida em Ciaccia, Patella e Zezula (1998), o estudo em Tasan e Ozsoyoglu (2004) sugere manter as distribuições baseadas em pivôs ao invés de descartá-las.

O estudo em Ciaccia, Nanni e Patella (1999) discute parcialmente o impactos de se substituir a distribuição de pares por distribuições baseadas em pivô com relação ao modelo CIA-98. Nesse estudo, um conjunto de pivôs $p_{i} \in \mathcal{P}$ (no trabalho original denominados testemunhas) é escolhido pelo método GNAT (BRIN, 1995; FREDRIKSSON, 2017) e são usados na construção de histogramas baseados em pivô independentes e isolados. Dessa forma, dada uma consulta por abrangência para ser resolvida por uma árvore métrica $T$, cada pivô $p_{j}$ é usado para fornecer uma estimativa ponderada com relação à um nó de $T$ enraizado por $s_{i}$ de acordo com a expressão na Equação 3.15.

$$
\operatorname{Prob}\left(\delta\left(s_{q}, p_{i}\right) \leq \xi+\xi_{i}\right) \approx\left(\sum_{j}^{\mathcal{P}} H_{j}\left(\xi+\xi_{i}\right) \cdot \alpha_{j}\right) \cdot\left(\sum_{j}^{\mathcal{P}} \frac{1}{\alpha_{j}}\right)
$$

sendo que os pesos $\alpha_{j}$ precisam ser escolhidos de forma a emular uma distribuição exponencial entre o centro de consulta $s_{q}$ e cada um dos pivôs usados, tal que $\alpha_{j}=\delta\left(s_{q}, p_{j}\right)^{-e_{\text {param }}}$. O parâmetro $e_{\text {param }}$ depende do usuário ou de um procedimento dispendioso de validação cruzada aninhada para consultas por abrangência e inviável para consultas por vizinhança devido ao alto custo de estimativas de raios. Após alguns testes heurísticos, os autores argumentam que um valor empírico adequado é usar $e_{\text {param }}=10$.

Finalmente, outro resultado que reforça que o uso de pivôs pode entregar resultados mais precisos do que o uso de distribuição de pares de distância é o estudo em Chen et al. (2017a). Embora esse modelo de custo não seja aplicável a árvores métricas, os autores aproveitam a construção da estrutura de indexação baseada em pivôs SPB-Tree para coletar pequenos histogramas locais com relação aos pivôs e regiões da estrutura. A estimativa do valor do raio para uma consulta por abrangência deriva da poda por múltiplos pivôs e os resultados apresentados sobre dois conjuntos de dados reais indicam que o modelo de custo proposto tem uma boa precisão considerando a estrutura de indexação utilizada. 


\subsection{Considerações Finais}

Neste capítulo, tratamos de diferenciar distribuição de dados e distribuição de distâncias usando uma notação comum a ambas. De acordo com a análise realizada, foram categorizados dois tipos de distribuições de distância: a distribuição de pares de distância e a distribuição de distância baseada em pivôs. Todas as abordagens revisadas caem em uma dessas duas categorias: individuais (CIACCIA; PATELLA; ZEZULA, 1998; JIN; KOUDAS; LI, 2004; SKOPAL; POKORNỲ; SNASEL, 2004; ŞARDAN, 2009) ou combinadas (TASAN; OZSOYOGLU, 2004).

É importante ressaltar que nenhum tipo de distribuição é armazenado diretamente, mas sim são compactadas em estruturas denominadas sinopses. Foi apresentada uma discussão sobre a categoria de sinopses mais usadas em SGBDs, os histogramas, e a forma como eles são definidos, categorizados e construídos. Para histogramas unidimensionais, as restrições de particionamento V-Optimal e Parametric Curve-Fitting são as que resultam em menor erro de aproximação de frequências, enquanto que no caso de histogramas multidimensionais as estratégias de Muralikrishna e DeWitt (1988), Poosala e Ioannidis (1997), Bruno, Chaudhuri e Gravano (2001) podem ser adequadas quando um número fixo de faixas é usado na construção da sinopse. Um uso imediato das sinopses de distribuição de distâncias é a estimativa da distância entre o centro de consulta e o seu $k$-ésimo vizinho, a distância $\xi_{s_{q} s_{k}}$. Foram apresentadas as sinopses Histograma NN, Evento de Busca e Distance Plot que resultaram nos algoritmos NNH-kNN, Evento-Busca-kNN e Fractal-kNN capazes de otimizar fisicamente uma consulta por vizinhança. Embora estes algoritmos sejam extensões do algoritmo bf-kNN, não encontramos nenhum trabalho com a comparação de desempenho entre eles.

Um segundo uso para as sinopses é a previsão do custo de uso de um dado método de indexação na resolução de uma consulta por similaridade. Supondo que o índice usado seja uma árvore métrica, alguns modelos de custo são candidatos a serem usados. Em particular, revisamos os modelos CIA-98, TAD-04, BAI-07 e STAIRCASE-15, que realizam a estimativa de custo de acessos a disco e de cálculos de distância em uma árvore métrica usando uma única sinopse para a distribuição de pares de distância. Esses modelos propõem uma estimativa enviesada, que desconsidera o elemento de consulta tanto em consultas por vizinhança quanto em consultas por abrangência. Uma estratégia comum a todos os modelos é reduzir uma consulta por vizinhança a uma consulta por abrangência por meio da estimativa de $\xi_{s_{q} s_{k}}$ e então estimar os custos da execução da consulta resultante. Embora os modelos tenham o mesmo objetivo de prever acessos a disco e cálculos de distância, também não foi encontrado nenhum trabalho de comparação direta entre eles, seja considerando a precisão das estimativas, seja considerando tempo de processamento ou espaço gasto em memória.

A seguir apresentaremos as primeiras contribuições deste trabalho: uma nova sinopse para consultas por similaridade para ser usada na otimização física. Essa nova sinopse também pode ser usada em um novo modelo de custo que estima a quantidade de nós visitados e de distâncias calculadas em uma árvore métrica levando em conta o centro de consulta. 


\title{
Histogramas Compactados de Distância e seu uso na otimização de consultas por similaridade
}

\author{
"Even though creating histograms \\ is more fun than human beings \\ should be allowed to have, the \\ ultimate objective is not creating a \\ histogram, but rather understand \\ something about the data."
}

Mario F. Triola - Elementary

Statistics

O primeiro passo na otimização lógica e física de consultas por similaridade depende da escolha/desenvolvimento de uma sinopse adequada tanto para a representação de distribuição de pares de distâncias como para distribuições baseadas em pivô. Uma alternativa é usar os histogramas existentes na literatura, tal como sugerido por alguns dos modelos de custo revisados nas seções anteriores, ainda que estes histogramas possam não ser os mais adequados para capturar características específicas desse tipo de distribuição. Por exemplo, os histogramas multidimensionais são adequados para capturar distribuição de dados considerando a densidade dos dados no espaço multidimensional onde estes estão imersos. A Figura 22(a) mostra a visualização de um conjunto de dados sintético gerado aleatoriamente com 50 elementos num espaço bidimensional, para o qual está definida a função de distância $L_{2}$. Na figura, os elementos são representados por círculos pintados, de forma que as regiões mais densas (com mais elementos) são as regiões mais escuras, enquanto que as regiões menos densas são as regiões mais claras. Naturalmente, é possível modelar a densidade dos dados do exemplo discretizando a distribuição dos dados como uma função de densidade contínua que também pode ser usada como uma função de probabilidade. De fato, essa é a intuição por trás da maioria dos modelos de custos revisados para espaços multidimensionais, sendo que em alguns casos a função de densidade usada é assumida como uma distribuição contínua ou uniforme. 
No entanto, para espaços métricos, não é possível definir nem a posição nem a orientação dos elementos, visto que os dados não são, necessariamente, multidimensionais. De fato, a única propriedade "quantificável" em espaços métricos é a distância entre os elementos, de forma que a intuição de densidade em distribuições de distância é mais restrita que no caso de distribuições de dados. Nesse contexto, faz mais sentido falar em densidade de distâncias para distribuições baseadas em pivôs do que para distribuições de pares de distância. Uma distribuição baseada em pivô indica como frequência a quantidade de elementos cuja distância para um dado pivô $p$ é um valor fixado e pode ser usado para representar a probabilidade com que um elemento aleatório esteja, por exemplo, a no máximo uma dada distância $\xi$ de um dado pivô.

Nesse contexto, um histograma unidimensional é usado para descrever como a distribuição baseada em pivô indica a "densidade" dos elementos ao redor de $p$. A Figura 22(b) mostra uma distribuição de distância baseada em pivô, para um pivô $p$ qualquer escolhido arbitrariamente dentre os elementos de SYNTHETIC, e sua aproximação por um histograma Equi-Width com a restrição de cinco faixas. Nessa figura, quanto mais elementos incluídos numa faixa do histograma, mais escura é a faixa. É importante destacar que a densidade de distâncias foi aproximada de acordo com o parâmetro fonte do histograma e que a densidade de elementos não dá uma noção de "regiões densas do espaço", pois um elemento a uma dada distância $\xi$ ' pode estar em qualquer ponto do extremo da bola que define aquela região.

Outro inconveniente de se usar a densidade de distâncias representada por um histograma com uma restrição de particionamento clássica também é ilustrado na Figura 22(b). Note que existem "bordas" bem definidas entre uma faixa e outra, sendo que a densidade ao redor dessas bordas tem um ponto de ruptura, i.e. estas partições não permitem representar a densidade de distâncias de forma contínua. Ter uma representação contínua é interessante, pois torna-se possível obter estimativas suavizadas independentemente da localização da bola da consulta por similaridade. Ainda que um histograma com a regra de partição Parametric Curve-Fitting seja empregado, o ponto de descontinuidade continua, potencialmente, a existir, pois esta regra

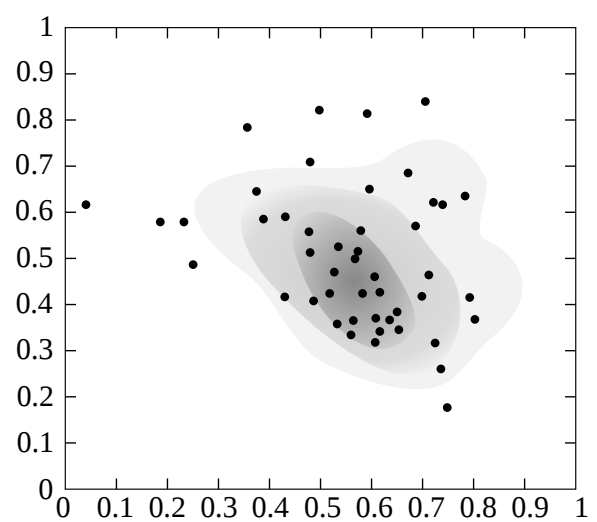

(a)

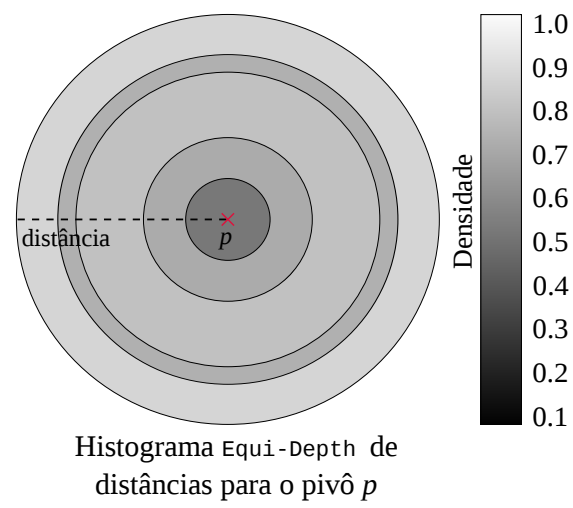

(b)

Figura 22 - Densidade de dados vs. densidade de distâncias. (a) Densidade de dados para amostra aleatória do conjunto de dados SYNTHETIC. (b) Densidade de distância para uma pivô aleatório da mesma amostra representada por um histograma Equi-Depth. As distâncias são medidas por $\delta=L_{2}$. 
de partição define cada faixa de valores em um intervalo aberto do tipo $\left[v_{p}(j), v_{p}(j+1)\right)$ para qualquer $v_{p}(j)$ do conjunto de valores distintos de distância da distribuição baseada em pivô $\mathcal{T}_{p}$.

Portanto, considerando que ( $i$ ) histogramas multidimensionais clássicos não podem ser diretamente usados na representação de densidade de dados em espaços métricos pois inexiste a noção de orientação, o que deixa como única alternativa a análise da densidade de distâncias, e que (ii) histogramas unidimensionais tradicionais podem apresentar o inconveniente de gerar uma aproximação da densidade de distâncias com pontos de descontinuidade, nós identificamos como a primeira necessidade para a otimização de consultas por similaridade: projetar uma sinopse unidimensional com garantia de erro que seja a mais adequada para lidar com distribuições de distância. Na sequência, apresentamos uma nova sinopse, como ela pode ser usada para otimização lógica e física, além de sua avaliação sobre conjuntos de dados reais na comparação com os métodos revisados da literatura.

\subsection{Histogramas Compactados de Distância - CDH}

Um Histogramas Compactado de Distância (CDH) é um histograma unidimensional construído com a restrição de particionamento que minimiza a diferença do erro absoluto (medido pela norma $L_{2}$ ) entre a frequência da distribuição e aproximado por uma spline. Adicionalmente, impõe-se a condição de que alguns pontos originais da distribuição sejam, necessariamente, interpolados. Embora a restrição possa ser empregada para representar uma distribuição de pares, este novo histograma é particularmente adequado para a distribuição de distâncias baseadas em pivô, pois permite a representação de densidade de distâncias sem pontos de descontinuidade. Formalmente, dado um atributo $A$ com domínio $\mathbb{S}$ de uma relação $\mathrm{T}$, um CDH é construído para um pivô $p \in \mathbb{S}$ através do particionamento da distribuição de distâncias baseada em pivô $\mathcal{T}_{p}$ para A em $\beta \geq 1$ faixas mutuamente disjuntas. Cada faixa $b_{l_{p}}=\left(i b_{l_{p}}, f b_{l_{p}}\right), l=1 \ldots \beta$ é definida no intervalo $i b_{l_{p}}=\left[\operatorname{low}_{p}(l), u p_{p}(l)\right)$, onde $\operatorname{low}_{p}(l), u p_{p}(l) \in \mathcal{T}_{p}$ são os limites de valores inferiores e superiores de cada faixa tal que $\operatorname{low}_{p}(l)<u p_{p}(l)$. Dessa forma, $\operatorname{low}_{p}(l)=u p_{p}(l-1)$ e o limite inferior da primeira faixa é dado por $v_{p}(1)$. A frequência $f b_{l_{p}}$ é uma função linear $\varphi$ que inclui ambos os pontos $\operatorname{low}_{p}(l)$ e $u p_{p}(l)$. Portanto, um histograma $\mathrm{CDH}=\left\{b_{1_{p}}, \ldots, b_{\beta_{p}}\right\}$ aproxima a distribuição $\mathcal{T}_{p}$ por uma função linear por partes $f_{p}(x), x \in \mathbb{R}_{+}$, tal como se segue:

$$
f_{p}(x)= \begin{cases}0 & \operatorname{para} x<\operatorname{low}_{p}(1) \\ \varphi_{1_{p}}(x)=a_{11_{p}} \cdot x+a_{21_{p}} & \text { para } x \in\left[\operatorname{low}_{p}(1), u p_{p}(1)\right) \\ \varphi_{2_{p}}(x)=a_{12_{p}} \cdot\left(x-u p_{p}(1)\right)+a_{22_{p}} & \\ \cdots & \\ \varphi_{\beta_{p}}(x)=a_{1 \beta_{p}} \cdot\left(x-u p_{p}(\beta-1)\right)+a_{2 \beta_{p}} & \operatorname{para} x \in\left[u p_{p}(\beta-1), u p_{p}(\beta)\right] \\ 0 & \operatorname{para} x>u p_{p}(\beta)\end{cases}
$$

onde $x$ é o parâmetro de ordenação (i.e. o valor da distância) e cada função $\varphi_{l_{p}}: \mathcal{V} \rightarrow \mathbb{R}_{+}$é 
uma função que aproxima a frequência dentro de cada faixa $b_{l_{p}}$, tal que $\varphi_{l_{p}}(x)=a_{1 l_{p}} \cdot(x-$ $\left.\operatorname{low}_{p}(l)\right)+a_{2 l_{p}}$, cuja inclinação angular é $a_{1 l_{p}}=\left(f_{\text {reqp }}\left(u p_{p}(l)\right)-f_{\text {reqp }}\left(\operatorname{low}_{p}(l)\right) /\left(\operatorname{up}_{p}(l)-\right.\right.$ $\left.\operatorname{low}_{p}(l)\right)$ e o coeficiente linear é dado por $\left(x-\operatorname{low}_{p}(l)\right)$. O erro na faixa $b_{l_{p}}, 1 \leq l<\beta$ é o erro da aproximação da frequência considerando a norma $L_{2}$ com relação à distribuição $\mathcal{T}_{p}$ no intervalo $\left[\operatorname{low}_{p}(l), u p_{p}(l)\right)$, tal que $\operatorname{erro}\left(\operatorname{low}_{p}(l), u_{p}(l)\right)=\sum_{\operatorname{low}_{p}(l) \leq v_{p}(j)<u p_{p}(l)} \mid f_{\text {reqp }}(j)-$ $\varphi_{p}(l)\left(v_{p}(j)\right) \mid$. Dessa forma, o erro para a $\beta$-ésima faixa é calculado de forma similar sobre o intervalo $\left[\operatorname{low}_{p}(\beta), u p_{p}(\beta)\right]$. O erro total para $f_{p}(x)$ é a soma do erro de todas as faixas do $\mathrm{CDH}$, ou seja, a diferença dada pela norma $L_{2}$ entre $\mathcal{T}_{p}$ e $f_{p}(x)$ em todo o intervalo de $\mathcal{T}_{p}$ tal que

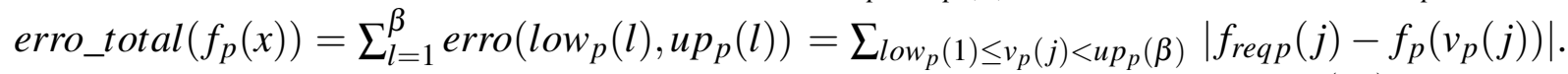
A distribuição acumulada de distâncias é derivada de $f_{p}(x)$ é dada por $\mathcal{T}_{p}^{\mathcal{C}} \leq \int_{0}^{v_{p}\left(m_{p}\right)} f_{p}(x) d x+$ erro_total $\left(f_{p}(x)\right)$.

Na comparação com as restrições V-Optimal e Parametric Curve-Fitting, a restrição CDH tende a obter um erro menor considerando a aproximação V-Optimal e um erro próximo, porém maior, ao alcançado na restrição Parametric Curve-Fitting. No entanto, ao contrário das outras duas, a restrição CDH não tem o inconveniente de apresentar pontos de descontinuidade. Mais do que isso, o custo de construção de um histograma CDH é mais próximo do V-Optimal do que do Parametric Curve-Fitting, visto que um CDH não precisa obter todas as possíveis interpolações por mínimos quadrados no intervalo de cada faixa. Nesse sentido, a restrição CDH se situa como uma solução com custo de construção comparável ao do V-Optimal e com erro médio de aproximação comparável ao do Parametric Curve-Fitting. A Figura 23 ilustra um exemplo de um $\mathrm{CDH}$ para representar uma distribuição arbitrária de distância baseada em pivô. A distribuição $\mathcal{T}_{p}$ é mostrada na Figura 23(a), enquanto que os histogramas V-Optimal, Parametric Curve-Fitting e CDH para a distribuição $\mathcal{T}_{p}$ são mostrados nas Figuras 23(b), (c) e (d), respectivamente. Note que cada histograma tem a mesma quantidade de faixas, mas eles obtêm erros de aproximação diferentes.

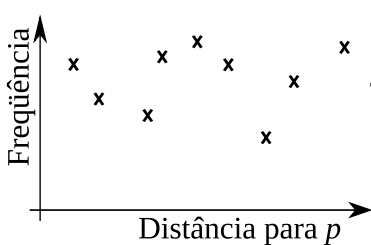

(a)

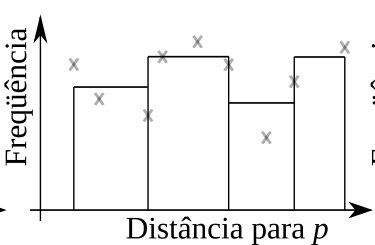

(b)

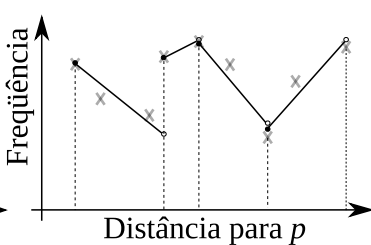

(c)

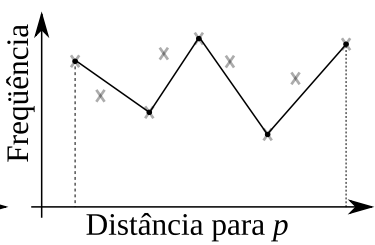

(d)

Figura 23 - Diferentes histogramas para compactar a mesma distribuição $\mathcal{T}_{p} \operatorname{com} \beta=4$. (a) Distribuição original $\mathcal{T}_{p}$. (b) Histograma V-Optimal. (c) Histograma Parametric Curve-Fitting. (d) Histograma CDH.

A construção de um $\mathrm{CDH}$ requer como parâmetro de entrada a quantidade máxima de faixas (limitado por memória), o erro de aproximação máximo tolerável (limitado por erro) ou ambos. Usar o erro máximo tolerável requer a compactação pelo número mínimo de faixas tal que o erro encontrado não ultrapasse o máximo tolerável, enquanto misturar as duas restrições indica que a compactação deve cessar quando a quantidade máxima de faixas for usada ou quando o erro máximo tenha sido atingido. Essas restrições são, virtualmente, as mesmas requeridas 
para construir um histograma com as restrições V-Optimal e Parametric Curve-Fitting. Portanto, é possível implementar uma única rotina para essas três sinopses, estendendo a solução de programação dinâmica proposta em Jagadish et al. (2001) como detalhado no Algoritmo 1. A ideia geral é tirar vantagem da estrutura do problema em si. Assim, uma vez que uma partição ótima para com $\mathrm{CDH} \operatorname{com} \beta^{\prime}$ faixas, $\beta^{\prime}<\beta$, tenha sido encontrada para o intervalo $\left[v_{p}(1), v_{p}\left(\beta^{\prime}\right)\right]$, ao se adicionar uma faixa no intervalo $\left[v_{p}\left(\beta^{\prime}\right), v_{p}\left(\beta^{\prime}+1\right)\right]$ produz-se um histograma idealmente compactado com relação ao intervalo $\left[v_{p}(1), v_{p}\left(\beta^{\prime}+1\right)\right]$. O Algoritmo 1 usa uma matriz esparsa err para armazenar o particionamento ótimo de $\mathcal{T}_{p}$ no intervalo $\left[v_{p}(1), v_{p}(j)\right]$ usando $\beta^{\prime}$ faixas.

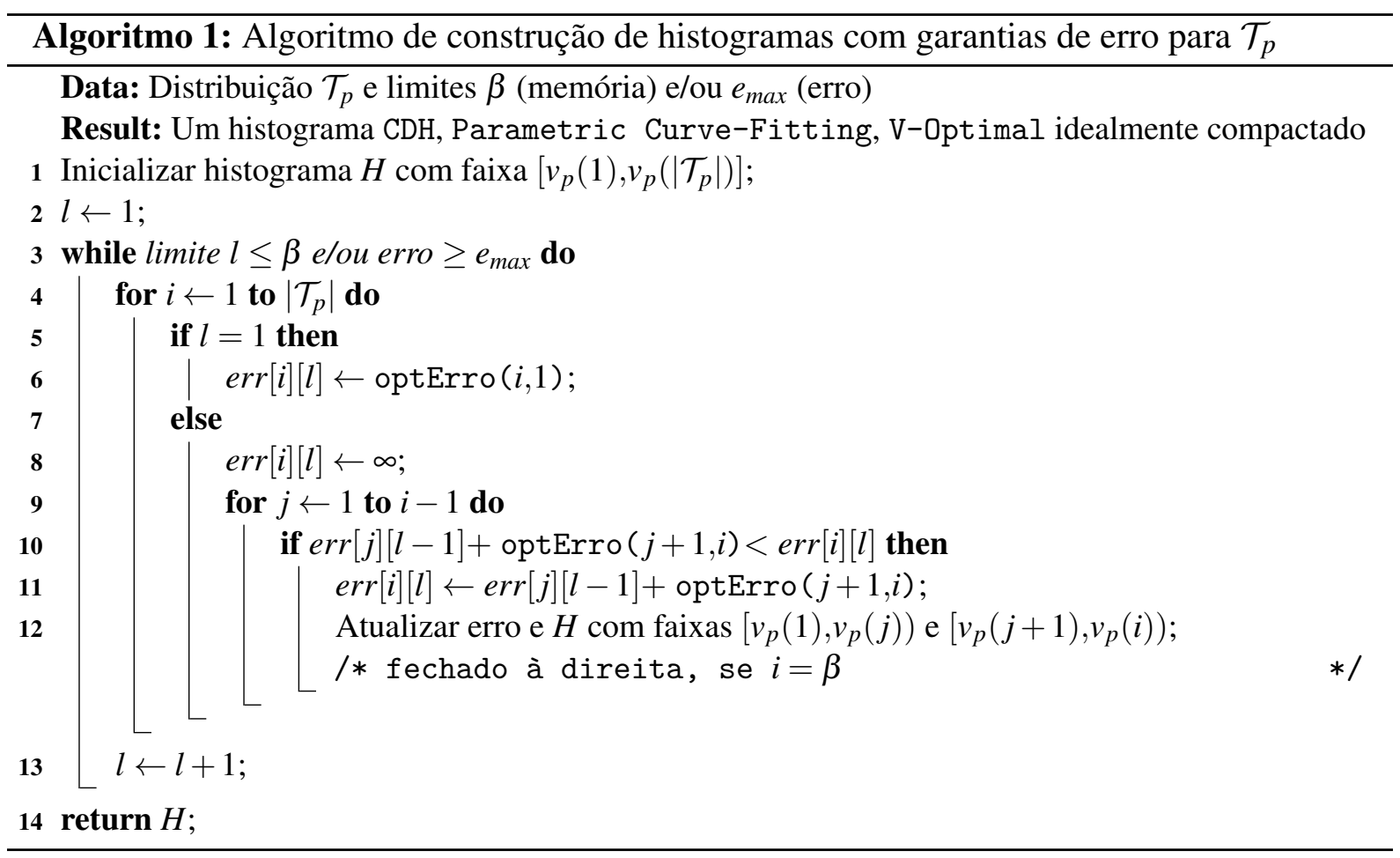

De acordo com o Algoritmo 1, apenas os elementos $v_{p}(j) \in \mathcal{T}_{p}$ são candidatos a limites de faixas, sendo que $v_{p}(1)$ é o primeiro limite da primeira faixa independentemente da restrição de particionamento. Não obstante, a frequência dentro de cada faixa é agregada de forma diferente de acordo com cada histograma. Consequentemente, a função de erro a ser minimizada também é diferente. Por exemplo, para um histograma CDH, o resultado da função optErro $(i, j)$ é a soma de todas as diferenças, considerando a norma $L_{2}$, de cada ponto em $\left[v_{p}(i), v_{p}(j)\right] \mathrm{e}$ a reta que conecta os pontos $\left\langle\left(v_{p}(i), f_{p}(i)\right\rangle,\left\langle\left(v_{p}(j), f_{p}(j)\right\rangle\right.\right.$. Por outro lado, para uma restrição Parametric Curve-Fitting, essa função é computada como a soma das diferenças entre cada ponto no intervalo $\left[v_{p}(i), v_{p}(j)\right)$ e a função linear obtida pela interpolação por quadrados mínimos considerando todos os pontos do intervalo. No caso de um histograma V-Optimal, optErro $(i, j)$ é a soma de todas as diferenças entre cada ponto no intervalo $\left[v_{p}(i), v_{p}(j)\right]$ e o valor médio neste intervalo, sendo que, sempre que a norma $L_{2}$ for usada para medir o erro em um histograma V-Optimal, a obtenção dessas diferenças pode ser substituída por obter a diferença de somas de valores e frequências. A Figura 24 apresenta um exemplo da compactação 
de uma distribuição de distância baseada em pivô sobre o conjunto SYNTHETIC de como o erro total de cada um dos três histogramas idealmente compactados varia em função da quantidade de faixas. Quando o número de faixas se aproxima do tamanho da distribuição os erros convergem, mas para um número reduzido de faixas (que é o cenário mais comum em um otimizador de consulta) existe uma variação entre os erros encontrados pelas três diferentes partições.

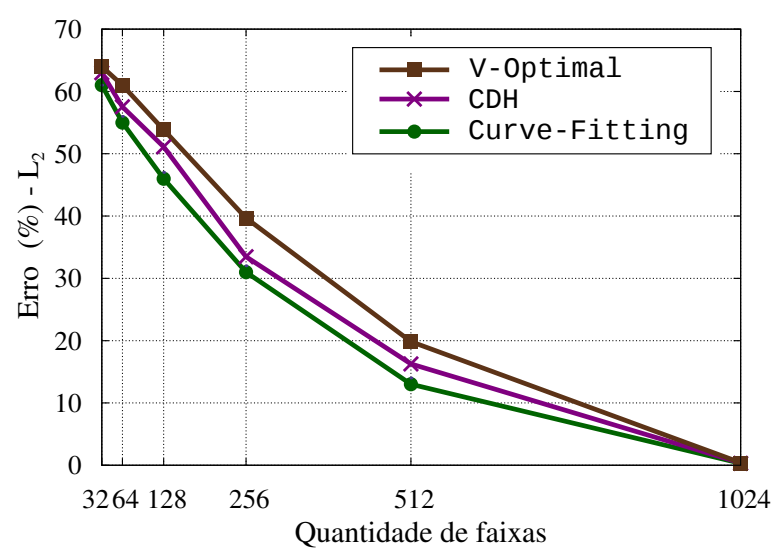

Figura 24 - Comparação de erro de aproximação em função da quantidade de faixas para uma distribuição $\mathcal{T}_{p}$, $\left|\mathcal{T}_{p}\right|=1024$, obtida do conjunto de dados SYNTHETIC.

\subsubsection{Usando histogramas $\mathrm{CDH}$ para previsão de raio}

Se assumirmos que a densidade é uniforme em função do pivô $p$ e do raio, que varia de acordo com a distribuição em CDH, é possível inferir um conjunto de regras para estimar a distância entre um centro de consulta e seu $k$-ésimo vizinho mais próximo $-\xi_{s_{q} s_{k}}$. A ideia é associar $f_{p}(x)$ à uma função de densidade de probabilidade de onde podemos estimar $\xi_{s_{q} s_{k}}$. A Figura 25(a) mostra um exemplo de $f_{p}(x)$ com a premissa de densidade uniforme, sendo que para um elemento de consulta arbitrário $s_{q}$, temos que sua posição com relação ao pivô $p$ é dada por $\delta\left(s_{q}, p\right)$. Se a quantidade de elementos na bola $\left\langle s_{q}, \xi_{s_{q} s_{k}}\right\rangle$ é $k$ (desconsiderando-se os empates), tal como mostrado na Figura 25(b), a frequência acumulada de $f_{p}(x)$ no intervalo $\left[\delta\left(p, s_{q}\right)-\xi_{s_{q} s_{k}}, \boldsymbol{\delta}\left(p, s_{q}\right)+\xi_{s_{q} s_{k}}\right]$ será $K, K \geq k$, uma vez que a bola da consulta está contida neste intervalo. Desta forma, é possível inferir $\xi^{\prime}$ a partir de $K$ e $f_{p}(x)$. Supondo que a quantidade de elementos $k$ seja proporcional tanto a $|\mathcal{S}|$ quanto a totalidade da frequência acumulada de $f_{p}(x)$ e que o erro de aproximação está uniformemente distribuído nas faixas do histograma $\mathrm{CDH}$, o raio $\xi^{\prime}$ pode ser estimado pela Equação 4.1.

$$
k= \begin{cases}\alpha_{q} \cdot \int_{\delta\left(p, s_{q}\right)-\xi^{\prime}}^{\delta\left(p, s_{q}\right)+\xi^{\prime}} f_{p}(x) d x, & \text { se }\left(\delta\left(p, s_{q}\right)-\xi^{\prime}\right) \geq 0 \text { e }\left(\delta\left(p, s_{q}\right)+\xi^{\prime}\right) \leq v_{p}\left(m_{p}\right) \\ \int_{0}^{\xi^{\prime}} f_{p}(x) d x, & \text { caso contrário. }\end{cases}
$$

onde $\alpha_{q}$ é uma proporção linear entre a distância do elemento de consulta e o pivô, i.e. $\alpha_{q}=1-\delta\left(s_{q}, p\right) / \int_{0}^{v_{p}\left(m_{p}\right)} f_{p}(x) d x$. A condição na estimativa permite usar a proporção li- 


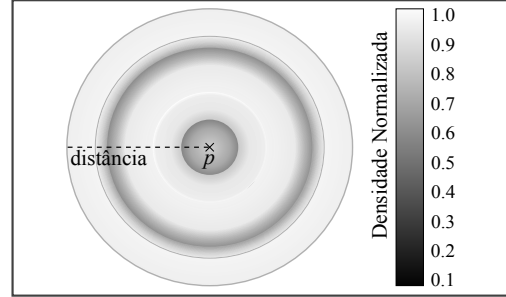

(a)

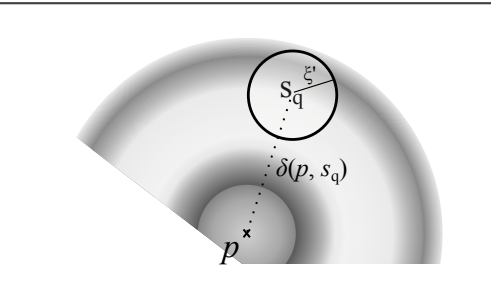

(b)

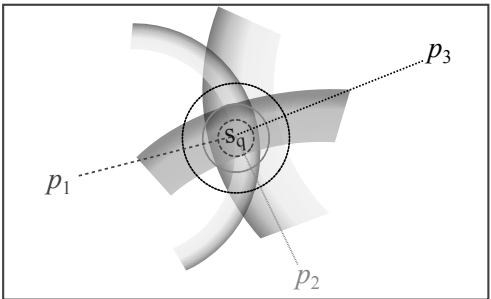

(c)

Figura 25 - Estimativa de $\xi^{\prime}$ por um CDH. (a) Estimativa de densidade considerando $f_{p}(x)$. (b) Estimativa baseada em densidade para um CDH. (c) Predições de acordo com vários histogramas CDH.

near para controlar as estimativas de centros de consulta que estejam a certa distância do pivô da distribuição, mas, no caso essa distância ser curta o suficiente, o próprio CDH é usado.

Com o objetivo de evitar subestimar raios, é possível usar múltiplos pivôs tal como na estratégia Histograma NN. Ao usar múltiplos pivôs $p_{i} \in \mathcal{P}$, será obtido um conjunto de funções $f_{p_{i}}(x)$ e consequentemente poderá ser avaliado um conjunto de estimativas (ao invés de apenas uma única). A Figura 25(c) ilustra uma situação na qual que três pivôs diferentes estimam três raios diferentes, de acordo com suas densidades locais. A ideia é combinar as estimativas de acordo com uma função de agregação para reduzir a incerteza gerada pela premissa da densidade uniforme. Nós denominamos CDH-kNN o algoritmo que usa um conjunto de CDH's para estimar o raio inicial em uma consulta bf-kNN limitada. Esse algoritmo pode usar três políticas (ou funções de agregação) para calcular o raio estimado, a saber, Tight, Avg e Relaxed, que são, respectivamente, o valor mínimo, o valor médio e o valor máximo para o raio estimado.

A intuição é que os valores preditos também podem ser usados para fazer o refinamento iterativo do raio, sempre que a primeira estimativa for subestimada. Por exemplo, suponha que a política Tight tenha sido escolhida e a estimativa $\xi^{\prime}$ foi insuficiente para recuperar os vizinhos mais próximos. A segunda estimativa de raio $\xi^{\prime \prime}$ será dada pela política Avg e, se necessário, uma terceira estimativa $\xi^{\prime \prime \prime}$ será dada pela política Relaxed. Se ainda assim não for possível obter os $k$-vizinhos mais próximos, o raio vai sendo aumentado seguindo uma progressão geométrica com relação a $\xi^{\prime \prime \prime}$. Caso a política Avg tenha sido escolhida, apenas as previsões de raio médio e máximo serão incluídas para análise, enquanto que se a política Relaxed tiver sido escolhida, então apenas o valor máximo atuará como o raio previsto.

A solução proposta para estender a rotina bf-kNN limitada como CDH-kNN é mostrada no Algoritmo 2. Os parâmetros do algoritmo são o centro de consulta $s_{q}$, o número de vizinhos $k$ e a política escolhida Agg. A função estimarRaios usa um conjunto de CDH's $=\left\{\mathrm{CDH}_{1}, \ldots, \mathrm{CDH}\right.$ $|\mathcal{P}|\}$ para gerar uma fila de prioridade de raios crescentes de acordo com a política Agg. O raio inicial $\xi^{\prime}$ é o menor valor retirado do topo da fila de prioridade. O método kEAbrangência implementa a função bf-kNN limitada, onde os nós são varridos pela ordem de proximidade e podados tanto pela distância a $s_{q}$ quanto pelo raio máximo tolerável $\xi^{\prime}$. Se o conjunto-resposta gerado por kEAbrangência gerar ao menos $k$ elementos, então a consulta foi resolvida. Do 
contrário, $\xi^{\prime}$ foi subestimado e é necessário obter $\xi^{\prime \prime}$. Para isso, o próximo valor do raio é obtido removendo o topo da fila de prioridade, ou, quando a fila está vazia, por uma progressão geométrica. Quando é necessário reajustar um raio, a rotina kEAnel é chamada. Ela é uma variação da rotina bf-kNN limitada, que examina as regiões pela ordem de proximidade e recupera o número de vizinhos restantes mais próximos que não estejam mais próximos que $\xi^{\prime}$ e que não estejam, simultaneamente, mais distantes que $\xi^{\prime \prime}$ de $s_{q}$.

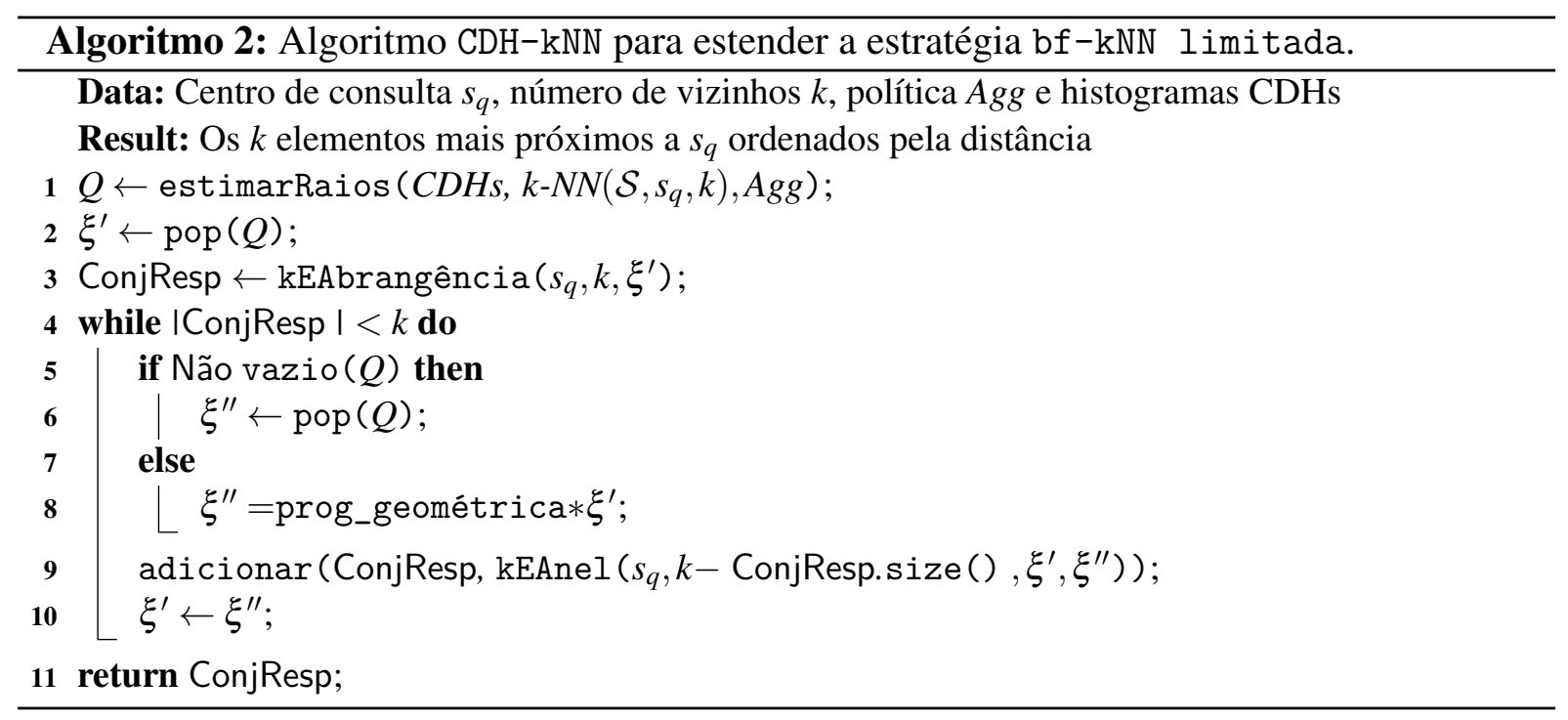

\subsubsection{Usando histogramas $\mathrm{CDH}$ para previsão de seletividade}

Embora a aplicação imediata de histogramas CDH seja na geração de estimativas de raio para otimização física, eles também podem ser estendidos para fornecer estimativas de seletividade e predizer a quantidade de elementos retornados em uma consulta por abrangência. A ideia é similar à otimização física e basicamente consiste em usar a Equação 4.1, sendo que o valor $\left|R q\left(\mathcal{S}, s_{q}, \xi\right)\right|^{\prime}$ para um valor fixado de abrangência $\xi$ é a quantidade de elementos retornados pela consulta. Em outras palavras, dada uma consulta por abrangência com centro de consulta $s_{q}$, um raio de cobertura dado $\xi$ e um histograma $\mathrm{CDH}$, a estimativa da quantidade de elementos retornados $\left|R q\left(\mathcal{S}, s_{q}, \xi\right)\right|^{\prime}$ no conjunto-resposta dessa consulta é calculada pela expressão detalhada na Equação 4.2.

$\left|R q\left(\mathcal{S}, s_{q}, \xi\right)\right|^{\prime}= \begin{cases}\alpha_{q} \cdot \int_{\delta\left(p, s_{q}\right)-\xi}^{\delta\left(p, s_{q}\right)+\xi} f_{p}(x) d x, & \text { se }\left(\delta\left(p, s_{q}\right)-\xi\right) \geq 0 \text { e }\left(\delta\left(p, s_{q}\right)+\xi\right) \leq v_{p}\left(m_{p}\right) \\ \int_{0}^{\xi} f_{p}(x) d x, & \text { caso contrário. }\end{cases}$

onde $\alpha_{q}$ é calculado como na Equação 4.1. Uma função de agregação Agg é usada para obter o mínimo, máximo ou a média das previsões considerando-se o uso de múltiplos histogramas CDH. Repare que as sinopses revisadas Histograma NN, Distance Plot e Evento de Busca também foram originalmente propostas para fornecer estimativas de raios para consultas por 
vizinhança, mas podem ser estendidas para prover estimativas de seletividade. Por exemplo, supondo que os vetores de distância são uma amostra da distribuição de distância, a sinopse Histograma NN permite obter um valor estimado de seletividade. Considerando-se a média de distâncias na amostra, o valor de seletividade para $\left|R q\left(\mathcal{S}, s_{q}, \xi\right)\right|^{\prime}$ é obtido pela Equação 4.3.

$$
\left|R q\left(\mathcal{S}, s_{q}, \xi\right)\right|^{\prime}=\frac{|\mathcal{S}|}{m a x \_k \cdot|\mathcal{P}|} \sum_{i=1}^{|\mathcal{P}|} \sum_{j=0}^{m a x \_k} B\left(p_{i}, j\right)
$$

onde $B\left(p_{i}, j\right)$ é 1 se $H\left(p_{i}, j\right) \leq \xi$, ou 0 caso contrário. Essas estimativas são limitadas para o valor máximo de distância dado por $\min \left(H\left(p_{i}, \max \_k\right)\right)$ considerando-se todo pivô $p_{i} \in \mathcal{P}$. No caso da sinopse Distance Plot, a estimativa de seletividade é bastante direta e pode ser obtida considerando-se a área do Distance Plot, tal como na Equação 4.4.

$$
\begin{gathered}
\log \left(|\mathcal{S}|\left(\left|R q\left(\mathcal{S}, s_{q}, \xi\right)\right|^{\prime}-1\right) / 2\right)-\log (|\mathcal{S}|(|\mathcal{S}|-1) / 2)=\mathcal{D} \cdot \log (\xi)-\mathcal{D} \cdot \log (R) \\
\log \left(\frac{\left|R q\left(\mathcal{S}, s_{q}, \xi\right)\right|^{\prime}-1}{|\mathcal{S}|-1}\right)=\log \left(\frac{\xi}{R}\right)^{\mathcal{D}} \\
\left|R q\left(\mathcal{S}, s_{q}, \xi\right)\right|^{\prime}=\frac{(|\mathcal{S}|-1) \cdot \xi^{\mathcal{D}}}{R^{\mathcal{D}}}+1
\end{gathered}
$$

Finalmente, com relação à estimativa de seletividade gerada pela sinopse Evento de Busca, basta empregar a distribuição de pares de distância para ponderar a seletividade gerada por cada histograma baseado em pivô, como mostrado na Equação 3.1. Dessa forma, dada uma consulta por abrangência $R q\left(\mathcal{S}, s_{q}, \xi\right)$ é possível estimar a quantidade de elementos retornados pela sinopse Evento de Busca de acordo com a Equação 4.5.

$$
\left|R q\left(\mathcal{S}, s_{q}, \xi\right)\right|^{\prime}=\sum_{i}^{|\mathcal{P}|} H_{g}\left(\delta\left(s_{q}, p_{i}\right)\right) \cdot\left(\int_{0}^{\xi} H_{p_{i}}(x) d x\right) \cdot \frac{1}{C_{\text {tas }}}
$$

\subsection{Comparação de sinopses por qualidade de previsões}

Uma vez que tanto a sinopse CDH quanto as sinopses revisadas Histograma NN, Distance Plot e Evento de Busca podem ser usadas para a previsão de raio e seletividade, é possível realizar uma comparação entre todas elas para verificar a adequabilidade de cada uma para as previsões de seletividade e raio. Nesse sentido, realizamos um estudo comparativo considerando todas essas sinopses com o objetivo de responder a duas questões de pesquisa, a saber:

- Quais sinopses geram as estimativas de seletividade mais precisas com relação às consultas por abrangência?

- Quais sinopses são mais adequadas para estender a estratégia bf-kNN limitada para espaços métricos? 
Para responder a estas questões, nós selecionamos um grupo de conjuntos de dados representativos com diferentes cardinalidades para realizar dois experimentos. A Tabela 2 lista os conjuntos de dados empregados nos experimentos, indicando sua cardinalidade e dimensionalidade. Também são listadas as funções de distância empregadas na execução de consultas por similaridade sobre o conjunto de dados, o expoente de distância $\mathcal{D}$ medido e o tamanho da página usada para indexação dos elementos em árvores métricas Slim-Tree. Todos as sinopses foram implementadas em uma mesma plataforma e todos os experimentos foram realizados sob um mesmo ambiente, tal como detalhado na Seção 6.5. Todos os índices Slim-Tree foram construídos usando as políticas de construção Min-Max e MinDist.

Tabela 2 - Conjuntos de dados empregados na comparação de sinopses para previsão de raio e seletividade.

\begin{tabular}{|l|r|c|c|l|l|}
\hline Nome & Dimens. & $\lceil\mathcal{D}\rceil$ & $|\mathcal{S}|$ & Métrica & Tam. Página \\
\hline \hline CANVAS & 16 & 10 & 3.879 & BrayCurtis & 2KB \\
\hline CITIES & 2 & 2 & 5.507 & $L_{2}$ & $2 \mathrm{~KB}$ \\
\hline BIKE & 7 & 2 & 17.379 & Canberra & $2 \mathrm{~KB}$ \\
\hline SENSOR & 48 & 6 & 58.509 & $L_{1}$ & $8 \mathrm{~KB}$ \\
\hline COREL & 32 & 10 & 66.616 & $L_{\infty}$ & $4 \mathrm{~KB}$ \\
\hline SYNTHETIC & 2 & 2 & 100.000 & $L_{2}$ & $2 \mathrm{~KB}$ \\
\hline ALOI & 13 & 8 & 110.250 & $L_{1}$ & $2 \mathrm{~KB}$ \\
\hline ROAD3D & 3 & 2 & 434.874 & $L_{2}$ & $2 \mathrm{~KB}$ \\
\hline
\end{tabular}

Foram construídas oito sinopses para representar as distribuições de distância dos conjuntos de dados. Os parâmetros usados na construção das sinopses são mostrados na Tabela 3. A escolha dos parâmetros das sinopses foi feita levando-se em consideração um aspecto objetivo: a quantidade mínima de espaço necessário para que a sinopse pudesse ser usada. Por exemplo, a quantidade de espaço requerido pela sinopse Distance Plot é fixa, independente do conjunto de dados. Já para as demais sinopses, outros fatores precisam ser levados em consideração. Por exemplo, o menor espaço gasto pela sinopse Evento de Busca depende do número de entradas no nó raíz da Slim-Tree, tal que essa é a menor quantidade de distribuições locais que podem ser obtidas levando-se em consideração o particionamento balanceado do índice. No caso da sinopse CDH a quantidade de pivôs aumenta de acordo com o expoente de distância que foi usado como a aproximação da dimensão intrínseca do conjunto de dados. A ideia de usar o número de pivôs de acordo com a dimensão intrínseca segue as indicações em Bustos, Navarro e Chávez (2003), Traina Jr. et al. (2007), onde resultados empíricos indicam correlação entre a quantidade de pivôs e a dimensão intrínseca. Seguindo a indicação de Traina Jr. et al. (2007) nós usamos $\mathcal{P}=2 \times\lceil\mathcal{D}\rceil+1$, de forma que seja possível explorar as consequências da política de escolha do raio/seletividade nos dois tipos de consultas por similaridade experimentados. Finalmente, para a sinopse Histograma NN, escolhemos a quantidade de pivôs de acordo com um limite máximo de espaço disponível que aumenta proporcionalmente com relação à cardinalidade do conjunto de dados. O parâmetro max_k foi escolhido em função do número máximo de vizinhos a serem avaliados. A Tabela 4 sumariza a quantidade de memória gasta por cada sinopse. 
Tabela 3 - Sinopses avaliadas e seus parâmetros de construção.

\begin{tabular}{|c|c|c|}
\hline Sinopse & Acrônimo & Parâmetros \\
\hline Distance Plot & DistPlot & Expoente de distâncias $\mathcal{D}$ \\
\hline Histograma NN & $\mathrm{NNH}$ & $\begin{array}{l}\text { Quantidade de pivôs } \mathcal{P}=\lceil 0.005 *|\mathcal{S}|\rceil \\
\text { Parâmetro } \max \_k=100 \\
\text { Método de Seleção de pivôs K-MEDOIDS }\end{array}$ \\
\hline $\mathrm{CDH}$ & $\mathrm{CDH}\{$ Tight $\}$ & $\begin{array}{l}\text { Quantidade de pivôs } \mathcal{P}=2 \times\lceil\mathcal{D}\rceil+1 \\
\text { Política de escolha da } 1^{a \cdot} \text { previsão }- \text { Tight } \\
\text { Método de Seleção de pivôs OMNI e } \beta=128\end{array}$ \\
\hline $\mathrm{CDH}$ & $\mathrm{CDH}\{\mathrm{Avg}\}$ & $\begin{array}{l}\text { Quantidade de pivôs } \mathcal{P}=2 \times\lceil\mathcal{D}\rceil+1 \\
\text { Política de escolha da } 1^{a} \text {. previsão }- \text { Avg } \\
\text { Método de Seleção de pivôs OMNI e } \beta=128\end{array}$ \\
\hline Evento de Busca & SE $\{$ Equi-Width $\}$ & $\begin{array}{l}\text { Histograma global Equi-Width para } \beta=128 \\
\text { Histogramas locais Equi-Width para } \beta=128 \\
\text { Quantidade de histogramas depende do índice }\end{array}$ \\
\hline Evento de Busca & SE $\{$ Equi-Depth $\}$ & $\begin{array}{l}\text { Histograma global Equi-Depth para } \beta=128 \\
\text { Histogramas locais Equi-Depth para } \beta=128 \\
\text { Quantidade de histogramas depende do índice }\end{array}$ \\
\hline Evento de Busca & $\mathrm{SE}\{\mathrm{V}-0 \mathrm{ptimal}\}$ & $\begin{array}{l}\text { Histograma global V-Optimal para } \beta=128 \\
\text { Histogramas locais V-Optimal para } \beta=128 \\
\text { Quantidade de histogramas depende do índice }\end{array}$ \\
\hline Evento de Busca & $\mathrm{SE}\{\mathrm{CF}\}$ & $\begin{array}{l}\text { Histograma global } \\
\text { Parametric Curve-Fitting para } \beta=128 \\
\text { Histogramas locais } \\
\text { Parametric Curve-Fitting para } \beta=128 \\
\text { Quantidade de histogramas depende do índice }\end{array}$ \\
\hline
\end{tabular}

Tabela 4 - Quantidade de memória (em kB) gasta por cada sinopse com relação aos conjuntos de dados da Tabela 2.

\begin{tabular}{l|r|r|r|r|r}
\multicolumn{1}{c}{ NNH } & $\begin{array}{c}\text { CDH } \\
\text { \{Avg, Tight }\end{array}$ & DistPlot & SE $\left\{\begin{array}{l}\text { Equi-Width } \\
\text { Equi-Depth } \\
\text { V-Optimal }\end{array}\right\}$ & SE $\{\mathrm{CF}\}$ \\
\hline Canvas & 17,71 & 46,12 & 0,34 & 16,80 & 32,28 \\
Cities & 22,14 & 10,42 & 0,34 & 9,41 & 18,70 \\
Bike & 73,96 & 10,62 & 0,34 & 9,65 & 18,94 \\
Sensor & 346,90 & 31,88 & 0,34 & 5,81 & 10,45 \\
Corel & 352,98 & 48,80 & 0,34 & 5,42 & 10,07 \\
2DPoints & 410,00 & 10,42 & 0,34 & 9,41 & 18,70 \\
Aloi & 500,31 & 39,92 & 0,34 & 6,62 & 12,82 \\
3D-Road & 1800,07 & 10,46 & 0,34 & 25,22 & 49,98
\end{tabular}

\subsubsection{Comparação de sinopses na estimativa de seletividade}

O objetivo da primeira comparação é determinar qual é a sinopse mais adequada para fornecer estimativas de seletividade. Este experimento foi executado segundo o critério de percentage split, onde aleatórios $90 \%$ do conjunto original foram usados para indexação e os restantes $10 \%$ foram usados como centros de consulta. Foram executadas consultas por abrangência para todos os centros de consulta, sendo que o valor do raio de cobertura foi definido 
em função do tamanho do conjunto-resposta, i.e. raios de consulta $\xi_{s_{q} s_{k}}$ foram escolhidos tal que $\left|R q\left(\mathcal{S}, s_{q}, \xi_{s_{q} s_{k}}\right)\right|=k$ para $k=5,10, \ldots, 95$. O valor $\xi_{s_{q} s_{k}}$ foi calculado pelo algoritmo bf-kNN, porque assim nenhuma estimativa é necessária de antemão. Dessa forma, nós usamos as sinopses para estimar o tamanho $\left|R q\left(\mathcal{S}, s_{q}, \xi_{s_{q} s_{k}}\right)\right|^{\prime}$ para todos os centros de consulta e anotamos a diferença entre valor estimado e o valor real na forma de uma medida de erro que denominamos Erro\%. Esta medida de erro nada mais é que a diferença absoluta entre o valor estimado e o valor real de seletividade multiplicado pela quantidade total de elementos e divido por uma centena, de forma a facilitar a comparação da qualidade das estimativas obtidas. A Figura 26 mostra a média e o desvio padrão de Erro\% para cada conjunto de dados avaliado, com $k$ variando de 5 até 95. De forma geral, é possível observar quatro sinopses vencedoras (SE\{Equi-Width\}, $\mathrm{SE}\{$ Equi-Depth\}, SE\{V-Optimal \} e CDH\{Tight\}), duas perdedoras (NNH e DistPlot) e duas que ficaram entre esses dois grupos ( $\mathrm{SE}\{\mathrm{CF}\}$ and $\mathrm{CDH}\{\mathrm{Avg}\})$.
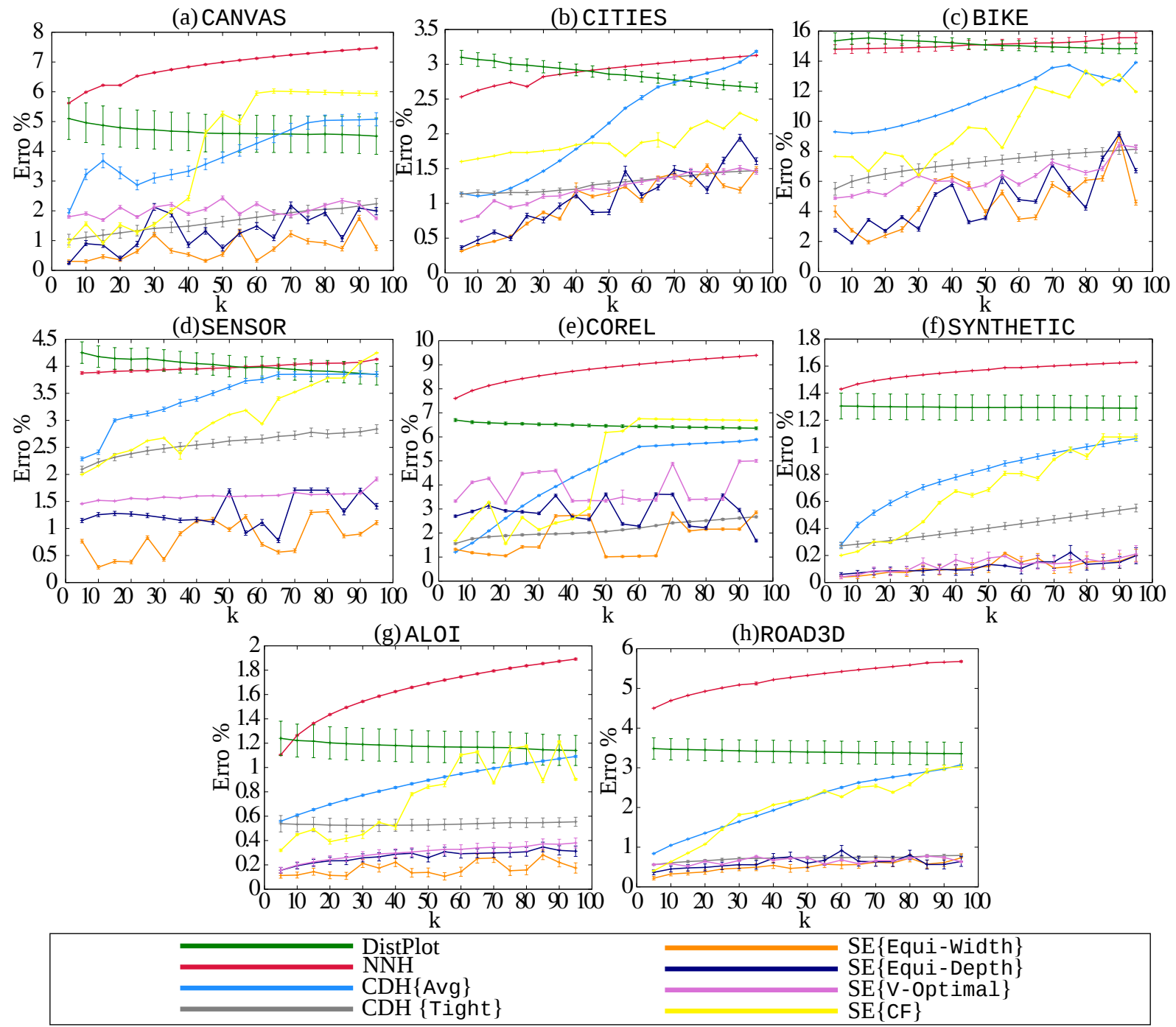

Figura 26 - Comparação da média e desvio padrão para Erro\% considerando-se previsões de oito sinopses.

Com o objetivo de identificar quais são as diferenças significativas entre as sinopses avaliadas, recorremos a um teste de hipótese. Como primeiro passo, foi aplicado o teste de 
ranking de Friedman (DEMSAR, 2006; GARCIA; HERRERA, 2008), com o objetivo de identificar se as predições obtiveram diferenças significativas entre si. Ao usarmos todos os centros de consulta e os resultados medidos por Erro\% para um nível de significância de 0.1 , o teste gerou um $p$-valor de $3,56 \times 10^{-4}$. De acordo este $p$-valor, é possível rejeitar a hipótese nula de que não existem diferenças significativas entre as oito abordagens e afirmar que pelo menos uma delas difere das demais. Portanto, como segundo passo, foi aplicado um pós-teste para verificar quais das sinopses alcançaram as melhores predições com significância. Em particular, aplicamos o teste de Nemenyi, que basicamente usa uma estratégia de ranking para determinar os $p$-valores entre pares de sinopses considerando a medida Erro\%. Nesse teste, quanto menor o $p$-valor do par comparado, mais significativa é a diferença entre as duas estratégias comparadas. A Figura 27 mostra um "mapa de calor" construído de acordo com os $p$-valores obtidos pelo teste de Nemenyi. Nesse mapa, quanto mais claro o fundo de uma célula, menor o módulo do $p$-valor obtido. Para facilitar a visualização, quando a sinopse da coluna ganha da sinopse na linha, o $p$-valor é mostrado como valor positivo, do contrário ele é mostrado como negativo. De acordo com estes critérios, categorizamos as diferenças entre os pares de sinopses comparadas em três grupos: (i) fortemente significante (95\% de confiança ou mais) destacado com duplo sublinhado, (ii) significante (90\% até $95 \%$ de confiança), destacado com sublinhado simples, and (iii) não significante (menos do que $90 \%$ de confiança), que são os valores que não estão em negrito.

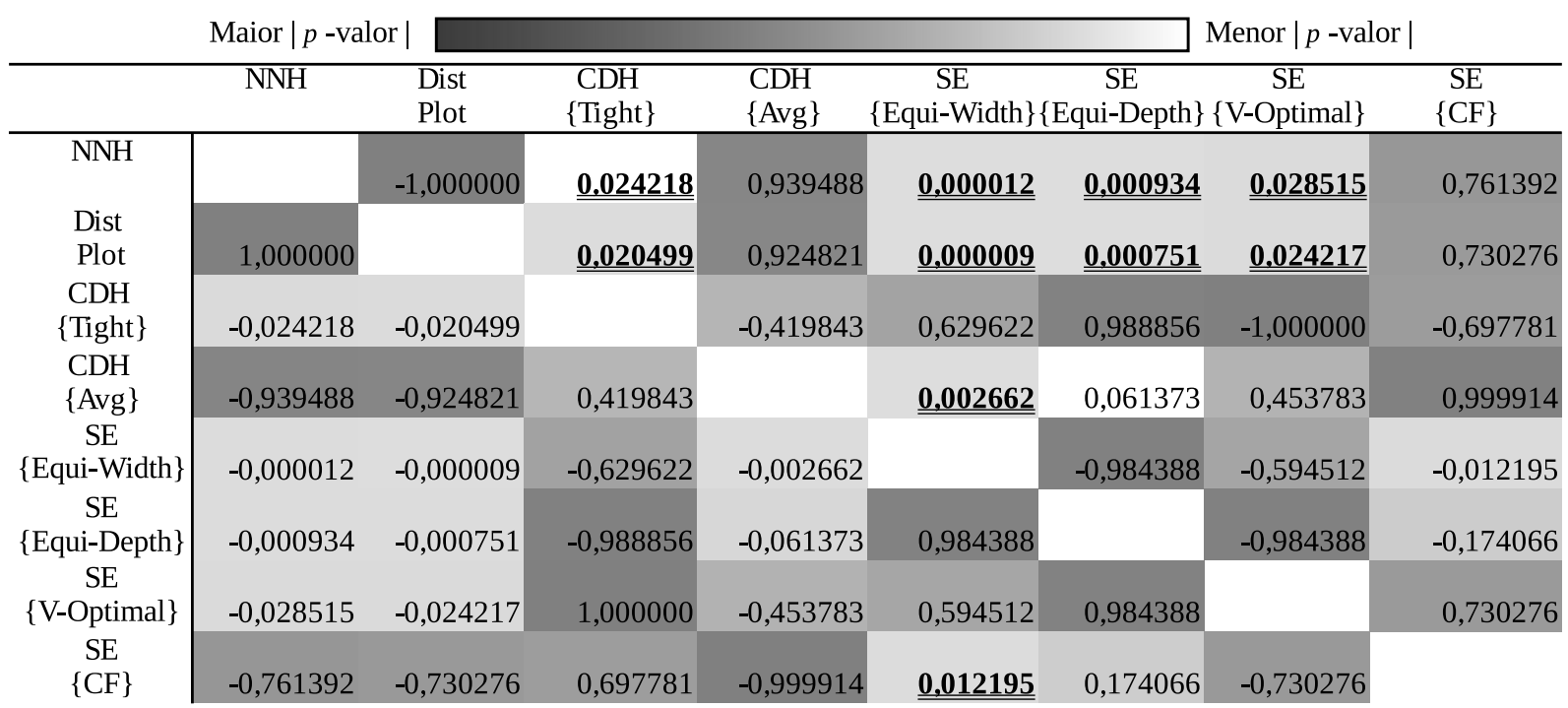

Figura 27 - Mapa de calor construído a partir dos $p$-valores de Nemenyi considerando-se Erro\%. Diferenças significativas entre pares de sinopses estão sublinhadas e em negrito.

A Figura 27 mostra as seguintes sinopses com diferenças significativas como sendo as melhores: $\mathrm{SE}\{$ Equi-Width\}, SE\{Equi-Depth\}, $\mathrm{CDH}\{$ Tight $\}$ e SE\{V-Optimal\}. Todas estas sinopses tiveram resultados melhores que as sinopses NNH e DistPlot, embora a sinopse SE\{V-Optimal\} tenha obtido níveis de significância menores. Ainda que a sinopse $\mathrm{SE}\{$ Equi-Width\} tenha obtido um melhor resultado no geral, destacamos que não houve diferença significativa nas estimativas geradas pelas sinopses $\mathrm{SE}\{$ Equi-Width\}, $\mathrm{SE}\{$ Equi-Depth\}, $\mathrm{CDH}\{$ Tight $\}$ e SE\{V-Optimal $\}$. 
(a) CANVAS

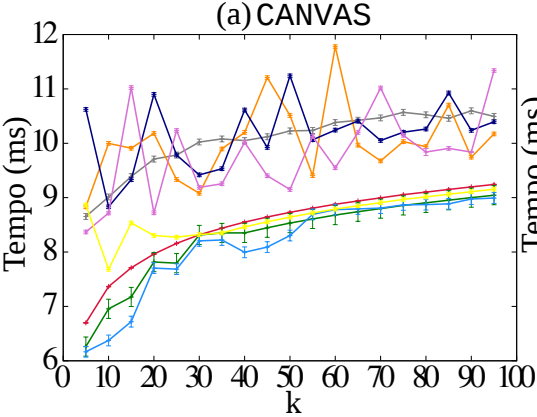

(d)SENSOR

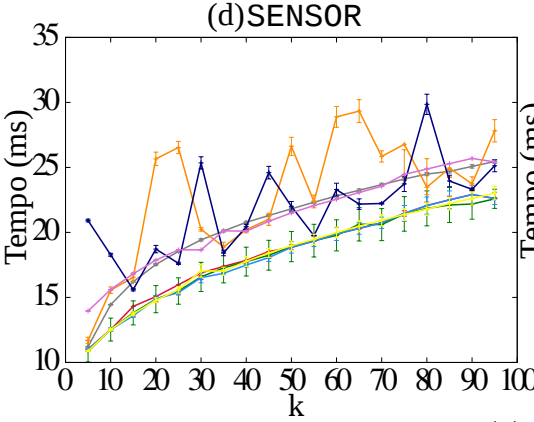

(g) ALOI

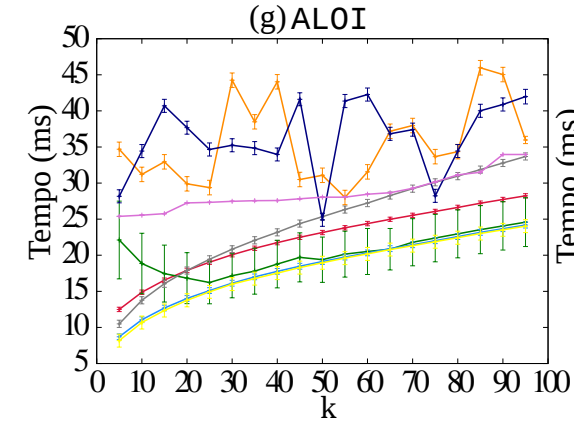

DistPlot

CDH $\{$ Avg $\}$

$\mathrm{CDH}\{$ Tight $\}$ (b) CITIES

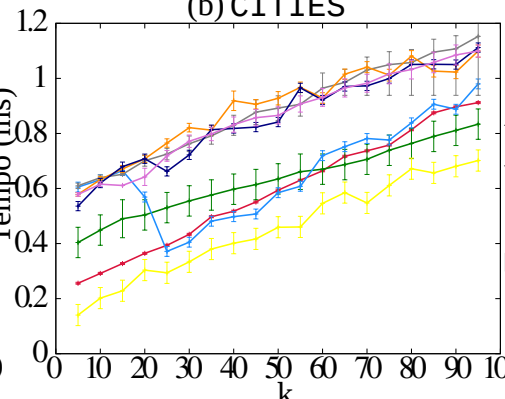

(e)COREL

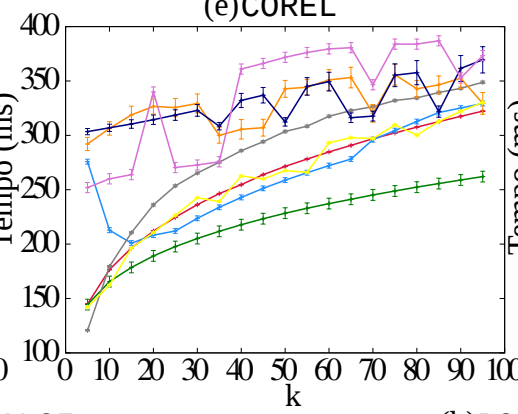

(c) BIKE

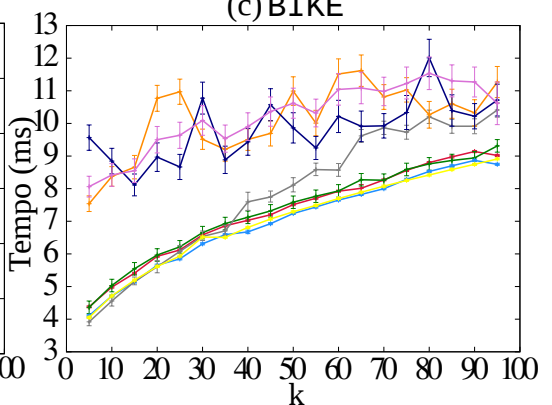

(f)SYNTHETIC

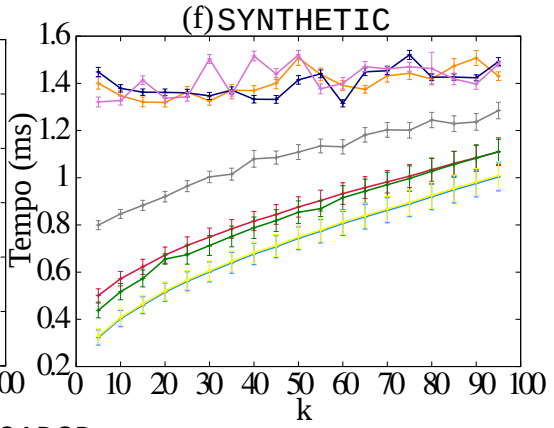

(h)ROAD3D

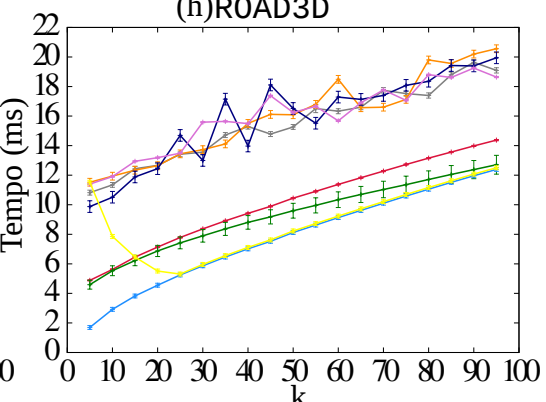

SE Equi-Width\}

SE\{Equi-Depth\}

SE $\{$ CF $\}$

Figura 28 - Comparação da média e desvio padrão para o tempo de execução de consultas por vizinhança considerando as previsões de raio por oito sinopses.

\subsubsection{Comparação das sinopses na estimativa de raio}

Uma vez identificadas as sinopses mais adequadas à estimativa de seletividade, comparamos também sinopses na tarefa de otimizar uma consulta por vizinhança. Repare que, diferentemente do experimento anterior, o objetivo aqui não é obter a estimativa mais próxima considerando o erro absoluto mas sim obter um bom valor de raio que otimize a rotina $b f-k N N$ limitada. Novamente, foi usada a divisão $90 \%$ - 10\% de elementos para indexação e teste, sendo que cada elemento do conjunto de testes foi empregado como centro de uma consulta por vizinhança, considerando a variação bf-kNN limitada gerada por cada uma das oito sinopses comparadas. A Figura 28 apresenta a média e o desvio padrão do tempo necessário para resolver uma consulta por vizinhança considerando cada rotina bf-kNN limitada avaliada. De modo geral, os gráficos mostram dois grupos, os ganhadores (CDH\{Avg\}), DistPlot, $\mathrm{SE}\{\mathrm{CF}\}$ e NNH) e os perdedores (CDH $\{$ Tight $\}), \mathrm{SE}\{$ Equi-Depth $\}, \mathrm{SE}\{$ Equi-Width $\}$ and $\mathrm{SE}\{\mathrm{V}$-Optimal $\})$.

Foi aplicado o teste de ranking de Friedman para detectar diferenças significativas 
entre os tempos gastos com relação às execuções associadas as sinopses. Considerando um nível de significância de 0.1 , foi obtido um $p$-valor de $2,88 \times 10^{-3}$, o que permite que a hipótese nula seja rejeitada. Como segundo passo, foi aplicado o teste de Nemenyi para verificar se existe diferença significativa de desempenho entre os pares de estratégias. A Figura 29 mostra os $p$-valores obtidos do teste como um mapa de calor, com o mesmo esquema de cores usado no mapa de calor da Figura 27. De acordo com os p-valores da Figura 29, os métodos $\mathrm{CDH}-\mathrm{kNN}$ com a sinopse $\mathrm{CDH}\{\mathrm{Avg}\}$, Evento-Busca-kNN com a sinopse $\mathrm{SE}\{\mathrm{CF}\}$ e Fractal-kNN superaram as estratégias Evento-Busca-kNN baseadas nas sinopses SE\{Equi-Width\}, SE\{Equi-Depth\} e SE\{V-Optimal\} dentro de níveis de significância. $O$ método $\mathrm{CDH}-\mathrm{kNN}$ com a sinopse $\mathrm{CDH}\{\mathrm{Avg}\}$ também superou com significância o método $\mathrm{CDH}-\mathrm{kNN}$ com a sinopse $\mathrm{CDH}\{$ Tight $\}$, enquanto o método NNH-kNN superou apenas o método Evento-Busca-kNN com a sinopse SE\{Equi-Width\} dentro de níveis de significância.

Estimativas subestimadas de raio prejudicaram a otimização bf-kNN limitada, e essa observação fica mais destacada tomando-se por baliza a rotina NNH-kNN, a qual sempre utiliza um raio sobre estimado. Quando uma subestimativa é usada na otimização, um refinamento que requer uma re-execução parcial da consulta diminui os ganhos originais da rotina bf-kNN limitada. Repare que subestimativas de raio foram penalizadas de modo crítico, enquanto que na estimativa de seletividade a medida de erro depende apenas do módulo da diferença. No cenário de estimativa de seletividade as sinopses SE\{Equi-Width\}, SE\{Equi-Depth\} e SE $\{$ V-Optimal $\}$ se destacaram, mas o desempenho destas sinopses na otimização de consultas por vizinhança foi baixo, pois geralmente foram gerados valores de raios subestimados. Os p-valores na Figura 29 reforçam esta observação ao mostrar que os métodos que empregam raios controladamente sobre estimados são preferíveis a estimativas mais próximas em módulo mas subestimadas. Nesse cenário, destacamos, por exemplo, que a sinopse $\mathrm{CDH}\{\mathrm{Avg}\}$ obteve

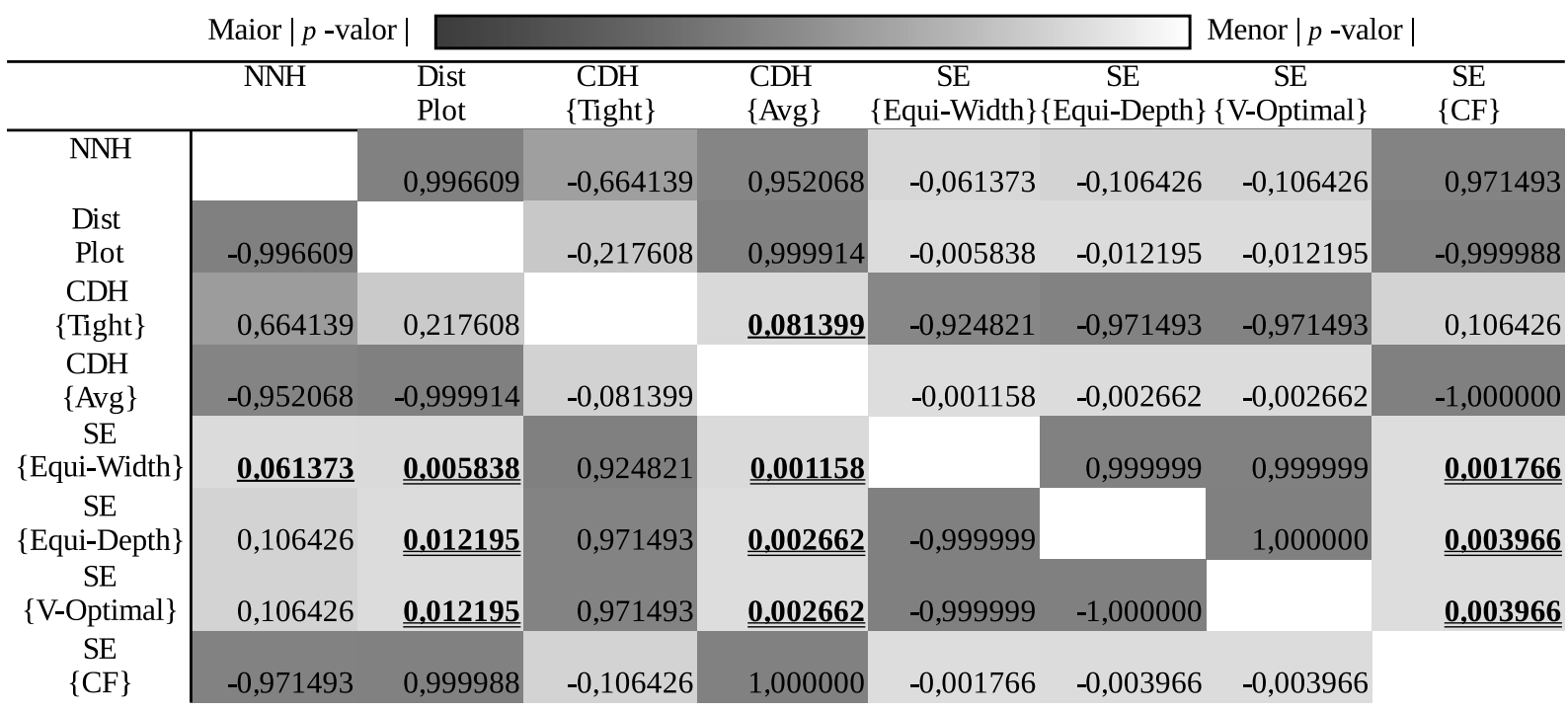

Figura 29 - Mapa de calor construído a partir dos p-valores de Nemenyi considerando-se o tempo de execução de consultas por vizinhança. Diferenças significativas entre pares de sinopses estão sublinhadas e em negrito. 
uma estimativa maior que sua variante $\mathrm{CDH}$ \{Tight $\}$ e que as sinopses mais adequadas para a estimativa de raio foram $\mathrm{CDH}\{\mathrm{Avg}\}$, DistPlot, $\mathrm{SE}\{\mathrm{CF}\}$ e $\mathrm{NNH}$.

A rotina $\mathrm{CDH}-\mathrm{kNN}$ com a sinopse $\mathrm{CDH}\{\mathrm{Avg}\}$ alcançou um dos melhores resultados para estimativa de raio, embora não tenha sido adequada para estimativa de seletividade. De forma complementar, a sinopse $\mathrm{CDH}$ \{Tigth\} figurou entre as sinopses mais adequadas para estimativa de seletividade. Uma observação importante aqui é que tanto $\mathrm{CDH}\{\mathrm{Avg}\}$ quanto $\mathrm{CDH}$ \{Tigth\} compartilham os mesmos histogramas. Portanto, a mesma sinopse CDH pode ser usada com a política Tight para obter estimativa de seletividade e com a política Avg para obter estimativa de raio. O mesmo raciocínio não pode ser empregado para as sinopses do tipo Evento de Busca, pois cada sinopse depende de um tipo diferente de histograma e, portanto, cada uma requer uma sinopse diferente. Nesse sentido, o uso de uma estratégia baseada em função de agregação torna a sinopse $\mathrm{CDH}$ a mais forte candidata para gerar tanto estimativas de raio quanto de seletividade.

\subsection{O modelo de custo Stockpile}

A seção anterior mostrou a adequabilidade da sinopse CDH para capturar distribuições de distâncias baseadas em pivô e a densidade de distâncias tanto para estimativa de raios quanto de seletividade. Baseados nestes resultados, usamos esta sinopse como base para definir um novo modelo de custo para árvores métricas. Ao contrário das estimativas de raio fornecidas para otimização física, um modelo de custo precisa avaliar o custo da execução de um determinado operador relacional por métodos de acesso cujas informações estão no módulo 'Espaço de Método-Estrutura' do otimizador de consultas de um SGBD. Nesse sentido, sempre que dois ou mais métodos de acesso possam ser usados para responder a mesma consulta ${ }^{2}$ é necessário avaliar qual deles traz maior economia de recursos computacionais. Em particular, para consultas por similaridade, os custos destes recursos são catalogados em dois grandes grupos, a saber $(i)$ custos de processamento (dado pela quantidade de cálculos de distância) e (ii) custos de memória (dado pela quantidade de acessos a disco).

Quando são usadas árvores métricas, o custo de acessos a disco é similar ao número de nós visitados. Nesse cenário, os modelos de custo revisados na literatura fazem, majoritariamente, uso da distribuição de pares de distância ao invés de distribuições de distância baseadas em pivô. Em particular, os modelos revisados CIA-98, TA0-04, BAI-07 e STAIRCASE-15 seguem uma premissa enviesada, no sentido de que se espera que os elementos de consulta estejam posicionados de acordo com a densidade expressa pela distribuição de pares de distância. No caso dos modelos multidimensionais TAO-04 e STAIRCASE-15 espera-se que a distribuição de distância siga uma distribuição uniforme, enquanto no modelo para espaços métricos de BAI-07 espera-se que a distribuição acumulada de pares siga a distribuição exponencial, tal que a aproximação dada pela dimensão fractal seja adequada.

2 A estimativa de custo já é um mecanismo necessário à otimização quando houver ao menos um índice sobre o atributo, uma vez que o método de acesso SeqScan sempre pode ser usado sobre qualquer atributo. 
A principal desvantagem desses modelos é que eles desconsideram a "localidade" do elemento de consulta, i.e. eles levam em consideração apenas a distribuição de pares (de maneira global) sem avaliar a densidade de distâncias próximas ao elemento de consulta. Para esta avaliação, é necessário empregar distribuições baseadas em pivô, uma vez que elas têm a característica de representar a densidade de acordo com os pivôs usados, tal como sugerido em alguns dos trabalhos revisados da literatura.

É de acordo com este raciocínio que propomos o modelo de custo a que denominamos Stockpile, o qual é baseado somente em distribuições baseadas em pivô. A ideia geral da abordagem é construir um pequeno conjunto de histogramas para distribuições de distâncias baseadas em pivô que tenham maior possibilidade de representar as densidades ao redor de um elemento de consulta aleatório. O modelo em si depende de grupos de estruturas de dados pré-computadas, a saber $(i)$ um conjunto de histogramas e (ii) meta-estatísticas sobre o índice empregado, e.g. o fator de gordura da árvore métrica. Essas estruturas são tipicamente mantidas em memória principal como uma pilha de recursos (e daí o nome Stockpile para o modelo) e são avaliados em tempo de execução de acordo com $(i)$ os elementos de consultas fornecidos pelos usuários e (ii) critérios de comparação.

Histogramas CDH são particularmente adequados nesse cenário, pois permitem a parametrização do espaço em termos da quantidade máxima de faixas $(\beta)$. Nesse sentido, cada CDH é uma função $f_{p}(x)$ construída como uma spline tal que $f_{p}(x) \approx \mathcal{T}_{p}$ para todo $p \in \mathcal{P}$. Repare que a quantidade de pivôs $|\mathcal{P}|$ também é limitada de acordo com a quantidade de memória disponível. Como esta quantidade de espaço é fixa, torna-se necessário balancear os parâmetros $\beta$ e $|\mathcal{P}|$ de alguma forma. Nesse sentido, pode ser executado um procedimento de validação cruzada aninhada considerando-se o equilíbrio entre cada uma das consultas por similaridade. No entanto, além de incorrer em um custo computacional que pode ser inadequado para grandes bases de dados, os resultados desse procedimento não podem ser generalizados para quaisquer conjuntos de dados. Uma solução heurística para o problema é usar um número de pivôs representativos de acordo com a dimensão intrínseca de cada conjunto de dados. Ao adotar essa abordagem, o modelo Stockpile usa $|\mathcal{P}|=\mathcal{D}$ e calcula a restrição $\beta$ de acordo com o restante da memória disponibilizada pelo otimizador de consultas.

A premissa geral do modelo leva em consideração a "localidade" de cada elemento de consulta assumindo que pivôs próximos ao elemento de consulta tendem a ter uma distribuição de distância que se assemelha a distribuição do centro de consulta. Essa suposição é particularmente adequada sempre que a densidade de distâncias ao redor do pivô for uniformemente distribuída de acordo com $f_{p}(x)$. Portanto, assumindo a premissa da densidade uniforme, o modelo Stockpile estima a probabilidade de um centro de consulta ter a mesma distribuição de um dado pivô como uma relação linear expressa pela distância entre eles. Formalmente, dado um centro de consulta $s_{q}$, um conjunto de pivôs $\mathcal{P}$ e seus respectivos histogramas $\mathrm{CDH}$, a probabilidade $\operatorname{Prob}\left(p, s_{q}\right)$ de $f_{p}(x)$ se assemelhar a distribuição de distâncias de $s_{q}$ é proporcional à $\delta\left(s_{q}, p\right)$ 
tal que $\operatorname{Prob}\left(p, s_{q}\right)=\left(C_{1}-\delta\left(s_{q}, p\right)\right) / C_{2}$, onde tanto $C_{1}$ quanto $C_{2}$ são valores calculados em função da totalidade de pivôs $\mathcal{P}$. Em particular, o valor $C_{1}$ é calculado como $C_{1}=\sum_{p}^{\mathcal{P}} \delta\left(s_{q}, p\right)$, enquanto o valor $C_{2}$ é calculado como $C_{2}=\sum_{p}^{\mathcal{P}} C_{1}-\delta\left(s_{q}, p\right)$. A probabilidade acumulada de $s_{q}$ assemelhar-se aos pivôs em $\mathcal{P}$ é dada pela Equação 4.6.

$$
\sum_{p \in \mathcal{P}} \operatorname{Prob}\left(p, s_{q}\right)=\frac{C_{1}-\delta\left(s_{q}, p_{1}\right)}{C_{2}}+\frac{C_{1}-\delta\left(s_{q}, p_{2}\right)}{C_{2}}+\cdots+\frac{C_{1}-\delta\left(s_{q}, p_{|\mathcal{P}|}\right)}{C_{2}}=\frac{C_{1}(|\mathcal{P}|-1)}{C_{1}(|\mathcal{P}|-1)}=1
$$

De acordo com essa fundamentação, o método Stockpile modela a probabilidade de visitar um nó de uma estrutura métrica como um combinação linear da distância do elemento de consulta a um pivô (informação de localidade) com a densidade dada pelo histograma $f_{p}(x)$.

\subsubsection{Estimativa de custos para consultas por abrangência}

Seja uma consulta por abrangência $R q\left(\mathcal{S}, s_{q}, \xi\right)$ a ser executada por meio de uma árvore de indexação métrica $T$. Todos os nós folhas em $T$ que interceptam a bola da consulta dada por $\left\langle s_{q}, \xi\right\rangle$ precisam ser visitados pois, potencialmente, eles armazenam elementos que estão dentro da bola da consulta. Os nós diretórios dessas folhas também precisam ser examinados. Portanto, a probabilidade local de ser necessário acessar um nó $\mathrm{N}\left(s_{j}\right)$ com relação à um dado pivô $p$ é modelado de acordo com o raio de cobertura do nó $\left(\xi_{j}\right)$ somado ao raio de cobertura da consulta por abrangência $(\xi)$, tal como expresso na Equação 4.7.

$$
\begin{array}{r}
\operatorname{Prob}\left(\text { nó N }\left(s_{j}\right) \text { seja acessado }\right)=\operatorname{Prob}\left\{\delta\left(p, s_{q}\right) \leq \xi_{j}+\xi\right\} \\
\approx \bar{F}_{p}\left(\xi_{j}+\xi\right)=\frac{\int_{0}^{\xi_{j}+\xi} f_{p}(x) d x}{\int_{0}^{v_{p}\left(m_{p}\right)} f_{p}(x) d x}
\end{array}
$$

Naturalmente, a probabilidade local é 1 sempre que $\xi_{j}+\xi>v_{p}\left(m_{p}\right)$. A probabilidade total de acessar um nó do índice $T$ é dada pela soma das probabilidades individuais de cada pivô $p \in \mathcal{P}$, o que resulta na combinação das Equações 4.6 e 4.7 como expresso pela Equação 4.8. De forma similar, as Equações 4.6 e 4.8 podem ser combinadas na Equação 4.9, que estima a quantidade de cálculos de distância em consultas por abrangência.

$$
\begin{gathered}
\text { nós_visitados }\left(T, s_{q}, \xi\right)_{a} \approx \sum_{j}^{\mathrm{N}} \sum_{p \in \mathcal{P}} \operatorname{Prob}\left(p, s_{q}\right) \cdot \bar{F}_{p}\left(\xi+\xi_{j}\right) \\
\text { distâncias_calculadas }\left(T, s_{q}, \xi\right) \approx \sum_{j}^{\mathrm{N}}\left|\mathrm{N}\left(s_{j}\right)\right| \cdot\left(\sum_{p \in \mathcal{P}} \operatorname{Prob}\left(p, s_{q}\right) \cdot \bar{F}_{p}\left(\xi+\xi_{j}\right)\right)
\end{gathered}
$$

A intuição da Equação 4.9 é que o número de cálculos de distância é proporcional à probabilidade de acessar cada nó, sendo que $\left|\mathrm{N}\left(s_{j}\right)\right|$ é usado tanto para denotar a quantidade de sub-árvores (no caso de nós diretório) ou número de elementos (no caso de nós folhas). 


\subsubsection{Estimativa de custos para consultas por vizinhança}

A estimativa de custos de consultas por vizinhança requer um passo adicional em comparação com as consultas por abrangência. Esse "passo extra" corresponde à redução de uma consulta por vizinhança à uma consulta por abrangência por meio da escolha do raio $\xi_{s_{q} s_{k}}$ para cada centro de consulta. Diferentemente da otimização física, o modelo Stockpile não pode usar o aumento progressivo do raio, pois precisa indicar um único valor como custo e não pode recorrer a nenhum tipo de refinamento da consulta. Não obstante, conforme destacado nos experimentos da Seção 4.2, a estimativa mais adequada para o método CDH-kNN é usar como função de agregação a média dos valores de raio oriundos de cada histograma CDH. O modelo Stockpile usa uma média ponderada para estimar $\xi_{s_{q} s_{k}}$ para qualquer consulta por vizinhança e, desta forma, pondera a contribuição de cada sinopse CDH. Formalmente, dada uma consulta k- $N N\left(\mathcal{S}, s_{q}, k\right)$ sobre um espaço métrico conhecido e um CDH para um pivô $p$, o método Stockpile estima $\xi_{s_{q} s_{k}}$ como $\xi_{p}^{\prime}$ por meio da Equação 4.10.

$$
\frac{|S|}{\int_{0}^{v_{p}\left(m_{p}\right)} f_{p}(x) d x} \cdot \int_{0}^{\xi_{p}^{\prime}} f_{p}(x) d x=k
$$

onde o termo $(|S|) /\left(\int_{0}^{v_{p}\left(m_{p}\right)} f_{p}(x) d x\right)$ é a distribuição uniforme do erro de aproximação do histograma entre suas faixas. A resolução da Equação 4.10 pode ser feita por um método numérico, tal como o método de Newton-Raphson, na medida em que a função primitiva para $f_{p}(x)$ é contínua e monotonicamente crescente. Portanto, torna-se possível combinar a probabilidade de escolher um pivô na Equação 4.6 com a Equação 4.10, tal que k-NN $\left(\mathcal{S}, s_{q}, k\right)$ é reduzida a uma consulta por abrangência cujo raio depende dos histogramas CDH. A quantidade de nós de $T$ visitados pela consulta por vizinhança é estimada pela Equação 4.11, enquanto a quantidade de cálculos de distância é estimada pela Equação 4.12.

$$
\begin{aligned}
\text { nós_visitados }\left(T, s_{q}, k\right) \approx \sum_{j}^{\mathrm{N}} \sum_{p \in \mathcal{P}} \operatorname{Prob}(p) \cdot\left(\frac{k}{|S|}+\frac{\int_{\xi_{p}^{\prime}}^{\xi_{p}^{\prime}+\xi_{j}} f_{p}(x) d x}{\int_{0}^{v_{p}\left(m_{p}\right)} f_{p}(x) d x}\right) \\
\text { distâncias_calculadas }\left(T, s_{q}, k\right) \approx \sum_{j}^{\mathrm{N}}\left|\mathrm{N}\left(s_{j}\right)\right| \cdot\left[\sum_{p \in \mathcal{P}} \operatorname{Prob}(p) \cdot\left(\frac{k}{|S|}+\frac{\int_{\xi_{p}^{\prime}}^{\xi_{p}^{\prime}+\xi_{j}} f_{p}(x) d x}{\int_{0}^{v_{p}\left(m_{p}\right)} f_{p}(x) d x}\right)\right]
\end{aligned}
$$

\subsubsection{Estimativas otimistas vs. pessimistas}

As estimativas de custo obtidas pelo método Stockpile são particularmente adequadas para árvores métricas ideais, i.e. árvores sem sobreposição entre seus nós. Portanto, nós 
Tabela 5 - Conjuntos de dados empregados na avaliação de modelos de custos.

\begin{tabular}{|l|c|c|c|c|}
\hline \hline Nome & Dimens. & $\boldsymbol{\delta}$ & $\lceil\mathcal{D}\rceil$ & Cardinalidade \\
\hline \hline CITIES & 2 & $L_{2}$ & 2 & 5.507 \\
\hline WINE & 11 & $L_{1}$ & 6 & 6.497 \\
\hline LETTER & 16 & $L_{\infty}$ & 9 & 20.000 \\
\hline CANVAS & 16 & $L_{2}$ & 6 & 3.879 \\
\hline
\end{tabular}

denominamos as predições dadas pelas Equações 4.8, 4.9, 4.11 e 4.12 do modelo Stockpile de estimativas otimistas. No entanto, a indexação de conjuntos de dados reais tipicamente resulta em uma quantidade não desprezível de sobreposições entre os nós da árvore. Felizmente, é possível quantificar a "qualidade" do particionamento de uma árvore métrica por meio do fator de gordura (Definição 2.3.1). De acordo com essa medida, propormos aplicar, propositalmente, uma ligeira sobre estimativa no número de acessos a disco e cálculos de distância para árvores métricas que não obtenham um particionamento adequado o suficiente. Nesse sentido, o modelo Stockpile pode usar o fator de gordura de $T$ para o cálculo das estimativas e escalar as Equações 4.8, 4.9, 4.11 e 4.12 pela constante $(1+f a t(T))$. Nós denominamos essas predições do modelo Stockpile como estimativas pessimistas, sendo que a escolha entre estimativas otimistas ou pessimistas pode ser facilmente trocada no contexto de otimização de um SGBD.

\subsection{Avaliação do modelo Stockpile}

Para avaliar a adequabilidade do modelo de custo proposto, realizamos experimentos sobre quatro conjuntos de dados reais ${ }^{3}$ descritos na Tabela 5 . Os conjuntos de dados CITIES, WINE, LETTER e CANVAS foram consultados usando métricas da família de Minkowski $\left(L_{p}\right)$ e indexados por árvores Slim-Tree cujo tamanho de páginas foi escolhido de forma que a mesma proporção de elementos pudesse ser incluída nos nós folhas, independentemente da dimensionalidade. $\mathrm{O}$ modelo de custo proposto empregou $\lceil\mathcal{D}\rceil$ pivôs selecionados pela estratégia K-MEDOIDS e gerou histogramas CDH compactados em 128 faixas. Além disso, o modelo foi configurado para fornecer estimativas pessimistas tanto para consultas por abrangência quanto para consultas por vizinhança. O modelo Stockpile foi comparado contra dois competidores:

1. O modelo em Ciaccia, Patella e Zezula (1998), que usa um único histograma Equi-Width de distribuição de pares de distância compactado por 256 faixas, e

2. O modelo em Baioco, Traina e Traina Jr. (2007), que usa a dimensão fractal obtida da sinopse Distance Plot.

Em todos os experimentos as estimativas dos modelos foram normalizadas em termos da diferença absoluta para a execução real da consulta. As consultas por abrangência seguiram o

\footnotetext{
3 Mais detalhes sobre estes conjuntos de dados podem ser encontrados no Apêndice B.
} 
algoritmo proposto em Ciaccia, Patella e Zezula (1997) para árvores métricas do tipo M-Tree, enquanto as buscas por vizinhança foram executadas de acordo com o algoritmo incremental proposto em Hjaltason e Samet (2003).

\subsubsection{Comparação das estimativas para consultas por abrangência}

Para evitar qualquer viés do algoritmo de construção da árvore ou parâmetros sobre ajustados nos modelos comparados, foi empregado o procedimento de validação cruzada com 10 -folds indexando $90 \%$ dos dados e usando os $10 \%$ restantes como centro de consultas, alternadamente em cada uma das dez iterações. Para cada conjunto de dados, foi usada a maior distância entre um par de elementos indexado (max) e 6 limites de $\xi$ para avaliar as consultas por abrangência. Os valores de $\xi$ foram escolhidos como uma porcentagem de max variando de $5 \%$ até $30 \%$ em passos de 5\%. A Figura 30 mostra a comparação entre os modelos Stockpile, em Ciaccia, Patella e Zezula (1998) e em Baioco, Traina e Traina Jr. (2007) com relação às predições de nós visitados e cálculos de distância.

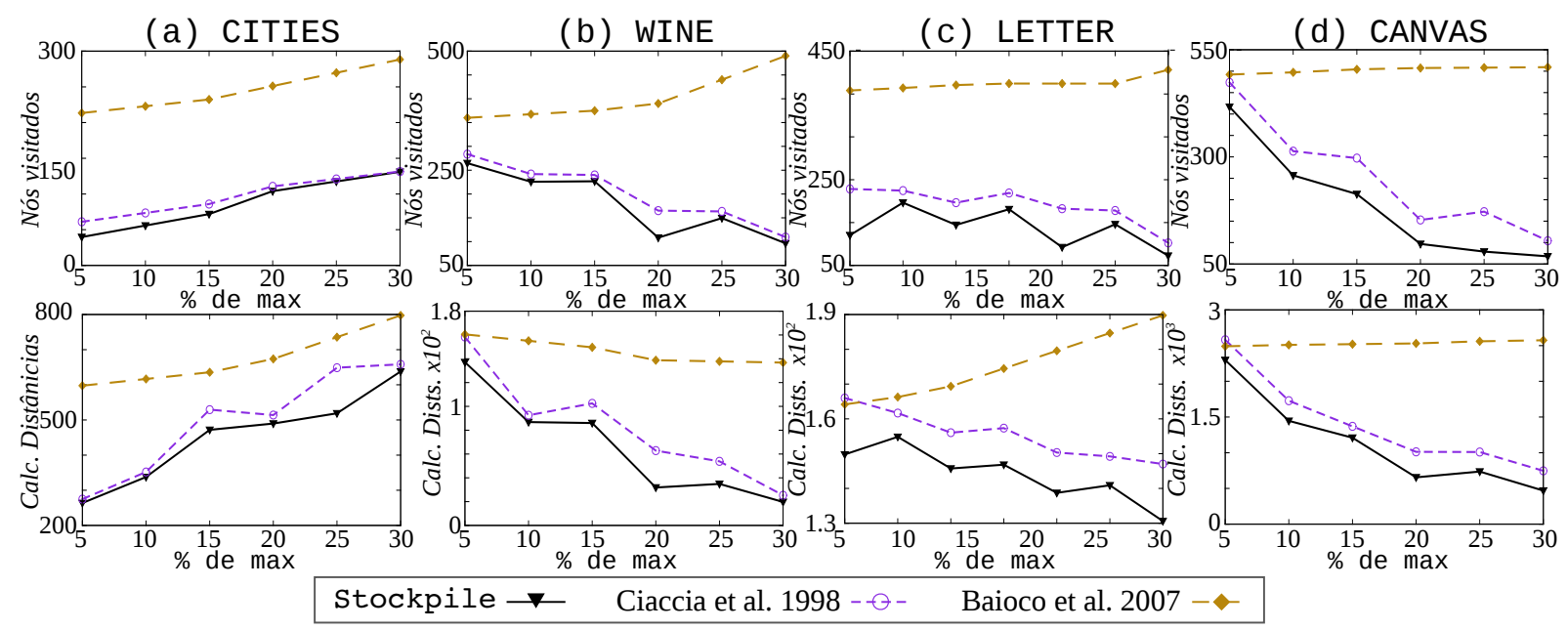

Figura 30 - Comparação entre os modelos de custo para consultas por abrangência.

O modelo Stockpile alcançou até 36\%, 31\%, 41\% e 54\% mais precisão na estimativa de nós visitados na comparação com o modelo em Ciaccia, Patella e Zezula (1998) com relação aos conjuntos de dados CITIES, WINE, LETTER e CANVAS, respectivamente. Nossa abordagem também alcançou até $85 \%, 78 \%, 62 \%$ e $81 \%$ mais precisão que o modelo em Baioco, Traina e Traina Jr. (2007) para as mesmas consultas nos mesmos conjuntos de dados.

Considerando-se as estimativas do número de cálculos de distância, nosso modelo também obteve ganhos similares, como mostrado na segunda parte da Figura 30. O modelo Stockpile foi até $51 \%, 49 \%, 11 \%$ e $23 \%$ mais preciso que o modelo em Ciaccia, Patella e Zezula (1998) nos conjuntos de dados CITIES, WINE, LETTER e CANVAS, respectivamente. O modelo Stockpile também foi até $64 \%, 73 \%, 25 \%$ e $69 \%$ melhor que o modelo em Baioco, Traina e Traina Jr. (2007) no mesmo cenário. 


\subsubsection{Comparação das estimativas para consultas por vizinhança}

Nós aplicamos o mesmo procedimento de validação cruzada da avaliação de consultas por abrangência para as consultas por vizinhança. Nesse experimento, nós variamos o parâmetro $k$ de 5 até 50 em passos de 5 vizinhos e medimos o desempenho dos modelos em termos de nós visitados e cálculos de distância. A Figura 31 mostra a comparação do modelo Stockpile com seus competidores. Aqui, a estimativa de qualidade reflete a precisão do modelo na tarefa de estimativa do raio (quanto melhor é a estimativa de raio, melhor tende a ser o modelo).

(a) CITIES
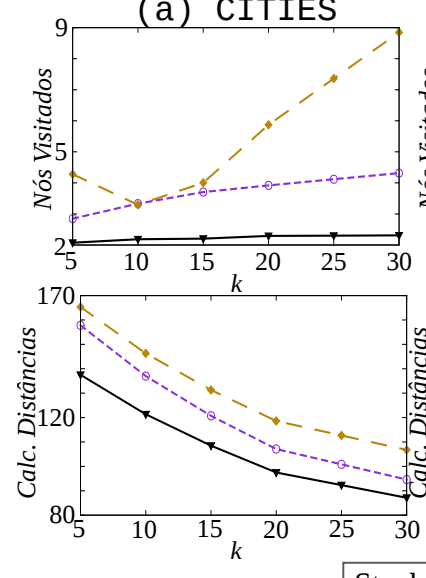

Stockpile $\rightarrow$

Figura 31 - Comparação entre os modelos de custo para consultas por vizinhança. (c) LETTER
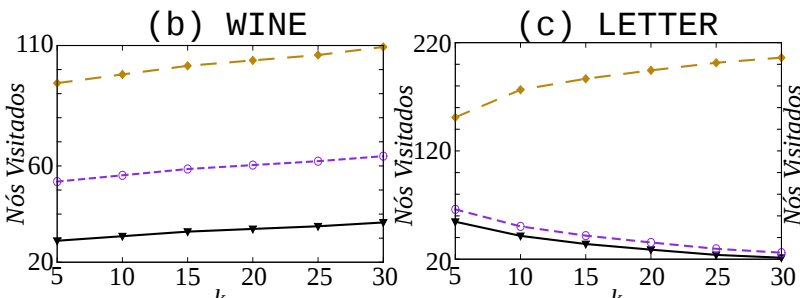

(d) CANVAS

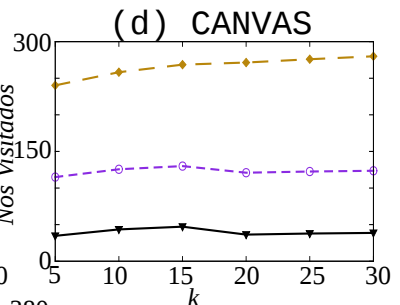

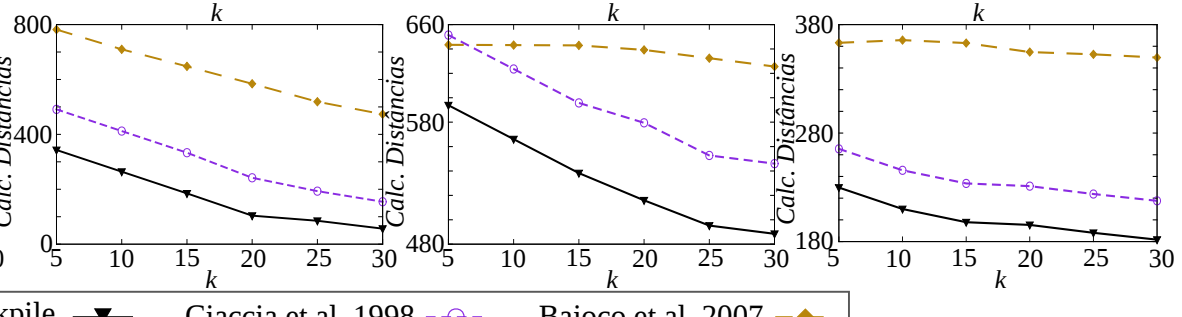

Baioco et al. 2007 -

A primeira parte da Figura 31 mostra que o modelo Stockpile foi até 46\%, 43\%, $19 \%$ e 54\% mais preciso que o modelo em Ciaccia, Patella e Zezula (1998) na estimativa de nós visitados de consultas por vizinhança nos conjuntos de dados CITIES, WINE, LETTER e CANVAS, respectivamente. Nosso modelo também foi até $73 \%, 69 \%, 85 \%$ e $83 \%$ melhor que o modelo em Baioco, Traina e Traina Jr. (2007) na mesma avaliação. De forma complementar, a segunda parte da Figura 31 mostra que o modelo Stockpile foi até 13\%, 30\%, 13\% e 12\% mais preciso que a abordagem em Ciaccia, Patella e Zezula (1998) na estimativa de cálculos de distância para consultas por vizinhança nos conjuntos CITIES, WINE, LETTER e CANVAS. Além disso, nossa abordagem também superou em até $20 \%, 80 \%, 26 \%$ e $45 \%$ a abordagem em Baioco, Traina e Traina Jr. (2007).

Portanto, o modelo Stockpile foi o mais preciso tanto em consultas por abrangência quanto em consultas por vizinhança, o que indica que o modelo proposto é o mais adequado para estimar valores de raios. Por exemplo, nossa abordagem não apenas superou seus competidores para valores de raio pequenos (em buscas $k$-NN com $k \leq 30$ ), mas também foi a opção mais adequada para valores maiores de raio (consultas por abrangência para $\xi>5 \%$ de max). Nesse sentido, destaca-se que as predições oriundas de distribuições de distância baseadas em pivô se mostraram versáteis o suficiente para alcançar predições que superaram as estimativas oriundas da distribuição de pares de distância. 


\subsection{Considerações Finais}

Neste capítulo foi apresentada uma discussão sobre quais sinopses são mais adequadas para a representação de distribuições de distância, levando-se em consideração a aplicação destas representações para otimização física e lógica. Nesse sentido, introduzimos a primeira contribuição desta tese: a sinopse de Histogramas Compactados de Distância (Histogramas CDH) e como estas estruturas podem ser usadas para reduzir consultas por vizinhança à consultas por abrangência. Um histograma CDH aproxima uma distribuição de distância baseada em pivô por meio de uma função linear por partes, construída como uma spline sobre a distribuição de distância original. Além disso, a sinopse proposta se encaixa como um novo critério de restrição de particionamento de histogramas e pode ser obtida de forma ótima por meio de um algoritmo incremental similar ao usado pelas restrições V-Optimal e Parametric Curve-Fitting.

Considerando que um histograma $\mathrm{CDH}$ pode ser usado para obter uma estimativa de cobertura máxima para uma consulta por vizinhança, nós propusemos uma variação da estratégia bf-kNN limitada, que denominamos CDH-kNN. Esse algoritmo emprega um grupo de histogramas $\mathrm{CDH}$ construídos a partir de diversos pivôs para inferir um conjunto de raios de cobertura que podem ser usados para guiar a consulta bf-kNN limitada. Três possíveis políticas, calculadas por funções de agregação, para o gerenciamento desses raios foram definidas, a saber, Tight, que inicia a consulta com a previsão do menor raio estimado, Avg, que inicia a busca por vizinhança com a média dos raios estimados pelos histogramas $\mathrm{CDH}$, e Relaxed, que executa a busca com o maior raio estimado pela sinopse. Sempre que a rotina $C D H-k N N$ usar um raio subestimado, é necessário um refinamento que aumenta o raio de acordo com a política empregada.

Foram realizados dois amplos experimentos com o objetivo de determinar a adequabilidade dos histogramas CDH para a estimativa de seletividade e para comparar o método CDH-kNN com as outras variações da estratégia bf-kNN limitada. No primeiro experimento, comparamos a precisão da sinopse proposta com as previsões obtidas pelas sinopses Histograma NN, Distance Plot e Evento de Busca com relação à seletividade das consultas por abrangência. De acordo com a medida de desvio-padrão obtida, optamos por realizar um teste de hipóteses, de onde constatamos que as sinopses com melhor desempenho nessa tarefa foram as sinopses Evento de Busca com histogramas Equi-Width, Equi-Depth e V-Optimal, além do CDH com política Tight para a escolha das estimativas.

De forma complementar, usamos o mesmo contexto de avaliação para determinar as variações da estratégia bf-kNN limitada mais adequadas para realizar a otimização física de consultas por vizinhança. Dentro de níveis de significância, as estratégias NNH-kNN, Fractal-kNN, Evento-Busca-kNN com histograma Parametric Curve-Fitting e CDH-kNN com política Avg apresentaram o melhor desempenho. De acordo com esses resultados, destacamos que os histogramas $\mathrm{CDH}$ são as sinopses mais adequadas tanto para estimativa de seletividade quanto estimativas de raio, visto que basta apenas trocar a política usada (que é calculada por uma função de agregação) para obter a melhor estimativa. Por exemplo, pode-se usar o menor valor 
predito para estimativas de seletividade, enquanto que e a estimativa média de previsões de raio é usada para a otimização física de consultas por vizinhança.

A validação da sinopse $\mathrm{CDH}$ como estrutura adequada para a representação da distribuição de distâncias permitiu usá-la em um modelo de custo. Nós desenvolvemos, para estruturas de árvores métricas, o modelo Stockpile que leva em consideração apenas distribuições de distâncias baseados em pivô para predizer a quantidade de nós visitados (custos de memória) e distâncias calculadas (custos de processamento). Na comparação com os modelos em Ciaccia, Patella e Zezula (1998) e em Baioco, Traina e Traina Jr. (2007), nosso modelo foi até 46\% e $85 \%$ mais preciso na previsão de nós visitados e até $30 \%$ e $80 \%$ mais adequado na estimativa de cálculos de distância quando comparado aos mesmos dois competidores.

Até agora, investigamos o uso de histogramas CDH de forma isolada considerando a possibilidade de unir as previsões individuais apenas por meio de uma função de agregação. No próximo capítulo examinaremos o uso destas estruturas de forma não independente, de maneira que seja possível obter um histograma multidimensional que capture a densidade de distâncias para consultas por abrangência e por vizinhança. 


\title{
Histogramas-Omni e métodos de acesso derivados
}

\author{
"What gets measured, gets \\ managed." \\ Provérbio derivado de uma aula de \\ William Thomson (Lord Kelvin)
}

O uso de histogramas isolados para distribuições de distância possibilita estimar a seletividade de operadores de comparação por similaridade, assim como predizer a quantidade de acessos a disco e cálculos de distância para executar estas consultas com o auxílio de determinadas estruturas de indexação. Estes histogramas também permitem estimar raios para otimizar fisicamente consultas por vizinhança, gerando variações da rotina bf-kNN limitada. No entanto, além das consultas que envolvem exclusivamente comparações por abrangência e por vizinhança, é também preciso levar em consideração consultas que misturam estes operadores de comparação por relações de similaridade com os operadores tradicionais de comparação por relações de igualdade de ordem. Para ilustrar esse problema, considere a seguinte consulta (C7) “Recupere as cinco pinturas renascentistas que são as mais similares a Monalisa”. Repare que, além da comparação por similaridade (pinturas mais similares a Monalisa), existe também uma comparação por igualdade sobre um outro atributo, a que denominamos atributo ortogonal, àquele usado para comparar por similaridade (pinturas renascentistas). A comparação adicional sobre o atributo ortogonal restringe o número de elementos candidatos ao conjunto-resposta. A essa classe de consultas, que mesclam comparações por similaridade, por identidade e por ordem, denominamos consultas híbridas.

Do ponto de vista do otimizador de consultas, alguns planos de execução para a consulta (C7) podem ser listados e ter seu custo estimado. A execução da consulta por meio do método SeqScan sempre é uma alternativa, bem como usar um índice sobre o atributo ortogonal para recuperar elementos cujo período = 'Renascença' e sobre eles aplicar a comparação por similaridade para recuperar as tuplas cujo atributo de pintura esteja entre as cinco mais parecidas à 'Monalisa'. Outra possibilidade é recuperar os elementos filtrados pelo atributo 
período = 'Renascença' em uma relação temporária, ordenar todos os elementos por similaridade considerando o atributo pintura em outra relação temporária e fazer a intersecção das duas relações. Além disso, também é possível usar um índice métrico no atributo Pintura e executar a rotina inc-kNN que verifica o atributo ortogonal período localizado fora do índice para responder a consulta. Finalmente, uma quinta possibilidade é executar a consulta sobre um índice híbrido que permita executar as comparações por similaridade e identidade simultaneamente. Para otimizar o número de acessos a disco e de cálculos de distância nessa estrutura híbrida, rotinas do tipo bf-kNN limitada precisam prover uma estimativa obtida pela combinação dos atributos comparados por similaridade e identidade. No entanto, tal como apresentado na seção anterior, as variações bf-kNN limitada usam raios estimados considerando apenas distribuições de distâncias, i.e. as estimativas são baseadas em sinopses para um único atributo.

Uma alternativa para possibilitar o uso de rotinas bf-kNN limitada na resolução de consultas híbridas é estimar um raio de cobertura que inclua os elementos a serem recuperados e que satisfaçam à condição de filtragem. Para isso estimativas de duas sinopses devem ser combinadas: uma sobre a distribuição de dados do atributo ortogonal à similaridade e outra sobre a distribuição de distâncias. Os erros da estimativa sobre a sinopse de distribuição de dados serão somados aos erros das estimativas sobre a sinopse de distribuição de distância, o que tende a aumentar o erro na estimativa final do raio. Como visto experimentalmente nas seções anteriores, um efeito colateral da estimativa de raios inadequados é que o conjunto-resposta da rotina bf-kNN limitada pode ser insuficiente e obrigar a um segunda execução com uma estimativa de raio refinada, o que degrada o desempenho geral da consulta. Alternativamente, uma opção é desenvolver uma sinopse que, sozinha, seja capaz de lidar com comparações de similaridade, identidade e ordem simultaneamente. Sinopses desse tipo também seriam sinopses “multidimensionais', pois mais de uma distribuição é representada simultaneamente. No entanto, essas sinopses diferem dos histogramas multidimensionais revisados, uma vez que pelo menos um dos atributos envolvidos não é comparável por relações de identidade ou ordem.

Diante desse contexto, apresentamos uma nova sinopse que permite representar distribuições de distâncias baseadas em pivô e distribuições de dados de forma interdependente sobre uma mesma relação. Nossa abordagem é baseada na ideia de se usar restrições de particionamento de histogramas para organizar elementos em espaços métricos de tal maneira que seja possível realizar contagens em regiões do espaço de busca de acordo com os pivôs usados. Além disso, a frequência nessas regiões é representada por um histograma sobre a distribuição de dados do atributo ortogonal. De acordo com a estrutura da nova sinopse, discutimos se o particionamento gerado não é suficiente para constituir também uma estrutura de índice na qual a quantidade máxima de cálculos de distância para uma consulta híbrida pode ser previamente conhecida. Nesse sentido, a sinopse proposta pode ser vista também como uma estrutura de indexação não-clusterizada. Para otimizar a execução de consultas por similaridade nessas novas estruturas, apresentamos um novo algoritmo para consultas híbridas e o comparamos com algumas das estratégias de busca correlatas revisadas no Capítulo 2. 


\subsection{Histogramas não independentes}

Até aqui, foram discutidas apenas as sinopses para distribuições de distâncias que são construídas e avaliadas de modo isolado e independente. Com relação às sinopses do tipo CDH, as estimativas obtidas por cada uma delas são agrupadas de acordo com uma função de agregação, sem que haja ligação entre quaisquer dois pivôs ou histogramas. Esse isolamento entre os pivôs é desejável para obter estimativas que levam em conta a "localidade" (densidade) do centro de consulta para buscas que envolvam exclusivamente comparações por similaridade. Ao se considerar que os pivôs não são isolados, a resultante distribuição de distâncias baseadas em pivô é, na verdade, uma distribuição multidimensional que faz uma contagem das frequências das distâncias dos elementos armazenados nas tuplas aos pivôs no espaço de busca. Por exemplo, a Figura 32(a) mostra como um único pivô permite mapear as distâncias aos elementos em um espaço unidimensional, enquanto que a Figura 32(b) apresenta a distribuição de distâncias para uma amostra aleatória de 100 pontos em duas dimensões, considerando-se dois pivôs. A densidade foi esboçada de acordo com dois histogramas CDH construídos, um para cada pivô.

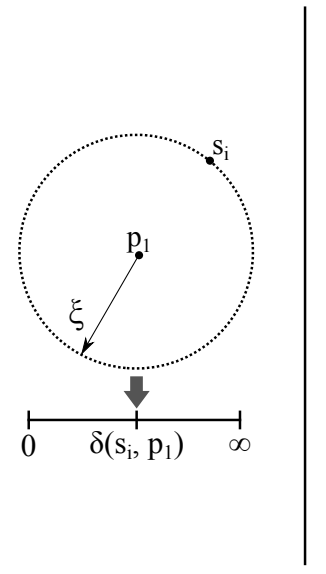

(a)

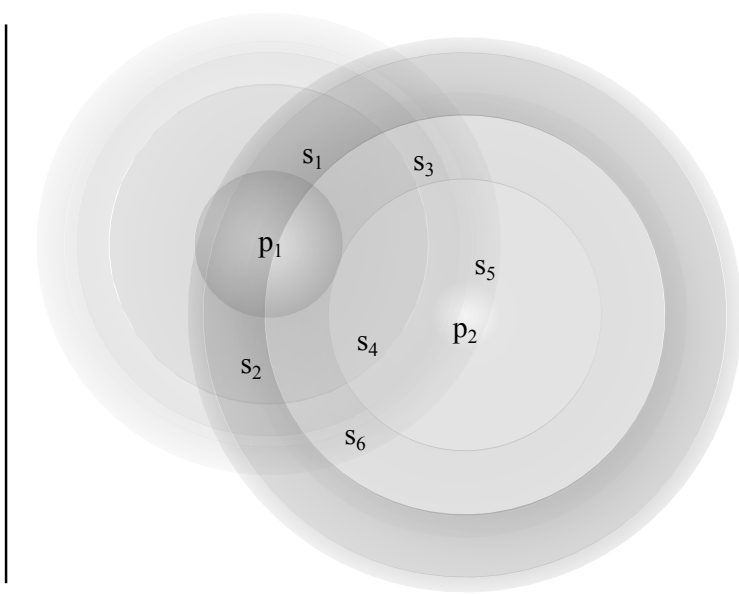

(b)

\begin{tabular}{|c|}
$\begin{array}{c}\text { Tuplas de distâncias } \\
\text { aos pivôs }\left\langle\mathbf{p}_{1}, \mathbf{p}_{2}\right\rangle\end{array}$ \\
\hline $\mathrm{s}_{1}=<0.15,7.32>$ \\
\hline $\mathrm{s}_{2}=<0.19,7.82>$ \\
\hline $\mathrm{s}_{3}=<2.33,5.40>$ \\
\hline $\mathrm{s}_{4}=<2.95,4,71>$ \\
\hline $\mathrm{s}_{5}=<6.73,1.22>$ \\
\hline $\mathrm{s}_{6}=<2.14,7.95>$ \\
\hline$\cdots$ \\
\hline
\end{tabular}

Figura 32 - Mapeamento de um espaço métrico para um espaço multidimensional considerando a norma $L_{2}$. (a) Mapeamento do valor de distância com relação à um dado pivô $p_{1}$ para um espaço unidimensional. (b) Distribuição de distâncias para uma amostra aleatória de 100 pontos, considerando-se dois pivôs escolhidos ao acaso. Sob a densidade uniforme, quanto mais escuro, mais densa é a região.

O particionamento da distribuição de distâncias, considerando-se o não isolamento entre os pivôs, gera um particionamento do espaço de busca em regiões definidas de acordo com a densidade de distâncias. Por exemplo, na Figura 32(b), os elementos $s_{1}$ e $s_{2}$ estão situados em "regiões" próximas devido a sua distância aos pivôs $p_{1}$ e $p_{2}$. O particionamento dado pelos histogramas $\mathrm{CDH}$ gera uma sinopse onde os elementos podem ser colocados em faixas mutuamente exclusivas com relação à um conjunto não independente de pivôs. Repare que um índice métrico (árvore ou não) também trata do particionamento do espaço de busca e, nesse caso, criar uma sinopse cujos histogramas não estejam isolados aproxima-se de criar um índice com partições mutuamente exclusivas para consultas por similaridade. Essa premissa permite explorar como aplicar as restrições de particionamento de histogramas revisadas (Equi-Width, 
Equi-Depth, V-Optimal, Parametric Curve-Fitting) junto com a restrição proposta na seção anterior (CDH) na construção de estruturas de indexação híbridas.

\subsection{Particionamento de tabelas de pivôs e métodos Omni}

Índices baseados em tabelas de pivôs se valem da premissa de "reescrever" cada elemento do conjunto de dados em um espaço multidimensional, onde cada dimensão é dada pela distância do elemento a um dado pivô, tal como exemplificado na Figura 32(a). No caso de uma consulta por similaridade, essa representação é usada para aplicar o critério do limite inferior em cada pivô e evitar o cálculo de distância entre o elemento de consulta e cada elemento indexado. Dessa forma, as estruturas dessa classe de índices se diferenciam entre si pela forma na qual $(i)$ os pivôs são escolhidos e (ii) é feito o armazenamento dos elementos originais, dos pivôs e dos elementos reescritos. A quantidade de pivôs usados é um parâmetro deste tipo de estruturas de indexação, assim como o critério com o qual eles são escolhidos.

Em particular, os índices da família Omni usam um conjunto de pivôs que são obtidos dentre os pares de elementos mais afastados entre si. Para estender esta classe de métodos de indexação com histogramas, adotamos a notação dos índices da família Omni e continuamos a denominar o mapeamento de cada elemento aos pivôs em $\mathcal{P}$ como coordenadas Omni. Estas coordenadas equivalem à uma entrada da tabela de pivôs, tal como dado pela Definição 5.2.1.

Definição 5.2.1 (Coordenada Omni). Dado um conjunto de pivôs $\mathcal{P}$ e um elemento $s_{i} \in \mathbb{S}$, a coordenada-Omni $O\left(s_{i}\right)$ de $s_{i}$ é o conjunto de distâncias (indexadas por pivô) de $s_{i}$ a cada pivô $p \in \mathcal{P}$, tal que $O\left(s_{i}\right)=\left\{\left\langle p_{1}, \delta\left(s_{i}, p_{1}\right)\right\rangle, \ldots,\left\langle p_{|\mathcal{P}|}, \delta\left(s_{i}, p_{|\mathcal{P}|}\right)\right\rangle\right\}$.

A notação em pares (indexada por 〈pivô, distância〉) é necessária porque não existe a ideia de ordenação entre os pivôs. As coordenadas Omni de todos os elementos $s_{i} \in \mathcal{S}$ a todos os pivôs $p \in \mathcal{P}$ são denotadas aqui por $O_{S}$. Por último, mas não menos importante, duas coordenadas Omni podem ser idênticas se os elementos originais estiverem em regiões diferentes do espaço de busca, porém equidistantes aos pivôs empregados.

Quando uma consulta por similaridade é executada, as coordenadas Omni e o princípio do limite inferior podem ser usadas para avaliar se o cálculo de distância entre o centro de consulta $s_{q}$ e um elemento $s_{i}$ é realmente necessário. Para simplificar a notação, suponha que o operador - (subtração) esteja definido para duas coordenadas Omni, de forma que $O\left(s_{i}\right)-O\left(s_{q}\right) \leq \xi$ retorna verdadeiro sempre que não for possível evitar o cálculo de distância entre $s_{i}$ e $s_{q}$ considerando a bola da consulta dada por $s_{q}$ e $\xi$, ou falso, caso contrário.

Uma característica particularmente interessante com relação aos métodos da família Omni em comparação com a maioria dos métodos de tabela de pivôs, é que um método dessa família depende de um método de acesso acoplado para gerenciar as coordenadas Omni, tanto para armazená-las quanto para evitar verificações $O\left(s_{i}\right)-O\left(s_{q}\right)$ desnecessárias. Note que a 
avaliação $O\left(s_{i}\right)-O\left(s_{q}\right)$ só ocorre após o acesso ao disco que recupera as regiões indexadas e, portanto, evitar essas comparações significa também evitar acessos desnecessários ao disco. Um método de acesso que é naturalmente candidato a ser usado pela família Omni é o SeqScan, o que origina o método Omni-Sequencial, uma versão estendida da estratégia LAESA que suporta paginação para tratar conjuntos de dados que não cabem em memória principal.

Qualquer outra estratégias de indexação acoplada particiona as coordenadas Omni de acordo com sua estratégia de construção, sendo que uma primeira poda nas coordenadas Omni pode ser realizada seguindo a divisão do espaço feita pelo método acoplado. Uma vez que as coordenadas Omni são multidimensionais, além das técnicas de particionamento compactadas revisadas, i.e. árvores métricas, índices espaciais clássicos, como a R-Tree, também podem ser empregados. Repare que um novo método de acesso é criado sempre que as coordenadas Omni são associadas à um índice existente. De forma geral, métodos da família Omni usam uma camada de abstração que inclui o conjunto de dados, $\mathcal{P}$, um particionamento para $O_{S}$ e um mapeamento entre o conjunto de dados e $O_{S}$. Nesse sentido, histogramas podem ser acoplados à proposta Omni, uma vez que as coordenadas Omni armazenam parte da distribuição de distâncias baseadas em pivô e que as restrições de particionamento podem ser usadas para dividir o espaço de coordenadas $O_{S}$ em um conjunto de faixas.

\subsection{Histogramas-Omni}

Apoiados na ideia de se usar tabelas de pivôs para evitar cálculos de distância, estendemos a família de métodos Omni para contemplar histogramas. Essa nova classe de métodos de acesso, a que denominamos Histogramas-Omni, pode ser usada tanto como uma sinopse multidimensional quanto como uma estratégia de indexação não-clusterizada. Histogramas-Omni se diferenciam de métodos anteriores da família Omni por causa das restrições de particionamento empregadas, que levam a organizações do espaço de busca que podem ser mais ou menos adequadas a um tipo específico de consulta por similaridade.

Em particular, aqui focamos no estudo de cinco variações de Histogramas-Omni, a saber Omni Equi-Width, Omni Equi-Depth, Omni V-Optimal, Omni Curve-Fitting e Omni CDH. A principal intuição nessas novas estruturas é a criação de regiões disjuntas e baseadas em pivô que são, ao mesmo tempo, limites de faixas de histogramas para as distribuições, coletadas à partir da perspectiva dos pivôs mais afastados do conjunto de dados. Com isso, a frequência dentro de cada região torna-se disponível antes da execução de cada consulta, o que permite prever os acessos a disco e as quantidades de cálculos de distância. Nesse caso, o método de acesso métrico gerado como um Histograma-Omni divide o espaço de busca de acordo com os pivôs escolhidos, sendo que o número de regiões depende da quantidade máxima de faixas disponíveis. De forma geral, os seguintes parâmetros definem uma instância específica de uma estrutura Histograma-Omni: 
1. Número de pivôs não independentes $-|\mathcal{P}|$.

2. Número máximo de faixas por pivô $-\beta$.

3. Restrição de particionamento de histograma $-\mathcal{R}$.

De forma geral, os Histogramas-Omni tiram proveito da camada de abstração Omni (que inclui as coordenadas Omni) para capturar distribuições de distâncias baseadas em pivô, de forma que estas sejam agrupadas de acordo com a restrição de particionamento do histograma. Portanto, um Histograma-Omni pode ser visto como o conjunto de regiões limitadas pelas faixas de histogramas de distâncias baseadas em pivôs que não são independentes. De modo formal, um Histogramas-Omni $\mathcal{H}$ é definido como o conjunto de pares $\mathcal{H}=\left\{\left\langle p, H_{p}\right\rangle, \forall p \in \mathcal{P}\right\}$, onde $H_{p}$ é o particionamento por um histograma de $\mathcal{T}_{p}^{+}$. O uso da notação em pares $\left\langle p, H_{p}\right\rangle$ é necessário, pois não é possível inferir ordenação entre os pivôs.

A Figura 33 apresenta um exemplo de um conjunto de dados em duas dimensões de coordenadas geográficas de cidades brasileiras e seu particionamento por dois Histogramas-Omni diferentes. A Figura 33(a) apresenta um exemplo de uma distribuição espacial com 60 elementos encontrados como centros pelo algoritmo de agrupamento K-MEDOIDS, enquanto que as Figuras 33(b) e (c) apresentam as partições geradas pelos métodos Omni Equi-Width e Omni CDH para o mesmo conjunto de dados e considerando a métrica $L_{2}$ em ambos os casos.

Uma Omni-faixa $b^{*}$ de $\mathcal{H}$ cobre uma região do espaço de busca que é definida de acordo com o conjunto de faixas não independentes definidas por diferentes histogramas de distância baseados em pivô $H_{p}$ de $\mathcal{H}$. Portanto, os limites da Omni-faixa $b^{*}$ são os limites das faixas $b_{i} \in H_{p}$ relacionados a $b^{*}$ e $\mathcal{H}$ por cada pivô $p \in \mathcal{P}$. Cada elemento do conjunto de dados original cairá em apenas uma Omni-faixa, que é calculada de acordo com as distâncias do elemento aos pivôs em $\mathcal{P}$. A frequência de cada Omni-faixa é o número de elementos que estão dentro da

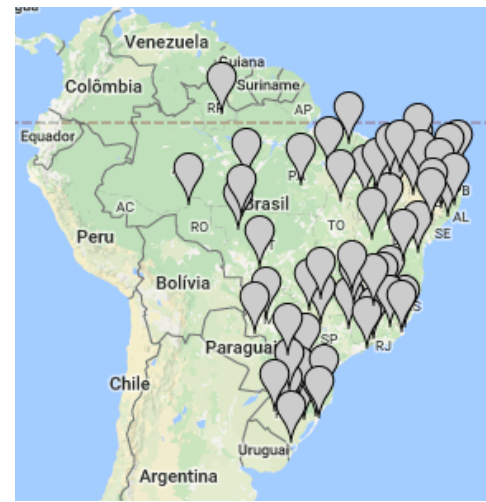

(a)

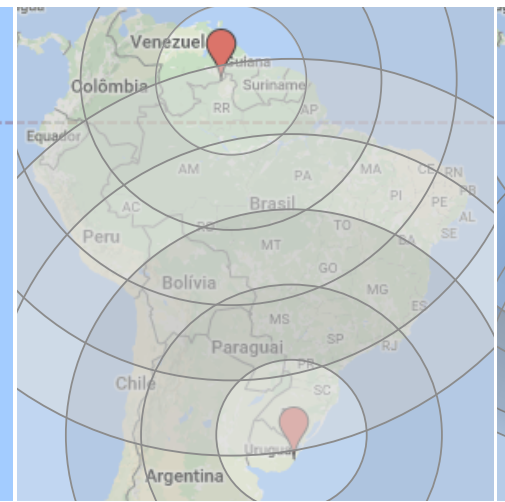

(b)

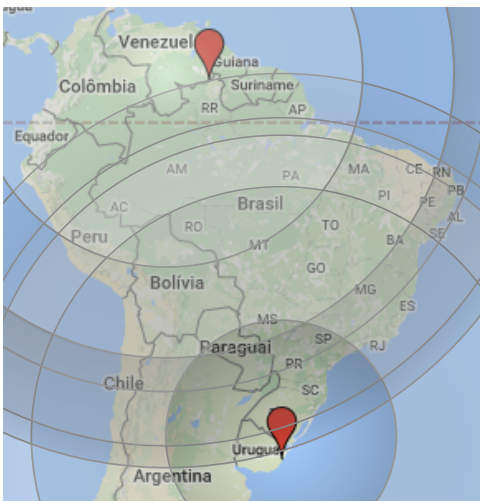

(c)

Figura 33 - Exemplo de um conjunto de dados geográfico (CITIES) em duas dimensões, em que a maioria das cidades está próxima ao litoral. Mais detalhes do conjunto estão no Apêndice B. Os Histogramas-Omni foram construídos para dois pivôs com a restrição de 5 faixas e considerando as distribuições de pivôs geradas pela distância $L_{2}$. Regiões mais escuras são as regiões mais densas. (a) Uma amostra dos dados obtidos por 60 medoids. (b) Regiões Omni Equi-Width. (c) Regiões Omni CDH. 
região correspondente. Nós chamamos de coordenada da Omni-faixa o mapeamento entre um dado elemento $s_{j} \in \mathbb{S}$ e sua Omni-faixa, tal como expresso na Definição 5.3.1.

Definição 5.3.1 (Coordenada da Omni-faixa). Dado um Histograma-Omni $\mathcal{H}$ e um elemento $s_{j} \in \mathbb{S}$, a coordenada da Omni-faixa $B\left(s_{j}\right)$ de $s_{j}$ endereça a Omni-faixa $b^{*}$ de $\mathcal{H}$ cujos limites incluem $s_{j}$. Portanto, $B\left(s_{j}\right)=\left\{\left\langle p, b_{i}\right\rangle \mid \forall\left\langle p, H_{p}\right\rangle \in \mathcal{H}, b_{i} \in H_{p} ; \operatorname{low}\left(b_{i}\right) \leq \delta\left(s_{j}, p\right)<u p\left(b_{i}\right)\right\}$,

sendo que o conjunto de coordenadas de Omni-faixas das coordenadas Omni de todos os elementos do conjunto de dados é denotado por $B_{S}$.

Os Histogramas-Omni permitem a organização do espaço de busca em três níveis. O primeiro nível inclui as Omni-faixas com todas as suas coordenadas $B_{S}$ e um mapeamento entre $O_{S}$ e $B_{S}$, que denotamos como $M\left(O_{S}, B_{S}\right)$. O segundo nível inclui as coordenadas Omni $O_{S}$ e um mapeamento entre o conjunto de dados $\mathcal{S}$ e $O_{S}$, que denotamos como $M\left(\mathcal{S}, O_{S}\right)$. Finalmente, o terceiro nível inclui todos os elementos de $\mathcal{S}$ e seu mapeamento em $O_{S}$ e $B_{S}$, que denotamos $M\left(\mathcal{S}, B_{S}\right)$. Nesse sentido, a camada de abstração de Histogramas-Omni inclui as Omni-faixas, $B_{S}, O_{S}, \mathcal{S}, M\left(\mathcal{S}, B_{S}\right), M\left(\mathcal{S}, O_{S}\right)$ e $M\left(O_{S}, B_{S}\right)$. Note que, caso os elementos do conjunto de dados ou seu mapeamento não estejam incluídos na camada de abstração, o resultado é uma sinopse que considera os pivôs não isolados e que possibilita a contagem das coordenadas

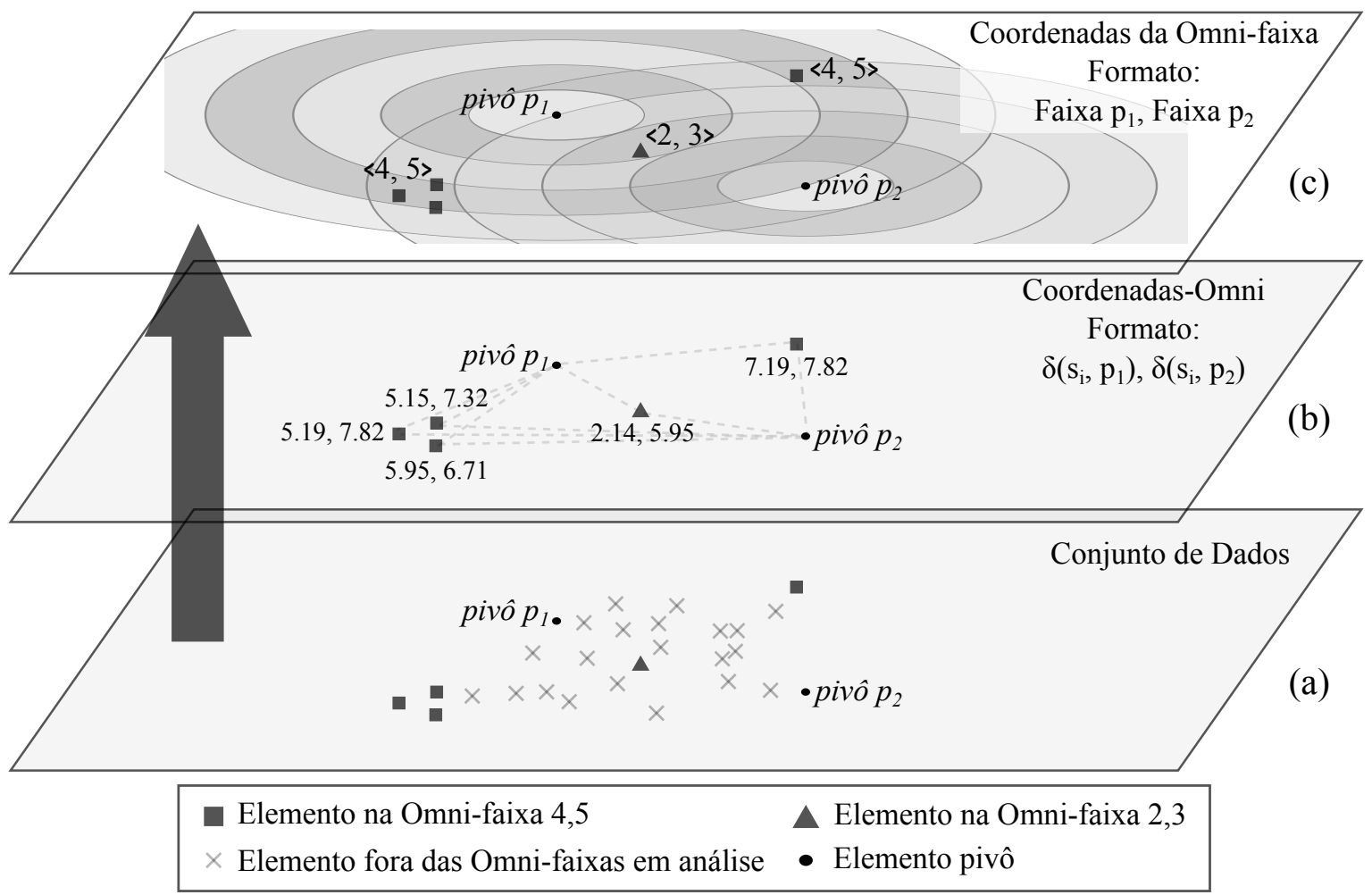

Figura 34 - Exemplo de particionamento de um conjunto de dados por um Histograma-Omni. Fixada a ordem dos pivôs como $p_{1}, p_{2}$, o objetivo do exemplo é descrever como as Omni-faixas $\langle 2,3\rangle$ e $\langle 4,5\rangle$ são formadas. (a) Os elementos do conjunto de dados são mapeados de acordo com suas coordenadas Omni e estes valores são usados para construir distribuições de distâncias baseadas em pivô. (b) A partir dessas distribuições, é possível empregar restrições de particionamento para dividir o espaço de busca em Omni-faixas. (c) Cada Omni-faixa guarda também a quantidade de elementos cobertos. 
Omni dentro de cada Omni-faixa. Caso contrário, a estrutura resultante é um método de acesso com particionamento disjunto que permite otimizar as consultas por similaridade ao limitar as regiões que incluem elementos candidatos ao conjunto-resposta.

A Figura 34 mostra um exemplo da estrutura de um Histograma-Omni em três camadas, onde a ordem dos pivôs está fixada como $p_{1}, p_{2}$. O objetivo é descrever como as Omni-faixas $\langle 2,3\rangle$ e $\langle 4,5\rangle$ foram obtidas. Na primeira camada estão colocados os elementos do conjunto de dados, sendo que, dentre eles, são escolhidos dois elementos pivôs. Essa escolha é feita usando o critério de pivôs da família Omni que encontra, heuristicamente, os elementos mais afastados entre si. Na segunda camada, os dois pivôs escolhidos são usados para "reescrever" todos os elementos do conjunto de dados. A terceira camada apresenta as Omni-faixas que foram construídas a partir de dois histogramas com restrição Equi-Width para os pivôs $p_{1} \mathrm{e}$ $p_{2}$. Os elementos são particionados de acordo com as faixas de cada pivô e são usados para descrever a densidade em cada faixa. Essa estrutura em níveis é que permite usar a estrutura ora como sinopse, ora como método de acesso com particionamento disjunto.

\subsection{Histogramas-Omni para consultas híbridas}

A frequência dentro de uma Omni-faixa é descrita como a quantidade de elementos que estão incluídos naquela região, uma característica similar aos histogramas unidimensionais para distribuições de distância. No entanto, a estrutura dos Histogramas-Omni permite expandir a forma como essa frequência é armazenada para além de um valor real. Note que a frequência dentro de uma Omni-faixa pode ser expressa como uma distribuição de dados com relação à um atributo ortogonal $A$. Nesse caso, a frequência em $b^{*}$ é também representada como um outro histograma sobre $A$, de forma que essa outra sinopse descreve a distribuição de dados dos elementos que estão delimitados pela região da Omni-faixa. De forma geral, o atributo $A$ pode ser substituído por qualquer combinação de atributos.

De acordo com este raciocínio, generalizamos o conceito de Histogramas-Omni para representar distribuições multidimensionais. A distribuição dos atributos ortogonais envolvidos em consultas híbridas é representada dentro de cada Omni-faixa como um histograma separado, que é construído sobre as tuplas cobertas pelas faixas. Em particular, é possível empregar restrições de particionamento diferentes para a criação das Omni-faixas disjuntas e para os histogramas sobre os atributos ortogonais, tal que partições mais adequadas à distribuições de distâncias possam ser combinadas com partições mais adequadas às distribuições de dados.

A Figura 35(a) apresenta um exemplo de um Histograma-Omni generalizado que representa uma distribuição multidimensional constituída por uma distribuição de distâncias baseada em pivô e por uma distribuição de dados. Cada Omni-faixa é numerada de acordo com a sua posição com relação aos histogramas construídos para cada pivô. Para cada Omni-faixa foi construído um histograma Equi-Width sobre o atributo ortogonal $A$ com relação às tuplas que 


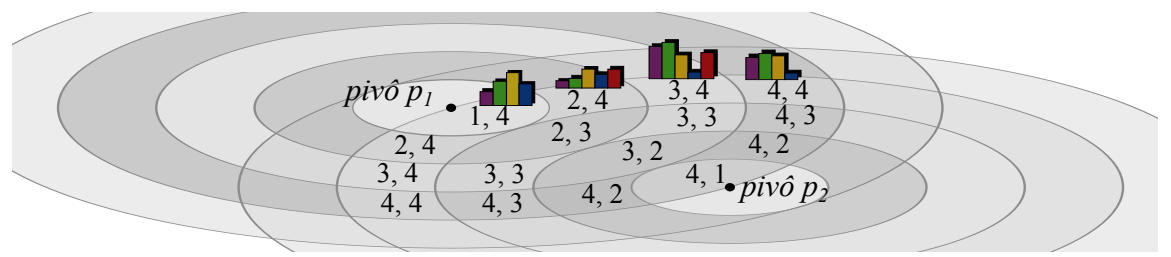

(a)

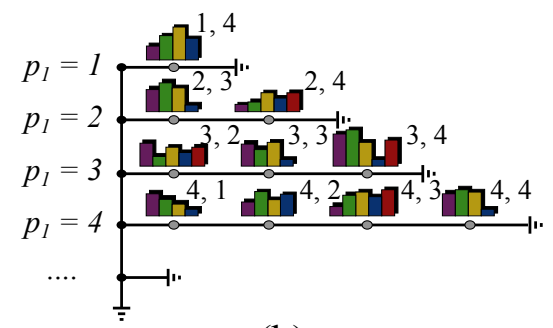

(b)

Figura 35 - Estrutura de um Histograma-Omni generalizado para consultas híbridas. (a) Histograma Omni Equi-Width construído para dois pivôs e cinco faixas com a distância $L_{2}$, onde cada Omni-faixa é numerada de acordo com a sua posição original no histograma de distâncias. Convencionou-se usar a primeira coordenada para a faixa do primeiro pivô e a segunda para o segundo pivô. (b) Lista de adjacência empregada para representar os histogramas para os atributos ortogonais vinculados a cada Omni-faixa, sendo que os histogramas podem ser uni- ou multidimensionais e construídos com uma restrição de particionamento diferente da usada inicialmente para as Omni-faixas.

são cobertas por $b^{*}$. A estrutura de dados empregada para suportar essa representação é mostrada na Figura 35(b). Basicamente, é empregada uma lista de adjacência com relação ao primeiro pivô, sendo que é encontrado um nó para o segundo pivô para cada entrada da lista. Esse nó pode incluir um histograma unidimensional sobre a distribuição de dados de um atributo ortogonal, um histograma multidimensional (inclusive com a mesma estrutura de um Histograma-Omni), ou apenas um valor numérico com a quantidade de elementos na Omni-faixa, caso a sinopse seja especificamente construída para atender a comparações exclusivamente por similaridade.

O Algoritmo 3 (CriarOmniHistograma) constrói um histograma Histograma-Omni generalizado que pode ser usado como índice para otimizar a resolução de consultas híbridas. Ele recebe como entrada as tuplas que incluem os conjuntos de valores assumidos pelos atributos $\mathcal{S}$ e $A$, duas restrições de particionamento que são usadas para o particionamento, uma para o atributo comparável por similaridade $\mathcal{R}_{1}$ e outra para o atributo ortogonal $\mathcal{R}_{2}$, além de duas restrições nos números máximos de faixas $\beta_{1}$ e $\beta_{2}$, que são usados para particionar os dois atributos envolvidos na sinopse. Como resposta, o método CriarOmniHistograma retorna a estrutura de um Histograma-Omni em três níveis.

O primeiro passo no Algoritmo 3 é encontrar os elementos mais afastados do conjunto de dados através da rotina pivôs_omni. Para cada um dos pivôs encontrados, o algoritmo obtém uma distribuição de distâncias baseadas em pivô $\mathcal{T}_{p}^{+}$e as particiona de acordo com a quantidade de faixas disponíveis pelo parâmetro $\beta_{1}$. Cada um dos histogramas gerados é então adicionado à estrutura do Histograma-Omni e os elementos $s_{i} \in \mathcal{S}$ são mapeados em $O_{S}$ e $B_{S}$, respectivamente. Finalmente, o algoritmo constrói um histograma $H_{b^{*}}$ para cada Omni-faixa $b^{*}$ 


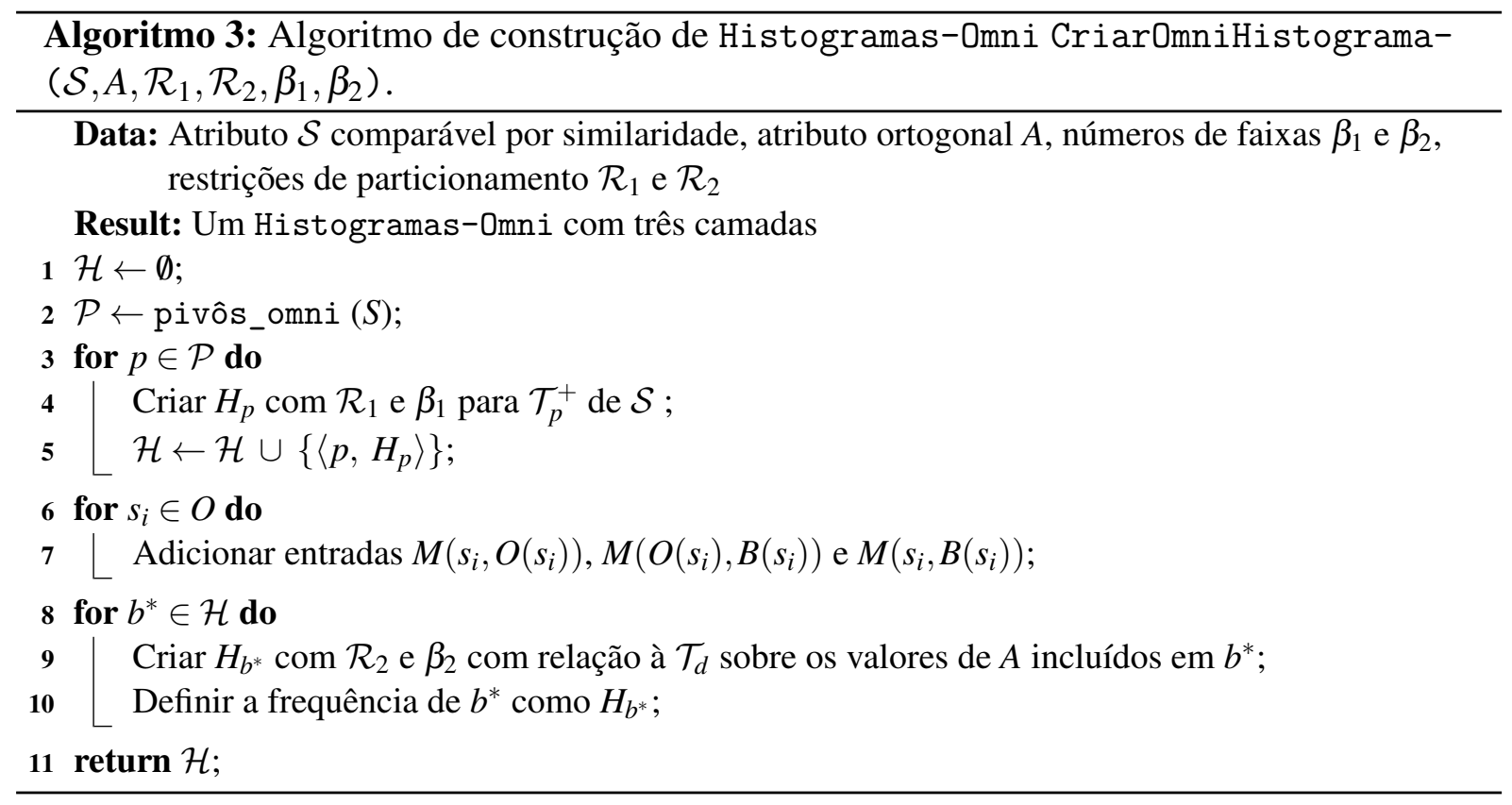

de $\mathcal{H}$ com relação à porção de valores do atributo ortogonal $A$ que está coberto pela Omni-faixa $b^{*}$. Esses histogramas sobre os atributos ortogonais são usados como os valores de frequências das Omni-faixas. Repare que a quantidade de valores que caem em cada Omni-faixa é também capturada pelo histograma sobre o atributo ortogonal e que o mapeamento $M\left(s_{i}, B\left(s_{i}\right)\right)$ transforma a sinopse como um índice com particionamento disjunto.

\subsection{Resolução de consultas híbridas com Histogramas-Omni}

A resolução de consultas por similaridade por meio de estruturas de Histogramas-Omni se beneficia tanto da restrição de particionamento para dividir o espaço de busca quanto da frequência armazenada em cada Omni-faixa para limitar a quantidade de regiões visitadas durante a resolução da consulta. Além disso, as coordenadas Omni são usadas para evitar cálculos de distância. Para uma consulta por abrangência $R q\left(\mathcal{S}, s_{q}, \xi\right)$ a execução da consulta usando a estrutura é direta. Primeiramente, localiza-se a Omni-faixa à qual o elemento de consulta $s_{q}$ pertence. Note que essa Omni-faixa sempre irá existir, uma vez que as distribuições $\mathcal{T}_{p}^{+}$foram particionadas e não apenas $\mathcal{T}_{p}$. Uma vez localizada a Omni-faixa, é possível saber exatamente quais são as regiões que precisam ser avaliadas ao se considerar a distância entre os valores mínimo e máximo de cada faixa e a distância de $s_{q}$ para os pivôs que compõem o Histograma-Omni. Com isso, evita-se carregar em memória principal regiões do espaço de busca que não incluem elementos candidatos ao conjunto-resposta.

Uma otimização para evitar cálculos de distância desnecessários é realizada neste ponto. Os elementos das regiões carregadas em memória são avaliados um a um, sendo que suas coordenadas Omni são examinadas primeiro. Em outras palavras, a segunda camada do Histograma-Omni é analisada e o operador $O\left(s_{i}\right)-O\left(s_{q}\right)<\xi$ é aplicado em cada elemento $s_{i}$ candidato 


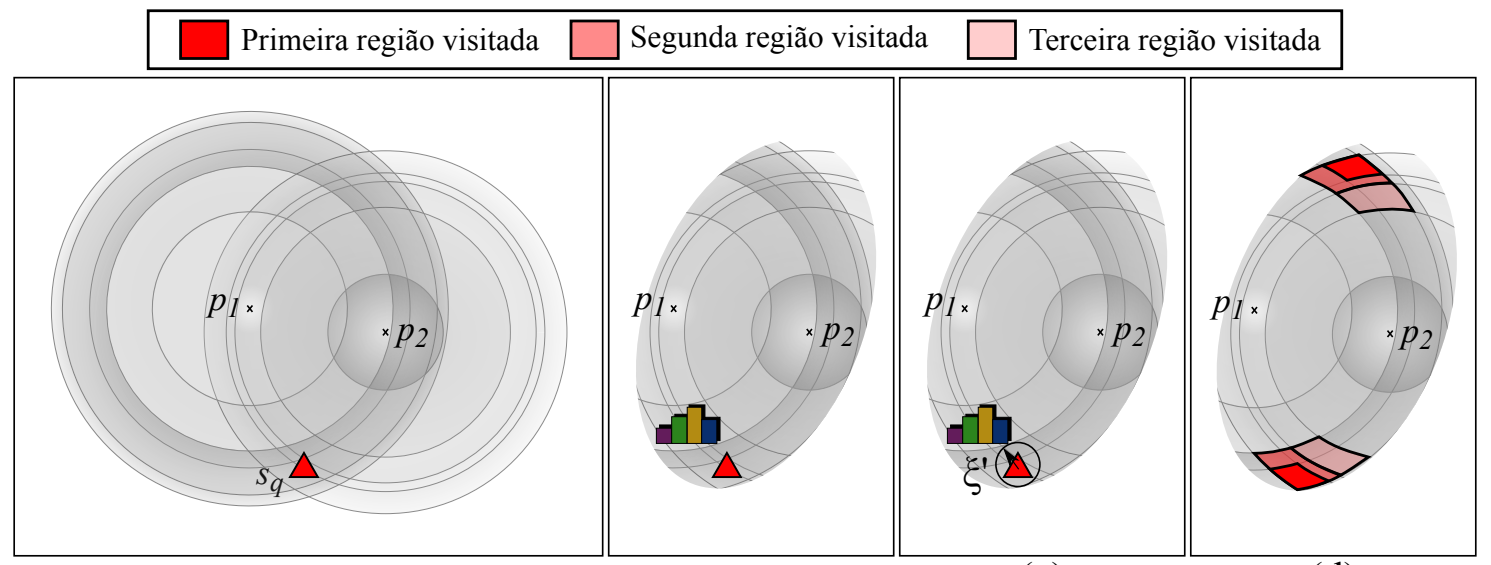

(a)

(b)

(c)

(d)

Figura 36 - Exemplo de uma consulta híbrida por vizinhança sobre um Histograma-Omni para um centro de consulta arbitrário $s_{q}$ e norma $L_{2}$. (a) Localização da Omni-faixa de $s_{q}$. (b) Histogramas no atributo ortogonal definem o raio máximo da consulta $\xi^{\prime}$, i.e. o raio máximo correspondente a distância de $s_{q}$ até seu $k$-ésimo vizinho. (c) Regiões que interceptam a bola da consulta são marcadas para avaliação. (d) Ordem de visitação das Omni-faixas na execução da consulta híbrida.

ao conjunto-resposta. Apenas os elementos que não são filtrados pelas coordenadas Omni têm suas distâncias avaliadas e, caso satisfaçam o critério da consulta, passam a compor o conjunto-resposta da busca por abrangência.

A resolução de uma consulta híbrida segue um raciocínio análogo. Para ilustrar essa execução considere, novamente, a consulta exemplo (C7) sobre as "cinco pinturas renascentistas que são as mais similares a Monalisa”. Suponha que um Histograma-Omni tenha sido construído para dar suporte à comparação do atributo pintura, enquanto que o atributo ortogonal empregado tenha sido o atributo período. Nesse caso, primeiramente localiza-se no Histograma-Omni a Omni-faixa onde se encontra a pintura "Monalisa". Na sequência, os histogramas no atributo ortogonal período são usados para determinar a quantidade de elementos dentro de cada Omni-faixa que satisfazem ao filtro período = 'Renascença'. A avaliação sobre esses histogramas é feita como uma busca em largura, considerando-se a proximidade entre as regiões do Histogramas-Omni e a Omni-faixa de $s_{q}$. Uma vez que a quantidade " 5 " tenha sido satisfeita, traça-se uma bola para a consulta por vizinhança. Apenas as regiões que interceptam a bola da consulta são trazidas para a memória principal.

Ao contrário de uma consulta por abrangência, duas otimizações devem ser consideradas nesse ponto da execução. Primeiro, as regiões devem ser avaliadas pela sua proximidade ao elemento de consulta. Para o cálculo dessa proximidade, considera-se a distância de $s_{q}$ aos pivôs do Histograma-Omni e os valores mínimo e máximo de cada Omni-faixa $b^{*}$. Caso duas regiões $b^{*}$ estejam igualmente próximas a $s_{q}$ (por exemplo, façam fronteira com a Omni-faixa na qual está localizado o elemento de consulta), elas são ordenadas pela distância máxima entre $s_{q}$ e as fronteiras das faixas de $b^{*}$. Após essa ordenação, os elementos de cada região examinada são avaliados no nível de coordenadas Omni, com o objetivo de evitar cálculos de distância desnecessários. Quando um primeiro conjunto candidato de $k$-elementos ordenados por distância 
for obtido dentro do conjunto-resposta ordenado por prioridade, o valor do raio da consulta é reajustado e algumas regiões em memória podem ser descartadas.

O conjunto-resposta pode ser retornado todo de uma vez, ou os elementos podem ser retornados incrementalmente, pois é necessário manter a ordenação das regiões candidatas a serem avaliadas. A Figura 36 ilustra a execução de uma consulta híbrida por vizinhança executada sobre um Histograma-Omni para um elemento de consulta arbitrário $s_{q}$ considerando a norma $L_{2}$. Na Figura 36(a), a Omni-faixa para o elemento de consulta é encontrada, ao passo que na Figura 36(b) os histogramas sobre o atributo ortogonal são usados para inferir o raio da consulta $\xi^{\prime}$. Com a definição do raio inicial, as Omni-faixas que interceptam a bola da consulta são marcadas para avaliação tal como mostrado na Figura 36(c). Finalmente, a Figura 36(d) mostra a ordem na qual as regiões são visitadas e cujos elementos são avaliados, primeiro por coordenadas Omni e, eventualmente, por meio da distância até o centro de consulta, tal como ilustrado pelas cores das regiões visitadas na Figura 36(d).

Nós destacamos que os Histogramas-Omni são particularmente interessantes para otimização de consultas híbridas, tanto por possibilitar limitar o número máximo de regiões avaliadas, quanto por minimizar o número de cálculos de distâncias. Essas otimizações se devem ao fato que a estrutura do índice: ( $i$ ) permite estimar o raio máximo da bola da consulta por meio da frequência de cada Omni-faixa e (ii) se beneficia das coordenadas Omni para evitar cálculos de distância desnecessários. Nesse sentido, as Omni-faixas que não interceptam a bola da consulta sequer são carregadas em memória para avaliação. Nós definimos uma rotina, denominada numElementos, que usa a condição de filtragem no atributo ortogonal para avaliar, em largura, os histogramas de frequência das Omni-faixas mais próximas aos elementos de consulta. Portanto, a estratégia numElementos é a responsável por determinar qual é o raio máximo de uma consulta híbrida $\xi^{\prime}$.

As regiões $b^{*}$ que interceptam a bola da consulta são carregadas em memória e as demais, descartadas. As faixas não descartadas são ordenadas de acordo com duas funções, que denominamos maxdist() e mindist (). A função mindist() para uma dada Omni-faixa $b^{*} \mathrm{e}$ um elemento de consulta $s_{q}$ é a distância mínima entre $s_{q}$ e uma fronteira de faixa de $b^{*}$. Esse valor é obtido como minímo $\left(\left|\operatorname{low}\left(b_{i}\right)-\delta\left(s_{q}, p\right)\right|,\left|u p\left(b_{i}\right)-\delta\left(s_{q}, p\right)\right|\right)$, onde $b_{i}$ é a faixa de $H_{p}$ com relação à cada pivô $p \in \mathcal{P}$ que define $b^{*}$. Por outro lado, a função maxdist() para $b^{*}$ é calculada como máximo $\left(u p\left(b_{i}\right)+\delta\left(s_{q}, p\right)\right)$ com relação à cada pivô $p \in \mathcal{P}$. A combinação da função mindist () com a rotina numElementos permite cortar as Omni-faixas que não incluem nenhum elemento candidato ao conjunto-resposta, Mais do que isso, as funções mindist() e maxdist () permitem a avaliação incremental das Omni-faixa que, potencialmente, incluem os elementos do conjunto-resposta.

O Algoritmo 4 (omni_hist-kNN) descreve uma consulta híbrida por vizinhança em um Histograma-Omni para um elemento de consulta $s_{q}$, uma quantidade de vizinhos $k$ e uma condição $A_{c}$ sobre o atributo ortogonal $A$. Primeiro, o algoritmo limita o número de regiões 


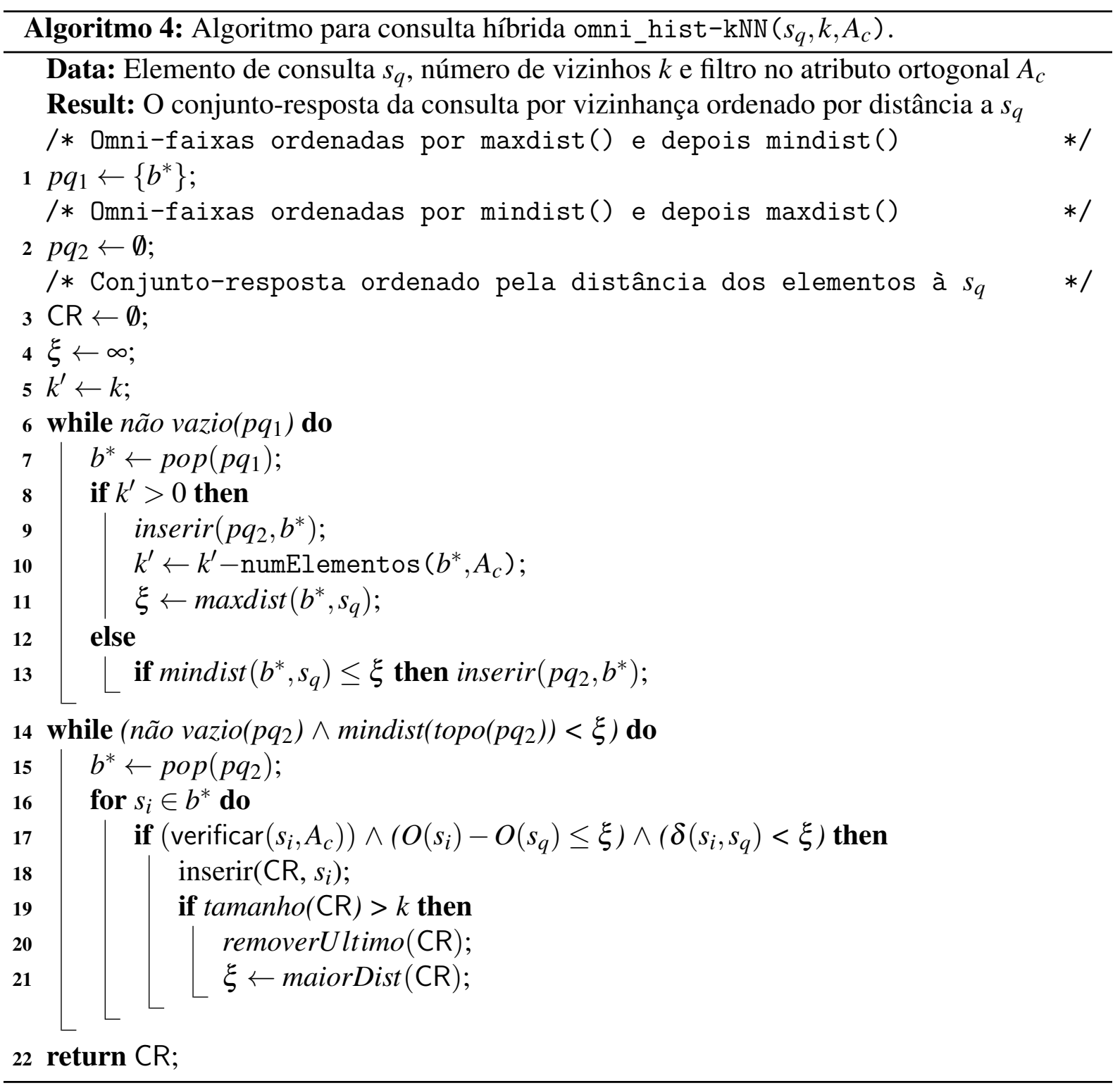

visitadas ao escolher e ordenar as Omni-faixa candidatas que interceptam a bola máxima da consulta através da fila de prioridade $p q_{2}$ e continua o processamento sobre essas regiões com o objetivo de prorrogar o cálculo de distâncias o máximo possível. A Omni-faixa $b^{*}$ mais próxima ao centro de consulta dentro da fila $p q_{2}$ é escolhida para avaliação e seus elementos $s_{i}$ são verificados com relação ao critério de filtragem no atributo ortogonal realizado pela rotina verificar $\left(s_{i}, A_{c}\right)$, que retorna verdadeiro ou falso. Se este critério é satisfeito, o algoritmo aplica o operador $O\left(s_{i}\right)-O\left(s_{q}\right) \leq \xi$, que possibilita descartar $s_{i}$ de acordo com valor máximo $\xi$.

A distância entre $s_{i}$ e $s_{q}$ é calculada apenas quando o critério empregado no atributo ortogonal é satisfeito e nenhuma poda pode ser realizada sob as coordenadas Omni. Nesse caso, a distância $\delta\left(s_{i}, s_{q}\right)$ é usada para inserir $s_{i}$ no conjunto-resposta, que é construído como uma fila de prioridade e cujos elementos são ordenados com relação à $s_{q}$. A solução do Algoritmo 4 não considera o tratamento de empates. Nesse caso, se $s_{i}$ é selecionado para inserção no conjunto de resposta e este já possui $k$ elementos, o algoritmo insere $s_{i}$ na fila de prioridades, remove o 
último elemento da fila de prioridades e atualiza o raio de busca. Para retornar todos os elementos empatados na $k$-ésima posição basta substituir a condição na linha 19 do Algoritmo 4 para considerar também a maior distância dentro da fila de prioridades.

\subsection{Avaliação de Histogramas-Omni}

Para avaliar a eficiência dos Histogramas-Omni como métodos de acesso, nós realizamos três conjuntos de experimentos sobre seis conjuntos de dados, tal como mostrado na Tabela 6 . Mais detalhes sobre os conjuntos de dados são encontrados no Apêndice B. No primeiro conjunto de experimentos, foram comparadas diferentes restrições de particionamento de histogramas para identificar quais são as mais adequadas para representar as distribuições de distância em Histogramas-Omni. Já no segundo experimento, os Histogramas-Omni foram comparados com outros métodos de acesso, a saber SeqScan, LAESA e Omni-R-Tree para a execução de consultas por vizinhança. No último experimento, comparamos esses mesmos métodos para resolver consultas híbridas. Nesse experimento, usamos como atributo ortogonal o atributo de classe dos conjuntos rotulados BANK, YEAST e CANVAS.

Tabela 6 - Conjunto de dados e parâmetros empregados na avaliação de Histogramas-Omni.

\begin{tabular}{|l|c|c|c|c|c|}
\hline \hline Nome & $A$ & Cardinalidade & Dimensionalidade & $\lceil\mathcal{D}\rceil$ & $\delta$ \\
\hline \hline CITIES & N/A & 5.507 & 2 & 2 & $L_{2}$ \\
\hline BIKE & N/A & 17.379 & 7 & 2 & $L_{\infty}$ \\
\hline COLORS & N/A & 112.682 & 112 & 9 & $L_{1}$ \\
\hline \hline BANK & Tipo & 1.372 & 4 & 2 & $L_{\infty}$ \\
\hline YEAST & Localidade & 1.484 & 8 & 4 & $L_{2}$ \\
\hline CANVAS & Período & 3.879 & 16 & 10 & $L_{1}$ \\
\hline
\end{tabular}

Os método de acesso Omni-R-Tree e LAESA executam o algoritmo de busca inc-kNN, enquanto que os Histogramas-Omni executam o algoritmo omni_hist-kNN. Todas as comparações foram realizadas de acordo com o procedimento de validação cruzada para 10 -folds ( $90 \%$ dos dados usados na indexação e os restantes $10 \%$ usados nas consultas, alternadamente) e medimos o tempo acumulado de execução das consultas. Todos os testes foram executados no mesmo ambiente de experimentos desta tese, que está detalhado na Seção 6.5.

\subsubsection{Comparação entre restrições de particionamento}

Para comparar o desempenho de diferentes restrições de particionamento na construção de Histogramas-Omni, os pivôs foram selecionados de acordo com o critério Omni que procura os elementos mais afastados entre si. A quantidade de pivôs foi escolhida seguindo a heurística de se usar a dimensão fractal de cada conjunto de dados, de forma que foram usados $|\mathcal{P}|=\lceil\mathcal{D}\rceil$ pivôs em cada conjunto avaliado. De forma similar, a quantidade de Omni-faixas foi escolhida de acordo com as restrições de memória disponíveis. Em particular, simulamos um ambiente 
(a) CITIES

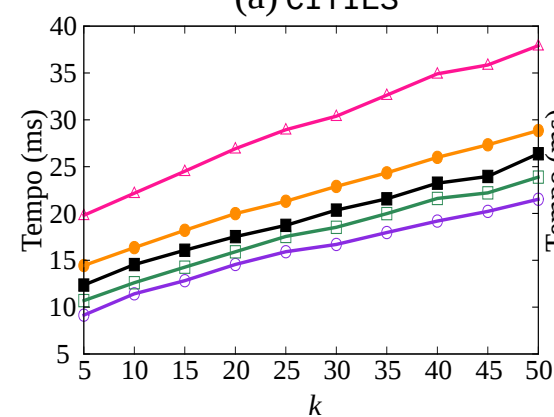

(d) YEAST

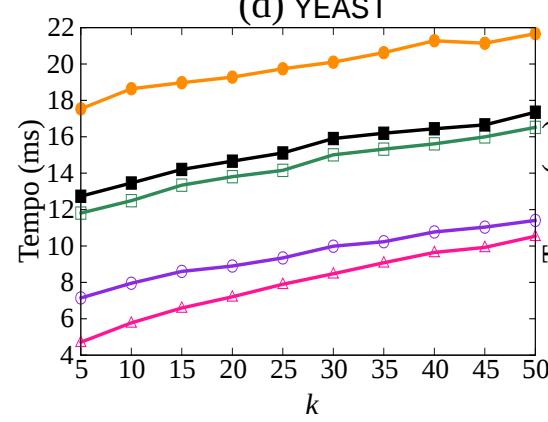

(b) BANK

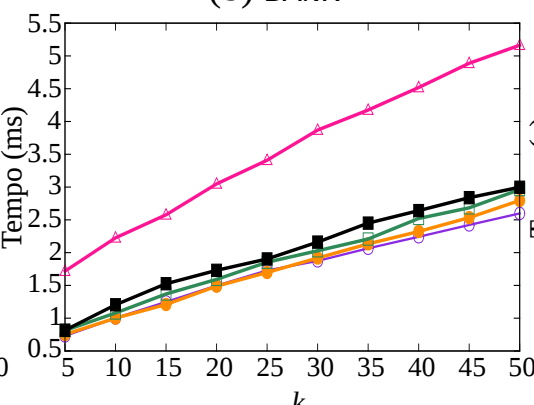

(e) CANVAS

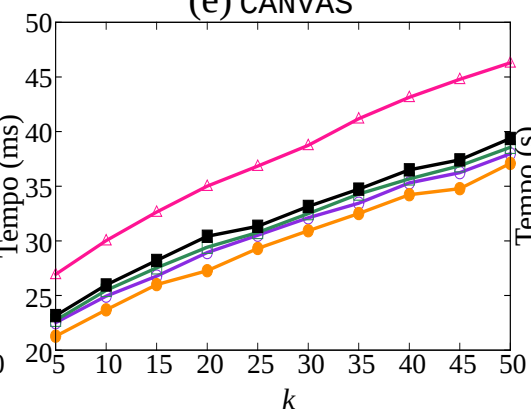

(c) BIKE

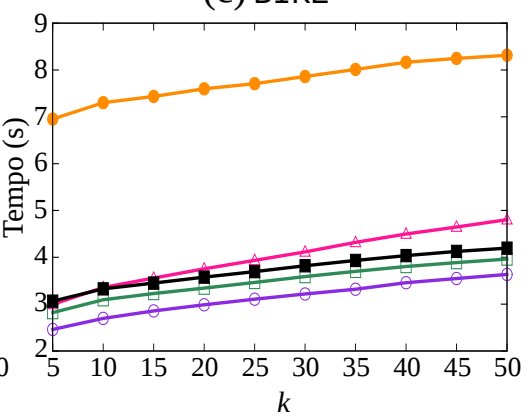

(f) COLORS

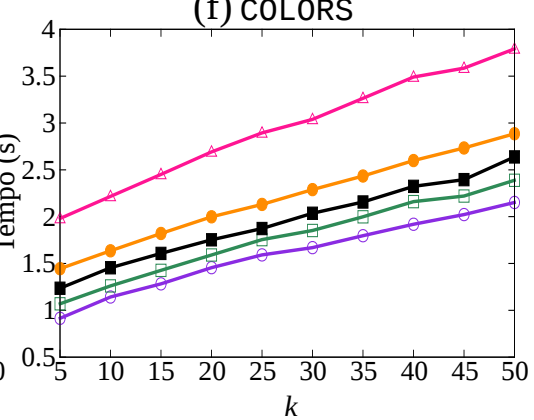

$$
\begin{aligned}
& - \text { Omni Equi-Width -Omni Curve-Fitting } \\
& \triangle \text { Omni V-Optimal }- \text { Omni Equi-Depth }
\end{aligned}
$$

Figura 37 - Comparação do desempenho de diferentes restrições de particionamento de Histogramas-Omni na execução das consultas por vizinhança.

de restrição de memória tal que a estrutura dos Histogramas-Omni deveria caber em menos de $0.001 \%$ da memória principal disponível no ambiente de teste. Como resultado deste critério, nós empregamos $\beta_{1}=5$ faixas para os conjuntos de dados CITIES, BIKE e BANK, $\beta_{1}=3$ faixas para o conjunto YEAST e $\beta_{1}=2$ faixas para os conjuntos COLORS e CANVAS.

Além disso, cinco restrições de particionamento foram avaliadas para a representação da distribuição de distâncias baseadas em pivô, que resultaram em cinco Histogramas-Omni diferentes, a saber Omni Equi-Width, Omni Equi-Depth, Omni V-Optimal, Omni CDH e Omni Curve-Fitting. A Figura 37 mostra a comparação geral, em termos do tempo de execução, que cada variação de Histograma-Omni requer para processar as consultas por vizinhança sem considerar qualquer atributo ortogonal. Ainda que o método Omni V-Optimal tenha obtido o melhor desempenho nos conjuntos de dados YEAST, ele também obteve um dos piores desempenhos no restante dos conjuntos avaliados. O método Omni Equi-Depth apresentou um comportamento similar. Por exemplo, esta restrição obteve a melhor performance no conjunto CANVAS, porém apresentou um baixo desempenho nos demais conjuntos de dados. Por outro lado, os métodos Omni Equi-Width e Omni CDH mostraram comportamentos estáveis, uma vez que eles atingiram um dos três melhores desempenhos, independentemente do conjunto de dados avaliado. Em particular, o método Omni Equi-Width conseguiu a melhor performance nos conjuntos CITIES e BIKE. De acordo com estes resultados, selecionamos tanto o índice Omni Equi-Width quanto o índice Omni CDH para a comparação com outras estratégias de indexação. 


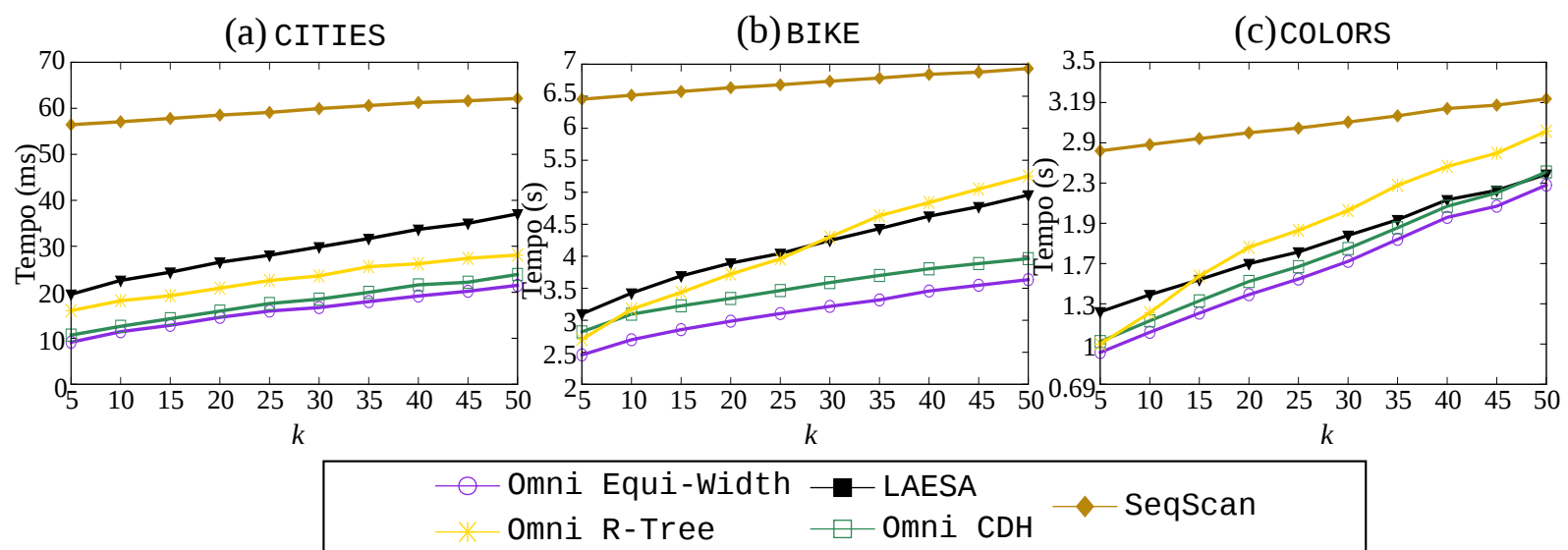

Figura 38 - Comparação de Histogramas-Omni e os métodos de acesso SeqScan, LAESA e Omni R-Tree com relação ao tempo gasto para executar consultas por vizinhança.

\subsubsection{Histogramas-Omni vs. métodos baseados em tabelas de pivôs}

Uma vez identificadas as duas restrições de particionamento mais adequadas, os Histogramas-Omni foram comparados com os métodos de acesso SeqScan, LAESA e Omni R-Tree. É importante mencionar que o método LAESA foi escolhido pois é o método de propósito geral do grupo de estruturas baseadas em tabelas de pivôs. Já o método Omni R-Tree, que armazena e recupera as coordenadas Omni por meio de um índice R-Tree para garantir melhor desempenho, foi escolhido por ser um dos índices mais eficientes da família Omni. A Figura 38 mostra a comparação entre os Histogramas-Omni e os outros métodos avaliados com relação ao tempo necessário para realizar consultas por vizinhança.

O método Omni Equi-Width superou a estratégia LAESA em até $113 \%$ e $41 \%$ para $k=50$ nos conjuntos de dados CITIES e BIKE, respectivamente. O método Omni CDH superou a estratégia LAESA em até $83 \%$ e $30 \%$ no mesmo cenário e mesmos valores de $k$. Tanto o Omni Equi-Width quanto o Omni CDH também superaram o método LAESA em praticamente todos os valores de $k$ para o conjunto de dados COLORS. Em particular, o método Omni Equi-Width foi até $5.4 \%$ mais rápido nesse caso, enquanto o método $\mathrm{Omni} \mathrm{CDH}$ superou o competidor LAESA em até $3.7 \%$. Os dois Histogramas-Omni também superaram a estratégia Omni R-Tree em todos os conjuntos avaliados. Destacamos que o método Omni Equi-Width foi até 500\%, $160 \%$ e $16.1 \%$ mais rápido que a solução SeqScan para os conjuntos CITIES, BIKE e COLORS, respectivamente. De forma similar, o método Omni CDH superou o SeqScan em até $443 \%, 131 \%$ e $12.4 \%$ com relação aos mesmos conjuntos de dados.

\subsubsection{Desempenho de Histogramas-Omni para consultas híbridas}

No último experimento realizado, o desempenho das estratégias SeqScan, Histogramas-Omni, LAESA e Omni R-Tree foram comparadas para resolver consultas híbridas. No caso dos Histogramas-Omni, foram construídos histogramas Equi-Width para o atributo ortogonal, tal que a quantidade máxima de faixas para cada um desses histogramas foi definida como $\beta_{2}=10$ 
(a) BANK

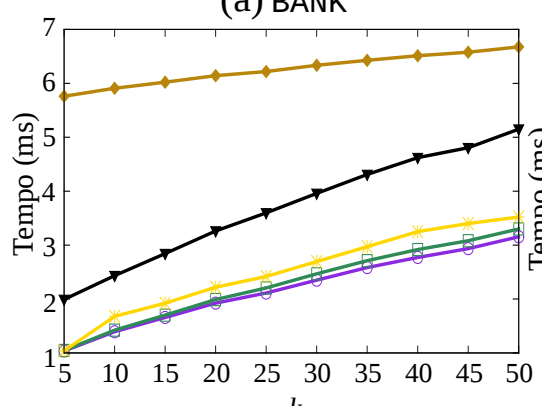

$k$ (b) YEAST

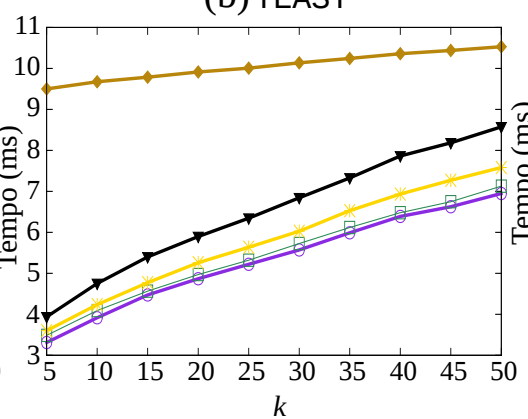

(c)CANVAS

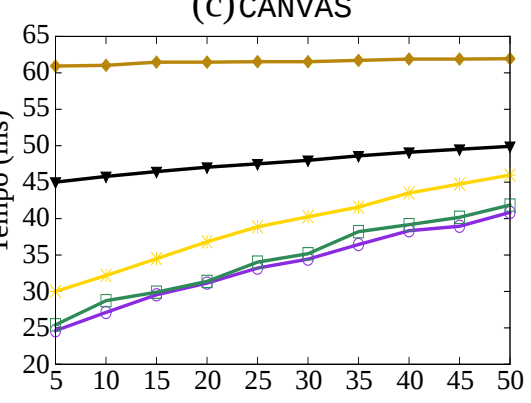

$k$

- Omni Equi-Width - LAESA

Omni R-Tree

$\square$ Omni $\mathrm{CDH}$

Figura 39 - Comparação de Histogramas-Omni e os métodos de acesso SeqScan, LAESA e Omni R-Tree com relação ao tempo gasto para executar consultas híbridas.

em função da memória disponível. Cada consulta foi realizada no seguinte formato: "Encontre os $k$ elementos mais próximos a $s_{q}$, onde o atributo ortogonal A esteja de acordo com a condição de filtragem $A_{c}$ ”. Os atributos ortogonais $A$ empregados nas consultas são mostrados na Tabela 6. Para estas consultas, nós definimos as condições de filtragem $A_{c}$ sobre o atributo ortogonal $A$ usando Período= 'Renascença' (20\% dos elementos), Localidade= 'Mitocôndria' (16.4\% dos elementos) e Tipo= 'Classe 0 ' (55.5\% dos elementos) considerando os conjuntos de dados CANVAS, YEAST e BANK, respectivamente.

A Figura 39 apresenta a comparação entre os métodos de acesso com relação ao tempo gasto para a execução das consultas híbridas. O método Omni Equi-Width superou a estratégia LAESA em até $47.2 \%, 16.1 \%$ e $44.8 \%$ para os conjuntos de dados BANK, YEAST e CANVAS, respectivamente. Da mesma forma, o método Omni $\mathrm{CDH}$ superou a estratégia LAESA em até $45.7 \%, 10.9 \%$ e $42.3 \%$ com relação aos mesmos conjuntos de dados avaliados. Destacamos que tanto o Omni Equi-Width quanto o Omni CDH superaram o método Omni R-Tree em cada um dos valores de $k$ avaliados. Finalmente, o método Omni Equi-Width superou a abordagem SeqScan em até $456 \%, 186 \%$ e $147 \%$ com relação aos conjuntos de dados BANK, YEAST e CANVAS. De maneira semelhante, o método Omni CDH apresentou um desempenho de até $455 \%$, $164 \%$ e $125 \%$ superior à abordagem SeqScan no mesmo cenário.

Baseados nestes resultados, conclui-se que os Histogramas-Omni alcançaram um desempenho superior tanto ao da técnica-base LAESA quanto do índice baseado em tabela de pivôs Omni R-Tree, em todos os conjuntos de dados avaliados, seja para consultas por vizinhança seja para consultas híbridas. O ganho médio alcançado pelos Histogramas-Omni chegou aos 47.2\% na comparação com o método LAESA e $31.7 \%$ na comparação com o método Omni R-Tree.

\subsection{Considerações Finais}

Quando se considera a recuperação de dados por similaridade, além de comparações exclusivas por abrangência e por vizinhança, existem também as comparações que misturam 
comparações envolvendo relações de similaridade com comparações envolvendo relações de identidade e ordem. Neste capítulo, denominamos essas comparações mistas de consultas híbridas. A otimização dessa classe de consultas por meio de um índice único exige que as sinopses representem, simultaneamente, distribuições de distâncias e de dados. Para isso, desenvolvemos uma nova classe de sinopses, os Histogramas-Omni. As sinopses propostas permitem a representação de distribuições de distâncias com relação à um grupo não independente de pivôs, de acordo com as restrições de particionamento de histogramas discutidas nas seções anteriores. Para cada uma das partições de um Histograma-Omni, denominadas Omni-faixas, constroem-se histogramas sobre o atributo ortogonal avaliado, cujas contagens são empregados como as frequências das Omni-faixas.

A estrutura dessa sinopse pode ser dividida em três camadas e a tornam apta a agir como um método de acesso não-clusterizado que estende os índices da família Omni. De acordo com essa estrutura, nós propusemos um novo algoritmo para consultas híbridas, de forma que o número de regiões visitadas é conhecido de antemão e a quantidade de cálculos de distância é minimizada. Após a realização de um conjunto de experimentos sobre dados reais, constatamos:

1. As restrições de particionamento que geram os Histogramas-Omni mais eficientes são aquelas geradas por histogramas Omni Equi-Width e Omni CDH.

2. Os métodos Omni Equi-Width e Omni CDH foram mais eficientes que os métodos LAESA e Omni $R$ Tree na execução de consultas por vizinhança.

3. Os métodos Omni Equi-Width e Omni CDH foram expressivamente mais eficientes que os métodos LAESA e Omni $R$ Tree na execução de consultas híbridas.

As sinopses Histogramas-Omni se somam às sinopses unidimensionais para as distribuições de distâncias discutidas nas seções anteriores. Na próxima seção, serão discutidos os componentes e a avaliação de um sistema que incorpora essas sinopses em um ambiente integrado, de modo a estender os módulos de 'Espaço de Distribuição de Dados' e 'Modelo de Custo' do otimizador de consultas de um SGBD. 


\title{
Um protótipo de otimizador com suporte à consultas por similaridade
}

\author{
"Never bet against the [SQL] \\ compiler."
}

M. Stonebraker, vencedor do

prêmio ACM Turing em $2014^{1}$

Como enfatizado nos capítulos anteriores, o otimizador de consultas de um SGBD é o módulo responsável por decidir qual é o plano de consulta mais adequado para cada consulta submetida ao SGBD. Além disso, o otimizador também precisa definir quais são os operadores físicos que serão empregados na resolução do plano de consulta escolhido. Todas essas decisões dependem da disponibilidade de uma representação adequada dos dados armazenados, de modelos de custo confiáveis e da descrição de metadados sobre índices que eventualmente possam ser usados. No caso particular de consultas envolvendo comparações por similaridade, o módulo de 'Espaço de Distribuição de Dados' precisa ser estendido para representar também distribuições de distância. Nesse sentido, o módulo 'Espaço de Distribuição de Dados e Distâncias' ampliado deve ser capaz de fornecer as entradas, ou seja, estimativas, para o módulo de 'Modelo de Custo', bem como prover eventuais sinopses para a criação de índices ou otimização de operadores físicos associados ao 'Espaço de Método/Estrutura'. A extensão desses módulos no otimizador de consultas consiste na avaliação da 'Hipótese da Extensão' discutida nesta teste.

Em essência, o módulo ampliado ‘Espaço de Distribuição de Dados e Distâncias’ deve conter um conjunto de algoritmos para construir e manter sinopses sobre distribuições de dados e distâncias, além de um conjunto de rotinas que permita a consulta destas mesmas estruturas. As sinopses precisam ser persistidas em disco, de forma que a extensão do otimizador deve incluir um catálogo de relações próprio para o armazenamento de estatísticas baseadas em distância. Por último, mas não menos importante, deve ser possível ao DBA escolher quais sinopses serão

1 O Prof. Michael Stonebraker proferiu a sentença acima em uma de suas palestras sobre a versatilidade de SGBDs para dados estruturados. Neste capítulo, apresentamos um esboço de otimizador com suporte à consultas por similaridade que pode ser integrado à SGBDs relacionais. 
construídas e quais serão os parâmetros utilizados. Também deve ser possível ao DBA visualizar as estruturas construídas para fins de análise estatística das distribuições armazenadas e de depuração das rotinas de consulta, tal como já ocorre para sinopses sobre dados comparados segundo relações de identidade e ordem. Portanto, definir os comandos de criação de estatísticas para distribuições de distância é um requisito-chave na extensão do otimizador de consultas.

Nessa seção, apresentamos o protótipo de um sistema para a extensão do otimizador de consultas de um SGBD que possibilita a construção, armazenamento e consulta de sinopses de distribuições de distância. O sistema desenvolvido, denominado Merkurion, um acrônimo para o nome em inglês Measuring radii and $\boldsymbol{k}$ using representations of distance distributions (Medindo valores de raios e $k$ usando representações de distribuições de distância, em português), é um protótipo que possibilita coletar distribuições de pares de distância ou baseadas em pivô para atributos sujeitos à comparação por similaridade.

Basicamente, o protótipo Merkurion é implementado como um conjunto de componentes em uma arquitetura modular e que possibilita usar um grupo específico de funções para o tratamento de comparações por similaridade em SGBDs. O protótipo implementa uma linguagem em alto nível que permite ao administrador da base de dados parametrizar a construção das sinopses de acordo com os requisitos de memória disponíveis. Por meio da mesma linguagem também é possível consultar o sistema Merkurion (com ou sem o uso de um SGBD acoplado) para obter dois tipos de estimativa:

1. Estimativa de seletividade para consultas por abrangência, o que permite obter a quantidade de elementos filtrados em uma comparação por abrangência.

2. Estimativa de raios para uma consulta por vizinhança, o que permite obter uma lista ordenada de valores estimados de raio que incluem, potencialmente, os $k$ elementos mais próximos em uma consulta por vizinhança.

Destacamos que os trabalhos prévios da literatura se focaram ou no desenvolvimento de sinopses isoladas, especialmente para estimativa de raios de consultas por vizinhança; ou ainda, no projeto de modelos de custo que dependem de uma sinopse específica, como nos modelos de custo que assumem a distribuição uniforme de distâncias. Esse cenário dificulta a comparação entre sinopses ou modelos de custo. Além disso, algumas das sinopses revisadas foram construídas para estratégias de indexação específicas e avaliadas sobre diferentes conjuntos de dados, o que dificulta ainda mais a comparação entre elas.

Nossa contribuição com o protótipo Merkurion é integrar os esforços mais relevantes revisados em um único sistema de arquitetura flexível e com uma interface orientada à comandos. De fato, o sistema Merkurion foi usado como a plataforma de referência em todas as comparações de sinopses e modelos de custo apresentadas até agora (Seções 4.2, 4.4 e 5.6). Na sequência, discutimos a arquitetura do sistema Merkurion, as sinopses e os comandos suportados pelo 
protótipo, além do estudo de um caso de uso sobre um conjunto de dados real. Uma versão de demonstração do sistema pode ser encontrada em: github.com/marcosivni/merkurion.

\subsection{O protótipo Merkurion}

O protótipo implementado pode ser visto como uma extensão de um otimizador de consultas, que pode ser adicionado ao processador de consultas de qualquer SGBD com o objetivo de dar suporte à comparações por similaridade. Devido à arquitetura do sistema proposto, essa extensão pode ser alcançada de duas formas. Primeiro, o módulo ampliado fornece métodos que podem ser diretamente invocados por uma linguagem de alto nível. Segundo, um conjunto de funções podem ser invocadas por meio de uma Interface de Programação de Aplicação (API) e, consequentemente, também podem ser diretamente adicionadas nas rotinas de busca do SGBD. No primeiro caso, o sistema Merkurion pode ser usado fora de um SGBD e chamado diretamente por uma aplicação, ainda que este não seja seu objetivo primário.

\subsubsection{Arquitetura do sistema Merkurion}

A arquitetura do sistema Merkurion é composta de seis componentes, como ilustrado na Figura 40. Usuários ou aplicações podem interagir com o sistema com e sem um SGBD. O protótipo Merkurion estende o processador de consultas do SGBD ao adicionar funcionalidades para o tratamento de comparações por similaridade por meio de: (i) definição de funções proxy no SGBD que são ligadas a funcionalidades do sistema Merkurion, uma estratégia que gera pouco acoplamento; ou ainda (ii) modificação do código fonte do processador de consultas do SGBD para que este passe a incluir funções de otimização da API do sistema proposto, uma estratégia que leva a um alto acoplamento entre o SGBD e o Merkurion. Para interagir com o sistema sem

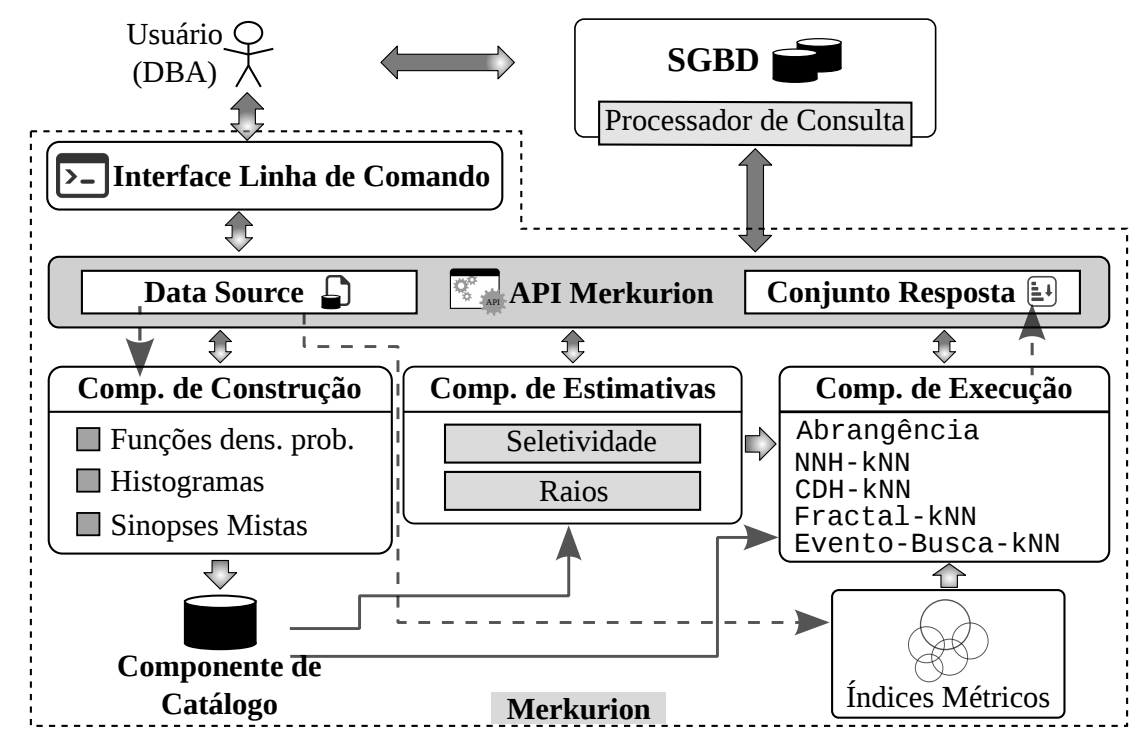

Figura 40 - Arquitetura do sistema Merkurion. 
usar um SGBD, é possível usar a Interface de Linha de Comando do Merkurion, denominada Merkurion CLI. Em todos os casos, internamente, o protótipo irá usar as funcionalidades disponíveis na API, que atua como uma interface entre o acesso dos usuários e os componentes internos que efetivamente manipulam as sinopses.

O Componente de Construção é um módulo chave do sistema. Ele é responsável por coletar as distribuições de distância para os atributos sujeitos à comparação por similaridade e comprimi-las na forma de sinopses cujos parâmetros são obtidos pela API do sistema. Este componente depende de uma abstração contida na API do sistema Merkurion que denominamos Data Source. Tal abstração é responsável por coletar os dados de entrada no sistema e pode ser configurada de acordo com a conveniência do DBA. Por exemplo, é possível obter os valores dos atributos diretamente das tabelas do SGBD, assim como é possível configurar a abstração para aceitar um arquivo de texto formatado como um documento . csv.

Todos os valores carregados em uma abstração são automaticamente indexadas por uma árvore métrica Slim-Tree. O Componente de Construção usa a abstração para coletar as distribuições de pares de distância ou baseada em pivô quando o DBA solicita a construção de uma sinopse. Portanto, o Componente de Construção é o responsável por gerar a sinopse de acordo com as restrições do DBA. Após a construção da estrutura, o Componente de Construção encaminha a representação de distâncias para o Componente de Catálogo. Este componente armazena as sinopses, bem como os metadados do sistema, em um conjunto interno de tabelas criado no Catálogo do SGBD acoplado. A Figura 41 mostra as tabelas internas usadas nesse armazenamento. Duas das mais importantes são a Parameter_Instance e a Synopses_Catalog. A primeira tabela armazena os parâmetros das sinopses de acordo com as especificações do usuário, enquanto que a última armazena a sinopse em si e as referências para o conjunto de dados e seus demais parâmetros de entrada.

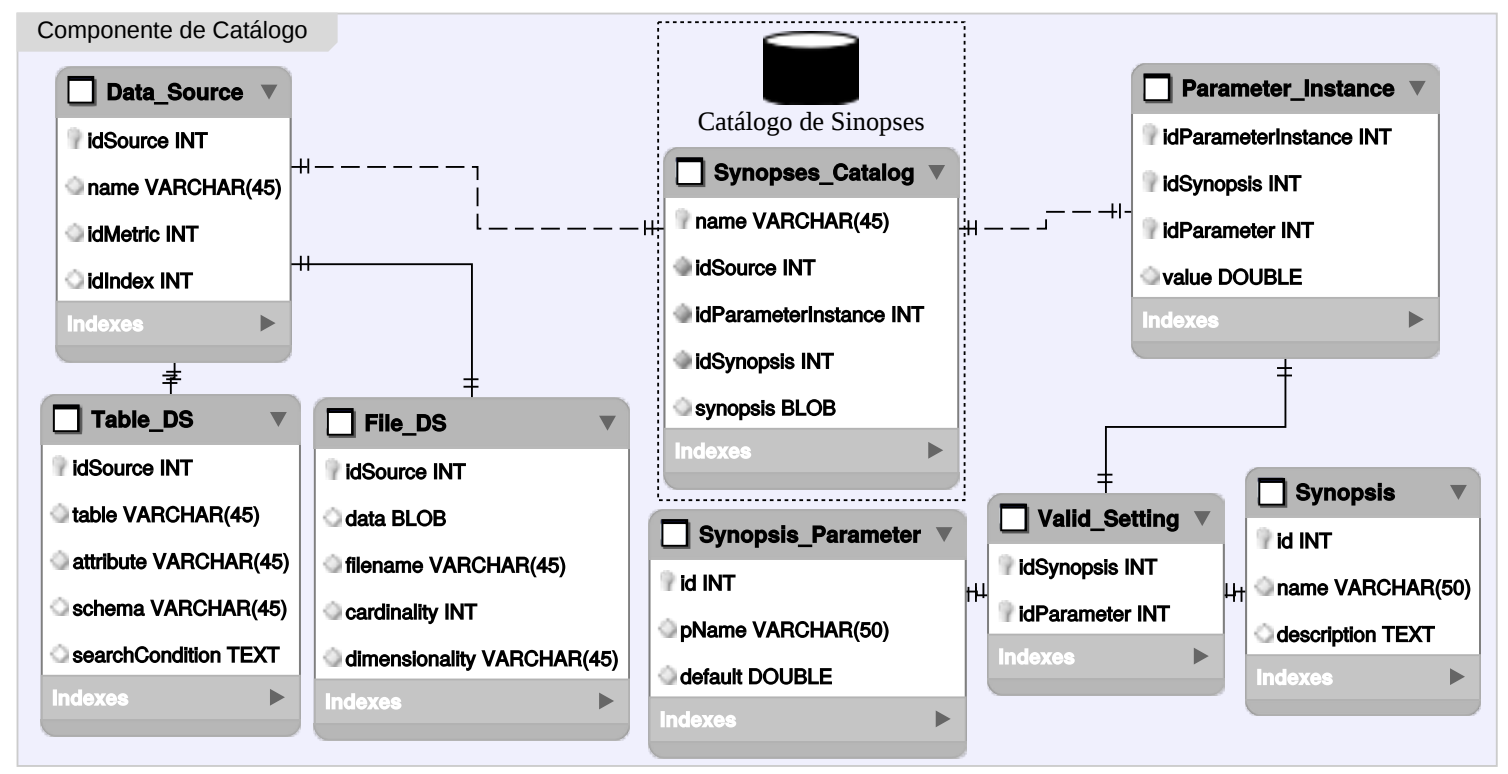

Figura 41 - Visão geral do modelo de dados para o Componente de Catálogo. 
O Componente de Estimativas é outro módulo chave do sistema. Ele permite consultar as sinopses construídas para obter estimativas de seletividade e raios para comparações por similaridade. Enquanto a seletividade é usada na fase de otimização lógica, as estimativas de raio são usadas para gerar as variações da rotina bf-kNN limitada. Nesse sentido, o sistema Merkurion também inclui diversos algoritmos para executar as consultas por vizinhança. Esses algoritmos estão implementados no módulo Componente de Execução, que interage com o Componente de Estimativas para obter os valores preditos e os emprega junto aos índices métricos para executar efetivamente a consulta.

A saída do Componente de Execução depende de outra abstração disponível na API do sistema, que denominamos Conjunto Resposta. Essa abstração é, basicamente, um conjunto iterável de identificadores de elementos que satisfazem a uma determinada comparação por similaridade. Nesse sentido, a abstração é muito similar à abstração já encontrada nas interfaces com SGBDs tradicionais e que permitem a recuperação de tuplas e elementos via identificadores de linhas (rowids). Essa abstração permite que aplicações que usem o protótipo Merkurion sem um SGBD acoplado possam iterar sobre o conjunto-resposta de uma consulta por similaridade, tal como já o fazem na abstração obtida por um SGBD tradicional.

\subsubsection{O Componente de Construção}

O Componente de Construção fornece sinopses baseadas em distâncias para otimização de consultas por similaridade. A construção de uma sinopse requer carregar o conjunto de dados na abstração do Merkurion e obter os parâmetros de construção definidos pelo DBA por meio da API do sistema. Portanto, sempre que o usuário informa um conjunto de dados, além de construir um índice com os elementos lidos, o protótipo Merkurion armazena os metadados do conjunto de dados e o índice construído no Componente de Catálogo. O Componente de Construção associa cada sinopse à um tipo de distribuição de distâncias de acordo com o conjunto de parâmetros informado, que pode incluir uma restrição de particionamento e um critério para a seleção de pivôs dentre os elementos do conjunto de dados.

A restrição de particionamento pode ser de dois tipos: (i) limitado por memória; ou (ii) limitado por erro. O limite por memória indica que a distribuição de dados coletada precisa

Tabela 7 - Sinopses implementadas pelo sistema Merkurion. Cada sinopse usa um tipo diferente de distribuição de distância e a representa de acordo com uma dada restrição de particionamento.

\begin{tabular}{|c|c|c|c|}
\hline Sinopse & Tipo & Distro. Distância & Restrição \\
\hline \hline Histograma NN & Histograma & Baseado em pivôs & Memória \\
\hline CDH & Histograma & Baseado em pivôs & Memória/Erro \\
\hline Distance Plot & Função Dens. Prob. & Pares & - \\
\hline Evento de Busca c/ Equi-Width & Misto & Ambas & Memória/Erro \\
\hline Evento de Busca c/ Equi-Depth & Misto & Ambas & Memória/Erro \\
\hline Evento de Busca c/ V-Optimal & Misto & Ambas & Memória/Erro \\
\hline Evento de Busca c/ Curve-Fitting & Misto & Ambas & Memória/Erro \\
\hline
\end{tabular}


ser compactada de acordo com o espaço máximo fornecido (e.g. número de faixas) tal que o erro de aproximação seja minimizado. Por outro lado, o limite por erro indica que a compactação deve obter um erro geral de aproximação menor do que um erro máximo tolerável. Como uma terceira opção, o sistema permite usar as duas restrições de Memória e Erro simultaneamente. Nesse caso, o Componente de Construção gera uma solução aproximada que é limitada pelo erro mínimo e por uma quantidade máxima de memória. A Tabela 7 mostra as sinopses disponíveis no protótipo Merkurion. Todas elas foram discutidas nas seções anteriores.

\subsubsection{Critérios para seleção de pivôs}

Um dos fatores que impacta a qualidade das estimativas obtidas por sinopses baseadas em pivô é o da representatividade dos elementos escolhidos como pivôs. O protótipo Merkurion implementa três critérios de seleção de pivôs, a saber K-MEDOIDS, OMNI e BRID. O primeiro critério seleciona como pivôs os $k$ elementos medóides dos grupos encontrados pelo algoritmo de agrupamento baseado em distância K-MEDOIDS (KAUFMAN; ROUSSEEUW, 1987). O objetivo dessa técnica é selecionar os pivôs que possam fornecer informações sobre os diferentes grupos presentes no mesmo conjunto de dados. O custo de execução do método K-MEDOIDS implementado no protótipo é $\mathcal{O}\left(|\mathcal{P}| \cdot|\mathcal{S}|^{2} \cdot i_{t}\right)$, onde $|\mathcal{P}|$ é a quantidade de pivôs, $|\mathcal{S}|$ é a cardinalidade do conjunto de dados e $i_{t}$ é o número máximo de iterações indicado por parâmetro.

O critério OMNI escolhe os pivôs que estão na "borda" do conjunto de dados, i.e. ele procura pelos elementos mais afastados entre si. A ideia é estender a solução encontrada para determinar os elementos que compõem um Conjunto de Convexidade de Hull, tal que os pivôs possam coletar informações bem diferentes entre si com relação à distribuição de distâncias. A implementação da técnica OMNI no Merkurion é baseada no algoritmo Omni Foci (TRAINA JR. et al., 2007). Como primeiro passo, o algoritmo implementado escolhe um elemento aleatório e encontra outro elemento que seja o mais distante dele, o qual é usado como o primeiro pivô $p_{1}$. $\mathrm{O}$ segundo pivô, $p_{2}$, é o elemento mais distante de $p_{1}$. O terceiro pivô é o elemento mais distante tanto do pivô $p_{1}$ quanto do pivô $p_{2}$, e assim por diante. $\mathrm{O}$ custo geral de se encontrar os pivôs indicados pela técnica OMNI no sistema é $\mathcal{O}(|\mathcal{P}| \cdot|\mathcal{S}|)$.

Finalmente, o critério BRID, tal como proposto em Santos et al. (2013), possibilita encontrar os elementos mais influentes com relação à um dado elemento de referência. A ideia é evitar coletar elementos muito próximos entre si tal que os pivôs sejam "diversificados". Repare que, se o elemento de consulta usado for o medóide do conjunto de dados, a estratégia BRID irá retornar os elementos mais diversificados entre si e que podem fazer a função de pivôs internos. Os elementos retornados são diferentes dos obtidos pela estratégia OMNI, uma vez que estão localizados no "interior" e não na "borda" do conjunto de dados. Os pivôs BRID também são diferentes daqueles obtidos pelo algoritmo K-MEDOIDS, pois eles não são, necessariamente, medóides de grupos. O sistema Merkurion implementa o algoritmo BRID usando o medóide do conjunto de dados como centro de consulta e usa o número desejado de pivôs como o parâmetro 
$k$ de número de vizinhos diversos. Nesse caso, a implementação BRID do sistema Merkurion faz uma busca sequencial sobre o conjunto de dados com custo $\mathcal{O}\left(|\mathcal{S}|^{2}+|\mathcal{P}| \cdot|\mathcal{S}|\right)$. A Tabela 8 apresenta as principais características dos critérios de seleção de pivôs e seus custos de execução na implementação no protótipo Merkurion.

Tabela 8 - Critérios de seleção de pivôs disponíveis no protótipo Merkurion.

\begin{tabular}{|l|l|l|}
\hline Critério & Tipos de pivôs & Custo de execução \\
\hline \hline K-MEDOIDS & Medóides de grupos & $\mathcal{O}\left(|\mathcal{P}| \cdot|\mathcal{S}|^{2} \cdot i_{t}\right)$ \\
\hline OMNI & Elementos afastados & $\mathcal{O}(|\mathcal{P}| \cdot|\mathcal{S}|)$ \\
\hline BRID & Elementos influentes & $\mathcal{O}\left(|\mathcal{S}|^{2}+|\mathcal{P}| \cdot|\mathcal{S}|\right)$ \\
\hline
\end{tabular}

\subsubsection{Componente de Estimativas e Componente de Execução}

O módulo Componente de Estimativas é o responsável por implementar a leitura e o cálculo das estatísticas para obtenção de estimativas baseadas em distância. Este módulo também é o responsável por implementar as estimativas das rotinas bf-kNN limitada para otimização física de consultas por vizinhança. Todas estimativas são calculadas usando um conjunto de funções acessíveis por meio da API do sistema Merkurion, que recupera as sinopses do Componente de Catálogo. Esse mesmo módulo é o responsável por calcular as estimativas de seletividade e também permite a visualização e consultas de sinopses que podem ser diretamente usadas por modelos de custo. De forma complementar, o módulo Componente de Execução inclui as rotinas NNH-kNN, CDH-kNN, Evento-Busca-kNN e Fractal-kNN além de um algoritmo de execução de consultas por abrangência que usa a estratégia branch-and-bound.

\subsection{A Interface Linha de Comando do Merkurion}

O componente Merkurion CLI fornece um interpretador em linha de comando para o uso do protótipo sem acoplamento à um sistema SGBD. Este módulo inclui um conjunto de comandos que possibilita ao usuário usar interativamente o sistema Merkurion, para otimização de consultas, além de apoio à depuração e visualização de resultados. A especificação completa e sintaxe dos comandos aceitos pelo Merkurion CLI é detalhada no Apêndice A. Os principais comandos disponíveis no sistema Merkurion são os seguintes:

LOAD - Carrega o conjunto de dados oriundo de uma relação ou de um arquivo-texto para uma abstração de dados do sistema e os indexa em uma árvore métrica.

CREATE/VIEW SYNOPSIS - Cria uma sinopse de acordo com um conjunto de parâmetros fornecidos pelo DBA e permite visualizar a distribuição de distâncias comprimida.

ESTIMATE KNN_RADIUS |RANGE_SELECTIVITY - Gera estimativas de raio ou seletividade para consultas por abrangência e vizinhança, considerando quaisquer elementos de consulta do mesmo domínio do conjunto de dados. 
EXECUTE KNN_SELECT|RANGE_SELECT - Executa um comando de Seleção que inclui uma única comparação por abrangência ou vizinhança sobre um conjunto de elementos de consulta. Retorna estatísticas, como números de acessos a disco e cálculos de distância, sobre a execução da consulta, além dos respectivos conjuntos-resposta.

\subsection{Estudo de caso para o conjunto de dados CITIES}

Nesta seção apresentamos um estudo de caso baseado no conjunto de dados CITIES que contém informações sobre coordenadas geográficas de cidades brasileiras. O conjunto inclui as coordenadas em duas dimensões das cidades, as quais são comparadas usando a métrica $L_{2}$. Destacamos que também é possível armazenar o conjunto de dados como um atributo de uma relação em um SGBD com suporte à consultas por similaridade. Nesse contexto, construímos uma relação denominada cities que possui os atributos coordinates (as coordenadas geográficas) e name (cadeia de caracteres com o nome da cidade brasileira). O comando $\mathbf{S 1}$ carrega o conjunto de valores do atributo sujeito à comparação por similaridade direto da relação cities para a abstração do sistema e o indexa em um índice Slim-Tree:

\section{S1: LOAD coordinates FROM cities INTO coordcity} METRIC EUCLIDEAN

Os identificadores das tuplas (rowids) são implicitamente carregados da tabela, no momento da criação das entradas no índice métrico. Como alternativa, os dados podem ser carregados diretamente de um arquivo-texto devidamente formatado. O comando $\mathbf{S 2}$ carrega 5507 entradas de coordenadas geográficas de um arquivo . csv sem cabeçalho, denominado cities.csv em uma abstração de dados do sistema.

\section{S2: LOAD cities.csv ELEMENTS 5507 DIMENSIONALITY 2 INTO coordcity METRIC EUCLIDEAN}

Nesse caso, o sistema automaticamente associa um identificador para cada entrada do conjunto de dados. Com os dados devidamente carregados, o usuário pode construir uma sinopse usando quaisquer dos métodos de representação disponíveis no sistema Merkurion. Por exemplo, o comando $\mathbf{S 3}$ cria um Histograma NN, com 150 pivôs escolhidos pelo método K-MEDOIDS e com vetores de vizinhos mais próximos de tamanho $\max \_k=100$.

\section{S3: CREATE SYNOPSIS nnh_kmed150_100 FOR coordcity TYPE NEAREST_NEIGHBOR_HISTOGRAM USING K-MEDOIDS_PIVOTS 150, MAX_K 100}

De forma análoga, o comando $\mathbf{S} 4$ constrói um conjunto de $6 \mathrm{CDH}$ 's associados à política de estimativas AVG, com pivôs escolhidos pelo método OMNI e compactados em 120 faixas . 
S4: CREATE SYNOPSIS cdh_omni6_avg_buckets_120 FOR coordcity TYPE COMPACT_DISTANCE_HISTOGRAM USING OMNI_PIVOTS 6 , POLICY AVERAGE, CONSTRAINT BUCKETS 120

O comando S5 usa uma sintaxe similar para construir um Distance Plot usando uma distribuição de pares de distância com 20 pontos de controle interpolados por mínimos quadrados.

S5: CREATE SYNOPSIS dp_20_least FOR coordcity TYPE DISTANCE_PLOT USING LEAST_SQUARES WITH 20 POINTS

O comando S6 gera uma sinopse de Evento de Busca composta por histogramas Equi-Depth compactados em 120 faixas.

S6: CREATE SYNOPSIS se_equidepth_buckets_120 FOR coordcity TYPE SEARCH_EVENT USING EQUI_DEPTH, CONSTRAINT BUCKETS 120

O DBA também pode visualizar a descrição da sinopse criada. Por exemplo, comando S7 mostra detalhes da sinopse Distance Plot criada pelo comando S5.

S7: VIEW SYNOPSIS dp_20_least

A criação das sinopses já possibilita ao DBA executar variações das rotinas bf-kNN limitada. O comando $\mathbf{S 8}$ a seguir usa uma sinopse Evento de Busca para executar uma rotina Evento-Busca-kNN e recuperar as quinze cidades mais próximas a cada capital, sendo que os elementos de consulta estão no arquivo capitals. csv.

S8: EXECUTE KNN_SELECT K 15 FOR coordcity

USING se_equidepth_buckets_120

QUERY_ELEMENTS capitals.csv ELEMENTS 27 DIMENSIONALITY 2

Na execução do comando S8, o sistema Merkurion realiza uma busca com raio inicial estimado pelo Componente de Estimativas em uma Slim-Tree, de acordo com a rotina Evento-Busca-kNN. A saída obtida para cada elemento de consulta é um conjunto-resposta contendo os identificadores dos $k$-vizinhos mais próximos e suas respectivas distâncias ordenadas para o elemento de consulta, além das estimativas geradas. $\mathrm{O}$ usuário pode verificar explicitamente as estimativas de raios gerados por meio do comando $\mathbf{S 9}$.

S9: ESTIMATE KNN_RADIUS K 15 FOR coordcity

USING se_equidepth_buckets_120

QUERY_ELEMENTS capitals.csv ELEMENTS 27 DIMENSIONALITY 2 
O comando S9 retorna um conjunto-resposta que inclui apenas as estimativas de raio para os elementos de consulta. Ao contrário dos comandos S8 e S9, cujos centros de consulta foram carregados de um arquivo formatado, o comando $\mathbf{S 1 0}$ fornece um exemplo de centros de consulta carregados como atributos de uma tabela usando a sintaxe nome_atributo FROM nome_tabela [WHERE condição_busca]. O comando S10 retorna as cidades que estão distantes em até 0.5 unidades de distância da cidade de São Carlos.

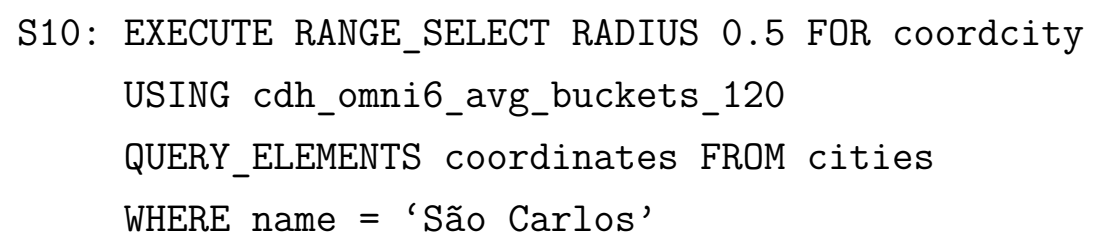

Finalmente, o comando S11 mostra um exemplo de como recuperar as estimativas de seletividade para consultas por abrangência, como ilustrado na consulta do comando S10. Nesse caso, o Componente de Estimativas calcula as estimativas de acordo com a sinopse CDH.

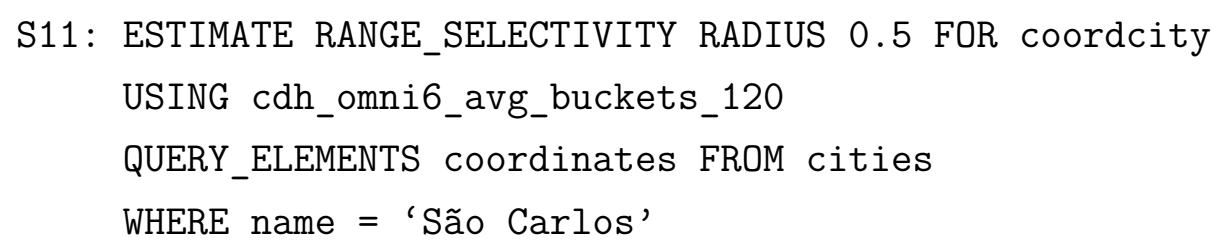

A Figura 42 detalha todo o fluxo de execução de comandos na interface em linha de comando do sistema, que ocorre da forma como se segue:

- LOAD - Permite carregar os elementos na abstração do sistema Merkurion: L1 o usuário envia um comando LOAD para o Merkurion CLI, que se conecta à API do sistema Merkurion e traduz os comandos em alto nível em rotinas da API; L2 a rotina chama o Componente de Construção e a seguir, em L3 lê os dados da abstração do protótipo e L4 cria a abstração e indexa o conjunto de dados em um índice Slim-Tree; finalmente, L5)-L6 retornam os status das operações para o usuário.

- CREATE SYNOPSIS - Permite criar uma sinopse após ser carregado o conjunto de dados: C1 o usuário submete o comando, que em C2 é encaminhado ao Componente de Construção; C3 o Componente de Construção constrói a distribuição de distâncias requisitada com relação aos dados do índice correspondente do sistema; C4 constrói uma sinopse e C5 a armazena junto aos metadados no Componente de Catálogo; finalmente C6-C7 retornam os status da operação para o usuário. 
- ESTIMATE - Permite obter estimativas: E1 o usuário informa o tipo da estimativa e seus parâmetros; E2 o Componente de Estimativas é invocado; E3 o Componente de Estimativas carrega os elementos do conjunto de dados indicado no comando e E4 acessa a sinopse no Componente de Catálogo para calcular as estimativas; E5-E6 as estimativas são organizados no conjunto-resposta que retorna ao usuário.

- EXECUTE - Permite executar uma consulta por similaridade: Q1 o usuário submete um comando EXECUTE KNN_SELECT | RANGE_SELECT; Q2 o comando chega ao Componente de Execução, que Q3 carrega os elementos de consulta em uma abstração de dados; sempre que a consulta solicitada usar o operador de comparação por vizinhança, Q4 o Componente de Execução requisita estimativas ao Componente de Estimativas fornecendo os elementos de consulta e os parâmetros; Q5 o Componente de Estimativas produz as estimativas requisitadas usando a sinopse indicada e Q6 retorna o conjunto-resposta de estimativas. Como próximo passo, Q7 o Componente de Execução chama o respectivo algoritmo de execução da consulta sobre a Slim-Tree do sistema Merkurion usando as estimativas iniciais; se o raio inicial para a variação bf-kNN limitada for subestimado, os passos Q4 Q6 são executados novamente para uma estimativa refinada. Finalmente, em Q8-Q10 o conjunto-resposta da consulta e algumas estatística da execução são retornadas ao usuário.
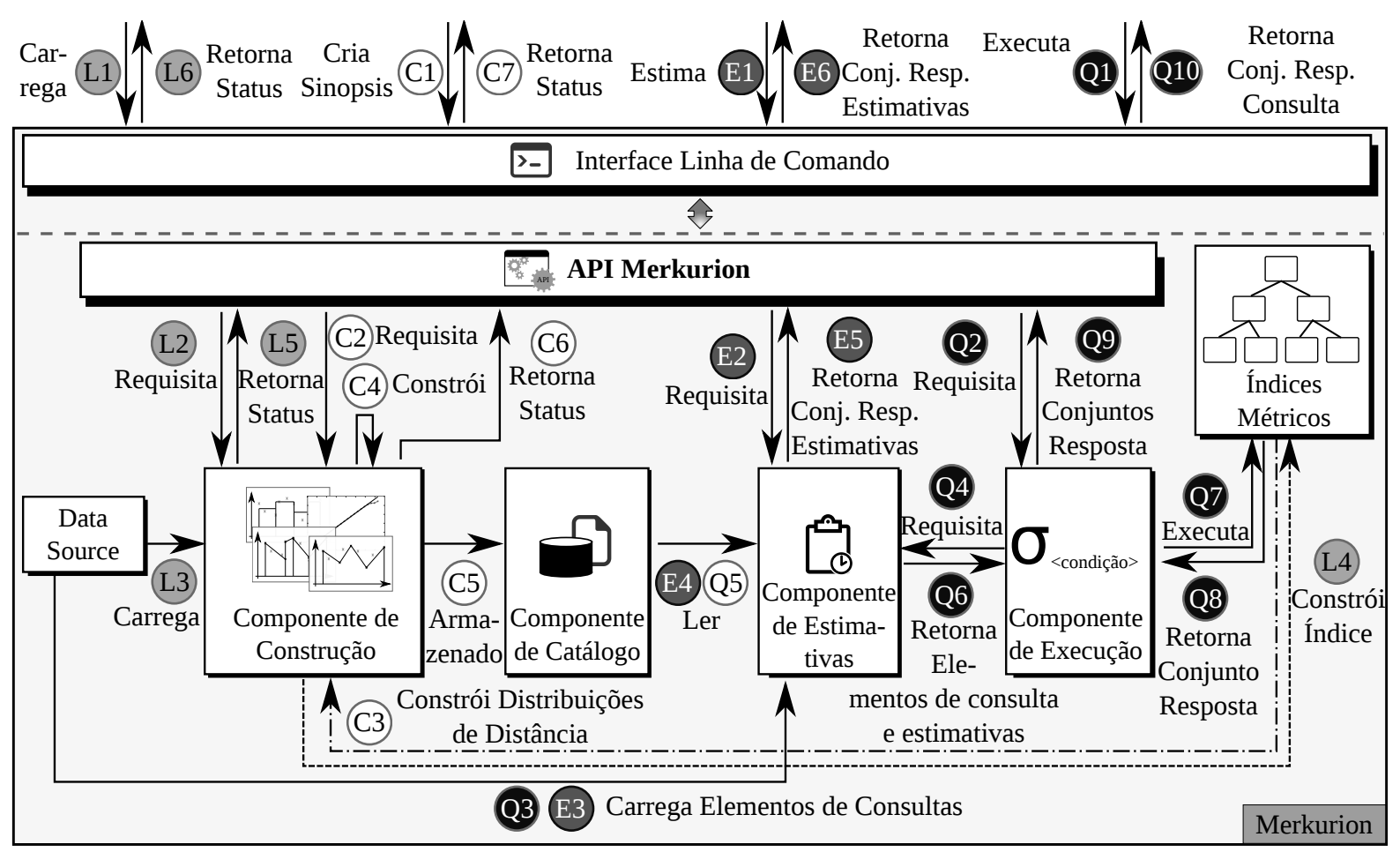

Figura 42 - Exemplo da execução de comandos no protótipo Merkurion. 


\subsection{Merkurion e Histogramas-Omni}

O sistema Merkurion trata especificamente da criação de sinopses unidimensionais para distribuições de distância. No entanto, a criação de estruturas Histogramas-Omni requer, simultaneamente, o tratamento de distribuições de distâncias e dados. Nesse caso, o protótipo Merkurion precisa ser usado de modo a complementar o Espaço de Distribuição de Dados de um otimizador de consultas do SGBD tradicional. O módulo de Espaço de Distribuição de Dados inclui o tratamento de distribuição de dados, além de incluir rotinas para a criação de sinopses sobre estas distribuições, enquanto que o sistema Merkurion permite o tratamento de distribuições de distâncias. Portanto, para construir uma estrutura do tipo Histograma-Omni basta usar os dois sistemas de forma combinada. Em particular, um workflow para implementar essas sinopses/estruturas de indexação para o tratamento de consultas híbridas pode ser construído de acordo com os seguintes passos:

1. Usar o sistema Merkurion para obter a distribuição de distâncias baseadas em pivô.

Para isso é necessário informar o critério de seleção de pivôs como sendo OMNI, a quantidade de elementos a serem usados como pivô $\mathcal{P}$, a restrição de particionamento $\mathcal{R}_{1}$ e a quantidade máxima de faixas $\beta_{1}$. Esse passo equivale as linhas $1-5$ do Algoritmo 3. Por exemplo, no caso da restrição CDH, o comando CREATE SYNOPSIS permite particionar o espaço de busca tal como já apresentado no comando S4. A API do sistema Merkurion permite a construção de Histogramas-Omni usando diversos critérios de escolha de pivô e restrições de particionamento.

2. Listar as faixas obtidas pelo particionamento básico e verificar as tuplas que caem dentro de cada Omni-faixa.

Para isso podem ser usados comandos em SQL estendido ou uma leitura sequencial das tuplas. Para cada uma das Omni-faixas obtém-se uma distribuição de dados diferente, que precisa ser compactada de acordo com uma restrição de particionamento $\mathcal{R}_{2}$ e uma quantidade máxima de faixas $\beta_{2}$. As representações geradas são associadas às respectivas Omni-faixas. Esse passo equivale às linhas 8 - 10 do Algoritmo 3.

3. Armazenar a estrutura do Histograma-Omni.

O armazenamento de Histogramas-Omni pode se valer do Componente de Catálogo para armazenar parte das informações diretamente como relações ou, ainda, armazenar a estrutura de indexação gerada como um arquivo externo. Esse passo equivale às linhas 6-7 do Algoritmo 3.

Note que usar o protótipo Merkurion para a construção de Histogramas-Omni junto com recursos já disponíveis no otimizador de consultas de um SGBD é uma abordagem simbiótica, que permite obter as novas estruturas com o menor acoplamento possível. 


\subsection{Ambiente de Testes}

Nós disponibilizamos a implementação do sistema Merkurion e uma versão de demonstração em um repositório público GitHub ${ }^{2}$. Todas as sinopses e modelos de custo implementados, sejam propostas nossas ou provenientes de métodos revisados da literatura, foram codificados e testados no mesmo framework que usamos para desenvolver o protótipo Merkurion. A linguagem usada para codificação foi a linguagem C++ no ambiente de desenvolvimento Qt 5.2.1 ${ }^{3}$ com o compilador g++ versão 4.9.2. A biblioteca externa de índices de código aberto Arboretum ${ }^{4}$ foi usada para dar suporte ao uso de índices métricos, tanto os baseados em árvore quanto os baseados em tabelas de pivô. Nós usamos a API do protótipo Merkurion para realizar todos os experimentos das Seções 4.2 e 4.4. Também empregamos a API do sistema Merkurion para construir e avaliar os Histograma-Omni cujos resultados estão listados na Seção 5.6. Todos os experimentos foram realizados em uma mesma máquina com a seguinte configuração:

- Processador: Intel Core i7 2.67 GHz.

- Memória: 6 GB RAM.

- Disco: SATA III 7200 RPM.

- Sistema Operacional: Ubuntu 64 bits versão 14.04 LTS.

\subsection{Considerações Finais}

O suporte à otimização de consultas por similaridades em SGBD passa por estender o módulo de 'Espaço de Distribuição de Dados' de forma que ele possa lidar com distribuições de distâncias. Esse capítulo apresentou o protótipo Merkurion, um projeto de otimizador que implementa as sinopses propostas nas seções anteriores além das sinopses da literatura mais significativas, revisadas nesta tese. O sistema Merkurion adota uma arquitetura flexível para lidar com distribuições de pares de distância ou baseadas em pivô. Por exemplo, o protótipo implementa as sinopses Histograma NN, Evento de Busca, CDH e Distance Plot.

Não obstante, a arquitetura empregada permite adicionar novas sinopses na medida em que estas venham a ser desenvolvidas. Além de lidar com distribuições de distância, o sistema também permite obter estimativas de seletividade e de raios para consultas por abrangência e por vizinhança, respectivamente. Estas estimativas são derivadas das sinopses implementadas e podem ser usadas para a otimização lógica e física. No caso da otimização física, o sistema também implementa variações da estratégia de resolução de consultas por vizinhança bf-kNN limitada, a saber, NNH-kNN, Evento-Busca-kNN, CDH-kNN, Fractal-kNN.

2 Link: github.com/marcosivni/merkurion

3 Link: qt.io/

4 Link: bitbucket.org/gbdi/arboretum 
O protótipo Merkurion possui uma API que permite: integrá-lo a um otimizador de consultas de acordo com a conveniência do desenvolvedor do SGBD; ou ainda, usá-lo separadamente por meio de comandos específicos. Foi apresentado um caso de uso sobre o protótipo Merkurion junto ao conjunto de dados real CITIES, onde foi possível construir e visualizar quatro tipos diferentes de sinopses, bem como solicitar estimativas de seletividade e raios. Além disso, destacamos que o protótipo desenvolvido foi usado nas avaliações realizadas nas Seções 4.2, 4.4 e 5.6, cujos resultados permitiram:

1. Escolher a sinopse unidimensional mais adequada para estimativas de seletividade.

2. Escolher a sinopse unidimensional mais adequada para estimativas de raios.

3. Criar e consultar sinopses para obter estimativas de acessos a disco e de cálculos de distância para modelos de custo.

4. Criar e visualizar sinopses sobre distribuições de distância baseadas em pivôs para criar Histogramas-Omni.

O protótipo desenvolvido permite comprovar, de forma experimental, a viabilidade da Hipótese da Extensão por meio da ampliação de diversos módulos de um otimizador de consultas de um SGBD. Não obstante, o sistema não trata de analisar, antes da execução de quaisquer consultas, quando não é possível realizar qualquer tipo de otimização devido à características inerentes ao conjunto de dados e à função de distância. Nesse cenário, o processo de tentar a otimização da consulta em si é uma sobrecarga e pode ser evitado. No próximo capítulo, apresentamos uma discussão sobre esse cenário e um modelo para identificar de antemão estes casos particulares e, assim, evitar o processo de otimização de consultas que seria infrutífero. 


\title{
Um modelo para averiguar quando sinopses não devem ser usadas
}

\author{
"In view of all that we have said in \\ the foregoing sections, the many \\ obstacles we appear to have \\ surmounted, what casts the pall \\ over our victory celebration? It is \\ the curse of dimensionality, a \\ malediction that has plagued the \\ scientist from the earliest days." \\ Richard Bellman - Adaptive \\ control processes: A guided tour
}

Ainda que as estratégias de indexação sejam úteis para otimizar a execução de consultas por similaridade, não são em todas as ocasiões que essas abordagens devem ser usadas para obter um desempenho otimizado na execução da consulta. Para consultas que precisam varrer muitas tuplas, o uso da estratégia SeqScan tende a ser a melhor opção, pois nesse caso um índice tem o efeito colateral de adicionar a sobrecarga de processar sua estrutura interna na busca. Espera-se que o otimizador de consultas seja capaz de apontar essa conclusão após analisar a distribuição de dados ou de distância. Além deste caso, existe também outros dois cenários bem conhecidos associados à buscas por similaridade, quando: (i) usar um índice para a execução de consulta por similaridade sempre tem alta possibilidade de gerar sobrecarga e (ii) a tolerância para estimativas de distancia é tão sensível que mesmo pequenas variações nas previsões podem levar a grandes erros no cálculo de seletividade. Para estes cenários conhecidos, o processo de otimização em si é também uma sobrecarga (uma vez que usa recursos de processamento) e deve ser evitado.

Esses cenários-limite ocorrem quando certas funções de distância, sob determinadas condições, são usadas para medir a distância entre elementos de dados imersos em espaços de alta dimensionalidade. Nesses casos, as distâncias estão tão concentradas em um intervalo de valores que nenhuma diferença significativa pode ser encontrada na distância entre a maioria dos 
elementos armazenados. Na presença deste fenômeno de concentração de distâncias, sabe-se que a distribuição de distância em pares converge para uma única frequência na medida em que a dimensionalidade do espaço de dados aumenta. Portanto, tarefas baseadas em comparações por distância, como indexação e classificação baseada em similaridade, são naturalmente ameaçadas pela concentração de distâncias. De fato, diversos trabalhos sobre as estruturas de indexação, sinopses e modelos de custo revisados apontam como limitação o fato destes métodos não serem aplicáveis à conjuntos de dados de alta dimensão. Na prática, essa restrição afeta diretamente a utilidade dos métodos estudados e propostos, visto que uma parte expressiva de conjuntos de dados obtidos do mundo real é representada em espaços de alta dimensionalidade.

Uma alternativa para evitar o fenômeno de concentração é pré-processar os conjuntos de dados de alta dimensionalidade, usando alguma abordagem existente, para reduzir suas dimensões. Essas abordagens são capazes de reduzir a dimensionalidade original a um valor de dimensões usualmente fixado pelo usuário. No entanto, se este parâmetro não for escolhido adequadamente, a distribuição de distância resultante permanecerá concentrada. Nesse capítulo ${ }^{2}$, apresentamos um modelo para guiar métodos de redução de dimensionalidade escolhidos pelo usuário considerando explicitamente as distribuições de distâncias. O modelo desenvolvido foi concebido para ser usado antes de qualquer fase de otimização ou de construção de índices para prevenir o fenômeno de concentração de distâncias.

\subsection{Referencial teórico para concentração de distâncias}

O estudo de Beyer et al. (1999) foi o pioneiro na caracterização da concentração de distâncias para funções de distância da família Minkowski. O estudo quantifica o fenômeno por meio de uma razão denominada contraste relativo $(C R)$. Os autores mostraram que o valor da razão se torna menor na medida em que a dimensionalidade aumenta. Sejam mindist e maxdist a menor e a maior distância, respectivamente, entre quaisquer elementos de um conjunto de dados. Então, o contraste relativo $C R$ é definido de acordo com a Equação 7.1.

$$
C R=\frac{\text { maxdist }- \text { mindist }}{\text { mindist }}
$$

Se os atributos do conjunto de dados forem independentes e uniformemente distribuídos (i.i.d.), o estudo em Beyer et al. (1999) demonstra, na forma de um teorema, que a probabilidade que os valores de máximo e mínimo sejam próximos converge na medida em que novas dimensões vão sendo acrescentadas. A Equação 7.2 resume o principal resultado em Beyer et al. (1999).

$$
\lim _{d \rightarrow \infty} \operatorname{Prob}(C R \leq \tau)=1,
$$

2 Nós separamos o referencial teórico para a definição de concentração de distâncias em espaços de alta dimensionalidade dos capítulos de revisão bibliográfica 2 e 3 e o apresentamos na Seção 7.1, uma vez que esse referencial teórico está especificamente relacionado à contribuição deste capítulo. 
para qualquer $\tau \in \mathbb{R}_{*}$ sendo que as dimensões adicionadas podem ser uma combinação de distribuições aleatória, uniforme ou normal. As condições de convergência em Beyer et al. (1999) implicam que as dimensões precisam ter certo nível de independência e não serem idênticas. $O$ termo contraste relativo para a razão $C R$ usada em Beyer et al. (1999) foi atribuído nos estudos posteriores de Aggarwal, Hinneburg e Keim (2001), Hinneburg, Aggarwal e Keim (2000), os quais sugerem que essa razão se comporta de forma diferente para os valores distintos de $p$ nas funções $L_{p}$. Considerando apenas dados uniformemente distribuídos, os autores argumentam que as funções $L_{p}$ se concentram de acordo com a constante $d^{(1 / p)-(1 / 2)}$ no caso i.i.d..

Um passo adiante foi dado por Francois, Wertz e Verleysen (2007), onde os autores observam que o contraste relativo não necessariamente aumenta quando o expoente $p$ das funções $L_{p}$ diminui. Além disso, os autores argumentam que mesmo para pequenos valores de contraste relativo, podem existir um número significativo de distâncias entre maxdist e mindist, principalmente quando o conjunto de dados não segue a hipótese i.i.d.. Nesse sentido, o estudo em Francois, Wertz e Verleysen (2007) suaviza a restrição i.i.d. e mostra que a distribuição de distâncias se concentra mesmo quando os atributos não são identicamente distribuídos, desde que os dados do conjunto estejam normalizados. Os autores propõem usar uma nova razão para representar a concentração de distâncias, denominada variância relativa $(V R(\mathcal{T}))$, que depende explicitamente da distribuição de pares de distância $\mathcal{T}$.

Neste capítulo, nós empregamos a mesma razão proposta em Francois, Wertz e Verleysen (2007) com o pequeno ajuste de normalizar também a distribuição de pares de distância $\mathcal{T}$ com relação ao parâmetro da distribuição, i.e. o valor de distância. Para simplificar a notação, denotamos a distribuição normalizada de pares de distância como $\overline{\mathcal{T}}$. O teorema de concentração para a variância relativa no estudo de Francois, Wertz e Verleysen (2007) pode ser escrito em função de $\overline{\mathcal{T}}$ como no Teorema 1 :

Teorema 1. [Concentração de distâncias - Adaptado de Francois, Wertz e Verleysen (2007)] Seja $\overline{\mathcal{T}}$ uma distribuição de pares de distância de um conjunto de dados sujeito às condições de convergência em Beyer et al. (1999) (atributos não são idênticos e com certo nível de independência). Então,

$$
\lim _{d \rightarrow \infty} \operatorname{VR}(\overline{\mathcal{T}})=0, \text { onde } \operatorname{VR}(\overline{\mathcal{T}})=\frac{\sigma(\overline{\mathcal{T}})}{\mu(\overline{\mathcal{T}})}
$$

sendo que $\sigma(\overline{\mathcal{T}})$ e $\mu(\overline{\mathcal{T}})$ são o desvio padrão e a média das distâncias em $\overline{\mathcal{T}}$, respectivamente.

De acordo com o Teorema 1, a variância relativa vai à zero na medida em que a dimensionalidade aumenta. Para ilustrar essa afirmação, a Figura 43 mostra a distribuição $\overline{\mathcal{T}}$ para a métrica $L_{2}$ considerando dois conjuntos de dados e variando suas dimensionalidades. $\mathrm{O}$ primeiro conjunto de dados, SYNTHETIC, é sintético e possui atributos i.i.d. obtidos no intervalo $[0,1]$, enquanto que o segundo conjunto de dados, AMAZON2, é um conjunto de dados real com 


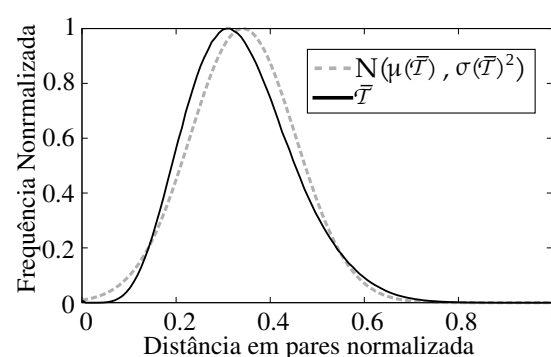

(a) $d=2$

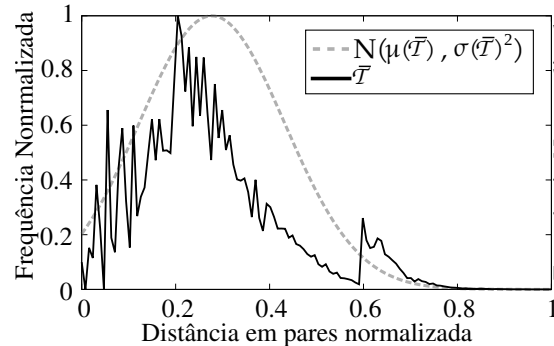

(d) $d=2$

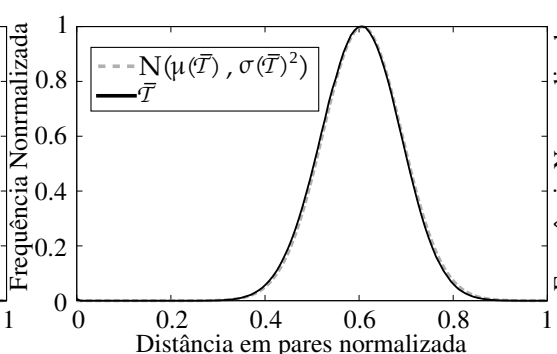

(b) $d=32$

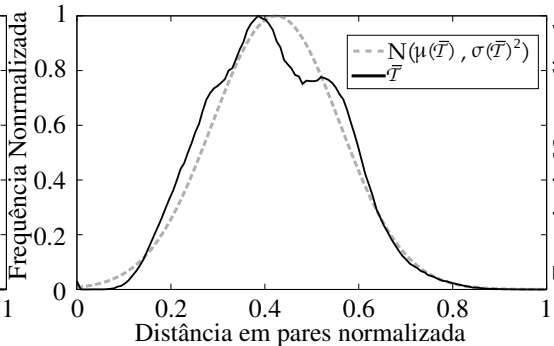

(e) $d=32$

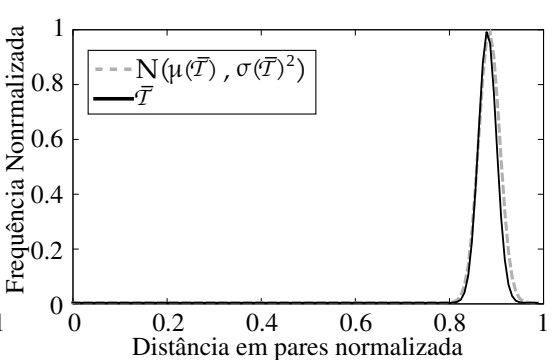

(c) $d=1500$

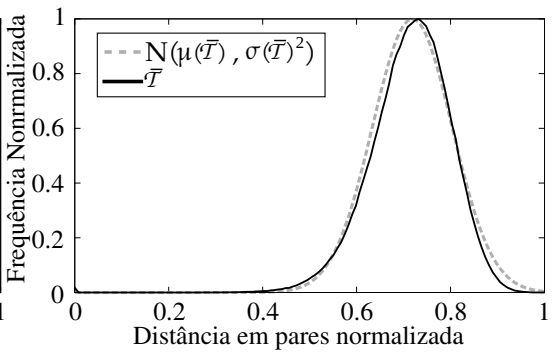

(f) $d=1500$

Figura 43 - Variância relativa para um conjunto de dados sintético e um conjunto de dados real. (a - c) Conjunto de dados SYNTHETIC. $(\mathrm{d}-\mathrm{f})$ Conjunto de dados AMAZON2.

1500 dimensões ${ }^{3}$. As Figuras 43(a - c) mostram a distribuição $\overline{\mathcal{T}}$ para dimensões inseridas segundo uma distribuição uniforme no conjunto de dados sintético, enquanto que as Figuras 43(d - f) apresentam a distribuição $\overline{\mathcal{T}}$ calculada para o conjunto AMAZON2 após a redução de dimensionalidade realizada pelo redutor FastMap (FALOUTSOS; LIN, 1995).

Note que as distâncias se concentram rapidamente sobre a hipótese i.i.d., enquanto que as correlações (ou dependências) entre os atributos podem ser usadas para combater a concentração no conjunto de dados real, ou seja, as distâncias parecem se "desconcentrar" mais lentamente na medida em que o FastMap reduz o número de dimensões. A Figura 43 apresenta um efeito capturado implicitamente pelo Teorema 1, no qual a distribuição de pares de distância $\overline{\mathcal{T}}$ é bem aproximada por uma distribuição Normal com parâmetros $N(\mu(\overline{\mathcal{T}}), \sigma(\overline{\mathcal{T}}))$ para dimensionalidades que sejam grandes o suficiente.

Esse resultado está em consonância com o estudo de Durrant e Kabán (2009), que discute uma caracterização assintótica para a concentração de distâncias usando as duas razões: contraste relativo e variância relativa. Embora essa caracterização assintótica reforce as garantias de convergência para $V R(\overline{\mathcal{T}})$, ela é insuficiente para apontar qual deve ser o valor da dimensionalidade para um conjunto real no qual as distâncias podem ser consideradas concentradas o suficiente, pois a quantidade de dimensões não é infinita na prática. Nesse sentido, outro ingrediente precisa ser, necessariamente, adicionado à esta receita: um método de redução de dimensionalidade $\phi(d, \mathcal{S})$, a ser escolhido pelas aplicações que usam o conjunto de dados.

A maioria dos métodos redutores, como a Análise de Componentes Principais (PCA) (PEARSON, 1901), também se beneficia da correlação entre os atributos e, involuntariamente, estão cientes do problema de concentração de distâncias (KABáN, 2011). No entanto, cada método

\footnotetext{
3 Mais detalhes sobre os conjuntos de dados estão disponíveis no Apêndice B.
} 
redutor segue seu próprio viés no sentido de possuir uma função objetivo a ser maximizada/minimizada e, consequentemente, eles não consideram a concentração de distâncias antes, durante ou depois da redução (PERES-NETO; JACKSON; SOMERS, 2005; CUNNINGHAM; GHAHRAMANI, 2015). Portanto, esses métodos não podem ser usados como soluções únicas e independentes para combater o fenômeno da concentração de distâncias. Paralelamente, algumas propostas têm procurado quantificar a concentração por meio de índices, rankings e teste de hipóteses (FRANCE; CARROLL, 2009; HSU; CHEN, 2008; KABÁN, 2012) sem levar em consideração o viés do método de redução de dimensionalidade, que varia caso a caso.

Com essas ponderações, argumentamos que uma solução geral para combater o fenômeno de concentração de distância requer o manejo de dois recursos: (i) a distribuição de pares de distância (que implicitamente captura o comportamento da função de distância empregada), e (ii) o método redutor de dimensionalidade (que implicitamente captura a estrutura entre os valores dos atributos de acordo com seu viés de redução). A solução que perseguimos neste capítulo é um modelo que usa explicitamente a variância relativa derivada da distribuição de distância para guiar o método redutor acoplado.

Nossa abordagem, denominada RVRM, um acrônimo para o inglês Relative Variance Reduction Model (Modelo de Redução por Variância Relativa, em português) segue as indicações dos estudos de Francois, Wertz e Verleysen (2007), Kabán (2012), Cunningham e Ghahramani (2015) e usa explicitamente a variância relativa como parte de uma função objetivo para guiar um método redutor acoplado, resultando em uma estratégia do tipo wrapper. Além da variância relativa, os seguintes conceitos também são usados na criação do modelo RVRM:

- Dimensão de imersão: A dimensão de imersão, denotada por $\mathcal{E}$, se refere a dimensionalidade usada para representar o conjunto de dados originalmente.

- Dimensão intrínseca: Embora existam diversos contextos nos quais o termo "dimensionalidade intrínseca" seja aplicável (TRAINA JR.; TRAINA; FALOUTSOS, 2000; KORN; MUTHUKRISHNAN, 2000; PESTOV, 2000; PESTOV, 2012; NAVARRO et al., 2017), usamos o termo dimensão intrínseca, denotada por $\mathcal{D}$, para nos referirmos ao número mínimo de dimensões nos quais os elementos do conjunto ainda possam ser identificados. Conceitualmente, se todas as dimensões de um conjunto de dados forem independentes, a dimensionalidade intrínseca é a dimensão de imersão.

Assim como diversas definições, existem também diversos métodos para calcular a dimensionalidade intrínseca. Por assumirmos $\mathcal{D}$ como a menor quantidade de dimensões, ao procurarmos pela dimensão intrínseca em um conjunto de dados, usaremos o método do "expoente de distância" calculado pela sinopse Distance Plot que, na prática, costuma obter valores de dimensionalidade baixos, tal como nos experimentos descritos em Traina Jr. et al. (2000), Korn e Muthukrishnan (2000), Navarro et al. (2017). 


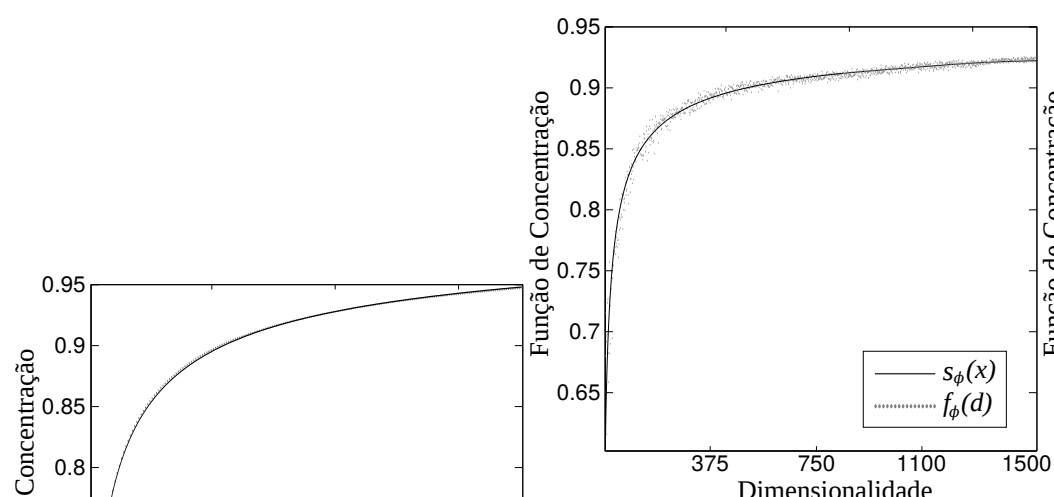

(b)

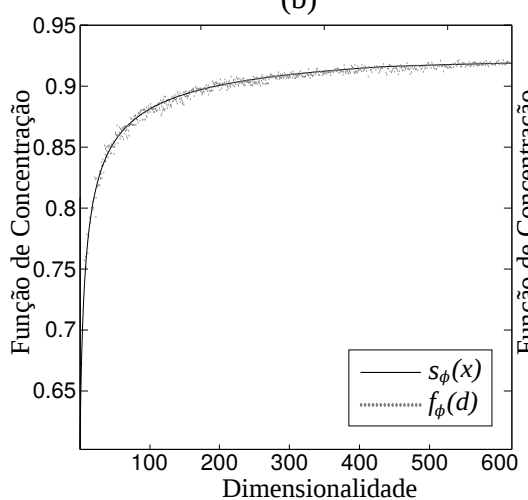

(d)

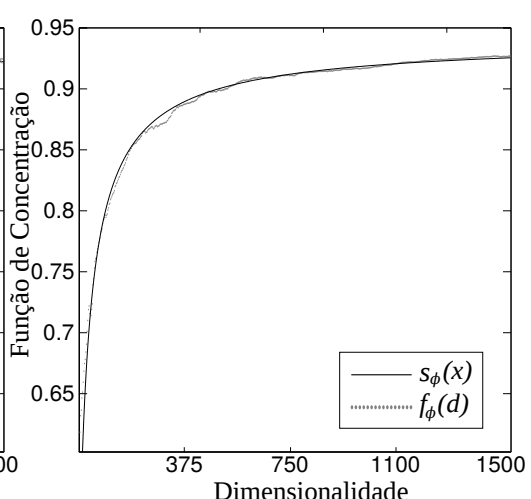

(c)

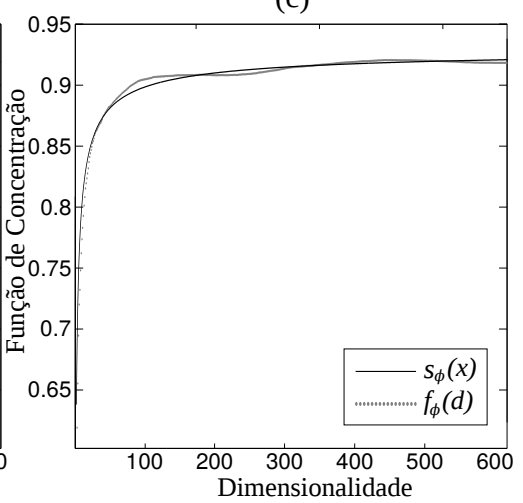

(e)

Figura 44 - Função de concentração para métrica $L_{2}$ com relação à um conjunto de dados sintético e dois conjuntos reais com diferentes dimensionalidades e distintos métodos de redução de dimensionalidade. As distâncias estão mais concentradas para os valores mais altos da função de concentração. (a) Conjunto SYNTHETIC com dimensões obtidas de uma distribuição uniforme em um hiper-cubo unitário.. (b) Conjunto AMAZON2 reduzido por FastMap. (c) Conjunto AMAZON2 reduzido por PCA. (d) Conjunto ISOLET reduzido por FastMap. (e) Conjunto ISOLET reduzido por PCA.

Destacamos que o objetivo do modelo RVRM é examinar um complemento para o conceito da dimensão intrínseca, ou seja, dado um redutor acoplado $\phi(d, \mathcal{S})$ procuramos encontrar o número máximo de dimensões até onde a concentração é evitada e os elementos do conjunto de dados permanecem propriamente caracterizados. Denominamos o número limiar de dimensões que satisfazem essas condições como a dimensão de concentração e a denotamos por $\mathcal{C}_{\phi}$.

\subsection{Modelo RVRM para concentração de distâncias}

Diferentes métodos aplicam distintas estratégias de redução de dimensionalidade, a depender do viés do redutor. Nossa observação é que esse viés pode afetar a concentração de formas diferentes. Portanto, nós propomos uma função de concentração $f_{\phi}(d)$ discretizada para cada valor de $d$ que permita modelar a concentração para um conjunto de dados $\mathcal{S}$ de acordo com o redutor acoplado $\phi(d, \mathcal{S})$ como na Equação 7.4 .

$$
f_{\phi}(d)=e^{-V R(\overline{\mathcal{T}})}
$$

onde $d=1,2, \ldots, \mathcal{E}, d \in \mathbb{N}$ é um valor de dimensionalidade qualquer. O uso da função 
exponencial limita a função $f_{\phi}(d)$ ao intervalo $(0,1]$, sendo que os valores de $f_{\phi}(d)$ próximos a 0 implicam em baixa concentração e os valores $f_{\phi}(d)$ próximos a 1 indicam alta concentração de distâncias. O Teorema 1 fornece as garantias de convergência para $f_{\phi}(d)$ uma vez que a função de concentração depende exclusivamente da variância relativa $\operatorname{VR}(\overline{\mathcal{T}})$.

A Figura 44 apresenta exemplos de funções de concentração para um conjunto de dados sintético e dois conjuntos de dados reais, onde $f_{\phi}(d)$ foi calculada para cada uma das dimensões $d \in[1, \mathcal{E}]$. A Figura 44(a) apresenta os valores de $f_{\phi}(d)$ para o conjunto de dados SYNTHETIC, cujos atributos são obtidos por uma distribuição uniforme definida no intervalo $[0,1]$. Como esperado, nesse caso bem controlado, onde se garante a i.i.d., a concentração aumenta rapidamente e atinge o valor de 0,9 para menos de 150 dimensões.

Por outro lado, as Figuras 44(b-e) mostram o comportamento de $f_{\phi}(d)$ para conjuntos de dados reais cujas dimensionalidades foram reduzidas pelos métodos FastMap e PCA. Outros detalhes sobre esses conjuntos de dados se encontram no Apêndice B. As Figuras 44(b-c) mostram o comportamento da função de concentração para o conjunto de dados AMAZON2, onde o redutor PCA permite desconcentrar distâncias mais rapidamente do que quando é usado o método FastMap. As Figuras 44(d - e) apresentam o comportamento da função de concentração de distância quando os mesmos redutores (PCA e FastMap) são usados no conjunto de dados ISOLET. No caso desse conjunto de dados, o método FastMap foi capaz de desconcentrar as distâncias mais rapidamente do que a estratégia PCA. Esses dois resultados diferentes para os dois conjuntos de dados analisados reforçam a nossa observação de que o viés do redutor impacta a concentração, em níveis diferentes, para cada conjunto real a ser analisado.

Além disso, ao contrário do comportamento observado para o caso i.i.d. artificial, os valores de concentração nos conjuntos reais não decresce monotonicamente quando as dimensões são reduzidas. Adicionalmente, a concentração parece decrescer em ritmo diferente para distintos intervalos de dimensões a depender do redutor empregado. Por exemplo, as primeiras 50 dimensões do conjunto de dados SYNTHETIC induzem um rápido crescimento na função de concentração, enquanto que as últimas 100 dimensões promovem apenas um aumento mínimo nos valores de $f_{\phi}(d)$. Em contraste, os valores de concentração do AMAZON2 reduzidos pelo PCA e FastMap não são sempre crescentes, mas a convergência se torna mais clara para dimensões maiores que 375. O mesmo comportamento é observado no conjunto de dados ISOLET, mas para um distinto intervalo de dimensões.

A premissa aqui é que os valores de $f_{\phi}(d)$ podem ser diretamente usados como um guia para determinar o número máximo de dimensões na redução, sendo que o viés do redutor acoplado é implicitamente levado em consideração. A ideia é definir um modelo que emprega $f_{\phi}(d)$ para delimitar o intervalo de dimensões no qual a saída do método acoplado não está concentrado o suficiente. A maior vantagem dessa abordagem é que ela possibilita que o redutor tenha ciência explícita da concentração ao mesmo tempo em que o viés da redução é mantido. 


\subsubsection{A função de concentração contínua}

A função de concentração $f_{\phi}(d)$ não é necessariamente monotônica com relação à redução realizada por $\phi(d, \mathcal{S})$ e não é contínua em $\mathbb{R}$. Com o objetivo de representar essa função discretizada em um domínio real, nós propomos a aproximação de $f_{\phi}(d)$ por uma função sigmoide logística $s_{\phi}(x)$ como expresso na Equação 7.5.

$$
s_{\phi}(x)=\left(\frac{1}{1+e^{-\left(\lambda_{0}+\lambda_{1} x\right)}}\right) \cdot L \approx f_{\phi}(d)
$$

onde $L$ é o limite superior de $f_{\phi}(d), \lambda_{0}$ e $\lambda_{1}$ são constantes reais e $x=\ln (d)$, onde $d$ é uma dimensionalidade arbitrária. Dessa forma, os valores de $\lambda_{0}$ e $\lambda_{1}$ podem ser determinados por meio de uma aproximação por mínimos quadrados como detalhado na Equação 7.6.

$$
y=\ln \left(\frac{f_{\phi}(d)}{L-f_{\phi}(d)}\right) \approx \lambda_{0}+\lambda_{1} x
$$

Essa equação pode ser resumida por um sistema linear que depende dos valores coletados a partir da função de concentração $f_{\phi}(d)$. Seja $\left\langle x_{d}, y_{d}\right\rangle=\left\langle\ln (d), f_{\phi}(d) /\left(L-f_{\phi}(d)\right)\right\rangle$ os pontos de dimensionalidade e da função de concentração calculados para um conjunto de dimensões $d \in D$, o sistema linear para a aproximação de $s_{\phi}(x)$ por $f_{\phi}(d)$ é dado na Equação 7.7.

$$
\left[\begin{array}{cc}
\sum_{d \in D} 1 & \sum_{d \in D} x_{d} \\
\sum_{d \in D} x_{d} & \sum_{d \in D} x_{d}^{2}
\end{array}\right]\left[\begin{array}{c}
\lambda_{0} \\
\lambda_{1}
\end{array}\right]=\left[\begin{array}{c}
\sum_{d \in D} y_{d} \\
\sum_{d \in D} x_{d} y_{d}
\end{array}\right]
$$

O último parâmetro da Equação 7.5 a ser calculado é o limite $L$ de $s_{\phi}(x)$. Embora o Teorema 1 forneça garantias de convergência para infinitas dimensões, em casos práticos o que se observa é que a função $f_{\phi}(d)$ converge para valores próximos a 1 quando a dimensionalidade é alta, porém finita. Portanto, o limite de convergência $L$ precisa ser estimado para conjuntos reais de dados de alta dimensionalidade. Para obter essa estimativa, nós recorremos novamente ao estudo de Francois, Wertz e Verleysen (2007), onde os autores argumentam que a variância relativa deve seguir a assíntota de $1 /(\sqrt{d} \cdot p)$ quando $d$ é grande o suficiente. Dessa forma, propomos uma função $g_{\phi}(x)$ para generalizar a assíntota $1 /(\sqrt{d} \cdot p)$ com medidas reais de onde pode ser estimado o limite de convergência $L$ quando $\lim _{d \rightarrow \infty} g_{\phi}(x)=L$. A função de generalização $g_{\phi}(x)$ é definida tal como na Equação 7.8 .

$$
g_{\phi}(x)=L+\frac{\lambda_{3}}{x-\lambda_{4}} \approx f_{\phi}(d)
$$

onde $x=\sqrt{d}$ e $\lambda_{3}$ e $\lambda_{4}$ são constantes reais. Ao substituirmos $\lambda_{5}=\lambda_{3}-\left(L \cdot \lambda_{4}\right)$ e $y=f_{\phi}(d)$, 
podemos reescrever a Equação 7.8 como a Equação 7.9.

$$
L \cdot x+\lambda_{4} \cdot y+\lambda_{5} \approx x \cdot y
$$

de forma que as constantes $L, \lambda_{4}$ e $\lambda_{5}$ podem ser obtidas empregando um raciocínio de aproximação por quadrados mínimos similar ao do Sistema 7.7. Dados os pontos $\left\langle x_{d}, y_{d}\right\rangle=\left\langle\sqrt{d}, f_{\phi}(d)\right\rangle$ calculados a partir de um conjunto de dimensões $d \in D$, o valor de $L$ é obtido a partir da resolução do sistema mostrado na Equação 7.10.

$$
\left[\begin{array}{ccc}
\sum_{d \in D} x_{d} & \sum_{d \in D} y_{d} & \sum_{d \in D} 1 \\
\sum_{d \in D} x_{d}^{2} & \sum_{d \in D} x_{d} y_{d} & \sum_{d \in D} x_{d} \\
\sum_{d \in D} x_{d} y_{d} & \sum_{d \in D} y_{d}^{2} & \sum_{d \in D} y_{d}
\end{array}\right]\left[\begin{array}{c}
L \\
\lambda_{4} \\
\lambda_{5}
\end{array}\right]=\left[\begin{array}{c}
\sum_{d \in D} x_{d} y_{d} \\
\sum_{d \in D} x_{d}^{2} y_{d} \\
\sum_{d \in D} x_{d} y_{d}^{2}
\end{array}\right]
$$

A função $g_{\phi}(x)$ é construída para obter o limite de convergência $L$, mas também é uma aproximação de $f_{\phi}(d)$. Argumentamos que a função $s_{\phi}(x)$ é mais adequada do que $g_{\phi}(x)$ para aproximar $f_{\phi}(d)$, pois é mais estável no sentido de não incluir nenhum ponto de descontinuidade no intervalo de dimensões analisado na prática $[1, \mathcal{E}]$. Dessa maneira, propomos obter o limite $L$ a partir de $g_{\phi}(x)$ e usá-lo para a construção da função de concentração contínua $s_{\phi}(x)$ como uma aproximação de $f_{\phi}(d)$. As Figuras $44(\mathrm{a}-\mathrm{e})$ apresentam a função $s_{\phi}(x)$ obtida a partir de $f_{\phi}(d)$ e com o limite calculado por $g_{\phi}(x)$ para os conjuntos de dados SYNTHETIC, AMAZON2 e ISOLET com os redutores FastMap e PCA.

Por último, mas não menos importante, precisamos definir o número de dimensões necessárias para aproximar $f_{\phi}(d)$ por $s_{\phi}(x)$. Naturalmente o erro quadrático de se aproximar $f_{\phi}(d)$ por $s_{\phi}(x)$ quando todas as medidas no intervalo $[1, \mathcal{E}]$ estão disponíveis, i.e. $D=D_{1}$, $D_{1}=\{d \mid 1 \leq d \leq \mathcal{E}, d \in \mathbb{N}\}$, será o mínimo, uma vez que o método de aproximação usado segue o viés dos mínimos quadrados. No entanto, heuristicamente, um erro pequeno também pode ser obtido com uma quantidade muito menor de medidas. Os exemplos nas Figuras 44(a-e) mostram que os pontos que mais inflexionam a curva são os das primeiras dimensões e não os das últimas. Portanto, propomos usar mais dimensões do primeiro trecho da curva e menos dimensões do final, de forma que $D=D_{2}, D_{2}=\left\{d \mid d=2^{l}, \mathcal{D} \leq 2^{l} \leq \mathcal{E}, l \in \mathbb{N}\right\}$, o que permite reduzir os custos de processamento do modelo. A Seção 7.3.1 fornece uma análise empírica sobre a aproximação de $f_{\phi}(d)$ por $s_{\phi}(x)$ quando o conjunto reduzido de dimensões $D_{2}$ é usado.

\subsubsection{Limitando o intervalo de concentração}

Embora seja possível obter uma boa aproximação de $f_{\phi}(d)$ por $s_{\phi}(x)$ com poucos pontos de controle, a função de concentração em si não determina um "ponto de corte" onde o comportamento da concentração muda abruptamente. Essa observação é facilmente verificável 
uma vez que a derivada $s_{\phi}^{\prime}(x)$ não tem um ponto de inflexão no intervalo $[\mathcal{D}, \mathcal{E}]^{4}$. Por outro lado, é observável nos exemplos das Figuras 44 que existe um intervalo de dimensões para os quais a distância entre pares se torna saturada. Propomos limitar esse intervalo de dimensões baseado na área sob a curva gerada pela função $s_{\phi}(x)$ e também por inspecionar o impacto de se remover cada dimensão ao se considerar toda a área da curva gerada por $s_{\phi}(x)$. A ideia é limitar a probabilidade de se incluir as dimensões $d$ que estejam fora da razão entre as áreas acumuladas de $s_{\phi}(x)$ de acordo com um dado nível de confiança $\alpha$. Uma função de área $a_{\phi}(x)$ baseada na função de concentração contínua pode ser obtida por $a_{\phi}(x)=\int s_{\phi}(x) d x$, sendo que a razão entre a função de área para um dado intervalo de $x$ pode ser normalizada com relação à área total da função de concentração contínua $s_{\phi}(x)$.

A razão de $a_{\phi}(x)$ dividido pela área total sob $s_{\phi}(x)$ fornece uma relação quase linear entre a dimensionalidade e a concentração. No entanto, os gráficos de $s_{\phi}(x)$ indicam que o impacto na concentração para as primeiras dimensões reduzidas é muito menor do que para as últimas reduções, o que implica que o impacto gradual das dimensões reduzidas na concentração não é linear. Nesse sentido, nós empregamos a função acumulada de área $A_{\phi}(x)$, i.e. a primitiva para $a_{\phi}(x)$, para que seja possível ponderar o impacto de reduzir uma dimensão $d_{l}$ considerando o contexto do intervalo $\left[d_{l}+1, \mathcal{E}\right]$. Para essa ponderação, empregamos a razão $r_{\phi}\left(x_{d}\right)$ na comparação dos intervalos de dimensões reduzidos de acordo com a Equação 7.10.

$$
r_{\phi}\left(x_{d}\right)=\frac{\int_{x_{(\mathcal{E}-d)}}^{x_{\mathcal{E}}} a_{\phi}(x) d x}{\int_{x_{\mathcal{D}}}^{x_{\mathcal{E}}} a_{\phi}(x) d x}
$$

onde $x_{(\mathcal{E}-d)}$ é o limite da integral com relação à um dado número de dimensões reduzidas. Portanto, balizar a comparação entre as áreas acumuladas depende de encontrar uma dimensão de concentração $d=\mathcal{C}_{\phi}, \mathcal{C}_{\phi} \leq \mathcal{E}-\mathcal{D}$ em relação à um dado intervalo de confiança $I C=1-\alpha$. A razão $r_{\phi}\left(x_{\mathcal{C}_{\phi}}\right)$ está dentro do intervalo de confiança $I C$ se $(1-\alpha) \leq\left(1-r_{\phi}\left(x_{\mathcal{C}_{\phi}}\right)\right)$, tal como detalhado na Equação 7.12.

$$
\begin{aligned}
(1-\alpha) & \leq \frac{A_{\phi}\left(x_{\mathcal{E}}\right)-A_{\phi}\left(x_{\mathcal{D}}\right)-\left[A_{\phi}\left(x_{\mathcal{E}}\right)-A_{\phi}\left(x_{\left(\mathcal{E}-\mathcal{C}_{\phi}\right)}\right)\right]}{A_{\phi}\left(x_{\mathcal{E}}\right)-A_{\phi}\left(x_{\mathcal{D}}\right)}, \\
\alpha & \geq \frac{L i_{2}\left(-e^{\lambda_{0}+\lambda_{1}\left(x_{\left(\mathcal{E}-\mathcal{C}_{\phi}\right)}\right)}\right)-L i_{2}\left(-e^{\lambda_{0}+\lambda_{1} x_{\mathcal{E}}}\right)}{L i_{2}\left(-e^{\lambda_{0}+\lambda_{1} x_{\mathcal{D}}}\right)-L i_{2}\left(-e^{\lambda_{0}+\lambda_{1} x_{\mathcal{E}}}\right)},
\end{aligned}
$$

onde $A_{\phi}(x)$ é expressa em termos da função $L i_{2}$, conhecida como função de Spence (MORRIS, 1979). Nesse ponto, podemos substituir de volta os valores originais das dimensões $x_{d}=\ln (d)$

4 De acordo com as definições adotadas, não faz sentido prático reduzir mais dimensões do que a quantidade indicada pela dimensionalidade intrínseca $\mathcal{D}$. Sem perda de generalidade, basta usar $\mathcal{D}=1$ para obter a dimensão de concentração sempre que a dimensionalidade intrínseca do conjunto de dados for desconhecida. 
na expressão da Equação 7.12, o que resulta na Equação 7.13.

$$
\begin{aligned}
L i_{2}\left(-e^{\lambda_{0}}\left(\mathcal{E}-\mathcal{C}_{\phi}\right)^{\lambda_{1}}\right) \leq & \alpha\left(L i_{2}\left(-e^{\lambda_{0}} \mathcal{D}^{\lambda_{1}}\right)-L i_{2}\left(-e^{\lambda_{0}} \mathcal{E}^{\lambda_{1}}\right)\right)+ \\
& L i_{2}\left(-e^{\lambda_{0}} \mathcal{E}^{\lambda_{1}}\right)
\end{aligned}
$$

onde as constantes podem ser agrupadas e renomeadas. Seja $\lambda_{6}=-e^{\lambda_{0}}, \lambda_{7}=\lambda_{6} \cdot \mathcal{E}^{\lambda_{1}}, \lambda_{8}=$ $\lambda_{6} \cdot \mathcal{D}^{\lambda_{1}}, \lambda_{9}=L i_{2}\left(\lambda_{7}\right)$ e $\lambda_{10}=L i_{2}\left(\lambda_{8}\right)-L i_{2}\left(\lambda_{7}\right)$. Então, a Equação 7.13 pode ser reescrita em termos de uma função delimitadora $b_{\phi}(\alpha)$ expressa na Equação 7.14.

$$
\begin{aligned}
& b_{\phi}(\alpha) \geq \operatorname{Li}_{2}\left(\lambda_{6} \cdot\left(\mathcal{E}-\mathcal{C}_{\phi}\right)^{\lambda_{1}}\right) \\
& b_{\phi}(\alpha)=\lambda_{10} \cdot \alpha+\lambda_{9}
\end{aligned}
$$

sendo que $b_{\phi}(\alpha)$ limita o número de dimensões para $\mathcal{C}_{\phi}$ de acordo com $\alpha$. Repare que, embora $L i_{2}^{-1}$ não possa ser expressa em termos de uma função analítica, a inversa ainda pode ser obtida por uma abordagem numérica, uma vez que $L i_{2}$ é contínua e derivável no intervalo $[\mathcal{D}, \mathcal{E}]$. Portanto, um método numérico, como o de Newton-Raphson, pode ser empregado para resolver a Inequação 7.14 e determinar $\mathcal{C}_{\phi}$ de acordo com um nível de confiança $\alpha$.

A Figura 45 mostra o comportamento da concentração de distâncias e da função delimitadora para o conjunto de dados ISOLET com os redutores FastMap e PCA. A Figura 45(a) mostra que os valores de $s_{\phi}(x)$ aumentam rapidamente nas duas reduções, mas o redutor FastMap obtém valores de $s_{\phi}(x)$ menores para as primeiras dimensões na comparação com a redução PCA. A Figura 45(b) ilustra que a função delimitadora $b_{\phi}(\alpha)$ captura o comportamento da concentração como uma curva de saturação para cada redução, sendo que a dimensionalidade de concentração depende do intervalo de dimensões reduzidas anteriormente.

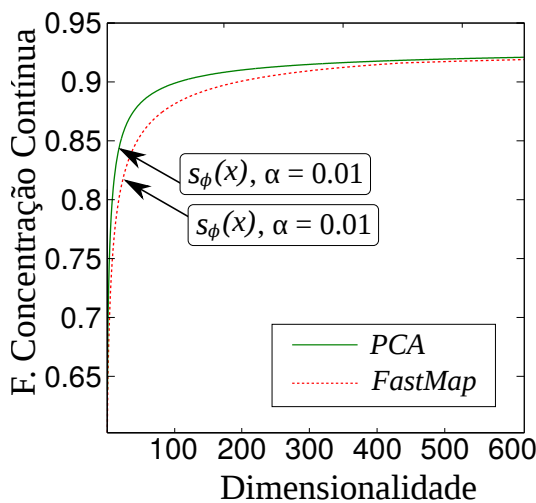

(a)

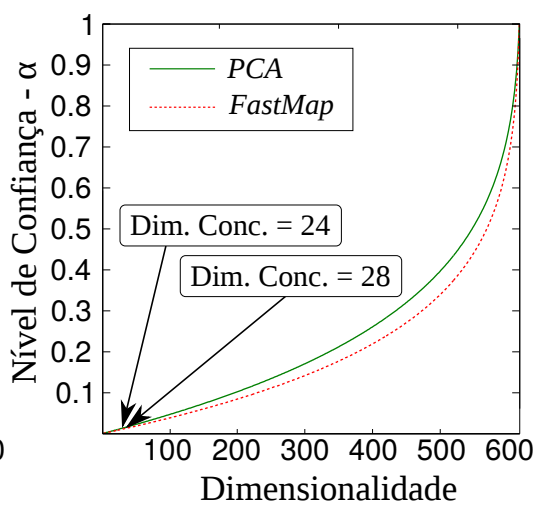

(b)

Figura 45 - Dimensionalidade de concentração $\mathcal{C}_{\phi}$ para valores distintos de $\alpha$ com relação à dois diferentes redutores acoplados PCA e FastMap. (a) Função $s_{\phi}(x)$ sobre o conjunto de dados ISOLET. (b) Função delimitadora $b_{\phi}(\alpha)$ sobre o conjunto de dados ISOLET com relação a todos os valores no intervalo de confiança.

Nesse cenário, para um nível de confiança de $\alpha=0.01$, a dimensionalidade de concentração para o conjunto de dados ISOLET com redutor PCA é limitado por 24 dimensões, enquanto 
que com o redutor FastMap esse limite sobe até 28 dimensões. Esses valores de dimensionalidade refletem o fato que a variância relativa pela redução PCA converge mais rapidamente do que quando o redutor FastMap é usado. Consequentemente, a dimensão de concentração para o redutor PCA é menor do que a do redutor FastMap para o mesmo nível de concentração. Repare que uma pequena variação do intervalo de níveis de confiança, i.e. $\alpha \leq 0.1$, cobre a maior parte das dimensões onde a concentração tem maior chance de não estar saturada.

\subsubsection{Modelo de Redução por Variância Relativa}

O Modelo de Redução por Variância Relativa (RVRM) pode ser visto como uma única rotina de integração, que depende tanto da função de concentração contínua quanto da função delimitadora. Portanto, dado um conjunto de dados $\mathcal{S}$ e um redutor escolhido pelo usuário $\phi(d, \mathcal{S})$, o modelo RVRM retorna o conjunto de dados $\mathcal{S}_{\mathcal{D}+\mathcal{C}_{\phi}}$ reduzido a uma dimensionalidade de concentração limite para um nível de confiança fixado $\alpha$. O Algoritmo 5 descreve os passos realizados pelo modelo RVRM. Primeiro, nosso modelo delimita o conjunto de dimensões $d$ que compõem os pontos de controle para a aproximação de $f_{\phi}(d)$ por $g_{\phi}(x)$ e $s_{\phi}(x)$. Para cada dimensão $d \in D$, o modelo RVRM reduz a dimensionalidade por meio do redutor $\phi(d, \mathcal{S})$, gerando o conjunto de dados com dimensões reduzidas $\mathcal{S}_{d}$.

O Algoritmo 5 coleta a distribuição de pares de distância $\overline{\mathcal{T}}$ para $\mathcal{S}_{d}$ e calcula o valor da variância relativa $R V(\overline{\mathcal{T}})$, que é o parâmetro da função de concentração $f_{\phi}(d)$. O modelo RVRM emprega os pontos transformado $\langle\sqrt{d}, f(d)\rangle$ para resolver o Sistema 7.10 e encontrar o limite $L$. Na sequência, o modelo aproxima a função de concentração $f_{\phi}(d)$ por uma função

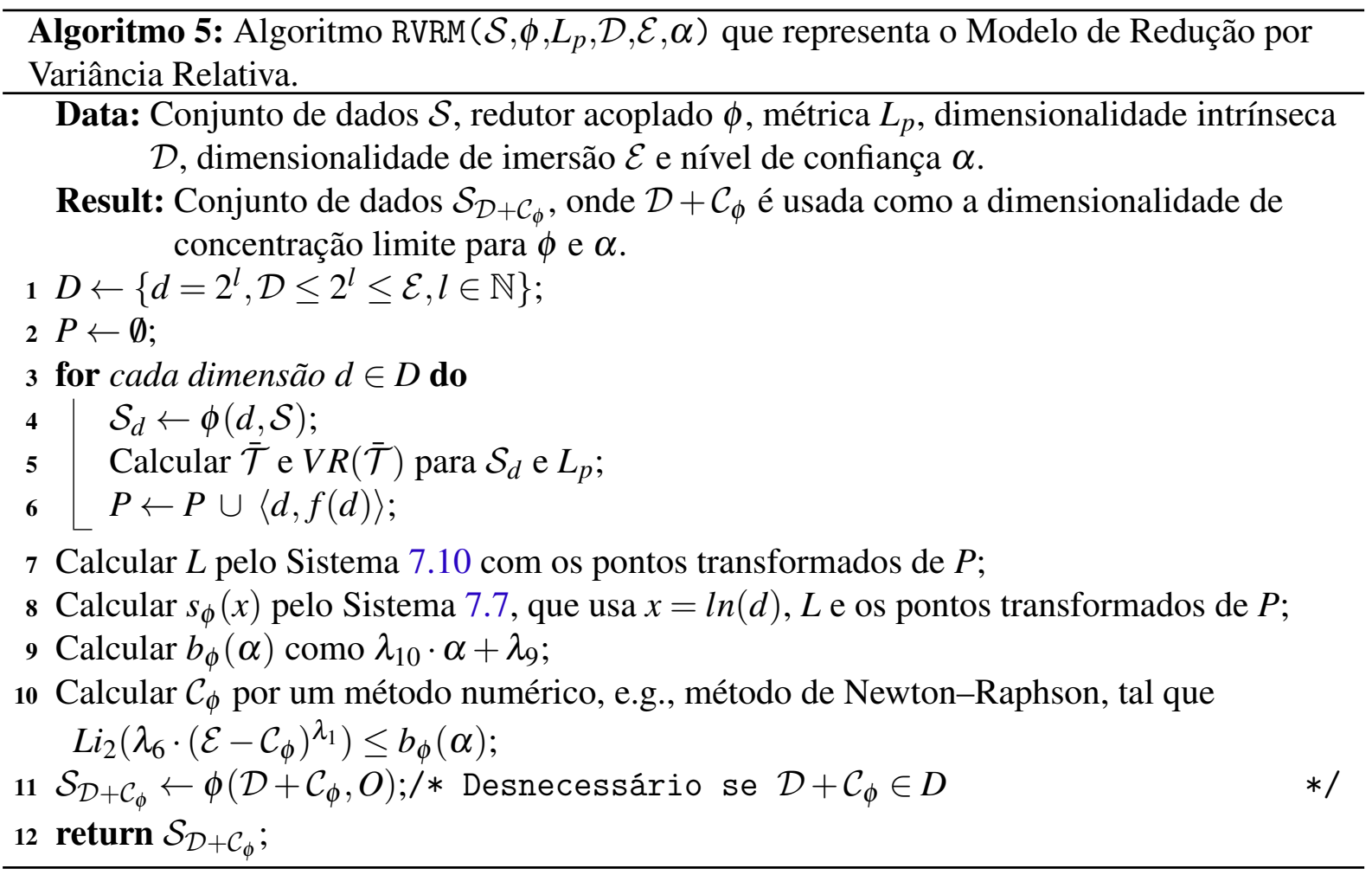


sigmoide logística $s_{\phi}(x)$ de acordo com o Sistema 7.7 por meio dos pontos transformados $\left\langle\ln (d), f_{\phi}(d) /\left(L-f_{\phi}(d)\right)\right\rangle$. A manipulação da função de concentração como $s_{\phi}(x)$ permite detectar a concentração por meio da razão $r_{\phi}\left(x_{d}\right)$. Portanto, dado um nível de confiança $\alpha$, o modelo RVRM calcula o valor da função delimitadora $b_{\phi}(\alpha)$. Essa função é usada para determinar a dimensão de concentração $\mathcal{C}_{\phi}$, tal que $L i_{2}\left(\lambda_{6} \cdot\left(\mathcal{E}-\mathcal{C}_{\phi}\right)^{\lambda_{1}}\right) \leq b_{\phi}(\alpha)$, onde $\mathcal{C}_{\phi}$ é encontrado pelo método Newton-Raphson. Finalmente, o modelo RVRM reduz a dimensionalidade de $\mathcal{S}$ por meio do redutor acoplado $\phi(d, \mathcal{S})$ e retorna o conjunto de dados $\mathcal{S}_{\mathcal{D}+\mathcal{C}_{\phi}}$.

\subsection{Avaliação do modelo RVRM}

Esta seção reporta uma avaliação experimental do modelo RVRM com relação à conjuntos reais de alta dimensionalidade. Após a normalização dos conjuntos de dados, foram realizados dois grupos de experimentos. Primeiro, nós avaliamos empiricamente se a função $s_{\phi}(x)$ é realmente mais adequada para a aproximação de $f_{\phi}(d)$ do que a função $g_{\phi}(x)$ e se algumas poucas dimensões são suficientes para uma boa aproximação de $s_{\phi}(x)$. Na sequência, nós experimentamos o modelo RVRM nas tarefas de classificação e indexação. O objetivo deste experimento é investigar as duas seguintes questões:

1. Qual o impacto do modelo RVRM em tarefas de classificação baseadas em distância? Nós avaliamos se a redução do modelo RVRM pode melhorar a qualidade de classificadores baseados em distância (Instance-based Learning - Ib $k$ ). O procedimento de validação cruzada com 10-folds foi usado para treinar e testar o conjunto de dados nas dimensões: intrínseca, de imersão e de concentração. Os valores de F-Measure foram coletados para um número crescente de vizinhos e usados para comparar o desempenho nos três cenários.

2. Qual o impacto do modelo RVRM na indexação do conjunto de dados? Nós avaliamos se a dimensionalidade de concentração pode prevenir a degeneração de estratégias de indexação na otimização de consultas por vizinhança. Foi aplicado o procedimento de validação cruzada com 10-folds para a indexação e consulta do conjunto de dados nas dimensões de imersão, concentração e intrínseca, sendo que os desempenhos de todos os casos foram comparados com o do procedimento SeqScan.

Em todas as avaliações empíricas, nós usamos $\underline{\alpha=0.01}$ e assim o modelo RVRM empregou um intervalo de confiança de 0.99. A Tabela 9 mostra as principais características de todos os conjuntos de dados avaliados, indicando nome, cardinalidade $(|\mathcal{S}|)$, métrica $\left(L_{p}\right)$, dimensionalidades de imersão $(\mathcal{E})$, concentração $\left(\mathcal{C}_{\phi}\right)$ e intrínseca $(\mathcal{D})$, o valor da média $(\mu(\mathcal{T}))$ e desvio padrão $\sigma(\mathcal{T})$ obtidos para a distribuição de pares de distância considerando a dimensão de imersão, além da quantidade máxima e mínima de instâncias por classe para os conjuntos de dados rotulados (\#Max/Min). Outros detalhes sobre o conjunto de dados podem ser encontradas na Apêndice B e o ambiente de testes é o mesmo descrito na Seção 6.5. Tanto a implementação do modelo RVRM 
Tabela 9 - Conjuntos de dados empregados na avaliação do modelo RVRM.

\begin{tabular}{|l|l|r|r|r|c|c|c|c|c|c|}
\hline Conjunto & $\mathbf{L}_{\mathbf{p}}$ & Cardin. & $\mathcal{E}$ & $\mathcal{D}$ & $\mathcal{D}+\mathcal{C}_{\phi=\mathrm{PCA}}$ & $\mathcal{D}+\mathcal{C}_{\phi=\mathrm{FM}}$ & $\mu(\mathcal{T})$ & $\sigma(\mathcal{T})$ & \#Class & \#Max/Min \\
\hline CNAE & $\mathrm{L}_{2}$ & 1080 & 856 & 5 & 28 & 26 & 2,6 & 0,7 & 9 & 120 \\
\hline GRASDRIFT & $\mathrm{L}_{\infty}$ & 13910 & 128 & 12 & 23 & 23 & 0,33 & 0,19 & 6 & $3009 / 1641$ \\
\hline ISOLET & $\mathrm{L}_{2}$ & 6238 & 617 & 4 & 24 & 28 & 7,7 & 1,33 & 26 & $240 / 238$ \\
\hline MADELON & $\mathrm{L}_{1}$ & 2600 & 500 & 2 & 23 & 48 & 78,2 & 3,3 & 2 & 1300 \\
\hline MAMMOCLEAR & $\mathrm{L}_{2}$ & 3457 & 1111 & 4 & 20 & 42 & 5,09 & 1,06 & 2 & $2005 / 1452$ \\
\hline MFEAT & $\mathrm{L}_{1}$ & 2000 & 649 & 2 & 28 & 23 & 184,6 & 36,9 & 26 & 240 \\
\hline MINIST & $\mathrm{L}_{1}$ & 10000 & 784 & 2 & 28 & 30 & 130,8 & 30,73 & 10 & $1135 / 958$ \\
\hline SEMEION & $\mathrm{L}_{1}$ & 1593 & 256 & 3 & 11 & 11 & 108,7 & 18,48 & 2 & $1435 / 158$ \\
\hline SMARTPRECOG & $\mathrm{L}_{\infty}$ & 7767 & 561 & 7 & 22 & 23 & 0,84 & 0,12 & 12 & $1223 / 23$ \\
\hline TIGER & $\mathrm{L}_{2}$ & 1220 & 230 & 6 & 11 & 12 & 0,57 & 0,44 & 2 & $676 / 544$ \\
\hline \hline FACES & $\mathrm{L}_{1}$ & 1016 & 761 & 2 & 49 & 40 & 108,4 & 9,09 & N/A & N/A \\
\hline AMAZON2 & $\mathrm{L}_{2}$ & 1500 & 1500 & 9 & 109 & 107 & 5,06 & 0,6 & N/A & N/A \\
\hline COLORS & $\mathrm{L}_{\infty}$ & 112682 & 112 & 10 & 19 & 19 & 0,38 & 0,2 & N/A & N/A \\
\hline
\end{tabular}

quanto os conjuntos de dados usados nos experimentos se encontram disponíveis no repositório público www.github.com/marcosivni/rvrm.

\subsubsection{Qualidade da aproximação da função de concentração}

O modelo RVRM depende dos valores coletados para a função $f_{\phi}(d)$, de acordo com as reduções realizadas pelo modelo acoplado. Não obstante, o modelo precisa aproximar $f_{\phi}(d)$ por uma função contínua e definida no conjunto dos números reais para permitir delimitar a dimensão de concentração. Neste experimento, comparamos a qualidade da aproximação de $f_{\phi}(d)$ por $s_{\phi}(x)$ e $g_{\phi}(x)$ com relação à três redutores diferentes e seis conjuntos de dados (três rotulados e três não-rotulados). Foram usados os redutores Coeficiente de Pearson (PCo), Análise de Componentes Principais (PCA) e FastMap (FM). A qualidade da aproximação foi medida como o erro quadrático médio relativo (RMSE), que captura as diferenças residuais entre os valores calculados e os valores observados de $f_{\phi}(d)$.

A medida RMSE é particularmente adequada para comparar a aproximação de uma única variável, tal como no caso das aproximações por $s_{\phi}(x)$ e $g_{\phi}(x)$. Para complementar a análise, nós também medimos o RMSE para todos os valores observados de $f_{\phi}(d)$ com relação à duas formas de coletar os pontos interpolados. A primeira forma $D_{1}$ usa todos os pontos da curva, enquanto a segunda $D_{2}$ usa apenas alguns poucos pontos de controle, sendo que $D_{2}$ contém as dimensões que seguem a regra $D_{2}=\left\{d \mid d=2^{l}, \mathcal{D} \leq 2^{l} \leq \mathcal{E}, l \in \mathbb{N}\right\}$. A Tabela 10 apresenta os valores da medida de erro RMSE coletados a partir das duas aproximações.

A aproximação de $f_{\phi}(d)$ por $s_{\phi}(x)$ para os pontos $D_{1}$ alcançou um erro RMSE menor do que a aproximação por $g_{\phi}(x)$ em todos os conjuntos avaliados. Mais do que isso, a aproximação de $f_{\phi}(d)$ por $s_{\phi}(x)$ com os pontos em $D_{2}$ também foi melhor do que a aproximação por $g_{\phi}(x)$ e até mesmo superou a aproximação por $s_{\phi}(x)$ com os pontos $D_{1}$ em seis 6 casos com os três 
Tabela 10 - Valores de RMSE na escala $\cdot 10^{-2}$ para $s_{\phi}(x)$ e $g_{\phi}(x)$

\begin{tabular}{|c|c|c|c|c|c|c|c|c|}
\hline 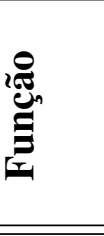 & $\theta$ & $\theta$ & $\begin{array}{l}\text { 空 } \\
\text { 豈 } \\
\end{array}$ & 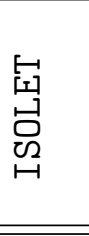 & 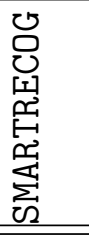 & 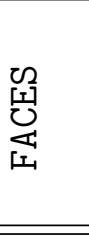 & 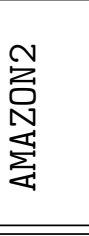 & 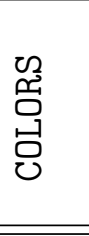 \\
\hline$g_{\phi}(x)$ & PCo & $D_{1}$ & 72,4 & 71,5 & 0,68 & 1,60 & 2,13 & 41,3 \\
\hline$g_{\phi}(x)$ & $P C A$ & $D_{1}$ & 47,9 & 5,42 & 21,5 & 9,51 & 1,55 & 3,44 \\
\hline$g_{\phi}(x)$ & $F M$ & $D_{1}$ & 7,16 & 1,59 & 27,5 & 7,52 & 1,85 & 3,52 \\
\hline$s_{\phi}(x)$ & PCo & $D_{1}$ & 4,86 & 4,56 & 0,48 & 0,64 & 0,67 & 4,81 \\
\hline$s_{\phi}(x)$ & $P C A$ & $D_{1}$ & 0,54 & 0,77 & 1,14 & 4,27 & 1,16 & 0,79 \\
\hline$s_{\phi}(x)$ & $F M$ & $D_{1}$ & 1,01 & $\mathbf{0 , 3 8}$ & 0,11 & 3,84 & 0,91 & 1,97 \\
\hline$s_{\phi}(x)$ & $P C o$ & $D_{2}$ & 4,78 & 6,73 & 0,80 & 1,75 & 0,75 & $\mathbf{0 , 1 2}$ \\
\hline$s_{\phi}(x)$ & $P C A$ & $D_{2}$ & 1,00 & 1,70 & $\mathbf{0 , 7 3}$ & 5,78 & 1,19 & 0,15 \\
\hline$s_{\phi}(x)$ & $F M$ & $D_{2}$ & $\mathbf{0 , 8 5}$ & 0,69 & 0,23 & 4,61 & 1,48 & 0,19 \\
\hline
\end{tabular}

diferentes redutores. Repare que usar o conjunto de pontos $D_{2}$ ao invés do conjunto de pontos $D_{1}$ reduz substancialmente o custo computacional do método, pois uma grande quantidade de reduções e cálculos de distribuição de pares de distância não precisam ser realizados. De acordo com estes resultados, nós empregamos apenas as dimensões no conjunto $D_{2}$ para aproximar $f_{\phi}(d)$ por $s_{\phi}(x)$ nos experimentos seguintes.

\subsubsection{Efeitos do modelo RVRM para classificação baseada em distância}

O classificador Instance-base Learning (IBk) foi usado para na avaliação dos efeitos do modelo RVRM em tarefas de classificação. O objetivo é verificar se usar uma quantidade controlada de dimensões pode levar a uma precisão de classificação maior. Nesse sentido, deve-se evitar situações nas quais diversos elementos estão empatados como vizinhos mais próximos, sendo que, nesse cenário, o classificador escolhe aleatoriamente um destes elementos empatados, potencialmente degradando o desempenho do classificador. Diante esse contexto, nós experimentamos a adequabilidade do modelo RVRM para tarefas de classificação ao verificar se a precisão do classificador IB $k$ aumenta ao realizarmos a redução de dimensionalidade orientada à dimensão de concentração e não à dimensão intrínseca.

O parâmetro de vizinhança $k$ do classificador IB $k$ foi configurado para assumir valores crescentes $k \in\{1,7,13\}$ e os dez conjuntos de dados rotulados foram empregados na avaliação. Três métricas $L_{p}$ diferentes foram usadas para consultar os conjuntos de dados, sendo que esses diferem em suas características, incluindo conjuntos balanceados, não balanceados ou quasebalanceados (número de instâncias por classe é aproximadamente o mesmo). Os atributos dos conjuntos variam em sua forma, sendo alguns atributos binários, outros sendo atributos inteiros e outros sendo atributos reais. Todos os conjuntos foram normalizados para o hiper-cubo unitário antes dos experimentos e o índice F-Measure (DICE, 1945) junto ao procedimento de validação cruzada de treino e teste foi empregado para medir a qualidade da classificação. Essa métrica 
Tabela 11 - Avaliação do modelo RVRM junto ao classificador Ibk. As setas indicam o resultado da comparação dos métodos das duas colunas anteriores. A coluna ZeroR indica o índice F-Measure mínimo para o qual a classificação realizada é razoável. A coluna Min indica o menor índice F-Measure alcançado pelo classificador Ib $k$ considerando todos os redutores e todas as dimensões avaliadas. A coluna Imersão indica os valores alcançados pelo classificador baseado em distância sem o uso de qualquer estratégia de redução de dimensionalidade. A coluna Max $\mathbf{M a n t}_{\text {Int }}$ indica o maior F-Measure alcançado por todos

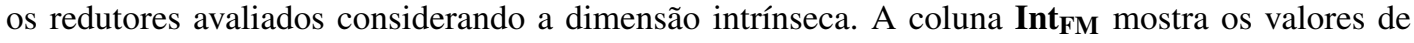
F-Measure alcançados quando a redução por FastMap é realizada com a dimensão intrínseca. A coluna

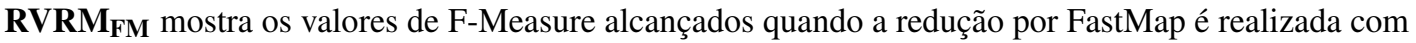
a dimensão de concentração. A coluna Int PCA mostra os valores de F-Measure alcançados quando a redução por PCA é realizada com a dimensão intrínseca. A coluna RVRMPCA mostra os valores de F-Measure alcançados quando a redução por PCA é realizada com a dimensão de concentração. A coluna Max RVRM mostra o maior F-Measure alcançado por todos os redutores avaliados considerando a dimensão de concentração.

\begin{tabular}{|c|c|c|c|c|c|c|c|c|c|c|c|}
\hline \multicolumn{2}{|c|}{ F-Measure } & ZeroR & Min & Max $_{\text {Int }}$ & Imersão & Int $_{\mathrm{FM}}$ & $\mathbf{R V R M}_{\mathrm{FM}}$ & Int $_{\text {PCA }}$ & RVRM $_{\text {PCA }}$ & $\operatorname{Max}_{\text {RVRM }}$ & Imersão \\
\hline \multirow{3}{*}{ CNAE } & $\mathrm{k}=1$ & \multirow{3}{*}{0.02} & 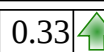 & \begin{tabular}{|l|}
0.79 \\
\end{tabular} & \begin{tabular}{|l|l|l|}
0.85 \\
\end{tabular} & 0.33 & 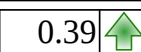 & 0.79 & \begin{tabular}{c|c|c|}
0.83 &
\end{tabular} & 0.83 & $0.85 \mid$ 全 \\
\hline & $\mathrm{k}=7$ & & 0.28 î & 0.79 & 0.83 (1) & 0.28 & 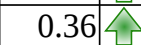 & 0.79 & 0.80 & 0.80 & 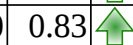 \\
\hline & $\mathrm{k}=13$ & & 0.27 & 0.76 & 0.83 술 & 0.27 & $0.34 \widehat{\widehat{N}}$ & 0.76 & 0.79 & 0.79 & \begin{tabular}{l|l|l|}
0.83 & \\
\end{tabular} \\
\hline \multirow{3}{*}{ GASDRIFT } & $\mathrm{k}=1$ & \multirow{3}{*}{0.08} & $0.99 \widehat{A}$ & 0.99 & 0.99 & 0.99 & 0.99 & 0.99 & 0.99 & 0.99 & 0.99 \\
\hline & $\mathrm{k}=7$ & & 0.97 년 & 0.99 & 0.99 & 0.97 & $0.98 \triangle$ & 0.99 & 0.99 & 0.99 & 0.99 \\
\hline & $\mathrm{k}=13$ & & 0.87 会 & 0.92 & 0.99 슨 & 0.87 & $0.94 \widehat{ث}$ & 0.92 & \begin{tabular}{l|l}
0.92 \\
\end{tabular} & 0.94 & 0.99 성 \\
\hline \multirow{3}{*}{ ISOLET } & $\mathrm{k}=1$ & \multirow{3}{*}{0.04} & 0.27 这 & 0.47 & $0.90 \widehat{-1}$ & 0.27 & $0.64 \widehat{\mathrm{O}}$ & 0.47 & $0.81 \widehat{~}$ & 0.81 & $0.90 \widehat{\text { Tn }}$ \\
\hline & $\mathrm{k}=7$ & & 0.31 숑 & 0.52 & 0.89 넉 & 0.31 & 0.63 会 & 0.52 & 0.82 & 0.82 & 0.89 类 \\
\hline & $\mathrm{k}=13$ & & 0.32 송 & 0.53 & 0.90 는 & 0.32 & $0.64 \widehat{\widehat{\theta}}$ & 0.53 & 0.82 & 0.82 & 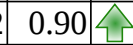 \\
\hline \multirow{3}{*}{ MADELON } & $\mathrm{k}=1$ & \multirow{3}{*}{0.33} & 0.51 | & 0.59 & 0.56 & 0.51 & 0.53 年 & 0.59 & 0.62 & 0.62 & 0.56 \\
\hline & $\mathrm{k}=7$ & & 0.51 솟 & 0.63 & 0.600 & 0.51 & $0.54 \widehat{\widehat{N}}$ & 0.63 & 0.67 & 0.67 & 0.60 \\
\hline & $\mathrm{k}=13$ & & 0.51 는 & 0.64 & $\begin{array}{ll}0.64 \\
\end{array}$ & 0.51 & $0.55 \widehat{-1}$ & 0.64 & & .68 & $0.64 \sqrt{8}$ \\
\hline \multirow{3}{*}{ MAMMOCLEAR } & $\mathrm{k}=1$ & \multirow{3}{*}{0.43} & 0.54 슨 & 0.55 & 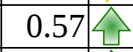 & 0.55 & 0.55 & 0.54 & 0.5 & 0.55 & $0.57 \widehat{\triangle}$ \\
\hline & $\mathrm{k}=7$ & & 0.55 는 & 0.56 & $0.57 \triangle$ & 0.56 & \begin{tabular}{l|l}
0.56 \\
\end{tabular} & 0.55 & 0.56 은 & 0.56 & 0.57 会 \\
\hline & $\mathrm{k}=13$ & & $0.54 \sqrt{2}$ & 0.56 & 0.59 & 0.54 & 0.57 会 & 0.56 & 0.57 & 0.57 & 0.59 \\
\hline \multirow{3}{*}{ MFEAT } & $\mathrm{k}=1$ & \multirow{3}{*}{0.02} & 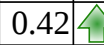 & 0.55 & 0.81 会 & 0.42 & $0.99 \widehat{\widehat{A}}$ & 0.55 & 0.5 & 0.99 & 0.81 V \\
\hline & $\mathrm{k}=7$ & & 0.47 송 & 0.63 & 0.81 会 & 0.47 & 0.99 会 & 0.63 & 0.5 & 0.99 & $0.81 \sqrt{2}$ \\
\hline & $\mathrm{k}=13$ & & 0.48 会 & 0.65 & 0.83 会 & 0.48 & $0.98 \widehat{\widehat{A}}$ & 0.65 & & 0.98 & $0.83 \square$ \\
\hline \multirow{3}{*}{ MNIST } & $\mathrm{k}=1$ & \multirow{3}{*}{0.02} & 0.32 L & 0.47 & 0.95 - & 0.32 & 0.85 会 & 0.47 & & 0.96 & 0.95 \\
\hline & $\mathrm{k}=7$ & & 0.37 셧 & 0.53 & $0.94 \widehat{\widehat{A}}$ & 0.37 & $0.85 \widehat{\widehat{A}}$ & 0.53 & & 0.95 & 0.94 \\
\hline & $\mathrm{k}=13$ & & 0.39 令 & 0.55 & $0.93 \triangle$ & 0.39 & $0.83 \widehat{-1}$ & 0.55 & & 0.95 & 0.93 \\
\hline \multirow{3}{*}{ SEMEION } & $\mathrm{k}=1$ & \multirow{3}{*}{0.85} & 0.83 & 0.91 & \begin{tabular}{l|l}
0.91 \\
0
\end{tabular} & 0.83 & $0.92 \widehat{-1}$ & 0.91 & $0.96 \widehat{ن}$ & 0.96 & 0.918 \\
\hline & $\mathrm{k}=7$ & & 0.86 令 & 0.93 & \begin{tabular}{l|l|}
0.86 \\
\end{tabular} & 0.86 & $0.92 \widehat{-}$ & 0.93 & $0.96 \widehat{-1}$ & 0.96 & 0.86 \\
\hline & $\mathrm{k}=13$ & & 0.85 논 & 0.94 & $0.85 \square$ & 0.86 & $0.90 \widehat{\mathrm{O}}$ & 0.94 & $0.96 \widehat{-1}$ & 0.96 & 0.85 \\
\hline \multirow{3}{*}{ SMARTPRECOG } & $\mathrm{k}=1$ & \multirow{3}{*}{0.06} & 0.43 会 & 0.85 & \begin{tabular}{l|l|l|}
0.43 \\
\end{tabular} & 0.81 & $0.89 \widehat{-}$ & 0.85 & $0.86 \widehat{-1}$ & 0.89 & 0.436 \\
\hline & $\mathrm{k}=7$ & & 0.46 는 & 0.86 & \begin{tabular}{l|l|l|}
0.46 & \\
\end{tabular} & 0.80 & $0.87 \widehat{ث}$ & 0.86 & $0.88 \widehat{-1}$ & 0.88 & $\begin{array}{ll}0.46 \sqrt{ } \\
\end{array}$ \\
\hline & $\mathrm{k}=13$ & & 0.47 定 & 0.86 & $0.47 \square$ & 0.78 & $0.86 \widehat{-}$ & 0.86 & $0.87 \widehat{\text { P }}$ & 0.87 & $0.47 \sqrt{6}$ \\
\hline \multirow{3}{*}{ TIGER } & $\mathrm{k}=1$ & \multirow{3}{*}{0.40} & 0.67 손 & 0.93 & \begin{tabular}{|l|l|}
0.73 \\
\end{tabular} & 0.93 & $0.98 \widehat{-1}$ & 0.67 & $0.69 \widehat{\mathrm{A}}$ & 0.98 & 0.736 \\
\hline & $\mathrm{k}=7$ & & $0.71 \mid \hat{2}$ & 0.93 & 0.71 & 0.93 & $0.97 \mathrm{~A}$ & 0.72 & 0.73 令 & 0.97 & $0.71 \square$ \\
\hline & $\mathrm{k}=13$ & & $0.71 \mid \widehat{\mid}$ & 0.92 & $\mid 0.71 \sqrt{ }$ & 0.92 & 0.97 会 & 0.72 & $0.73 \mid \widehat{A}$ & 0.97 & $0.71 区$ \\
\hline
\end{tabular}

expressa a qualidade da classificação como uma média harmônica entre precisão e revocação, desconsiderando-se os falso-negativos encontrados, como um único valor.

A Tabela 11 mostra os resultados de F-Measure alcançados em todos os cenários possíveis e a comparação entre eles. De forma complementar, a Figura 46 mostra, no formato de um gráfico de coordenadas paralelas, a evolução dos valores de F-Measure obtidos pelo classificador para 


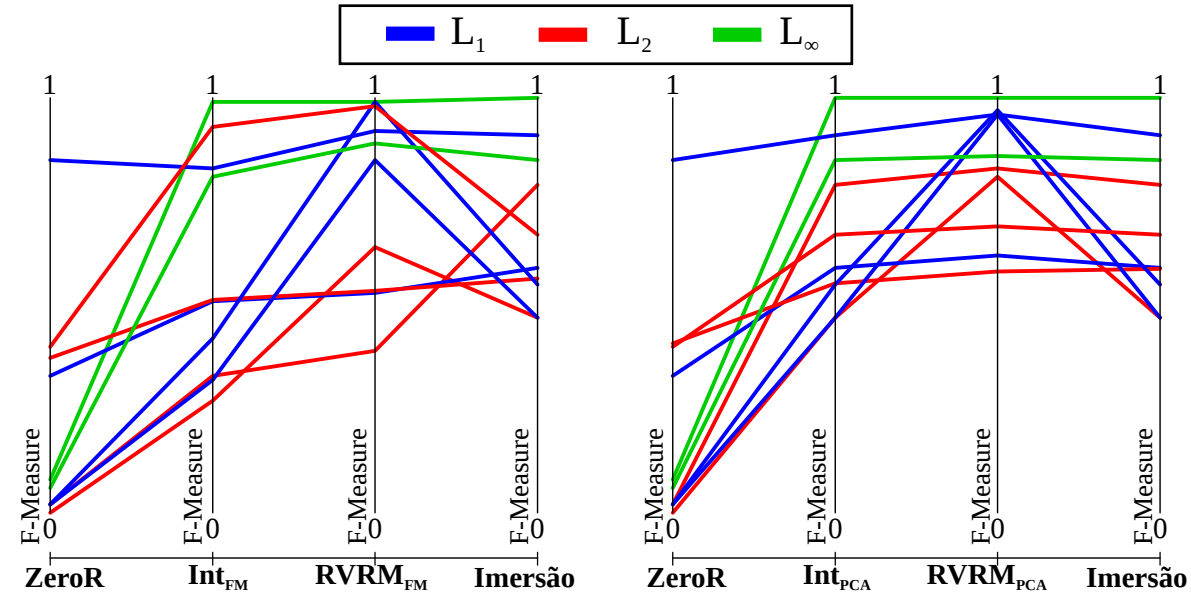

(a)

(b)

Figura 46 - Desempenho do classificador Ib $k$ para $k=1$ considerando a análise em diversas dimensionalidades. Cada linha é um conjunto de dados analisado. (a) Dimensões reduzidas pelo redutor FastMap. (b) Dimensões reduzidas pelo redutor PCA.

$k=1$ onde a dimensionalidade varia desde a dimensão intrínseca até a dimensão de concentração e, finalmente, para a dimensão de imersão. A Figura 46(a) apresenta os resultados com relação ao redutor FastMap, enquanto a Figura 46(b) mostra os resultados obtidos com o redutor PCA. Dos resultados mostrados pela Tabela 11 e ilustrados na Figura 46 destacamos:

- As reduções realizadas são adequadas ao problema de classificação, visto que o pior desempenho considerando todas as dimensões avaliadas (Min) foi superior ao limitebase (ZeroR) em todos os casos, com a exceção de $k=1$ para o conjunto de dados SEMEION. Esse resultado é um indicativo que a tarefa de classificação pode ser analisada da perspectiva das reduções realizadas.

- Não há como afirmar que classificar o conjunto de dados na dimensão de imersão é sempre a melhor opção, visto que reduções para dimensões intrínsecas permitiram obter melhores resultados em alguns casos. Por outro lado, classificar o conjunto de dados diretamente com sua dimensionalidade original também não garante que o resultado será pior do que reduzir o conjunto para a dimensionalidade intrínseca.

- O índice F-Measure obtido na dimensão de concentração foi sempre melhor ou igual do que a taxa obtida na dimensão intrínseca. Em particular:

- A dimensão de concentração foi melhor em 27 dos 30 casos, tendo empatado nos 3 casos restantes, tanto para o redutor FastMap, quanto para o redutor PCA. No entanto, os casos de empates foram diferentes para os dois redutores avaliados.

- O maior ganho da dimensão de concentração sobre a dimensão intrínseca foi de expressivos 0.57 com o redutor FastMap e 0.49 com o redutor PCA (o índice FMeasure varia no intervalo [0,1]). 
- O maior ganho da dimensão de concentração com relação à dimensão intrínseca foi de 0.46 e a menor perda foi de 0.09 .

- Os resultados na Figura 46 indicam que o desempenho para classificação é menor na dimensão intrínseca, melhora para a dimensão de concentração e pode melhorar ou piorar na dimensão de imersão. Os resultados na Tabela 11 mostram que a dimensão de concentração superou ou igualou a dimensão de imersão em 20 dos 30 experimentos.

Finalmente, realizamos uma avaliação mais detalhada sobre três dos dez conjuntos rotulados, onde variamos o valor de $k$ de 1 a 15 aumentando o número de vizinhos de 2 em 2 . As Figuras 47 (a - c) mostram os resultados obtidos para os conjuntos de dados MFEAT, ISOLET e SMARTRECOG. Todos os valores de F-Measure alcançados na redução para dimensionalidades intrínsecas foram superadas pelos obtidos na dimensão de concentração, independentemente do redutor. De fato, o modelo RVRM com o redutor FastMap alcançou um melhor resultado do que a redução com o FastMap para a dimensionalidade intrínseca em até $133 \%$, 138\% e $25.7 \%$ nos conjuntos de dados MFEAT, ISOLET e SMARTRECOG. O modelo RVRM com o redutor PCA também superou sua versão com a dimensão intrínseca em até $77.1 \%, 75.4 \%$ e $2.7 \%$ no mesmo cenário.

Os valores obtidos na dimensão de imersão variaram completamente de um conjunto de dados para outro. Por exemplo, a dimensão de imersão obteve o melhor desempenho no conjunto ISOLET, um desempenho intermediário para o conjunto MFEAT e o pior desempenho no conjunto SMARTRECOG. Dessa forma, os resultados indicam que aumentar o número de dimensões pode melhorar a performance do classificador IB $k$ em um cenário em que as instâncias permanecem adequadamente descritas e as distâncias não se concentram. Porém, o uso de um número arbitrariamente grande de dimensões (dimensão de imersão) poder levar à queda de desempenho na tarefa de classificação. Nesse contexto, usar o modelo RVRM com um redutor acoplado foi a solução mais adequada, pois permitiu melhorar o desempenho do classificador na comparação com a dimensão intrínseca e, ao contrário da dimensão de imersão, seu desempenho não degradou para um menor número de dimensões reduzidas.

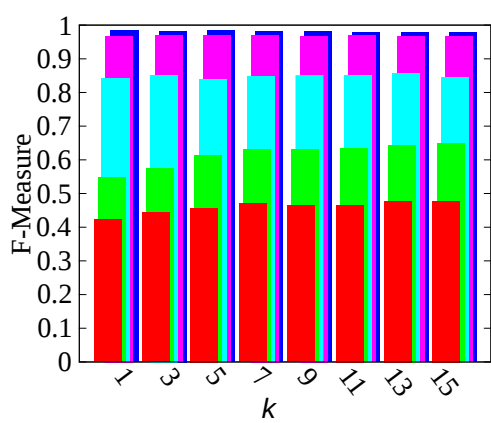

(a) - MFEAT

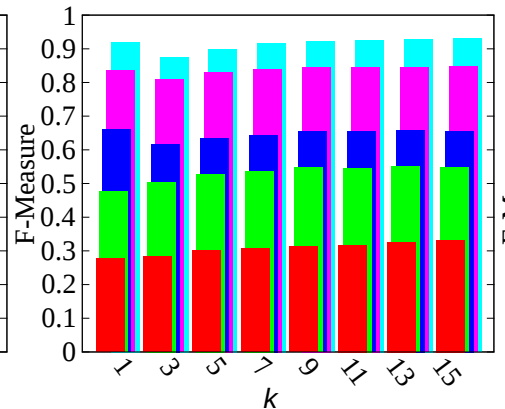

(b) - ISOLET

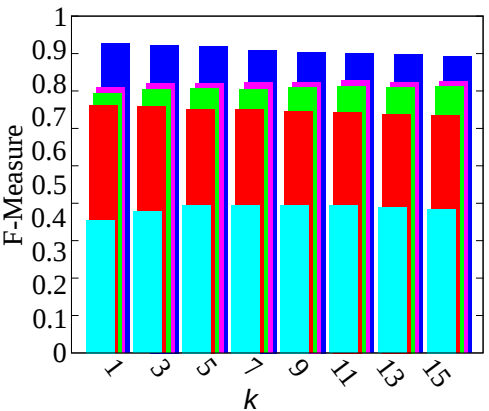

(c) - SMARTRECOG

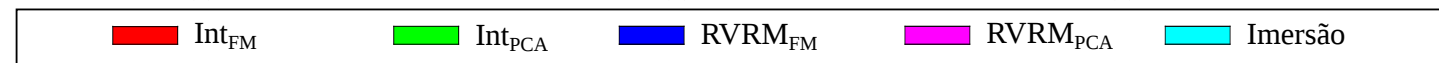

Figura 47 - Valores de F-Measure obtidos para diferentes dimensionalidades e valores de $k$ com o classificador Ib $k$, considerando os conjuntos de dados (a) MFEAT, (b) ISOLET e (c) SMARTRECOG. 

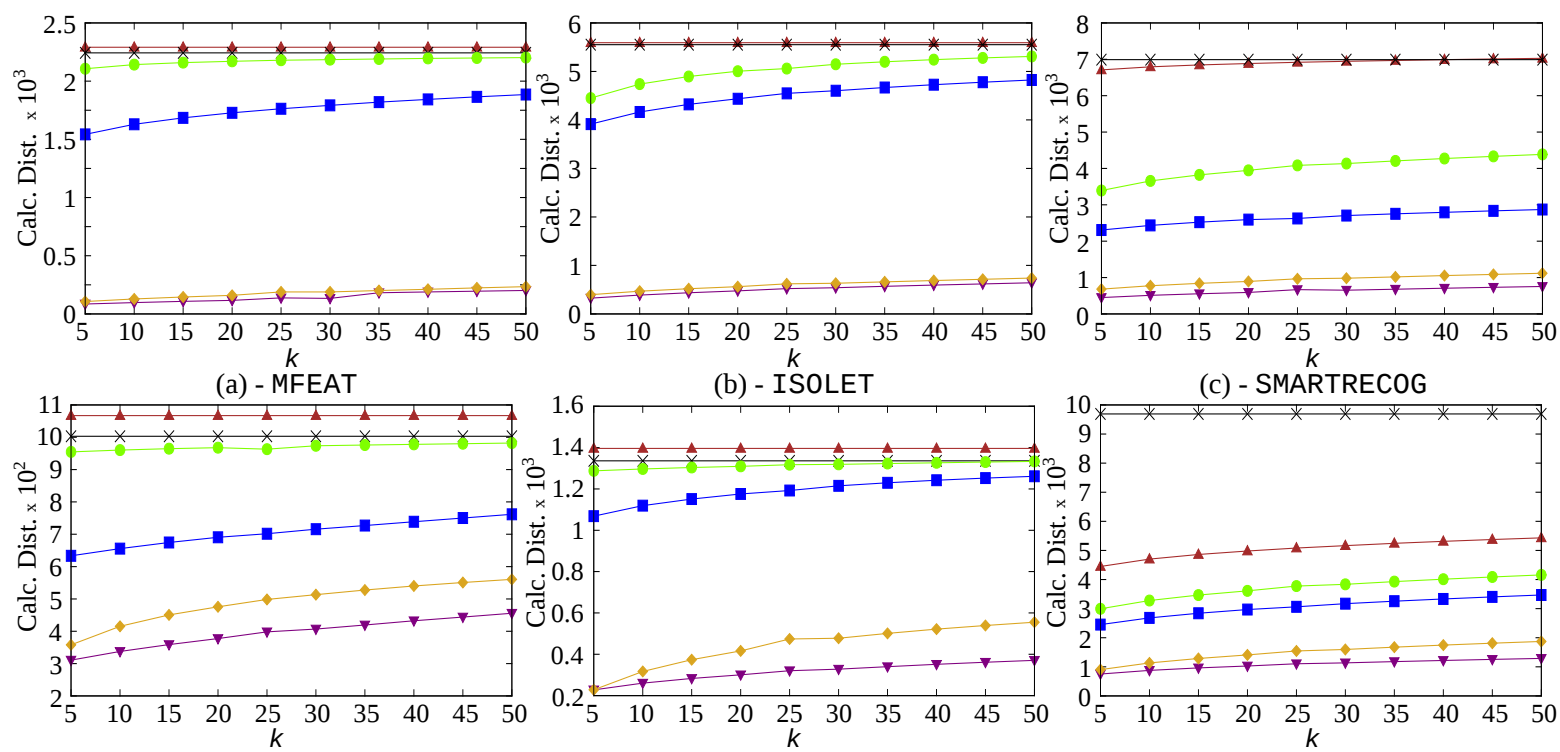

(b) - ISOLET

(d) - FACES

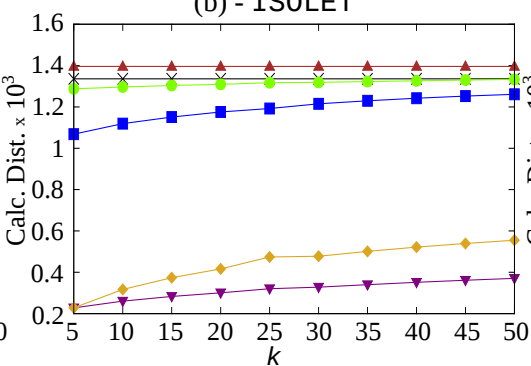

(e) - AMAZON2 (c) - SMARTRECOG

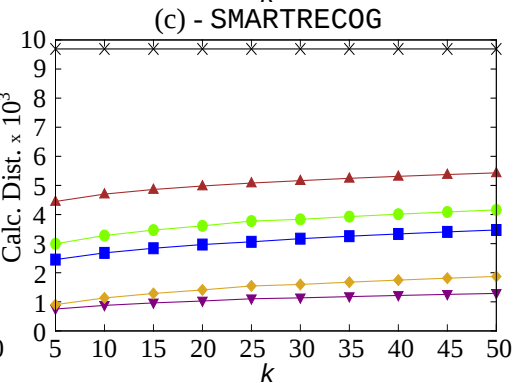

(f) - COLORS

$$
\begin{aligned}
& \longrightarrow \text { Slim-Tree - Imersão } \longrightarrow \text { Slim-Tree - RVRMPCA } \\
& \longrightarrow \text { Slim-Tree - Int } F M
\end{aligned} \longrightarrow \text { Slim-Tree - } \text { Int }_{P C A} \longrightarrow \text { Slim-Tree - RVRM }
$$

Figura 48 - Quantidade de cálculos de distâncias necessários para executar uma consulta por vizinhança considerando-se as dimensionalidades intrínseca, de concentração e de imersão. Os redutores PCA e FastMap foram usados para o processo de redução de dimensionalidade nos conjuntos de dados MFEAT, ISOLET, SMARTRECOG, FACES, AMAZON2 e COLORS.

\subsubsection{Efeitos do modelo RVRM na indexação de dados}

Para a avaliação dos efeitos do modelo RVRM em tarefas de indexação, realizamos experimentos sobre seis conjuntos de dados, três rotulados (MFEAT, ISOLET e SMARTRECOG) e três não-rotulados (FACES, AMAZON2 e COLORS). Os conjuntos de dados foram indexados em uma árvore métrica Slim-Tree, cuja página de dados foi configurada para conter a mesma quantidade de elementos independentemente da dimensão avaliada. Na sequência, foram realizadas consultas por vizinhança sobre estes índices e sobre o mecanismo de busca padrão SeqScan. O objetivo é verificar se o modelo RVRM pode prevenir a degeneração da estrutura Slim-Tree que pode ser mais lenta do que o método SeqScan para buscas por vizinhança de conjuntos de dados imersos em espaços de alta dimensionalidade.

Nós empregamos a rotina de validação cruzada em 10-folds (90\% dos dados para indexação e $10 \%$ para as consultas, alternadamente). As consultas foram realizadas usando a rotina de busca incremental inc-kNN, que é ótima em termos da quantidade de nós visitados. Para validar o desempenho das estruturas de busca, medimos a quantidade de cálculos de distância realizados. Essa medida é particularmente interessante pois permite medir a capacidade da estratégia de particionar o espaço de busca em sub-árvores representativas tal que seja possível podá-las durante a execução de uma consulta por vizinhança. Dessa forma, a intuição na análise dos experimentos é que os elementos de dados podem ser eficientemente recuperados se a consulta sob o índice requerer menos cálculos de distância do que uma busca linear.

A Figura 48 mostra a comparação geral com relação às dimensões intrínseca, de concen- 
tração e de imersão nos métodos de resolução de consultas avaliados. Para o caso da dimensionalidade de imersão, o método SeqScan foi melhor do que usar a busca indexada pelo método Slim-Tree em todos conjuntos, a exceção do conjunto COLORS. De fato, a abordagem SeqScan precisou de até $2,16 \%, 0,9 \%, 0,7 \%, 7,1 \%$ e 4,3\% menos cálculos de distância para realizar uma consulta por vizinhança nos conjuntos de dados MFEAT, ISOLET, SMARTRECOG, FACES e AMAZON2, respectivamente.

Por outro lado, a redução dos conjuntos de dados para suas dimensões intrínsecas possibilitou um corte drástico na quantidade de cálculos de distância para as consultas por vizinhança quando o método de indexação foi empregado na resolução das consultas. Por exemplo, reduzir os conjuntos às suas dimensionalidades intrínsecas com o método FastMap permitiu a Slim-Tree reduzir o número de cálculos de distância em até 93,5\%, 90,7\%, 93,6\%, 96,5\%, 82,9\% e 92,2\% para os conjuntos de dados MFEAT, ISOLET, SMARTRECOG, FACES, AMAZON2 e COLORS na comparação com o método SeqScan. Da mesma forma, a redução dos conjuntos às suas dimensões intrínsecas com o método PCA possibilitou ganhos de desempenho do método Slim-Tree na comparação com a busca SeqScan em até $91,9 \%, 89,1 \%, 86,5 \%, 56,93 \%, 67,1 \%$ e $84,5 \%$ para os mesmos conjuntos avaliados.

De modo complementar, os resultados na Figura 48 também mostram que os conjuntos de dados reduzidos às suas dimensões de concentração foram eficientemente consultados pelas estruturas de indexação. Nós destacamos que, embora os ganhos de desempenho sejam menores do que os alcançados com a redução à dimensão intrínseca, a consulta por vizinhança por meio do índice considerando-se o modelo RVRM superou a abordagem SeqScan, independentemente do redutor acoplado. Por exemplo, as consultas por vizinhança com o apoio do índice Slim-Tree com a dimensionalidade escolhida pelo modelo RVRM e o redutor acoplado FastMap requereram até $27,3 \%, 24,9 \%, 65,2 \%, 38,4 \%, 16,3 \%$ e 72,3\% menos cálculos de distância na comparação com a abordagem SeqScan considerando-se os conjuntos de dados MFEAT, ISOLET, SMARTRECOG, FACES, AMAZON2 e COLORS, respectivamente. De forma similar, a combinação do índice Slim-Tree com o modelo RVRM e o redutor PCA acoplado superou a abordagem SeqScan em até $4,5 \%, 14,6 \%, 47,7 \% 4,7 \%, 2,9 \%$ e $66,1 \%$ nos mesmos conjuntos de dados.

Além disso, os experimentos confirmam que a dimensão de concentração tende a ser o limite da redução de dimensionalidade que não compromete o desempenho da estrutura de indexação. De fato, para os conjuntos MFEAT, ISOLET, FACES e AMAZON2, o desempenho das consultas estiveram próximos, ainda que melhores, do que usar a abordagem SeqScan. A execução das consultas por vizinhança com as dimensões guiadas pelo modelo RVRM requereram menos cálculos de distância para todos os conjuntos de dados, independentemente do método redutor escolhido para diminuir a quantidade de dimensões. Nesse sentido, argumentamos que a dimensionalidade calculada pelo modelo RVRM pode servir como um "limite máximo" para a consulta de conjuntos de dados onde a indexação ainda é efetiva, enquanto que a dimensionalidade intrínseca pode servir como um "limite mínimo" para o mesmo cenário. 
Os experimentos também mostram um "trade-off" entre a qualidade da representação do conjunto de dados, que é melhor representada pela dimensão de concentração para tarefas de classificação, e o desempenho da consulta por vizinhança, que é executada mais rapidamente com a dimensionalidade intrínseca. Por sua vez, o uso da dimensão de imersão descarta o uso de estratégias de indexação (a abordagem SeqScan é quase sempre a melhor alternativa), sendo que também não existem garantias de uma boa qualidade para tarefas de classificação.

Portanto, os resultados nos experimentos de classificação e indexação indicam que a dimensão de concentração pode ser vista como uma dimensão de fronteira onde ainda é possível obter um desempenho otimizado de consulta com uma melhor qualidade de representação dos dados. Nesse sentido, caso a aplicação requeira uma melhor qualidade em termos de precisão, o intervalo entre as dimensões de concentração e imersão deve ser analisado. Por outro lado, caso a aplicação requeira o melhor desempenho, o intervalo entre as dimensões intrínseca e de concentração deve ser levado em consideração.

\subsection{Considerações finais}

O fenômeno de concentração de distâncias inviabiliza o uso de várias das técnicas discutidas nos capítulos anteriores dessa tese em um ambiente de otimização de consultas por similaridade, seja envolvendo comparações por abrangência ou vizinhança. Uma alternativa viável, é tentar pré-processar os conjuntos de dados que estão inicialmente imersos em espaços de alta dimensionalidade para que sejam reduzidos a uma representação onde o fenômeno de concentração esteja suavizado.

Nesse capítulo, argumentamos que a redução da concentração de distâncias em conjuntos de alta dimensionalidade depende tanto da correlação (ou da estrutura) entre os atributos quanto da distribuição de pares de distância. Mais do que isso, na prática, um método redutor de dimensionalidade também precisa ser levado em consideração. No entanto, o objetivo primário destes métodos é a preservação de características dos dados e não o combate da concentração de distâncias. Nesse sentido, nós propusemos um modelo para redução de dimensionalidade, denominado de Modelo de Redução por Variância Relativa (RVRM), que permite aliviar o problema de concentração de distâncias em tarefas baseadas em similaridade. Nossa solução é, basicamente, um método wrapper que usa uma função objetivo para configurar o número de dimensões obtidas pelo redutor acoplado. A meta é obter um conjunto de dados cuja distribuição de distâncias não esteja concentrada, para permitir a execução otimizada de consultas por similaridade.

Após a realização de experimentos com o modelo RVRM, observamos que:

1. A concentração de distâncias pode ser adequadamente capturada pela função de concentração contínua que propusemos, sendo que uma dimensionalidade limite, denominada “dimensão de concentração", pode ser expressa em termo de um nível de confiança, que é 
calculado em termos de uma função de área acumulada,

2. O uso do modelo RVRM permitiu melhorar o desempenho de tarefas de classificação para o classificador baseado em distâncias Ib $k$. Nos conjuntos avaliados, o modelo RVRM sempre obteve precisão melhor na comparação com a dimensão intrínseca e, na maioria dos casos, obteve também um melhor desempenho na comparação com a dimensão de imersão.

3. O modelo RVRM preveniu a degeneração do métodos de acesso métrico Slim-Tree na execução de consultas por vizinhança. Nos conjuntos avaliados, a dimensão de concentração serviu como uma dimensão limite para a realização, com alguma eficiência, de uma consulta por vizinhança indexada.

4. Os resultados nos experimentos de classificação e indexação indicam que a dimensionalidade guiada pelo modelo RVRM pode ser vista como uma dimensão de fronteira onde ainda é possível obter um desempenho otimizado com uma melhor representação dos dados. Assim, caso a aplicação requeira o máximo de precisão possível, as dimensões de concentração e imersão são candidatas. Por outro lado, caso a aplicação requeira o melhor desempenho possível, as dimensões intrínseca e de concentração devem ser analisadas.

Por fim, mas não menos importante, destacamos que os diferentes redutores avaliados permitiram combater o fenômeno de concentração em diferentes níveis, uma vez que a dimensão de concentração não foi a mesma para todos os casos. Não obstante, o modelo RVRM conseguiu obter um conjunto de dados onde a concentração está igualmente aliviada sem prejudicar o viés do redutor. Dessa forma, o DBA pode escolher o redutor de acordo com a tarefa, sendo que a otimização de consultas por similaridade ainda será uma opção viável. 


\section{Conclusão}

Diante do contexto de inclusão de consultas por similaridade em um SGBD relacional, o processo de otimização de consultas por similaridade envolve diversas frentes de pesquisa. Nesta tese, nos focamos especificamente na análise de sinopses de distância para estender os módulos de 'Espaço de Distribuição de Dados' e 'Modelo de Custo' para que o otimizador de consultas possa tratar adequadamente os atributos sujeitos à comparação por similaridade. Antes deste trabalho não existia um arcabouço comum para implementação e testes de sinopses de distribuições de distância com o objetivo de fornecer estimativas de seletividade, raio e quantidades de acessos a disco e de cálculos de distância. Para desenvolver esse arcabouço, foi necessário categorizar as distribuições abarcadas por cada uma das sinopses revisadas (baseadas em pares de distância ou em pivôs) e investigar o uso dessas estruturas na otimização de consultas por similaridade. Esse estudo levou à implementação e avaliação dos esforços mais relevantes revisados, além da criação de uma nova sinopse (CDH) e um novo modelo de custo (Stockpile). Além disso, foi desenvolvido e avaliado um modelo para decidir quando é possível utilizar as sinopses estudadas na otimização de consultas em espaços de alta dimensionalidade.

A investigação conduzida nesta tese mostrou que sinopses podem ser efetivamente usadas na otimização lógica e física de consultas por similaridade, sendo que algumas sinopses são mais adequadas que outras, a depender do tipo da consulta e recurso-alvo da otimização desejada. Identificamos, experimentalmente, que a nova sinopse $\mathrm{CDH}$ alcança desempenho superior a muitas das estruturas revisadas. Além disso, mostramos que o modelo de custo Stockpile sempre atinge desempenho comparável ou superior aos dos modelos correlatos. Não obstante, nem as técnicas revisadas nem os métodos desenvolvidos são adequados para a otimização de consultas sobre atributos imersos em espaço de alta dimensionalidade. Ao investigarmos essa limitação, exploramos propriedades da distribuição de pares de distância para realizar reduções de dimensionalidade com o objetivo de combater a concentração de distâncias. Esse raciocínio permitiu estender a usabilidade do ferramental de otimização de consultas por similaridade também para conjuntos de alta dimensionalidade.

O desenvolvimento desta tese envolveu acompanhamento bibliográfico, de buscas à referenciais teóricos, de criação e implementação, além de trabalho experimental. Os experi- 
mentos realizados permitiram identificar os casos em que as estruturas e os métodos avaliados são úteis para aumentar o desempenho das consultas e os cenários em que eles falham. Nesse sentido, foi empregado um grande esforço inicial para integrar os trabalhos relacionados em uma plataforma comum, denominada Merkurion, que, na sequência, facilitou a experimentação de novas estruturas e técnicas. As avaliações conduzidas nesta tese tiveram o objetivo de cobrir os aspectos mais relevantes na otimização de consultas por abrangência e por vizinhança, uma vez que estes são os dois tipos de consultas mais usados na literatura revisada.

Em particular, foram estudadas oito sinopses (incluindo parametrizações de histogramas) com o objetivo de obter estimativas de seletividade para otimização lógica de consultas por abrangência e oito variações da estratégia bf-kNN limitada para a otimização física de consultas por vizinhança. Também foram avaliadas cinco sinopses multidimensionais na forma de Histogramas-Omni para dar suporte à otimização de consultas híbridas. Todas as estruturas e modelos foram avaliados sobre conjuntos de dados diversificados de baixa e média dimensionalidade, que permitiram comprovar a efetividade das técnicas propostas. Complementarmente, o modelo RVRM, que possibilita o uso das técnicas de otimização propostas em conjuntos de alta dimensionalidade, foi avaliado sob o mesmo arcabouço de implementação, considerando conjuntos de dados de alta dimensionalidade.

A Seção 8.1 apresenta as dificuldades encontradas ao longo deste trabalho, enquanto a Seção 8.2 resume as principais contribuições desta tese. A Seção 8.3 destaca algumas das possibilidades de trabalhos futuros derivados dos resultados aqui reportados. Finalmente, a Seção 8.4 apresenta as publicações geradas durante este doutoramento.

\subsection{Dificuldades}

A primeira grande dificuldade encontrada para o desenvolvimento desta tese foi a necessidade de unificação das sinopses e modelos de custo revisados na literatura em um mesmo arcabouço de avaliação. As diversas propostas haviam sido testadas sobre diferentes conjuntos de dados (frequentemente sintéticos) e em plataformas variadas, impedindo sua comparação. Além disso, os resultados são reportados na literatura com distintas medidas de avaliação. Para dificultar ainda mais esse cenário, essas estruturas podem depender de parametrizações de outras estruturas de dados (como índices), que impactam o resultado final da avaliação. Para contornar essa dificuldade, empregamos reuso de código e, nas poucas vezes em que foi possível ${ }^{1}$ usamos bibliotecas de terceiros, para construir o nosso próprio ambiente unificado de testes.

Também destacamos aqui a dificuldade teórica em usar métricas significativas para medir o desempenho da execução das consultas sobre estruturas de indexação e, consequentemente, dos algoritmos de busca para consultas por similaridade. Enquanto uma vertente de pesquisadores

1 A biblioteca Arboretum (www. bitbucket. com/gbdi/arboretum) foi usada na construção dos métodos de acessos métricos. 
defende o uso do tempo de execução como uma medida mais justa (TRAINA JR. et al., 2007; SKOPAL, 2010) é também esperado que fatores externos à lógica de construção dessas estruturas, como a substituição de discos magnéticos por discos de estado sólido ou até mesmo a dimensionalidade dos conjuntos testados, venham a afetar a medida de tempo de alguma forma. Nesse sentido, outros pesquisadores empregam a quantidade de cálculos de distância para quantificar a qualidade do particionamento do índice (HJALTASON; SAMET, 2003; CHEN et al., 2017b).

Procuramos sempre expressar os valores medidos nos experimentos em relação à busca sequencial (SeqScan), o que permite normalizar os resultados em futuras comparações. Também procuramos usar o procedimento de validação cruzada para quantificar os valores de desempenho das consultas para evitar: (i) casos em que um pivô particularmente adequado tenha sido escolhido; (ii) o sobreajuste de técnicas que envolvam algum tipo de regressão.

\subsection{Contribuições}

As contribuições desta tese se referem aos cinco objetivos iniciais definidos para este trabalho, da forma como se segue:

1. Histograma Compactado de Distância - CDH: Permite representar distribuições de distância baseadas em pivôs como uma spline onde o erro de aproximação é conhecido e as restrições de memória são definidas pelo DBA. Esta sinopse é também uma nova restrição de particionamento de histogramas, que minimiza o espaço ocupado em memória principal, construída por um algoritmo incremental. Os experimentos mostraram que as frequências armazenadas em um $\mathrm{CDH}$ podem ser usadas em estimativas de seletividade e raio.

Múltiplos CDH's podem ser usados independentemente para reduzir os erros de estimativas derivadas da suposição da densidade uniforme de distâncias. Cada CDH produz uma estimativa individual que é agrupada por uma função de agregação. Experimentos indicaram que a função de agregação Avg é a mais indicada para as estimativas de raio, enquanto que a função de agregação Mínimo é a mais adequada para as estimativas de seletividade.

2. Modelo de custo Stockpile: Permite obter uma estimativa da quantidade de cálculos de distâncias e de acessos a disco para executar uma consulta por similaridade sobre uma árvore métrica. Ao contrário dos modelos existentes na literatura, nosso modelo é baseado em múltiplos CDH's e permite capturar as "densidades locais" (no sentido de serem obtidas mais próximas ao elemento de referência da consulta) e, por isso, entregar previsões mais precisas para consultas por abrangência e por vizinhança.

3. Histogramas-Omni: Permitem construir uma estrutura de indexação métrica a partir de uma sinopse baseada em restrições de particionamento de histogramas. Essa estrutura é capaz de lidar com consultas híbridas. Os Histograma-Omni representam o espaço de busca em hiper-regiões, denominadas Omni-faixas, que são construídas de acordo com 
distribuições não-independentes de distâncias baseadas em pivô. A frequência dentro de cada Omni-faixa pode ser expressa como um outro histograma (considerando qualquer restrição de particionamento) sobre uma distribuição de dados de um atributo ortogonal. Uma vez que as frequências das Omni-faixas ficam disponíveis de antemão, a execução de consultas híbridas sobre esse índice é otimizada. Além disso, as quantidades de acessos a disco e de cálculos de distância são delimitados, o que beneficia os algoritmos de busca por vizinhança. As restrições Equi-Width e CDH foram as que obtiveram os melhores desempenhos no particionamento de atributos sujeitos à comparação por similaridade.

4. Protótipo Merkurion: Permite construir um amplo grupo de sinopses para distribuição de distâncias e empregá-las tanto para a previsão de seletividade quanto para a estimativa de raios. O protótipo também inclui uma sintaxe em alto nível, que possibilita criar e usar sinopses para a otimização de consultas por abrangência ou por vizinhança com ou sem apoio de um SGBD. Nesse sentido, a ferramenta pode ser usada como um middleware, API ou como um framework de otimização de consultas.

5. Modelo RVRM: Permite calcular a "dimensão de concentração", que definimos como sendo um determinado valor de dimensionalidade até o qual é vantajoso utilizar um arcabouço de otimização de consultas. Assim, foi possível identificar que, para dimensionalidades mais altas do que a indicada pelo modelo, tentar a otimização tende apenas a sobrecarregar a execução da consulta. O modelo é do tipo wrapper, onde o usuário/aplicação tem liberdade para informar o método de redução de dimensionalidade que se pretende usar. Essa característica é particularmente desejável, pois permite que se mantenha o viés do redutor de acordo com a finalidade da aplicação.

O modelo RVRM usa a distribuição de pares de distância para guiar o redutor acoplado, de maneira que o conjunto de dados é reduzido à um estado onde as distâncias não se encontram concentradas o suficiente. A avaliação do modelo indicou que: ( $i$ ) as reduções realizadas permitem aumentar a qualidade das tarefas de classificação; (ii) é possível executar eficientemente as consultas indexadas para um conjunto de dados cuja dimensionalidade foi reduzida pelo modelo RVRM.

\subsection{Desdobramentos futuros}

As contribuições desta tese podem ser usadas como ponto de partida para novas iniciativas envolvendo a otimização de consultas por similaridade. Em particular, é possível divisar trabalhos futuros baseados nos resultados obtidos nas seguintes frentes de pesquisa:

- Usar as sinopses para fornecer estimativas para Junção por Similaridade: Os métodos CDH e Histograma-Omni precisam ser avaliados em estimativas de Junção por similaridade no futuro. O uso combinado de distribuições de distância baseadas em pivô compactadas por 
histogramas independentes e não-independentes têm o potencial para entregar estimativas adequadas para esses tipos de consulta.

- Métodos de Acesso baseados em Histogramas: Os Histogramas-Omni são uma indicação de que é possível obter estruturas de indexação particionadas por frequências de distâncias para otimizar o desempenho de consultas por abrangência, por vizinhança e híbridas. Nesse sentido, combinar distribuições de distâncias e de dados por restrições de particionamento de histogramas unidimensionais e multidimensionais, e.g. MHIST, ST-Hole, etc., é um caminho a ser experimentalmente avaliado.

- Avaliação paralelizada de Histogramas-Omni: O particionamento obtido por Histogramas-Omni permite colocar elementos próximos em uma mesma hiper região. A forma como essas regiões podem ser armazenadas e consultadas de forma distribuída é uma lacuna a ser estudada e novas propostas podem ser construídas a partir deste ponto.

- Avaliação do modelo RVRM para tarefas de agrupamento: Os resultados obtidos pelo modelo RVRM foram significativos para tarefas de classificação e indexação. Uma outra necessidade é examinar o desempenho do modelo para tarefas de agrupamento, bem como avaliar a adequabilidade do modelo para outras tarefas não supervisionadas.

\subsection{Publicações geradas}

Atualmente estão em fase de finalização de escrita um artigo sobre Histogramas-Omni, a ser submetido em conferência da área, e um um artigo sobre o modelo RVRM a ser submetido em revista com seletiva política editorial. As publicações já realizadas sobre as contribuições desta tese estão enumeradas abaixo:

1. (Revista - Aceito para publicação) - The Merkurion approach for similarity searching optimization in Database Management Systems. Data \& Knowledge Engineering (DKE).

2. (Revista) - Seamless integration of distance functions and feature vectors for similarityqueries processing. Journal of Information and Data Management (JIDM) (BEDO; TRAINA; TRAINA JR., 2014).

3. (Conferência - Aceito para publicação) A Spline-based Cost Model for Metric Trees. Brazilian Symposium on Databases (SBBD).

4. (Conferência) - Compact Distance Histogram. International Conference on Scientific and Statistical Database Management (SSDBM) (BEDO et al., 2015).

5. (Conferência) - SHRuB - Searching through Heuristics for the Best Query-Execution Plan. Brazilian Symposium on Databases - Demo Session (BEDO et al., 2014). 
Além destas, outras publicações oriundas de trabalho colaborativo que também envolvem resultados reportados nesta tese foram geradas no decorrer do trabalho de doutorado e se encontram numeradas na sequência:

1. (Conferência - Aceito para publicação) - MAMMOSET: An Enhanced Dataset of Mammograms. Brazilian Symposium on Databases - Dataset Showcase.

2. (Revista) - Endowing a Content-Based Medical Image Retrieval System with Perceptual Similarity Using Ensemble Strategy. Journal of Digital Imaging (JDI) (BEDO et al., 2016).

3. (Capítulo de Livro - Em fase de impressão) - Making Content-Based Medical Image Retrieval Systems worth for Computer-Aided Diagnosis: From Theory to Application. Medical Image Analysis and Informatics. Taylor \& Francis.

4. (Capítulo de Livro) - Fire Detection from Social Media Images by Means of Instance-Based Learning. Lecture Notes in Business Information Processing (BEDO et al., 2016b).

5. (Conferência) - Unveiling smoke in social images with the SmokeBlock approach. ACM Symposium on Applied Computing (SAC) (CAZZOLATO et al., 2016).

6. (Conferência) - A Label-Scaled Similarity Measure for Content-Based Image Retrieval. International Symposium on Multimedia (ISM) (BLANCO et al., 2016).

7. (Conferência) - Color and Texture Influence on Computer-Aided Diagnosis of Dermatological Ulcers. International Symposium on Computer-Based Medical Systems (CBMS) (BEDO et al., 2015c).

8. (Conferência) - Techniques for Effective and Efficient Fire Detection from Social Media Images. International Conference on Enterprise Info. Systems (ICEIS) (BEDO et al., 2015b).

9. (Conferência) - Being Similar is Not Enough: How to Bridge Usability Gap through Diversity in Medical Images. International Symposium on Computer-Based Medical Systems (CBMS) (SANTOS et al., 2014).

Os seguintes softwares foram desenvolvidos durante este trabalho:

1. SHRuB - www.github.com/marcosivni/SHRuB

2. Merkurion-www.github.com/marcosivni/merkurion

3. RVRM- www.github.com/marcosivni/rvrm 


\section{Referências}

ACHARYA, S.; GIBBONS, P. B.; POOSALA, V. Aqua: A fast decision support systems using approximate query answers. In: International Conference on Very Large Data Bases. [S.1.]: Morgan Kaufmann Inc., 1999. p. 754-757. Citado na página 68.

AFFONSO, C.; ROSSI, A. L. D.; VIEIRA, F. H. A.; CARVALHO, A. C. P. d. L. F. Deep learning for biological image classification. Expert Systems with Applications, Elsevier, v. 85, p. 114-122, 2017. Citado na página 44.

AGARWAL, P. K.; ARONOV, B.; HAR-PELED, S.; PHILLIPS, J. M.; YI, K.; ZHANG, W. Nearest-neighbor searching under uncertainty. Transactions on Algorithms, ACM, v. 13, n. 1, p. 3, 2016. Citado na página 77.

AGGARWAL, C. C.; HINNEBURG, A.; KEIM, D. A. On the surprising behavior of distance metrics in high dimensional space. In: International Conference on Database Theory. [S.1.]: Springer, 2001. p. 420-434. Citado na página 149.

AHA, D. W.; KIBLER, D.; ALBERT, M. K. Instance-based learning algorithms. Machine Learning, Springer, v. 6, n. 1, p. 37-66, 1991. Citado na página 47.

AKGÜL, C. B.; RUBIN, D. L.; NAPEL, S.; BEAULIEU, C. F.; GREENSPAN, H.; ACAR, B. Content-based image retrieval in radiology: current status and future directions. Journal of Digital Imaging, Springer, v. 24, n. 2, p. 208-222, 2011. Citado na página 45.

ALY, A. M.; AREF, W. G.; OUZZANI, M. Spatial queries with two knn predicates. Proceedings of the VLDB Endowment, VLDB Endowment, v. 5, n. 11, p. 1100-1111, jul. 2012. ISSN 2150-8097. Citado 2 vezes nas páginas 30 e 31.

Cost estimation of spatial k-nearest-neighbor operators. In: International Conference on Extending Database Technology. [S.1.: s.n.], 2015. p. 457-468. Citado 7 vezes nas páginas $33,52,53,54,86,88$ e 89.

AMATO, G.; DEBOLE, F.; FALCHI, F.; GENNARO, C.; RABITTI, F. Large scale indexing and searching deep convolutional neural network features. In: International Conference on Big Data Analytics and Knowledge Discovery. [S.1.]: Springer, 2016. p. 213-224. Citado na página 44.

AMATO, G.; MAINETTO, G.; SAVINO, P. A query language for similarity-based retrieval of multimedia data. In: European Conference on Advances in Databases and Information Systems. [S.1.]: Nevsky Dialect, 1997. p. 196-203. Citado na página 31. 
ARENTZ, W. A.; HETLAND, M. L.; OLSTAD, B. Retrieving musical information based on rhythm and pitch correlations. Journal of New Music Research, Taylor \& Francis, v. 34, n. 2, p. 151-159, 2005. Citado na página 30 .

ASTRAHAN, M. M.; BLASGEN, M. W.; CHAMBERLIN, D. D.; ESWARAN, K. P.; GRAY, J. N.; GRIFFITHS, P. P.; KING, W. F.; LORIE, R. A.; MCJONES, P. R.; MEHL, J. W. et al. System R: Relational approach to database management. Transactions on Database Systems, ACM, v. 1, n. 2, p. 97-137, 1976. Citado na página 29.

BAIOCO, G. B.; TRAINA, A. J. M.; TRAINA JR., C. Mamcost: Global and local estimates leading to robust cost estimation of similarity queries. In: International Conference on Scientific and Statistical Database Management. [S.1.]: IEEE, 2007. p. 6-6. Citado 8 vezes nas páginas $82,86,87,88,110,111,112$ e 114 .

BALTRUNAS, L.; MAZEIKA, A.; BOHLEN, M. Multi-dimensional histograms with tight bounds for the error. In: International Symposium on Database Engineering and Applications. [S.1.]: IEEE, 2006. p. 105-112. Citado na página 77.

BARIONI, M. C. N.; RAZENTE, H.; TRAINA, A.; TRAINA JR, C. SIREN: A similarity retrieval engine for complex data. In: International conference on Very large Data Bases. [S.1.]: VLDB Endowment, 2006. p. 1155-1158. Citado 2 vezes nas páginas 30 e 31.

BARIONI, M. C. N.; RAZENTE, H. L.; TRAINA, A. J. M.; TRAINA JR, C. Seamlessly integrating similarity queries in SQL. Software: Practice and Experience, Wiley Online Library, v. 39, n. 4, p. 355-384, 2009. Citado na página 31.

BATISTA, G. E. A. P. A.; SILVA, D. F. How k-nearest neighbor parameters affect its performance. In: Argentine Symposium on Artificial Intelligence. [S.1.]: SN, 2009. p. 1-12. Citado 2 vezes nas páginas 42 e 47 .

BATKO, M.; FALCHI, F.; LUCCHESE, C.; NOVAK, D.; PEREGO, R.; RABITTI, F.; SEDMIDUBSKY, J.; ZEZULA, P. Building a web-scale image similarity search system. Multimedia Tools and Applications, Springer, v. 47, n. 3, p. 599-629, 2010. Citado na página 30.

BATKO, M.; NOVAK, D.; ZEZULA, P. Messif: Metric similarity search implementation framework. Digital Libraries: Research and Development, Springer, p. 1-10, 2007. Citado 2 vezes nas páginas 31 e 35 .

BAY, H.; ESS, A.; TUYTELAARS, T.; GOOL, L. V. Speeded-up Robust Features (SURF). Computer vision and image understanding, Elsevier, v. 110, n. 3, p. 346-359, 2008. Citado na página 44.

BEDO, M. V. N.; CAZZOLATO, M. T.; COSTA, A. F.; BLANCO, G.; JR, J. F. R.; TRAINA, A. J. M.; TRAINA JR, C. Techniques for effective and efficient fire detection from social media images. In: International Conference Enterprise Information Systems. [S.1.]: Springer, 2015b. v. 241, p. 23. Citado na página 174.

BEDO, M. V. N.; KASTER, D. S.; TRAINA, A. J. M.; TRAINA JR., C. Compact Distance Histogram: a novel structure to boost k-nearest neighbor queries. In: International Conference on Scientific and Statistical Database Management. [S.1.]: ACM, 2015. p. 36:1-36:6. Citado na página 173. 
BEDO, M. V. N.; OLIVEIRA, W. D.; CAZZOLATO, M. T.; COSTA, A. F.; BLANCO, G.; JR., J. F. R.; TRAINA, A. J. M.; TRAINA JR., C. Fire detection from social media images by means of instance-based learning. In: Revised Selected Papers Enterprise Information Systems. [S.1.]: Springer, 2016b. p. 23-44. Citado na página 174.

BEDO, M. V. N.; OLMES-CARVALHO, L.; PIERRO, G. V.; JUNIOR, C. T. SHRuB: searching through heuristics for the better query-execution plan. In: Brazilian Symposium on Databases - Demos and Applications Session. [S.1.]: SBC, 2014. Citado 2 vezes nas páginas 53 e 173.

BEDO, M. V. N.; SANTOS, D. P.; PONCIANO-SILVA, M.; AZEVEDO-MARQUES, P. M. de; TRAINA JR., C. Endowing a content-based medical image retrieval system with perceptual similarity using ensemble strategy. Journal of digital imaging, Springer, v. 29, n. 1, p. 22-37, 2016. Citado na página 174.

BEDO, M. V. N.; SANTOS, L. F. D.; OLIVEIRA, W. D.; BLANCO, G.; TRAINA, A. J. M.; FRADE, M. A.; MARQUES, P. M. A.; TRAINA JR., C. Color and texture influence on computeraided diagnosis of dermatological ulcers. In: International Symposium on Computer-Based Medical Systems. [S.1.]: IEEE, 2015c. p. 109-114. Citado na página 174.

BEDO, M. V. N.; TRAINA, A. J. M.; TRAINA JR., C. Seamless integration of distance functions and feature vectors for similarity-queries processing. Journal of Information and Data Management, v. 5, n. 3, p. 308-320, 2014. Citado na página 173.

BEHLEY, J.; STEINHAGE, V.; CREMERS, A. B. Efficient radius neighbor search in threedimensional point clouds. In: International Conference on Robotics and Automation. [S.1.]: IEEE, 2015. p. 3625-3630. Citado na página 79.

BELUSSI, A.; FALOUTSOS, C. Estimating the Selectivity of Spatial Queries Using the Correlation Fractal Dimension. In: International Conference of Very Large Databases. [S.1.]: Morgan Kaufmann Inc., 1995. p. 299-310. Citado 5 vezes nas páginas 33, 82, 84, 86 e 87.

BERCHTOLD, S.; BöHM, C.; KEIM, D. A.; KRIEGEL, H.-P. A cost model for nearest neighbor search in high-dimensional data space. In: Symposium on Principles of Database Systems. [S.1.]: ACM, 1997. p. 78-86. Citado na página 86.

BEYER, K.; GOLDSTEIN, J.; RAMAKRISHNAN, R.; SHAFT, U. When is "nearest neighbor" meaningful? In: International Conference on Database Theory. [S.1.]: Springer, 1999. p. 217-235. Citado 2 vezes nas páginas 148 e 149.

BEZDEK, J. C.; CHUAH, S. K.; LEEP, D. Generalized k-nearest neighbor rules. Fuzzy Sets and Systems, Elsevier, v. 18, n. 3, p. 237-256, 1986. Citado na página 47.

BLANCO, G.; BEDO, M. V. N.; CAZZOLATO, M. T.; SANTOS, L. F. D.; JORGE, A. E. S.; TRAINA JR., C.; AZEVEDO-MARQUES, P. M.; TRAINA, A. J. M. A label-scaled similarity measure for content-based image retrieval. In: International Symposium on Multimedia. [S.1.]: IEEE, 2016. p. 20-25. Citado na página 174.

BöHM, C.; KREBS, F. The k-Nearest Neighbour Join: Turbo Charging the KDD Process. Knowledge and Information Systems, v. 6, n. 6, p. 728-749, 2004. Citado 2 vezes nas páginas 47 e 52.

BOZKAYA, T.; OZSOYOGLU, M. Distance-based indexing for high-dimensional metric spaces. In: SIGMOD Record. [S.1.]: ACM, 1997. v. 26, n. 2, p. 357-368. Citado na página 62. 
BRIN, S. Near neighbor search in large metric spaces. In: International Conference on Very Large Data Bases. [S.1.]: Morgan Kaufmann Inc., 1995. p. 574-584. Citado na página 89.

BRUNO, N.; CHAUDHURI, S.; GRAVANO, L. ST-Holes: A Multidimensional Workload-aware Histogram. SIGMOD Record, ACM, v. 30, n. 2, p. 211-222, 2001. Citado 3 vezes nas páginas 68,77 e 90.

BUCCAFURRI, F.; LAX, G.; SACCà, D.; PONTIERI, L.; ROSACI, D. Enhancing Histograms by Tree-like Bucket Indices. The VLDB Journal, Springer, v. 17, n. 5, p. 1041-1061, 2008. Citado 3 vezes nas páginas 70, 76 e 77 .

BUDIKOVA, P.; BATKO, M.; ZEZULA, P. Query language for complex similarity queries. In: East European Conference on Advances in Databases and Information Systems. [S.1.]: Springer, 2012. p. 85-98. Citado na página 31.

BUGATTI, P. H.; TRAINA, A. J. M.; TRAINA JR., C. Assessing the best integration between distance-function and image-feature to answer similarity queries. In: Symposium On Applied Computing. [S.1.]: ACM, 2008. p. 1225-1230. Citado 3 vezes nas páginas 42, 44 e 45.

BUSTOS, B.; NAVARRO, G.; CHáVEZ, E. Pivot selection techniques for proximity searching in metric spaces. Pattern Recognition Letters, Elsevier Science Inc., v. 24, n. 14, p. 2357-2366, 2003. Citado 2 vezes nas páginas 80 e 100.

BUSTOS, B.; SKOPAL, T. Non-metric similarity search problems in very large collections. In: International Conference on Data Engineering. [S.1.]: IEEE, 2011. p. 1362-1365. Citado na página 42.

CAMASTRA, F.; VINCIARELLI, A. Estimating the intrinsic dimension of data with a fractalbased method. Transactions Pattern Analysis and Machine Intelligence, IEEE, v. 24, n. 10, p. 1404-1407, 2002. Citado 2 vezes nas páginas 83 e 88.

CARVALHO, L. O.; OLIVEIRA, W. D. de; POLA, I. R. V.; TRAINA, A. J.; TRAINA JR, C. A wider concept for similarity joins. Journal of Information and Data Management, v. 5, n. 3, p. 210, 2014. Citado na página 52.

CASANOVA, G.; ENGLMEIER, E.; HOULE, M. E.; KRÖGER, P.; NETT, M.; SCHUBERT, E.; ZIMEK, A. Dimensional testing for reverse k-nearest neighbor search. Proceedings of the VLDB Endowment, VLDB Endowment, v. 10, n. 7, p. 769-780, 2017. Citado 2 vezes nas páginas 45 e 48 .

CAZZOLATO, M. T.; BEDO, M. V. N.; COSTA, A. F.; SOUZA, J. A.; TRAINA JR., C.; JR., J. F. R.; TRAINA, A. J. M. Unveiling smoke in social images with the smokeblock approach. In: Symposium on Applied Computing. [S.1.]: ACM, 2016. p. 49-54. Citado na página 174.

CHA, S.-H. Comprehensive survey on distance/similarity measures between probability density functions. International Journal of Mathematical Models and methods in Applied Sciences, v. 1, n. 2, p. 8, 2007. Citado na página 43.

CHAUDHURI, S.; NARASAYYA, V. Self-tuning database systems: A decade of progress. In: International Conference on Very Large Data Bases. [S.1.]: VLDB Endowment, 2007. p. 3-14. Citado na página 38. 
CHÁVEZ, E.; MARROQUÍN, J. L.; BAEZA-YATES, R. Spaghettis: An array based algorithm for similarity queries in metric spaces. In: International Workshop on Groupware and String Processing and Information Retrieval Symposium. [S.1.]: IEEE, 1999. p. 38-46. Citado 2 vezes nas páginas 54 e 61.

CHÁVEZ, E.; NAVARRO, G.; BAEZA-YATES, R.; MARROQUÍN, J. L. Searching in metric spaces. Computing Surveys, ACM, v. 33, n. 3, p. 273-321, 2001. Citado 5 vezes nas páginas $29,30,45,56$ e 59.

CHEN, L.; GAO, Y.; LI, X.; JENSEN, C. S.; CHEN, G. Efficient metric indexing for similarity search. In: International Conference on Data Engineering. [S.1.]: IEEE, 2015. p. 591-602. Citado 2 vezes nas páginas 54 e 63.

Efficient metric indexing for similarity search and similarity joins. Transactions on Knowledge and Data Engineering, IEEE, v. 29, n. 3, p. 556-571, 2017. Citado 3 vezes nas páginas 64,86 e 89.

CHEN, L.; GAO, Y.; ZHENG, B.; JENSEN, C. S.; YANG, H.; YANG, K. Pivot-based metric indexing. Proceedings of the VLDB Endowment, VLDB Endowment, v. 10, n. 10, p. 10581069, 2017. Citado 5 vezes nas páginas 31, 34, 56, 63 e 171.

CHRISTODOULAKIS, S. Implications of certain assumptions in database performance evauation. Transactions on Database Systems, ACM, v. 9, n. 2, p. 163-186, 1984. Citado 3 vezes nas páginas 33, 82 e 87.

CIACCIA, P.; NANNI, A.; PATELLA, M. A query-sensitive cost model for similarity queries with m-tree. In: Australasian Database Conference. [S.1.]: Springer, 1999. p. 65-76. Citado 2 vezes nas páginas 86 e 89.

CIACCIA, P.; PATELLA, M.; ZEZULA, P. M-tree: An efficient access method for similarity search in metric spaces. In: International Conference on Very Large Data Bases. [S.1.]: Morgan Kaufmann Inc., 1997. p. 426-435. Citado 6 vezes nas páginas 31, 34, 54, 56, 60 e 111.

A cost model for similarity queries in metric spaces. In: Symposium on Principles of Database Systems. [S.1.]: ACM, 1998. p. 59-68. Citado 11 vezes nas páginas 32, 33, 47, 86, $87,89,90,110,111,112$ e 114.

CLARKSON, K. L. Nearest neighbor queries in metric spaces. In: Symposium on Theory of Computing. [S.1.]: ACM, 1997. p. 609-617. Citado na página 42.

CODD, E. F. A relational model of data for large shared data banks. Communications of the ACM, ACM, v. 13, n. 6, p. 377-387, 1970. Citado 3 vezes nas páginas 29, 45 e 51.

COHEN, E.; GROSSAUG, N.; KAPLAN, H. Processing top k queries from samples. In: CoNEXT Conference. [S.1.]: ACM, 2006. p. 7:1-7:12. Citado na página 69.

CORMODE, G.; GAROFALAKIS, M.; HAAS, P. J.; JERMAINE, C. Synopses for massive data: Samples, histograms, wavelets, sketches. Foundations and Trends in Databases, Now Publishers Inc., v. 4, n. 1-3, p. 1-294, 2012. Citado 5 vezes nas páginas 32, 69, 72, 76 e 82.

CORRAL, A.; MANOLOPOULOS, Y.; THEODORIDIS, Y.; VASSILAKOPOULOS, M. Cost models for distance joins queries using R-trees. Data \& Knowledge Engineering, Elsevier, v. 57, n. 1, p. 1-36, 2006. Citado na página 86. 
CSISZÁR, I.; SHIELDS, P. C. Information theory and statistics: A tutorial. Foundations and Trends $\mathbb{R}$ in Communications and Information Theory, Now Publishers, Inc., v. 1, n. 4, p. 417-528, 2004. Citado na página 42.

CUNNINGHAM, J. P.; GHAHRAMANI, Z. Linear dimensionality reduction: Survey, insights, and generalizations. Journal of Machine Learning Research, JMLR.org, v. 16, n. 1, p. 28592900, 2015. Citado na página 151.

DAGAN, I.; LEE, L.; PEREIRA, F. Similarity-based methods for word sense disambiguation. In: Annual Meeting of the Association for Computational Linguistics. [S.1.]: Association for Computational Linguistics, 1997. p. 56-63. Citado na página 42.

DATE, C. J. SQL and relational theory: how to write accurate SQL code. [S.1.]: O'Reilly Media, Inc., 2011. Citado 4 vezes nas páginas 45, 51, 52 e 53.

DEMSAR, J. Statistical comparisons of classifiers over multiple data sets. Journal of Machine Learning Research, JMLR.org, v. 7, p. 1-30, 2006. Citado na página 103.

DEPEURSINGE, A.; VARGAS, A.; PLATON, A.; GEISSBUHLER, A.; POLETTI, P.-A.; MÜLLER, H. 3D Case-Based Retrieval for Interstitial Lung Diseases. In: Medical ContentBased Retrieval for Clinical Decision Support. [S.1.]: Springer, 2010. p. 39-48. Citado na página 30.

DESCHACHT, K.; MOENS, M.-F. Semi-supervised semantic role labeling using the latent words language model. In: Conference on Empirical Methods in Natural Language Processing. [S.1.]: Association for Computational Linguistics, 2009. p. 21-29. Citado na página 41.

DESELAERS, T.; KEYSERS, D.; NEY, H. Features for image retrieval: an experimental comparison. Information Retrieval, Springer, v. 11, n. 2, p. 77-107, 2008. Citado na página 44.

DESHPANDE, A.; GAROFALAKIS, M.; RASTOGI, R. Independence is Good: Dependencybased Histogram Synopses for High-dimensional Data. In: International Conference on Management of Data. [S.1.]: ACM, 2001. p. 199-210. Citado na página 69.

DEVROYE, L. Sample-based non-uniform random variate generation. In: Conference on Winter Simulation. [S.1.]: ACM, 1986. p. 260-265. Citado 2 vezes nas páginas 69 e 70.

DICE, L. R. Measures of the amount of ecologic association between species. Ecology, Wiley Online Library, v. 26, n. 3, p. 297-302, 1945. Citado na página 161.

DROSOU, M.; JAGADISH, H.; PITOURA, E.; STOYANOVICH, J. Diversity in big data: A review. Big Data, Mary Ann Liebert, Inc., v. 5, n. 2, p. 73-84, 2017. Citado na página 49.

DROSOU, M.; PITOURA, E. Search result diversification. SIGMOD Record, ACM, v. 39, n. 1, p. 41-47, 2010. Citado 2 vezes nas páginas 45 e 49.

DURRANT, R. J.; KABÁN, A. When is 'nearest neighbour' meaningful: A converse theorem and implications. Journal of Complexity, Elsevier, v. 25, n. 4, p. 385-397, 2009. Citado 4 vezes nas páginas 32, 34, 37 e 150 .

ESTAN, C.; NAUGHTON, J. F. End-biased samples for join cardinality estimation. In: International Conference on Data Engineering. [S.1.]: IEEE, 2006. p. 1-20. Citado na página 73. 
FALOUTSOS, C.; LIN, K. FastMap: A Fast Algorithm for Indexing, Data-Mining and Visualization of Traditional and Multimedia Datasets. In: SIGMOD Record. [S.1.]: ACM, 1995. p. 163-174. Citado na página 150.

FERREIRA, M. R.; SANTOS, L. F.; TRAINA, A. J.; DIAS, I.; CHBEIR, R.; TRAINA JR., C. Algebraic properties to optimize knn queries. Journal of Information and Data Management, v. 2, n. 3 , p. 385, 2011. Citado 4 vezes nas páginas 31, 46, 51 e 52.

FRANCE, S.; CARROLL, D. Is the Distance Compression Effect Overstated? Some Theory and Experimentation. In: International Workshop on Machine Learning and Data Mining in Pattern Recognition. [S.1.]: Springer, 2009. p. 280-294. Citado na página 151.

FRANCOIS, D.; WERTZ, V.; VERLEYSEN, M. The concentration of fractional distances. Transactions on Knowledge and Data Engineering, IEEE, v. 19, n. 7, p. 873-886, 2007. Citado 6 vezes nas páginas 32, 34, 37, 149, 151 e 154.

FREDRIKSSON, K. Geometric near-neighbor access tree (gnat) revisited. Pattern Recognition Letters (No prelo), 2017. Citado na página 89.

GANTER, B.; WILLE, R. Formal concept analysis: mathematical foundations. [S.1.]: Springer Science \& Business Media, 2012. Citado na página 29.

GARCIA-MOLINA, H.; ULLMAN, J. D.; WIDOM, J. Database system implementation. [S.1.]: Prentice Hall, 2000. v. 654. Citado 7 vezes nas páginas 31, 37, 52, 53, 67, 69 e 72.

GARCIA, S.; HERRERA, F. An extension on "Statistical comparisons of classifiers over multiple data sets" for all pairwise comparisons. Journal of Machine Learning Research, JMLR.org, v. 9, p. 2677-2694, 2008. Citado na página 103.

GIANNELLA, C.; SAYRAFI, B. An information theoretic histogram for single dimensional selectivity estimation. In: Symposium on Applied Computing. [S.1.]: ACM, 2005. p. 676-677. Citado na página 74.

GRAEFE, G. The cascades framework for query optimization. Data Engineering Bulletin Issues, IEEE, v. 18, n. 3, p. 19-29, 1995. Citado 3 vezes nas páginas 31, 33 e 67.

Modern B-Tree Techniques. Foundation and Trends in databases, Now Publishers Inc., v. 3, n. 4, p. 203-402, 2011. Citado na página 63.

GRAEFE, G.; MCKENNA, W. J. The volcano optimizer generator: Extensibility and efficient search. In: International Conference on Data Engineering. [S.1.]: IEEE, 1993. p. 209-218. Citado 3 vezes nas páginas 31, 32 e 68 .

GUHA, S.; SHIM, K. A note on linear time algorithms for maximum error histograms. Transactions on Knowledge and Data Engineering, IEEE, v. 19, n. 7, p. 993-997, 2007. Citado 3 vezes nas páginas 74,75 e 76.

GUNOPULOS, D.; KOLLIOS, G.; TSOTRAS, V. J.; DOMENICONI, C. Approximating multidimensional aggregate range queries over real attributes. In: SIGMOD Record. [S.1.]: ACM, 2000. v. 29, n. 2, p. 463-474. Citado na página 77.

GUTTMAN, A. R-trees: A dynamic index structure for spatial searching. [S.1.]: ACM, 1984. v. 14 . Citado 3 vezes nas páginas 64,77 e 87. 
HAFNER, J.; SAWHNEY, H. S.; EQUITZ, W.; FLICKNER, M.; NIBLACK, W. Efficient color histogram indexing for quadratic form distance functions. Transactions on Pattern Analysis and Machine Intelligence, IEEE, v. 17, n. 7, p. 729-736, 1995. Citado na página 43.

HAMMING, R. W. Error detecting and error correcting codes. Bell Labs Technical Journal, Wiley Online Library, v. 29, n. 2, p. 147-160, 1950. Citado na página 43.

HE, Z.; LEE, B. S.; WANG, X. S. Proactive and reactive multi-dimensional histogram maintenance for selectivity estimation. Journal of Systems and Software, Elsevier Science Inc., v. 81, n. 3, p. 414-430, 2008. Citado na página 76.

HELLERSTEIN, J. M.; RÉ, C.; SCHOPPMANN, F.; WANG, D. Z.; FRATKIN, E.; GORAJEK, A.; NG, K. S.; WELTON, C.; FENG, X.; LI, K. The MADlib analytics library. Proceedings of the VLDB Endowment, VLDB Endowment, v. 5, n. 12, p. 1700-1711, 2012. Citado na página 68 .

HINNEBURG, A.; AGGARWAL, C. C.; KEIM, D. A. What is the nearest neighbor in high dimensional spaces? Proceedings of the VLDB Endowment, VLDB Endowment, p. 506-515, 2000. Citado na página 149.

HINTON, G. E.; KRIZHEVSKY, A.; WANG, S. D. Transforming auto-encoders. In: HONKELA, T.; DUCH, W.; GIROLAMI, M.; KASKI, S. (Ed.). International Conference on Artificial Neural Networks. [S.1.]: Springer, 2011. p. 44-51. Citado 2 vezes nas páginas 43 e 44.

HJALTASON, G. R.; SAMET, H. Incremental distance join algorithms for spatial databases. In: International Conference on Management of Data. [S.1.]: ACM, 1998. p. 237-248. Citado na página 60.

Distance browsing in spatial databases. Transactions on Database Systems, ACM, v. 24, n. 2, p. 265-318, 1999. Citado na página 34.

Index-driven similarity search in metric spaces (survey article). Transactions on Database Systems, ACM, v. 28, n. 4, p. 517-580, 2003. Citado 4 vezes nas páginas 34, 60, 111 e 171.

HOULE, M. E.; KRIEGEL, H.-P.; KRÖGER, P.; SCHUBERT, E.; ZIMEK, A. Can sharedneighbor distances defeat the curse of dimensionality? In: International Conference on Scientific and Statistical Database Management. [S.1.]: Springer, 2010. p. 482-500. Citado na página 30 .

HSU, C.-M.; CHEN, M.-S. On the design and applicability of distance functions in highdimensional data space. Transactions on Knowledge and Data Engineering, IEEE, v. 21, p. 523-536, 2008. Citado na página 151.

HUTTENLOCHER, D. P.; KLANDERMAN, G. A.; RUCKLIDGE, W. J. Comparing images using the hausdorff distance. Transactions on Pattern Analysis and Machine Intelligence, IEEE, v. 15, n. 9, p. 850-863, 1993. Citado na página 43.

IOANNIDIS, Y. The history of histograms (abridged). In: International conference on Very large Data Bases. [S.1.]: VLDB Endowment, 2003. p. 19-30. Citado 3 vezes nas páginas 70, 71 e 75.

IOANNIDIS, Y. E. Universality of serial histograms. In: International Conference on Very Large Data Bases. [S.1.]: Morgan Kaufmann Inc., 1993b. p. 256-267. Citado 2 vezes nas páginas 71 e 72 . 
. Query optimization. Computing Surveys, ACM, v. 28, n. 1, p. 121-123, 1996. Citado 4 vezes nas páginas $31,32,33$ e 74 .

IOANNIDIS, Y. E.; CHRISTODOULAKIS, S. Optimal histograms for limiting worst-case error propagation in the size of join results. Transactions on Database Systems, ACM, v. 18, n. 4, p. 709-748, 1993. Citado 5 vezes nas páginas 33, 67, 69, 74 e 75.

JACCARD, P. The distribution of the flora in the alpine zone. New phytologist, Wiley Online Library, v. 11, n. 2, p. 37-50, 1912. Citado na página 43.

JACOBS, D.; WEINSHALL, D.; GDALYAHU, Y. Class representation and image retrieval with non-metric distances. Transaction on Pattern Analysis and Machine Intelligence, IEEE, v. 22, n. 6, p. 583-600, 2000. Citado na página 42.

JAGADISH, H. V.; JIN, H.; OOI, B. C.; TAN, K.-L. Global optimization of histograms. In: International Conference on Management of Data. [S.1.]: ACM, 2001. p. 223-234. Citado 4 vezes nas páginas $68,72,74$ e 95 .

JIN, L.; KOUDAS, N.; LI, C. Nnh: Improving performance of nearest-neighbor searches using histograms. In: International Conference on Extending Database Technology. [S.1.]: Springer, 2004. p. 385-402. Citado 5 vezes nas páginas 33, 34, 79, 80 e 90.

KABáN, A. On the distance concentration awareness of certain data reduction techniques. Pattern Recognition, Elsevier Science Inc., v. 44, n. 2, p. 265-277, 2011. Citado na página 150.

KABÁN, A. Non-parametric detection of meaningless distances in high dimensional data. Statistics and Computing, Springer, v. 22, n. 2, p. 375-385, 2012. Citado 2 vezes nas páginas 34 e 151.

KANELLAKIS, P. C. Elements of relational database theory. [S.1.]: Brown University, Department of Computer Science, 1989. Citado 2 vezes nas páginas 29 e 51.

KANNE, C.-C.; MOERKOTTE, G. Histograms reloaded: The merits of bucket diversity. In: International Conference on Management of Data. [S.1.]: ACM, 2010. p. 663-674. Citado na página 71.

KASTER, D. S.; BUGATTI, P. H.; TRAINA, A. J. M.; TRAINA JR, C. Fmi-sir: A flexible and efficient module for similarity searching on oracle database. Journal of Information and Data Management, v. 1, n. 2, p. 229, 2010. Citado na página 31.

KASTRATI, F.; MOERKOTTE, G. Optimization of conjunctive predicates for main memory column stores. Proceedings of VLDB Endowment, VLDB Endowment, v. 9, n. 12, p. 1125 1136, 2016. Citado na página 68.

KAUFMAN, L.; ROUSSEEUW, P. Clustering by means of medoids. [S.1.]: North-Holland, 1987. Citado 2 vezes nas páginas 81 e 138.

KEOGH, E.; RATANAMAHATANA, C. A. Exact indexing of dynamic time warping. Knowledge and Information Systems, Springer, v. 7, n. 3, p. 358-386, 2005. Citado na página 42. 
KIM, S. J.; AL-KATEB, M.; SINCLAIR, P.; CROLOTTE, A.; ZHANG, C.; ROSE, L. Dynamic Statistics Collection in the Teradata Unified Data Architecture. In: International Conference on Data Engineering. [S.1.]: IEEE, 2017. p. 255-258. Citado 2 vezes nas páginas 29 e 68.

KINOSHITA, S. K.; AZEVEDO-MARQUES, P. M. de; PEREIRA, R. R.; RODRIGUES, J. A. H.; RANGAYYAN, R. M. Content-based retrieval of mammograms using visual features related to breast density patterns. Journal of Digital Imaging, Springer, v. 20, n. 2, p. 172-190, 2007. Citado na página 44.

KÖNIG, A.; WEIKUM, G. Combining histograms and parametric curve fitting for feedbackdriven query result-size estimation. In: International Conference on Very Large Data Bases. [S.1.]: Morgan Kaufmann Inc., 1999. p. 423-434. Citado na página 75.

A framework for the physical design problem for data synopses. Advances in Database Technology, Springer, p. 627-645, 2002. Citado 4 vezes nas páginas 32, 72, 75 e 76.

KORN, F.; MUTHUKRISHNAN, S. Influence Sets Based on Reverse Nearest Neighbor Queries. In: International Conference on Management of Data. [S.1.]: ACM, 2000. p. 201-212. Citado 3 vezes nas páginas 48, 52 e 151 .

KORN, F.; PAGEL, B.; FALOUTSOS, C. On the 'Dimensionality Curse' and the 'Self-Similarity Blessing'. Transactions on Knowledge and Data Engineering, IEEE, v. 13, n. 1, p. 96-111, 2001. Citado 5 vezes nas páginas 69, 78, 82, 83 e 87.

KORTH, H.; SUDARSHAN, S.; SILBERSCHATZ, A. Database System Concepts. [S.1.]: McGraw-Hill Education, 2010. ISBN 9780073523323. Citado 6 vezes nas páginas 29, 33, 37, 38,54 e 67.

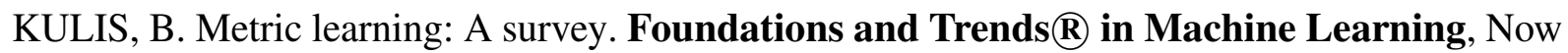
Publishers, Inc., v. 5, n. 4, p. 287-364, 2013. Citado na página 45.

LECUN, Y.; BENGIO, Y.; HINTON, G. Deep learning. Nature, Nature Research, v. 521, n. 7553, p. 436-444, 2015. Citado na página 44.

LEVENSHTEIN, V. I. Binary codes capable of correcting deletions, insertions, and reversals. In: Soviet physics doklady. [S.1.: s.n.], 1966. v. 10, n. 8, p. 707-710. Citado 2 vezes nas páginas 33 e 43.

LI, C.; CHANG, K. C.-C.; ILYAS, I. F.; SONG, S. RankSQL: Query Algebra and Optimization for Relational Top-k Queries. In: International Conference on Management of Data. [S.l.]: ACM, 2005. p. 131-142. Citado na página 51.

LIPKUS, A. H. A proof of the triangle inequality for the tanimoto distance. Journal of Mathematical Chemistry, Springer, v. 26, n. 1, p. 263-265, 1999. Citado na página 42.

LIU, Y.; ZHANG, D.; LU, G.; MA, W.-Y. A survey of content-based image retrieval with high-level semantics. Pattern recognition, Elsevier, v. 40, n. 1, p. 262-282, 2007. Citado 3 vezes nas páginas 41,43 e 44.

LOKOČ, J.; BLAŽEK, A.; SKOPAL, T. On effective known item video search using feature signatures. In: International Conference on Multimedia Retrieval. [S.1.]: ACM, 2014. p. 524. Citado na página 30. 
LOKOČ, J.; GROŠUP, T.; SKOPAL, T. Sir: The smart image retrieval engine. In: International Conference on Similarity Search and Applications. [S.1.]: Springer, 2012. p. 240-241. Citado 3 vezes nas páginas 30,31 e 35 .

LOWE, D. G. Distinctive image features from scale-invariant keypoints. International Journal of Computer Vision, Springer, v. 60, n. 2, p. 91-110, 2004. Citado na página 44.

MANDELBROT, B. B. Self-affine fractals and fractal dimension. Physica scripta, IOP Publishing, v. 32, n. 4, p. 257, 1985. Citado na página 82.

MANJUNATH, B. S.; SALEMBIER, P.; SIKORA, T. Introduction to MPEG-7: multimedia content description interface. [S.1.]: John Wiley \& Sons, 2002. v. 1. Citado na página 43.

MAO, R.; MIRANKER, W. L.; MIRANKER, D. P. Pivot selection: Dimension reduction for distance-based indexing. Journal of Discrete Algorithms, Elsevier, v. 13, p. 32-46, 2012. Citado na página 63.

MARRI, W. J. A.; MALLUHI, Q.; OUZZANI, M.; TANG, M.; AREF, W. G. The similarity-aware relational intersect database operator. In: International Conference on Similarity Search and Applications. [S.1.]: Springer, 2014. p. 164-175. Citado na página 31.

The similarity-aware relational database set operators. Information Systems, Elsevier, v. 59, p. 79-93, 2016. Citado na página 30.

MIC, V.; NOVAK, D.; ZEZULA, P. Speeding up similarity search by sketches. In: International Conference on Similarity Search and Applications. [S.1.]: Springer, 2016. p. 250-258. Citado na página 70.

MICÓ, L.; ONCINA, J.; CARRASCO, R. C. A fast branch \& bound nearest neighbour classifier in metric spaces. Pattern Recognition Letters, Elsevier, v. 17, n. 7, p. 731-739, 1996. Citado na página 61.

MIKOLAJCZYK, K.; SCHMID, C. A performance evaluation of local descriptors. Transactions on Pattern Analysis and Machine Intelligence, IEEE, v. 27, n. 10, p. 1615-1630, 2005. Citado na página 44.

MINKOWSKI, H. Zur Geometrie der zahlen. [S.1.]: Leipzig: Teubner, 1910. v. 1. Citado na página 42.

MORRIS, R. The dilogarithm function of a real argument. Mathematics of Computation, v. 33, n. 146, p. 778-787, 1979. Citado na página 156.

MOŠKO, J.; LOKOČ, J.; SKOPAL, T. Clustered pivot tables for i/o-optimized similarity search. In: International Conference on Similarity Search and Applications. [S.1.]: ACM, 2011. p. 17-24. Citado 4 vezes nas páginas 54, 56, 62 e 80.

MURALIKRISHNA, M.; DEWITT, D. J. Equi-depth multidimensional histograms. SIGMOD Record, ACM, v. 17, n. 3, p. 28-36, 1988. Citado 4 vezes nas páginas 15, 76, 77 e 90.

NAVARRO, G.; NEKRICH, Y. Top-k document retrieval in optimal time and linear space. In: Symposium on Discrete Algorithms. [S.1.]: Society for Industrial and Applied Mathematics, 2012. p. 1066-1077. Citado na página 30. 
NAVARRO, G.; PAREDES, R.; REYES, N.; BUSTOS, C. An empirical evaluation of intrinsic dimension estimators. Information Systems, v. 64, p. 206-218, 2017. Citado 2 vezes nas páginas 38 e 151 .

NIXON, M. S.; AGUADO, A. S. Feature extraction \& image processing for computer vision. [S.1.]: Academic Press, 2012. Citado na página 43.

NOVAK, D.; BATKO, M.; ZEZULA, P. Metric index: An efficient and scalable solution for precise and approximate similarity search. Information Systems, Elsevier, v. 36, n. 4, p. 721733, 2011. Citado na página 31.

OSBORNE, J. W.; OVERBAY, A. The power of outliers (and why researchers should always check for them). Practical assessment, research \& evaluation, v. 9, n. 6, p. 1-12, 2004. Citado na página 75 .

O'SEARCOID, M. Metric spaces. [S.1.]: Springer Science \& Business Media, 2006. Citado 2 vezes nas páginas 42 e 43 .

PANG, C.; ZHANG, Q.; ZHOU, X.; HANSEN, D.; WANG, S.; MAEDER, A. Computing unrestricted synopses under maximum error bound. Algorithmica, v. 65, n. 1, p. 1-42, 2013. Citado na página 69.

PAVLO, A.; PAULSON, E.; RASIN, A.; ABADI, D. J.; DEWITT, D. J.; MADDEN, S.; STONEBRAKER, M. A comparison of approaches to large-scale data analysis. In: International Conference on Management of Data. [S.1.]: ACM, 2009. p. 165-178. Citado na página 29.

PEARSON, K. On lines and planes of closest fit to systems of points in space. Philosophical Magazine and Journal of Science, Taylor \& Francis, v. 2, n. 11, p. 559-572, 1901. Citado na página 150.

PERES-NETO, P. R.; JACKSON, D. A.; SOMERS, K. M. How many principal components? Stopping rules for determining the number of non-trivial axes revisited. Computational Statistics \& Data Analysis, Elsevier, v. 49, n. 4, p. 974-997, 2005. Citado na página 151.

PESTOV, V. On the geometry of similarity search: dimensionality curse and concentration of measure. Information Processing Letters, Elsevier, v. 73, n. 1-2, p. 47-51, 2000. Citado 3 vezes nas páginas 30, 32 e 151.

Indexability, concentration, and VC theory. Journal of Discrete Algorithms, Elsevier, v. 13, p. 2-18, 2012. Citado na página 151.

Is the k-nn classifier in high dimensions affected by the curse of dimensionality? Computers \& Mathematics with Applications, Elsevier, v. 65, n. 10, p. 1427-1437, 2013. Citado 3 vezes nas páginas 30,37 e 77 .

PHAM, H. T. A.; SEVCIK, K. C. Structure choices for two-dimensional histogram construction. In: Conference of the Centre for Advanced Studies on Collaborative Research. [S.1.]: IBM Press, 2004. p. 13-27. Citado 2 vezes nas páginas 68 e 76.

PIERRO, G. V.; FERREIRA, M. R. P.; OLIVEIRA, W. D. d.; SANTOS, L. F. D.; TRAINA, A. J. M.; TRAINA JR, C. Embedding $k$-nearest neighbor queries into relational database management systems. Journal of Information and Data Management, v. 5, n. 1, p. 1-14, 2014. Citado na página 47. 
POOSALA, V.; HAAS, P. J.; IOANNIDIS, Y. E.; SHEKITA, E. J. Improved histograms for selectivity estimation of range predicates. SIGMOD Record, ACM, v. 25, n. 2, p. 294-305, 1996. Citado na página 75.

POOSALA, V.; IOANNIDIS, Y. E. Selectivity estimation without the attribute value independence assumption. In: International conference on Very large Data Bases. [S.1.]: Morgan Kaufmann Inc., 1997. v. 97, p. 486-495. Citado 3 vezes nas páginas 74, 77 e 90.

RADOVANOVIĆ, M.; NANOPOULOS, A.; IVANOVIĆ, M. Hubs in space: Popular nearest neighbors in high-dimensional data. Journal of Machine Learning Research, JMLR.org, v. 11, p. 2487-2531, 2010. Citado 2 vezes nas páginas 45 e 49.

RAZAVIAN, A. S.; AZIZPOUR, H.; SULLIVAN, J.; CARLSSON, S. Cnn features off-theshelf: an astounding baseline for recognition. In: Conference on Computer Vision and Pattern Recognition. [S.1.]: IEEE, 2014. p. 806-813. Citado na página 44.

REED, T.; DUBUF, J. A review of recent texture segmentation and feature extraction techniques. Computer Vision and Image Understanding, Elsevier Science Inc., v. 57, n. 3, p. 359 - 372, 1993. Citado na página 43.

ROUSSOPOULOS, N.; KELLEY, S.; VINCENT, F. Nearest neighbor queries. In: Sigmod record. [S.1.]: ACM, 1995. v. 24, n. 2, p. 71-79. Citado 2 vezes nas páginas 48 e 59.

RUBNER, Y.; TOMASI, C.; GUIBAS, L. J. The earth mover's distance as a metric for image retrieval. International Journal of Computer Vision, Springer, v. 40, n. 2, p. 99-121, 2000. Citado na página 42.

RUIZ, G.; SANTOYO, F.; CHÁVEZ, E.; FIGUEROA, K.; TELLEZ, E. S. Extreme pivots for faster metric indexes. In: International Conference on Similarity Search and Applications. [S.1.]: Springer, 2013. p. 115-126. Citado na página 61.

SADAGOPAN, T.; MADABHUSHANAM, R.; PASALAPUDI, S.; BRUNET, D.; ELS, A.; ANTHONY, J.; LAWLESS, C.; VISSER, A. Oracle Databases on Amazon Web Services: A Foundational Approach. [S.1.]: Elsevier Science \& Technology, 2017. Citado na página 29.

SAMET, H. Foundations of multidimensional and metric data structures. [S.1.]: Morgan Kaufmann, 2006. Citado 3 vezes nas páginas 29, 45 e 59.

K-nearest neighbor finding using maxnearestdist. Transactions on Pattern Analysis and Machine Intelligence, IEEE, v. 30, n. 2, p. 243-252, 2008. Citado na página 34.

Foundations of nearest neighbor queries in euclidean space. In: Encyclopedia of GIS (No prelo). [S.1.]: Springer, 2017. Citado na página 79.

SANTOS, L. F.; BEDO, M. V.; PONCIANO-SILVA, M.; TRAINA, A. J.; TRAINA JR., C. Being similar is not enough: how to bridge usability gap through diversity in medical images. In: International Symposium on Computer-Based Medical Systems. [S.1.]: IEEE, 2014. p. 287-293. Citado 2 vezes nas páginas 50 e 174.

SANTOS, L. F. D.; OLIVEIRA, W. D.; FERREIRA, M. R. P.; TRAINA, A. J. M.; TRAINA JR., C. Parameter-free and domain-independent similarity search with diversity. In: International Conference on Scientific and Statistical Database Management. [S.1.]: ACM, 2013. p. 5:15:12. Citado 3 vezes nas páginas 49, 50 e 138. 
SAPPELLI, M.; VERBERNE, S.; KRAAIJ, W. Evaluation of context-aware recommendation systems for information re-finding. Journal of the Association for Information Science and Technology, Wiley Online Library, v. 68, n. 4, p. 895-910, 2017. Citado na página 41.

ŞARDAN, C. Efficient k-nearest neighbor query processing in metric spaces based on precise radius estimation. Tese (Doutorado) - Bilkent University, 2009. Citado 2 vezes nas páginas 85 e 90.

SCHWEIZER, B.; SKLAR, A. Probabilistic metric spaces. [S.1.]: Courier Corporation, 2011. Citado na página 43.

SEDMIDUBSKY, J.; MIC, V.; ZEZULA, P. Face image retrieval revisited. In: International Conference on Similarity Search and Applications. [S.1.]: Springer, 2015. p. 204-216. Citado na página 30.

SHARMA, M.; SINGH, S. Evaluation of texture methods for image analysis. In: Australian and New Zealand Intelligent Information Systems Conference. [S.1.]: IEEE, 2001. p. 117-121. Citado na página 43.

SIDDIQUIE, B.; GUPTA, A. Beyond active noun tagging: Modeling contextual interactions for multi-class active learning. In: Conference on Computer Vision and Pattern Recognition. [S.1.]: IEEE, 2010. p. 2979-2986. Citado na página 41.

SILVA, Y. N.; ALY, A. M.; AREF, W. G.; LARSON, P.-A. SimDB: A Similarity-aware Database System. In: International Conference on Management of Data. [S.1.]: ACM, 2010. p. 12431246. Citado 4 vezes nas páginas 30, 31, 35 e 54 .

SILVA, Y. N.; AREF, W. G.; ALI, M. H. The similarity join database operator. In: International Conference on Data Engineering. [S.1.]: IEEE, 2010b. p. 892-903. Citado 2 vezes nas páginas 33 e 52.

SILVA, Y. N.; AREF, W. G.; LARSON, P.-A.; PEARSON, S. S.; ALI, M. H. Similarity queries: their conceptual evaluation, transformations, and processing. The VLDB Journal, v. 22, n. 3, p. 395-420, 2013. Citado 7 vezes nas páginas 30, 31, 41, 46, 51, 52 e 68.

SIM, K.; GOPALKRISHNAN, V.; ZIMEK, A.; CONG, G. A survey on enhanced subspace clustering. Data Mining and Knowledge Discovery, Springer, v. 26, n. 2, p. 332-397, 2013. Citado na página 30.

SKOPAL, T. Unified framework for fast exact and approximate search in dissimilarity spaces. Transactions on Database Systems, ACM, v. 32, n. 4, p. 29, 2007. Citado na página 54.

Where Are You Heading, Metric Access Methods?: A Provocative Survey. In: International Conference on Similarity Search and Applications. [S.1.]: ACM, 2010. p. 13-21. Citado na página 171.

SKOPAL, T.; POKORNỲ, J.; SNASEL, V. PM-tree: Pivoting Metric Tree for Similarity Search in Multimedia Databases. In: European Conference on Advances in Databases and Information Systems. [S.1.]: Springer, 2004. Citado 6 vezes nas páginas 31, 54, 57, 63, 86 e 90 .

SKOPAL, T.; POKORNỲ, J.; SNÁSEL, V. Nearest Neighbours Search using the PM-tree. In: International Conference on Database Systems for Advanced Applications. [S.1.]: Springer, 2005. v. 5, p. 803-815. Citado 2 vezes nas páginas 56 e 63. 
STEFANIDIS, K.; PITOURA, E.; VASSILIADIS, P. Adding Context to Preferences. In: International Conference on Data Engineering. [S.1.]: IEEE, 2007. p. 846-855. Citado na página 29.

STONEBRAKER, M.; CETINTEMEL, U. "One size fits all”: an idea whose time has come and gone. In: International Conference on Data Engineering. [S.1.]: Springer, 2005. p. 2-11. Citado na página 65.

STONEBRAKER, M.; ROWE, L. A. The design of Postgres. [S.1.]: ACM, 1986. v. 15. Citado 2 vezes nas páginas 29 e 54 .

STONEBRAKER, M.; WEISBERG, A. The VoltDB Main Memory DBMS. Data Engineering Bulletin Issues, IEEE, v. 36, n. 2, p. 21-27, 2013. Citado 2 vezes nas páginas 29 e 67.

TANG, J.; RANGAYYAN, R. M.; XU, J.; NAQA, I. E.; YANG, Y. Computer-aided detection and diagnosis of breast cancer with mammography: recent advances. Transactions on Information Technology in Biomedicine, IEEE, v. 13, n. 2, p. 236-251, 2009. Citado na página 44.

TANG, M.; TAHBOUB, R. Y.; AREF, W. G.; ATALLAH, M. J.; MALLUHI, Q. M.; OUZZANI, M.; SILVA, Y. N. Similarity group-by operators for multi-dimensional relational data. Transactions on Knowledge and Data Engineering, IEEE, v. 28, n. 2, p. 510-523, 2016. Citado 2 vezes nas páginas 31 e 52.

TANGELDER, J. W.; VELTKAMP, R. C. A survey of content based 3d shape retrieval methods. In: Shape Modeling Applications. [S.1.]: IEEE, 2004. p. 145-156. Citado na página 30.

TAO, Y.; ZHANG, J.; P., D.; MAMOULIS, N. An efficient model for optimization of kNN in low and medium dimensional spaces. Transactions on Knowledge and Data Engineering, IEEE, v. 16, n. 10, p. 1169-1184, 2004. Citado 6 vezes nas páginas 33, 34, 60, 79, 86 e 87.

TASAN, M.; OZSOYOGLU, Z. M. Improvements in distance-based indexing. In: Scientific and Statistical Database Management. [S.1.]: IEEE, 2004. p. 161-170. Citado 10 vezes nas páginas 32, 33, 34, 47, 68, 79, 81, 88, 89 e 90.

TOMAŠEV, N.; RADOVANOVIĆ, M.; MLADENIĆ, D.; IVANOVIĆ, M. Hubness-based fuzzy measures for high-dimensional k-nearest neighbor classification. International Journal of Machine Learning and Cybernetics, Springer, v. 5, n. 3, p. 445-458, 2014. Citado 2 vezes nas páginas 30 e 49 .

TOMASEV, N.; RADOVANOVIC, M.; MLADENIC, D.; IVANOVIC, M. The role of hubness in clustering high-dimensional data. Transactions on Knowledge and Data Engineering, IEEE, v. 26, n. 3, p. 739-751, 2014b. Citado na página 30.

TRAINA, A. J. M.; TRAINA JR., C.; FALOUTSOS, C.; SEEGER, B. Fast indexing and visualization of metric data sets using slim-trees. Transactions on Knowledge and Data Engineering, IEEE, v. 14, n. 2, p. 244-260, 2002. Citado 2 vezes nas páginas 58 e 59.

TRAINA JR., C.; FILHO, R. F. S.; TRAINA, A. J. M.; VIEIRA, M. R.; FALOUTSOS, C. The omni-family of all-purpose access methods: a simple and effective way to make similarity search more efficient. The VLDB Journal, n. 4, p. 483-505, 2007. Citado 6 vezes nas páginas 54, 64, $65,100,138$ e 171. 
TRAINA JR., C.; TRAINA, A.; SEEGER, B.; FALOUTSOS, C. Slim-trees: High performance metric trees minimizing overlap between nodes. In: International Conference on Extending Database Technology. [S.1.]: Springer, 2000. p. 51-65. Citado 4 vezes nas páginas 31, 54, 57 e 151 .

TRAINA JR., C.; TRAINA, A. J. M.; FALOUTSOS, C. Distance Exponent: A New Concept for Selectivity Estimation in Metric Trees. In: International Conference on Data Engineering. [S.1.]: IEEE, 2000. p. 195-195. Citado na página 151.

TRAINA JR., C.; TRAINA, A. J. M.; VIEIRA, M. R.; ARANTES, A. S.; FALOUTSOS, C. Efficient Processing of Complex Similarity Queries in RDBMS Through Query Rewriting. In: International Conference on Information and Knowledge Management. [S.1.]: ACM, 2006. p. 4-13. Citado na página 68.

VIEIRA, M. R.; RAZENTE, H. L.; BARIONI, M. C.; HADJIELEFTHERIOU, M.; SRIVASTAVA, D.; TRAINA JR., C.; TSOTRAS, V. J. On query result diversification. In: International Conference on Data Engineering. [S.1.]: IEEE, 2011. p. 1163-1174. Citado na página 49.

VIEIRA, M. R.; TRAINA JR., C.; TRAINA, A. J.; ARANTES, A.; FALOUTSOS, C. Boosting k-nearest neighbor queries estimating suitable query radii. In: International Conference on Scientific and Statistical Database Management. [S.1.]: IEEE, 2007. p. 10-10. Citado 9 vezes nas páginas $33,34,60,79,82,83,84,85$ e 88 .

VINYALS, O.; TOSHEV, A.; BENGIO, S.; ERHAN, D. Show and tell: A neural image caption generator. In: Conference on Computer Vision and Pattern Recognition. [S.1.]: IEEE, 2015. p. 3156-3164. Citado 2 vezes nas páginas 41 e 44.

WORBOYS, M.; DUCKHAM, M. GIS: A Computing Perspective. Boca Raton, FL, USA: CRC Press, Inc., 2004. ISBN 0415283752. Citado na página 29.

WU, W.; NAUGHTON, J. F.; SINGH, H. Sampling-based query re-optimization. In: International Conference on Management of Data. [S.1.]: ACM, 2016. p. 1721-1736. Citado na página 69.

YAO, B.; LI, F.; KUMAR, P. k-Nearest Neighbor queries and kNN-Joins in large relational databases (almost) for free. In: International Conference on Data Engineering. [S.1.]: IEEE, 2010. p. 4-15. Citado na página 47.

YI, K.; WANG, L.; WEI, Z. Indexing for Summary Queries: Theory and Practice. Transactions on Database Systems, ACM, v. 39, n. 1, p. 2:1-2:39, 2014. Citado na página 70.

YIANILOS, P. N. Data structures and algorithms for nearest neighbor search in general metric spaces. In: Symposium on Discrete Algorithms. [S.1.]: ACM, 1993. v. 93, n. 194, p. 311-321. Citado na página 61.

ZEZULA, P.; AMATO, G.; DOHNAL, V.; BATKO, M. Similarity search: the metric space approach. [S.1.]: Springer Science \& Business Media, 2006. v. 32. Citado 11 vezes nas páginas $29,30,32,34,42,47,55,56,60,61$ e 68 . 


\section{Apêndice 1 - Sintaxe de comandos Merkurion}

Este apêndice inclui a sintaxe detalhada para comandos do sistema Merkurion. Palavras em maiúsculas são termos reservados, enquanto palavras em minúsculas são parâmetros.

O comando LOAD carrega os dados de um conjunto de dados.

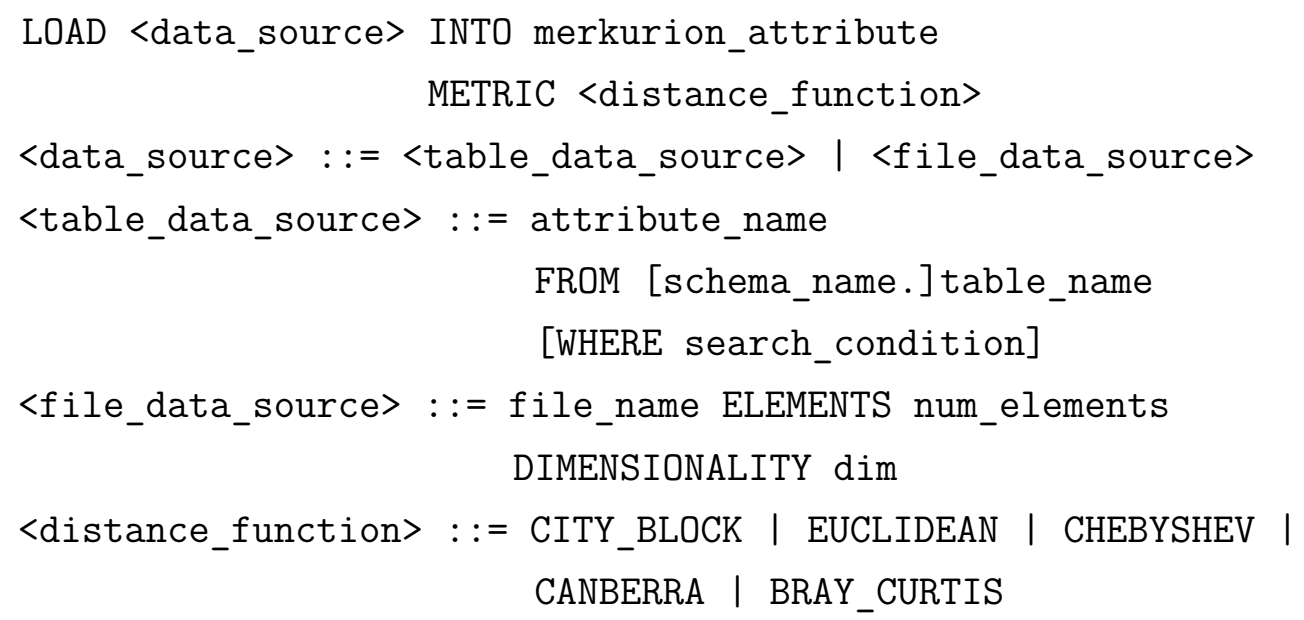

Os comandos CREATE SYNOPSIS e VIEW SYNOPSIS gerenciam as sinopses.

CREATE SYNOPSIS synopsis_name FOR merkurion_attribute TYPE <synopsis_type>

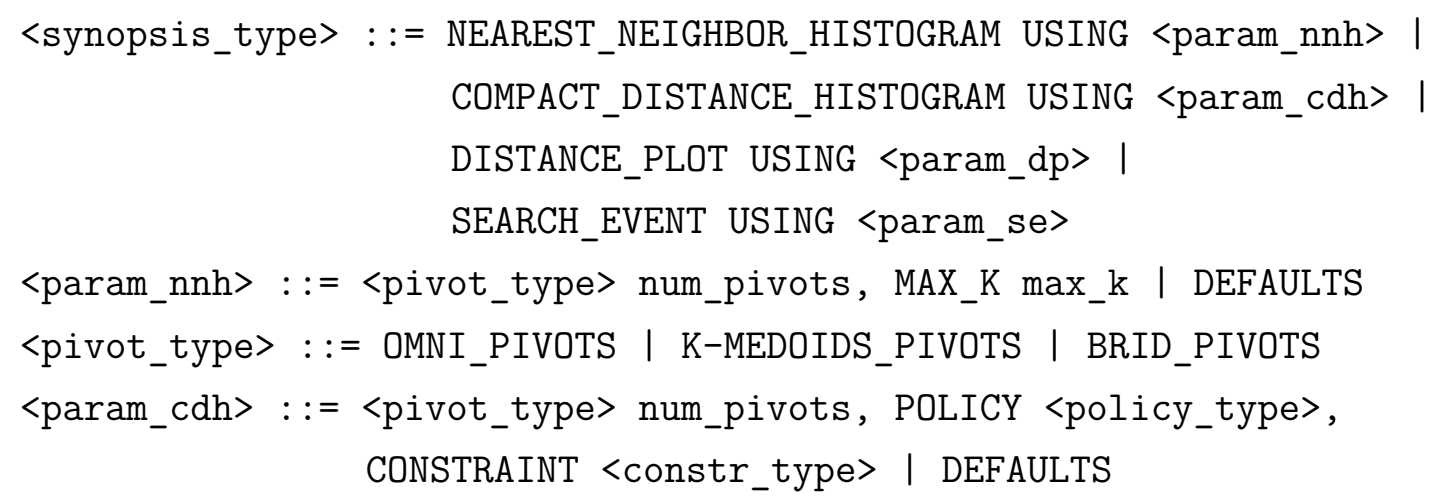




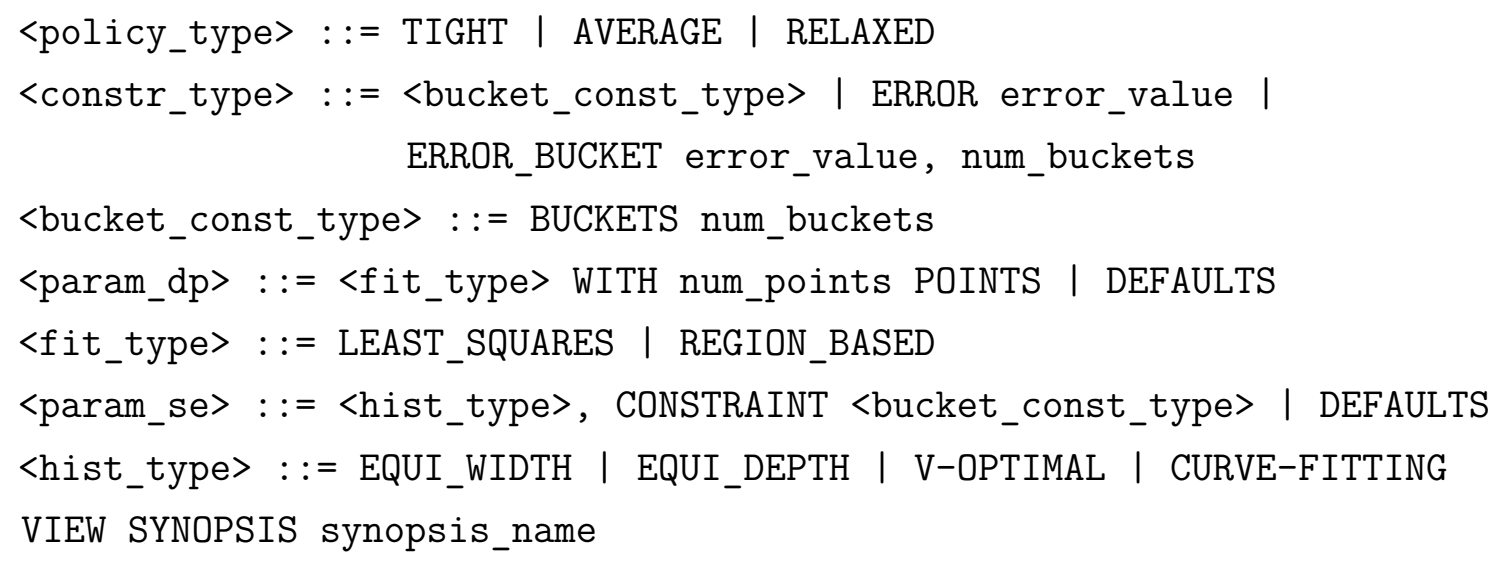

As previsões do sistema Merkurion são acessadas por meio dos comandos ESTIMATE.

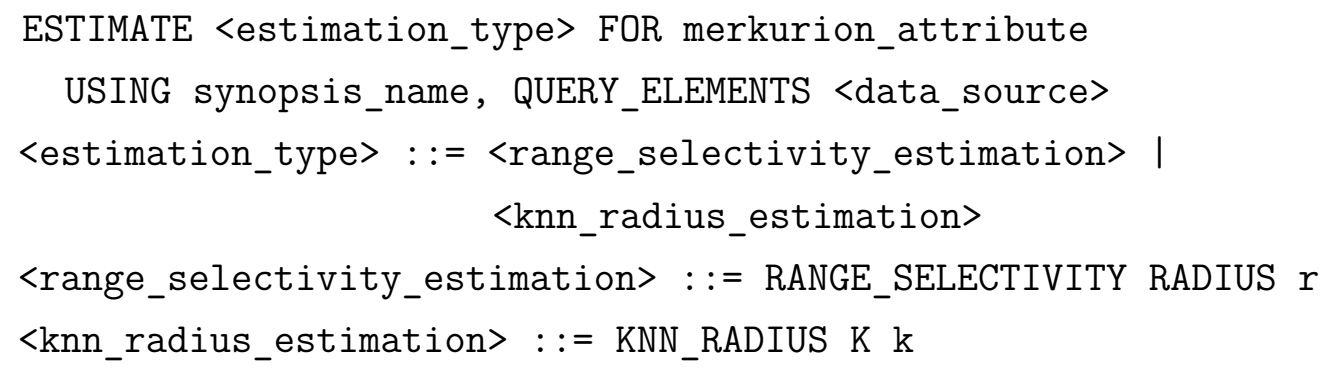

A execução das rotinas bf-kNN limitada são disparadas por meio dos comandos EXECUTE.

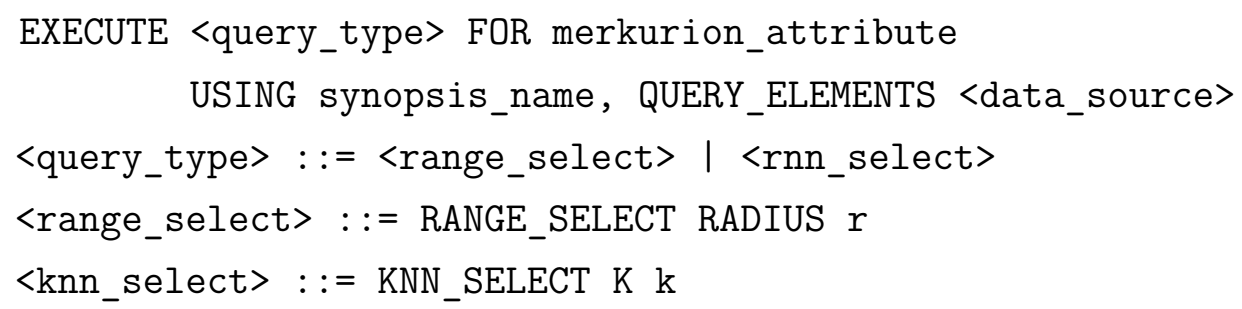




\section{Apêndice 2 - Conjuntos de dados avaliados}

A Tabela 12 lista os detalhes de todos os conjuntos de dados usados nos experimentos desta tese. Os atributos incluem nome do conjunto, dimensionalidade de imersão $(\mathcal{E})$, cardinalidade $(|\mathcal{S}|)$, número de classes (\#C), quantidade de elementos por classe (Max/Min), uma pequena descrição do conjunto e endereço web de onde os conjuntos foram obtidos (Link). Os conjuntos estão ordenados por dimensionalidade e cardinalidade.

Tabela 12 - Descrição de todos os conjuntos de dados usados nos experimentos desta tese.

\begin{tabular}{|c|c|c|c|c|c|}
\hline Nome & $\mathcal{E}$ & $|\mathcal{S}|$ & \#C & Max/Min & Descrição \\
\hline CITIES & 2 & 5.507 & N/A & N/A & $\begin{array}{l}\text { Coordenadas (latitude, longitude) } \\
\text { de cidades brasileiras. }\end{array}$ \\
\hline \multicolumn{6}{|c|}{ Link: ibge.gov.br } \\
\hline SYNTHETIC & 2 & 100.000 & N/A & N/A & $\begin{array}{l}\text { Pontos gerados em } \mathrm{R} \text { conside- } \\
\text { rando a distribuição normal com } \\
\text { média }(0,0) \text { e matriz de covariân- } \\
\text { cia }\left(\begin{array}{cc}10 & 4 \\
4 & 2\end{array}\right) .\end{array}$ \\
\hline \multicolumn{6}{|c|}{ Link: N/A } \\
\hline ROAD3D & 3 & 434.874 & N/A & N/A & $\begin{array}{l}\text { Conjuntos de pontos de latitude, } \\
\text { longitude e altitude de estradas } \\
\text { em North Jutland na Dinamarca. }\end{array}$ \\
\hline \multicolumn{6}{|c|}{ Link: archive.ics.uci.edu/ml/datasets/3D+Road+Network+(North+Jutland,+Denmark) } \\
\hline BIKE & 7 & 17.379 & N/A & N/A & $\begin{array}{l}\text { Conjunto de valores reais de siste- } \\
\text { mas de compartilhamento de bici- } \\
\text { cletas medidos por sensores (ve- } \\
\text { locidade, momento, força, etc.). }\end{array}$ \\
\hline \multicolumn{6}{|c|}{ Link: archive.ics.uci.edu/ml/datasets/bike+sharing+dataset } \\
\hline & & & & & Continua na próxima página \\
\hline
\end{tabular}


Tabela 12 - continuação da página anterior

\begin{tabular}{|l|c|c|c|c|l|}
\hline Nome & $\mathcal{E}$ & $|\mathcal{S}|$ & \#C & Max/Min & Descrição \\
\hline ALOI & 13 & 110.250 & N/A & N/A & $\begin{array}{l}\text { Objetos 3D capturados com di- } \\
\text { ferentes ângulos e iluminações e } \\
\text { representados por 13 característi- } \\
\text { cas de Haralick. }\end{array}$ \\
\hline COREL & 32 & 66.616 & N/A & N/A & $\begin{array}{l}\text { Várias características extraídas } \\
\text { de fotos coloridas de diversas ca- } \\
\text { tegorias. }\end{array}$ \\
\hline \multicolumn{7}{|c|}{ Link: aloi.science. uva.nl } \\
\hline SENSOR & 48 & 58.509 & N/A & N/A & $\begin{array}{l}\text { Sinais elétricos de direção de veí- } \\
\text { culos medidos em doze situações } \\
\text { por diversas vezes. }\end{array}$ \\
\hline
\end{tabular}

Link: archive.ics.uci.edu/ml/datasets/dataset+for+sensorless+drive+diagnosis

\begin{tabular}{|l|l|l|l|l|l|}
\hline COLORS & 112 & 112.682 & N/A & N/A & $\begin{array}{l}\text { Características extraídas de diver- } \\
\text { sas imagens usando extratores de } \\
\text { cor. }\end{array}$ \\
\hline
\end{tabular}

\begin{tabular}{|l|l|l|l|l|l|}
\hline \multicolumn{9}{|c|}{ Link: sisap.org./dbs.html } \\
\hline FACES & 761 & 1.016 & N/A & N/A & $\begin{array}{l}\text { Características extraídas de ima- } \\
\text { gens de rosto para reconheci- } \\
\text { mento facial. }\end{array}$ \\
\hline
\end{tabular}

\begin{tabular}{|l|c|c|c|c|l|}
\hline \multicolumn{4}{|c|}{ Link: sisap.org./dbs.html } \\
\hline AMAZON2 & 1.500 & 1.500 & N/A & N/A & $\begin{array}{l}\text { Conjunto com revisões de usuá- } \\
\text { rios para autores na plataforma } \\
\text { Amazon. }\end{array}$ \\
\hline
\end{tabular}

Link: archive.ics.uci.edu/ml/datasets/amazon+commerce+reviews+set

\begin{tabular}{|l|c|c|c|c|l|}
\hline \hline BANK & 4 & 1.372 & 2 & $686 / 686$ & $\begin{array}{l}\text { Características de imagens para } \\
\text { autenticar notas de dinheiro em } \\
\text { bancos. }\end{array}$ \\
\hline \multicolumn{7}{|c|}{ Link: archive.ics.uci.edu/ml/datasets/banknote+authentication } \\
\hline YEAST & 8 & 1.484 & 10 & $463 / 5$ & $\begin{array}{l}\text { Conjuntos de dados para identifi- } \\
\text { cação de localização proteica. }\end{array}$ \\
\hline WINE & 11 & 6.497 & 3 & $71 / 48$ & $\begin{array}{l}\text { Atributos que descrevem vinhos, } \\
\text { tais como teor de álcool e alcali- } \\
\text { nidade. }\end{array}$ \\
\hline
\end{tabular}


Tabela 12 - continuação da página anterior

\begin{tabular}{|c|c|c|c|c|c|}
\hline Nome & $\mathcal{E}$ & $|\mathcal{S}|$ & \#C & Max/Min & Descrição \\
\hline \multicolumn{6}{|c|}{ Link: archive.ics.uci.edu/ml/datasets/wine } \\
\hline CANVAS & 16 & 3.879 & 5 & $779 / 775$ & $\begin{array}{l}\text { Características extraídas de fotos } \\
\text { de quadros clássicos pelo extrator } \\
\text { Color Layout. }\end{array}$ \\
\hline \multicolumn{6}{|c|}{ Link: commons.wikimedia.org/wiki/Category:Paintings } \\
\hline LETTER & 16 & 20.000 & 26 & $813 / 734$ & $\begin{array}{l}\text { Conjunto de letras em retângulos } \\
\text { de tamanho uniforme em escala } \\
\text { preto e branco considerando-se } \\
20 \text { fontes diferentes. }\end{array}$ \\
\hline \multicolumn{6}{|c|}{ Link: archive.ics.uci.edu/ml/datasets/letter+recognition } \\
\hline GASDRIFT & 128 & 13.910 & 6 & $3009 / 1641$ & $\begin{array}{l}\text { Inclui medidas de } 16 \text { sensores } \\
\text { químicos usados em simulação } \\
\text { para seis gases em diversos níveis } \\
\text { de concentração. }\end{array}$ \\
\hline \multicolumn{6}{|c|}{ Link: archive.ics.uci.edu/ml/datasets/gas+sensor+array+drift+dataset } \\
\hline TIGER & 230 & 1.220 & 2 & $676 / 544$ & $\begin{array}{l}\text { Descrição obtida com extração } \\
\text { de características de fotos de ti- } \\
\text { gre. }\end{array}$ \\
\hline \multicolumn{6}{|c|}{ Link: sci2s.ugr.es/keel/datasets.php } \\
\hline SEMEION & 256 & 1.593 & 2 & $1435 / 158$ & $\begin{array}{l}\text { Dígitos } 0-9 \text { escritos, escanea- } \\
\text { dos e colocados em retângulos de } \\
16 \times 16 \text { pixels em escala de cinza. }\end{array}$ \\
\hline \multicolumn{6}{|c|}{ Link: archive.ics.uci.edu/ml/datasets/semeion+handwritten+digit } \\
\hline MADELON & 500 & 2.600 & 2 & $1300 / 1300$ & $\begin{array}{l}\text { Conjuntos de dados gerados } \\
\text { como } 32 \text { clusters nos vértices de } \\
\text { um hiper-cubo e rotulados aleato- } \\
\text { riamente em duas classes. }\end{array}$ \\
\hline \multicolumn{6}{|c|}{ Link: archive.ics.uci.edu/ml/datasets/madelon } \\
\hline SMARTRECOG & 561 & 7.767 & 12 & $1223 / 23$ & $\begin{array}{l}\text { Conjunto com registros de } 30 \text { in- } \\
\text { divíduos realizando tarefas diá- } \\
\text { rias cujos movimentos foram cap- } \\
\text { turas por sensores de smartpho- } \\
\text { nes. }\end{array}$ \\
\hline
\end{tabular}

Link: ...uci.edu/ml/datasets/human+activity+recoginition+using+smartphones 
Tabela 12 - continuação da página anterior

\begin{tabular}{|l|c|c|c|c|l|}
\hline Nome & $\mathcal{E}$ & $|\mathcal{S}|$ & \#C & Max/Min & Descrição \\
\hline ISOLET & 617 & 6.238 & 26 & $240 / 238$ & $\begin{array}{l}\text { Contém o áudio de todas as letras } \\
\text { do alfabeto repetidas diversas ve- } \\
\text { zes por vozes humanas. }\end{array}$ \\
\hline MFEAT & 649 & 2.000 & 26 & $240 / 240$ & $\begin{array}{l}\text { Inclui características de números } \\
0-9 \text { escritos a mão. }\end{array}$ \\
\hline Link: archive.ics.uci.edu/ml/datasets/Multiple+Features
\end{tabular}





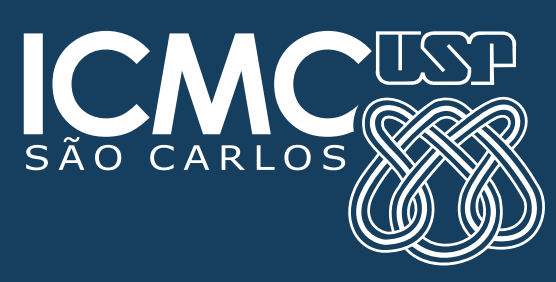

